\title{
DEVELOPMENT OF ANALYTICAL PROCEDURES FOR COPROCESSING FINAL TECHNICAL REPORT
}

\author{
R. P. Anderson, \\ J. B. Green \\ and \\ j. W. Vogh
}

Work Performed Under Contract DE-AC22-88PC 88810

Prepared for the

U.S. Department of Energy

Pittsburgh Energy Technology Center

Pittsburgh, Pennsylvania

This report was prepared as an account of work sponsored by an agency of the United States Government. Neither the United States Government nor any agency thereof, nor any of their employees, makes any warranty, expressed or implied, or assumes any legal liability or responsibility for the accuracy, completeness, or usefulness of any information, apparatus, product, or process disclosed, or represents that its use would not infringe privately owned rights. Reference herein to any specific commercial product, process, or service by trade name, trademark, manufacturer, or otherwise, does not necessarily constitute or imply its endorsement, recommendation, or factoring by the United States Government or any agency thereof. The views and opinions of authors expressed herein do not necessarily state or reflect those of the United States Government or any agency thereof.

IIT R.esearch Institute NATIONAL INSTITUTE FOR DFTROLEUM AND ENERGY RESEARCH

P. O. Box 2128

Bartlesville, Oklahoma 74005

(918) 336-2400 


\section{DEVELOPMENT OF ANALYTICAL PROCEDURES FOR COPROCESSING}

\section{TABLE OF CONTENTS}

Page

Abstract............................................................................ 1

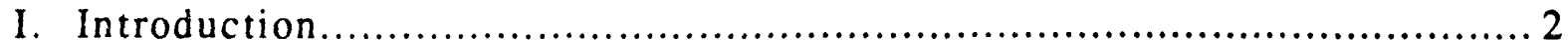

II. Results, Discussion and Conclusions ....................................... 3

II.A. Batch Autoclave Runs ................................................ 3

II.B. Carbon Isotope Studies.................................................... 3

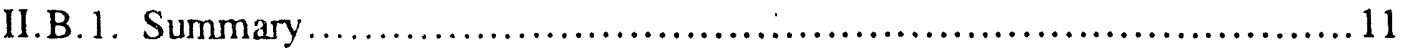

II.B.2. Introduction ................................................. 11

II.B.3 Results and Discussion........................................ 14

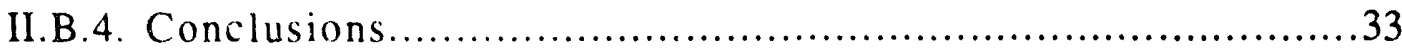

II.B.5. Elemental Compositions and Carbon Isotope Ratios ....................33

II.C. Detailed Composition Studies ...................................... 42

II.C.1. Introduction .............................................. 42

II.C.2. Analysis Light Distillates........................................ 44

II.C.3. Analysis of $175-350^{\circ} \mathrm{C}\left(347-662^{\circ} \mathrm{F}\right)$ and $350-538^{\circ} \mathrm{C}\left(1000^{\circ} \mathrm{F}\right)$ Distillates......................................46

II.C.3.a. Separation into Acid, Base and Neutral Fractions ............46

II.C.3.b. Acids Analysis ......................................50

II.C.3.b.1. Nonaqueous Titrations ......................50

II.C.3.b.2. Chemical Derivatization/Gas

Chromatography/Mass

Spectrometry or the Acid Fractions ...........51

II.C.3.b.3. Nuclear Magnetic Resonance (NMR)

Analysis of Methylated Acid Fractions ........56

II.C.3.c. Analysis Base Fractions .............................61

II.C.3.d. Neutral Class Analysis .....................................62

II.C.3.d.1. Neutral Class Subfractionation...................62

II.C.3.d.2. Mass Spectral Analysis Neutral Fractions ........65

II.C.4. Resid Fractionation and Analysis ..................................69

II.C.5. Conclusions................................................ 70

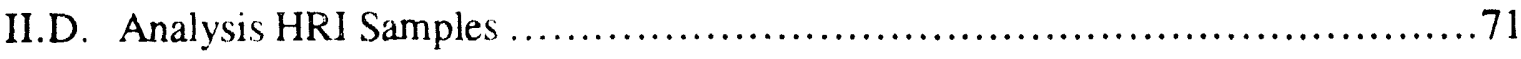

II.D.1. Introduction.................................................. 71

II.D.2. Separation into Acids, Bases and Neutrals..............................73 


\section{TABLE OF CONTENTS (continued)}

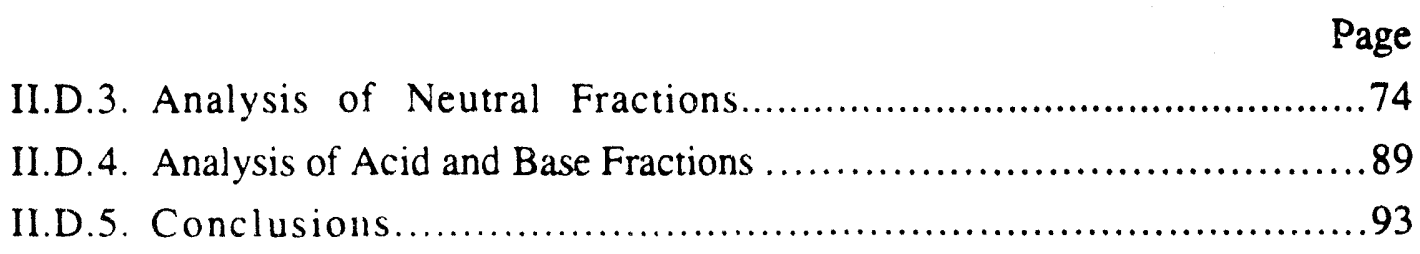

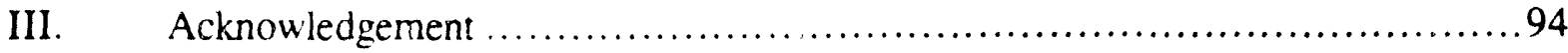

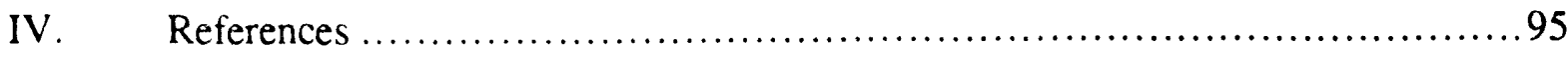

Appendix A Detailed Description Batch Autoclave Coprocessing Runs..................1-1

Appendix B Analytical Procedures.........................................................

Appendix C Detailed Results, Light Distillate Analysis ............................... 3-1

\section{TABLES}

Table 1. Hydrogen/carbon ratios for coprocessing products.................................... 8

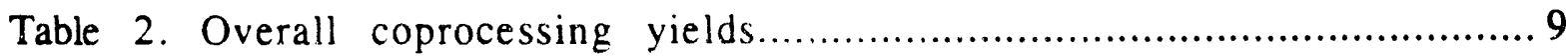

Table 3. Carbon isotope ratios for reactor products .................................. 15

Table 4. Carbon isotope ratios values for distillation fractions .......................... 19

Table 5. Carbon isotope ratios for distillate acid-base-neutral fractions ..................20

Table 6. Carbon isotope ratios for neutral subfractions.........................................25

Table 7. Carbon isotope ratios coprocessing resid subfractions..........................29

Table 8. Carbon isotope ratios for Maya crude fractions ................................... 31

Table 9. Carbon isotope ratios for Maya resid fractions ................................. 32

Table 10. Elemental composition of coprocessing fractions............................ 35

Table 11. Observed and calculated carbon isotope ratios $(20,30$ and $40 \%$ coal) f..........37

Table 12. Observed and calculated carbon isotope ratios, $2 \%$ coal ........................40

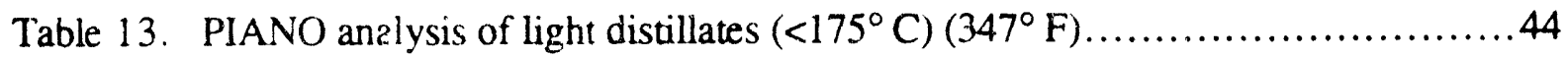

Table 14. Selectivity and RPY values of distillate subfractions ..........................50

Table 15. Acid fraction titrations........................................................

Table 16. Acids of $175-350^{\circ} \mathrm{C}\left(347-662^{\circ} \mathrm{F}\right), 20$ percent coal product,

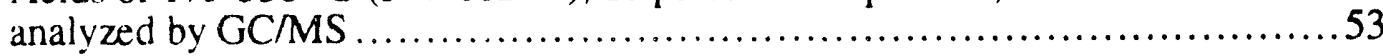

Table 17. Titration analysis of base fractions................................................61

Table 18. Base class composition of coprocessing distillates ..........................66

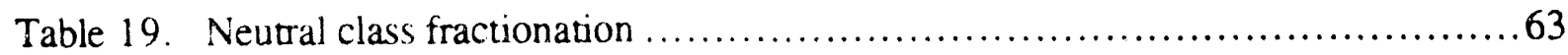

Table 20. Yields of neutral saturate and aromatic fractions. Whole filtrate basis...........64

Table 21. Selectivity and RPY values for saturates and aromatics.......................64 


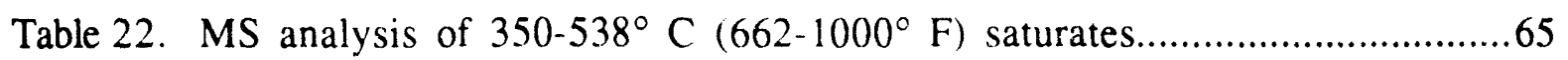

Table 23. MS analysis of neutral factions, $175-350^{\circ} \mathrm{C}\left(347-662^{\circ} \mathrm{F}\right)$ wt percent ...........67

Table 24. MS analysis of aromatic neutral subfractions, $350-538^{\circ} \mathrm{C}\left(662-1000^{\circ} \mathrm{F}\right)$

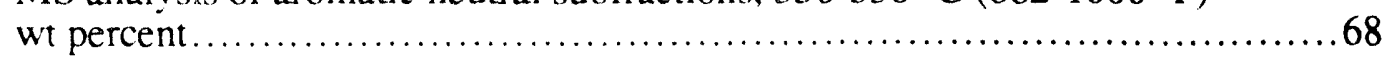

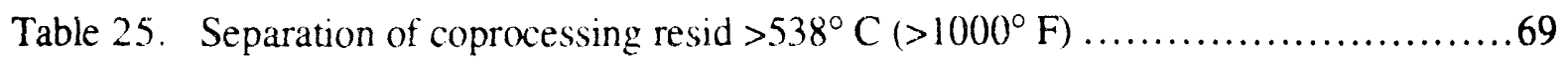

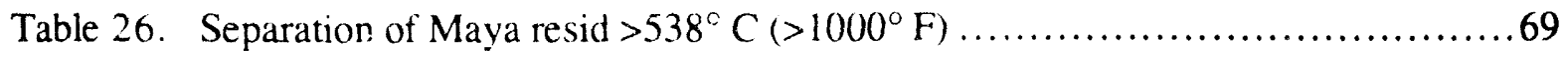

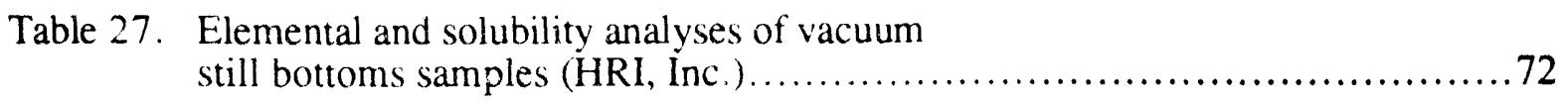

Table 28. Liquid chromatographic fractionation of HRI resids .........................74

Table 29. Liquid chromatographic separation of neutrals into

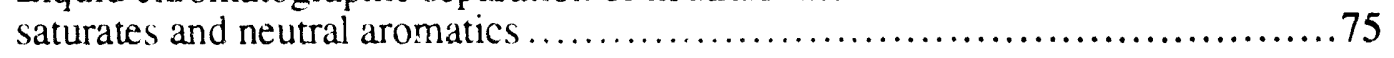

Table 30. High temperature simulated distillation...............................................8

Table 31. Elemental analyses of $L C$ fractions and benzene insolubles from HRI coprocessing resids ........................................... 88

Table 32. H/C ratios of saturated hydrocarbon homologs with molecular weights near 550 and 620

Table 33. H/C ratios of $\underline{n}$-alkyl-substituted aromatic hydrocarbons with molecular weights near 600 ..

Table 34. H/C ratios of 4-ring aromatic hydrocarbons, ca. 600 molecular weight, with varying numbers of napththenic rings..................90

Table 35. Results from nonaqueous titration of base fractions..........................91

Table 36. Estimated average molecular weights for selected LC fractions.................992

Table 37. Speciation of nitrogen in acid fractions $(w t \% N)$........................... 94 Appendix A

Tabie A-1. Maya crude resid $>1000^{\circ} \mathrm{F}\left(<538^{\circ} \mathrm{C}\right)$, elemental composition.............1-2

Table A-2. Analysis of Illinois No. 6 coal............................................1-3

Table A-3. Composition of coprocessing reactants, grams...............................1-4

Table A-4. Gas product compusition, percent ................................... 1-6

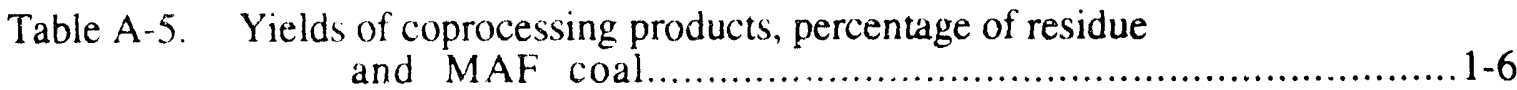

Table A-6. Filtrate distillation ............................................. 1-10

Table A-7. Distillation cuts of THF solubles (by simulated distillation) ............ 1-11

Table A-8. Overall coprocessing yields .................................... 1-12

Table A-9. Coprocessing fractions, elemental composition ...................... 1-13

Table A-10 Nitrogen and sulfur removal in coprocessing reactions ................ 1-14 


\section{TABLES (continued)}

Page

\section{Appendix B}

Table B-1. Class composition of distillates........................................2-2

Table B-2. Proton $\left({ }^{1} \mathrm{H}\right)$ and carbon-13( $\left.{ }^{13} \mathrm{C}\right)$ chemical shift of

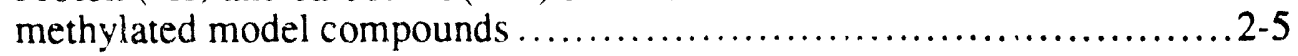

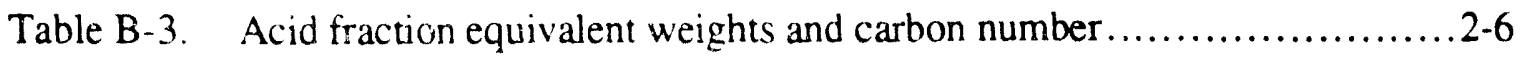

Table B-4. Quantitative carbon-13 NMR peak integrals ........................ 2-18

Table B-5. Intermediate values ......................................... 2-19

Table B-6. Quantitative subdivision of oxygen functionalities................... 2-20

Table B. 7. Net peak integral values ................................... 2-21

Table B-8. Number of functional groups per average molecule .................. 2-22 Appendix C

Table C-1. PIANO analysis light distillate, $40 \%$ coal run

\section{FIGURES}

Figure 1. Workup procedure for coprocessing runs ................................5

Figure 2. Yields of gaseous products versus coal concentration...............................6

Figure 3. Yields of reactor products versus coal concentration ......................... 7

Figure 4. Coprocessing yields versus coal concentration................................. 10

Figure 5. Carhon isotope ratios for reactor products ................................ 16

Figure 6. Carbon isotope ratios for distillation fractions.....................................21

Figure 7. Carbon isotope ratios for acid-base-neutral fractions of $175-350^{\circ} \mathrm{C}\left(347-662^{\circ} \mathrm{F}\right)$ distillate.

Figure 8. Carbon isotope ratios for acid-base-neutral fractions of

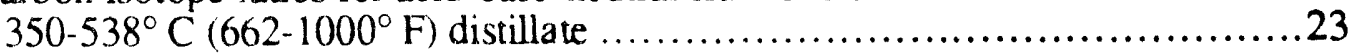

Figure 9. Carbon isotope ratios for neutral subfractions of

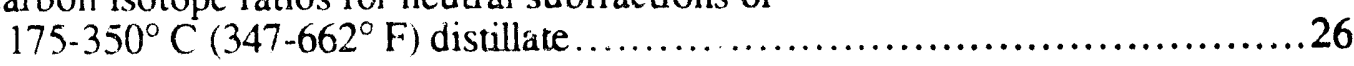

Figure 10. Carbon isotope ratios for neutral subfractions of

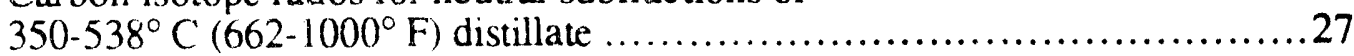

Figure 11. Carbon isotope ratios for resid fractions ............................... 30

Figure 12. Plot of calculated vs. observed carbon isotope ratios for the 20, 30, and 40 percent coal coprocessing.... 38

Figure 13. Plot of calculated vs. observed carbon isotope ratios for the 2 percent coal coprocessing products 
FIGURES (continued)

Figure 14. Schematic for separation and analysis of conventional, heavy, or synthetic crudes and their products.

Figure 15. Compound classes in $<175^{\circ} \mathrm{C}\left(357^{\circ} \mathrm{F}\right)$ distillate versus coal concentrations

Figure 16. Acid-base neutral classes $175-350^{\circ} \mathrm{C}\left(347-662^{\circ} \mathrm{F}\right)$ distillate versus coal concentration

Figure 17. Acid-base neutral classes $350-538^{\circ} \mathrm{C}\left(662-1000^{\circ} \mathrm{F}\right)$ distillate versus coal concentration

Figure 18. Hypothetical yield structure for coprocessing

Figure 19. TIC chromatogram of methyl derivative of $175-350^{\circ} \mathrm{C}\left(347-662^{\circ} \mathrm{F}\right)$ coprocessing acid fraction.

Figure 20. Molecular weight distribution of phenol acids of $175-350^{\circ} \mathrm{C}$ $\left(347-662^{\circ} \mathrm{F}\right)$ coprocessing product $^{\circ}$

Figure 21. Molecular weight distribution of nitrogen acids of $175-350^{\circ} \mathrm{C}\left(347-662^{\circ} \mathrm{F}\right)$ coprocessing product

Figure 22. Number of functional groups per molecule for the

$175-350^{\circ} \mathrm{C}\left(347-662^{\circ} \mathrm{F}\right)$ products .57

Figure 23. Number of functional groups per molecule for the $350-538^{\circ} \mathrm{C}\left(662-1000^{\circ} \mathrm{F}\right)$ products.

Figure 24. Distribution of oxygen functional groups in the $175-350^{\circ} \mathrm{C}\left(347-662^{\circ} \mathrm{F}\right)$ products

Figure 25. Distribution of oxygen functional groups in the $350-538^{\circ} \mathrm{C}$ products

Figure 26. HTGC chromatograms of saturate fractions from HRI coprocessing resids

Figure 27. HTGC chromatograms of neutral-aromatic fractions from HRI coprocessing resids.

Figure 28. Cumulative percent of saturates eluted as a function of apparent carbon number (carbon number scale based on n-paraffin elution times).

Results calculated from GC chromatograrns in figure 26.

Figure 29. Cumulative percent of neutral-aromatics eluted as a function of apparent carbon number (carbon number scale based on n-paraffin elution times). Results calculated from GC chromatograms in figure 27 .

Figure 30. Chromatogram of known compounds on DNAP-silica ..................81

Figure 31. Chromatogram of 238-8-5 neutral aroratics on DNAP-silica ...............83

Figure 32. Chromatogram of 238-8-9 neutral aromatics on DNAP-silica 
Figure 33. Chromatogram of 238-10-8 neutral aromatics on DNAP-silica ................85 Appendix

Figure A-1. Simulated distillation of filtrate and THF solubles, $2 \%$ coal run ...........1-8

Figure A-2. Simulated distillation of filtrate and THF solubles, $20 \%$ coal run............1-8

Figure A-3. Simulated distillation of filtrate and THF solubles, 30\% coal run............1-9

Figure A-4. Simulated distillation of filtrate and THF solubles, $40 \%$ coal run............ 1-9 Appendix B

Figure B-1. Two-dimensional CHSHF spectrum. Acid fraction of 2 percent coal, $175-350^{\circ} \mathrm{C}\left(347-662^{\circ} \mathrm{F}\right)$ distillate

Figure B-2. Two-dimensional C.HSHF spectrum. Acid fraction of 20 percent coal, $175-350^{\circ} \mathrm{C}\left(347-662^{\circ} \mathrm{F}\right)$ distillate

Figure B-3. Two-dimensional CHSHF spectrum. Acid fraction of 30 percent coal, $175-350^{\circ} \mathrm{C}\left(347-662^{\circ} \mathrm{F}\right)$ distillate

Figure B-4. Two-dimensional CHSHF spectrum. Acid fraction of 40 percent coal, $175-350^{\circ} \mathrm{C}\left(347-662^{\circ} \mathrm{F}\right)$ distillate

Figure B-5. Two-dimensional CHSHF spectrum. Acid fraction of 2 percent coal, $350-538^{\circ} \mathrm{C}\left(662-1000^{\circ} \mathrm{F}\right)$ distillate

Figure B-6. Two-dimensional CHSHF spectrum. Acid fraction of 20 percent coal, $350-538^{\circ} \mathrm{C}\left(662-1000^{\circ} \mathrm{F}\right)$ distilate

Figure B-7. Two-dimensional CHSHF spectrum. Acid fraction of 30 percent coal, $350-538^{\circ} \mathrm{C}\left(662-1000^{\circ} \mathrm{F}\right)$ distillate .

Figure B-8. Two-dimensional CHSHF spectrum. Acid fraction of 40 percent coal, $350-538^{\circ} \mathrm{C}\left(662-1000^{\circ} \mathrm{F}\right)$ distillate

Appendix C

Figure C-1. Hydrocarbon distribution of the $<175 \mathrm{C}\left(347^{\circ} \mathrm{F}\right)$

distillate of 2 percent coal processing product.

Figure C-2. Hydrocarbon distribution of the $175 \mathrm{C}\left(347^{\circ} \mathrm{F}\right)$ distillate of 20 percent coal processing product

Figure C-3. Hydrocarbon distribution of the $<175 \mathrm{C}\left(347^{\circ} \mathrm{F}\right)$ distillate of 30 percent coal processing product

Figure C-4. Hydrocarbon distribution of the $<175 \mathrm{C}\left(347^{\circ} \mathrm{F}\right)$ distillate of 40 percent coal processing product 


\begin{abstract}
One phase of improving understanding of the fundamental chemistry of coprocessing involves development of the ability to distinguish between products originating from coal versus those originating from petroleum resid. A primary objective of this project was to develop analytical techniques to determine the source (coal versus resid) of the various compound types found in coprocessing products. A corollary objective was to develop an expanded knowledge of the detailed composition of coprocessing products. This knowledge will aid in the development of improvements in coprocessing, guide development of refining methods for coprocessing liquids and provide information on the quality of coprocessing products. Two approaches were evaluated for distinguishing between products originating from coal and those originating from petroleum resid. One was based on the use of carbon isotope ratios and the other was based on variations in compound classes in response to changes in the ratio of coal to resid in the coprocessing feed. Other researchers using carbon isotope ratios to determine the origin of products have typically examined distillation fractions. This project involved determination of the origin of chemical classes (e.g., saturates, neutral aromatics, phenols, indoles, etc.) rather than distillate classes. Maya resid and Illinois No. 6 coal (with coal feed varying from 2 to 40 percent) were coprocessed in a batch autoclave to obtain products for detailed analysis.
\end{abstract}

Coprocessing products were separated into a number of fractions--first by distillation and then by a comprehensive chromatographic separation scheme developed at NIPER. The use of carbon isotope ratios to determine the source of particular compound classes was made more difficult by substantial isotope fractionation between compound classes. For example it was found that acid and base fractions are strongly enriched in the carbon-13 isorope--even in a completely petroleurn derived product. Relationships between concentrations of particular compound classes and the ratio of coal and resid in the feed were established. As an example, it was shown that coal was clearly the dominant source of both acids and bases. The acid fractions consisted primarily of phenols and, to a lesser extent, pyrrolic nitrogen compounds (indoles and carbazoles) while bases were primarily aromatic amines and pyridine types (quinolines, benzoquinolines, etc.).

Similar techniques were used for analysis of coprocessing products produced by another DOE contractor using a continuous product development unit. Emphasis was placed on determination of the composition of the coprocessing resid; composition of this material is of interest as it is the material which failed to be converted to the desired distillate range material. 


\section{INTRODUCTION}

Coprocessing of coal with petroleum resid is a potentially promising method for conversion of these low value materials to useful distillate products. As the supply of high quality petroleum diminishes and the use of lower quality crudes increases, coprocessing could provide the means to convert the increasing amounts of resid to distillate products and to initiate the utilization of coal for the production of transportation fuels.

The overall objective of this project was to improve our understanding of the fundamental chemistry of coprocessing. More specifically, the primary objective was the development of methods by which the specific contributions of coal or petroleum resid to the composition of the coprocessing products could be determined. The conversion products of coal and petroleum resid show some unique differences as well as substantial amounts of equivalent materials. The unique products will tend to be present in amounts proportional to the coal or resid in the coprocessing feed, although this may be altered if reaction routes of either is strongly affected by the presence of the other. Other components produced by both reactants cannot be distinguished by direct analysis and must be associated with their source by other means. Carbon isotope ratio measurement was evaluated for its utility in determining the relative contribution of the coal and resid to specific compound classes found in coprocessing products.

Carbon isotope ratios have been used by other researchers to determine the type and yield of coal-derived materials in coprocessing products (see Section II.B.2). These other studies showed evidence of some selective isotopic fractionation between the lighter and heavier components in the products. However, satisfactory information on the presence of coal-derived material in distillation fractions was obtained. This project differs from the other studies in that the emphasis in this project is on determination of the source of chemical classes as opposed to distillation fractions.

A corollary objective of this project was to obtained detailed knowledge on the composition of coprocessing products. Extensive separation and analysis procedures developed at NIPER for the analysis of petroleum products were applied to coprocessing products made in batch autoclave runs at NIPER and also to products made by HRI, Inc., in a continuous process development unit.

Most of the analyses in this project were conducted on coprocessing products made in a series of batch autoclave runs. Maya vacuum resid $\left(>538^{\circ} \mathrm{C}, 1000^{\circ} \mathrm{F}\right)$ and Illinois No. 6 coal were used as reactants. After establishing satisfactory conditions for the desired conversion levels, a series of 
runs was made in which the only variable was the ratio of coal to resid in the feed. Coal concentration ranged from 2 to 40 percent. Products from these runs were used for both carbon isotope ratio and detailed composition studies.

Results of the batch autoclave runs are discussed in Section II.A while experimental details are provided in Appendix A. The carbon isotope ratio studies conducted in this project as well as the results of other researchers are discussed in Section II.B. Conclusions from the isotope ratios are summarized in Section II.B.4. Detailed analyses of the batch autoclave coprocessing products and the relationships between coal concentration in the feed and compositions of the coprocessing products are discussed in Section II.C. Selectivity factors that indicate the proportions of particular compound classes produced from coal or from resid are presented. Conclusions from the detailed analyses of coprocessing products made with variable coal:resid feed ratios are summarized in Section II.C.5. Additional details of the analytical procedures are provided in Appendix B, and detailed analytical results for light distillates are provided in Appendix C. Analyses of HRI process development unit samples an discussed in Section II.D.

\section{RESULTS, DISCUSSION AND CONCLUSIONS}

\section{II.A. BATCH AUTOCLAVE RUNS}

A șeries of batch autoclave coprocessing runs was conducted to produce a set of materials for detailed study. The materials produced in these runs were used both in carbon isotope ratio studies and detailed compositional studies. Details of the batch autoclave runs, workup procedures and yield determinations are provided in Appendix A.

Materials selected for this study were Maya vacuum resid $\left(>538^{\circ} \mathrm{C}, 1000^{\circ} \mathrm{F}\right)$ and Illinois No. 6 coal. These materials have been used in other coprocessing studies $(1)^{*}$. Ammonium tetrathiomolybdate at a 0.1 percent Mo level based on the whole reaction mix was used as catalyst. The thiomolybdate salt has been shown to be quite effective in coal liquefaction reactions (2). The catalyst was applied by aqueous impregnation of the coal. Several runs were made to establish conditions for a satisfactory conversion to distillate. Conditions established for the analytical study were one hour at $445^{\circ} \mathrm{C}\left(833^{\circ} \mathrm{F}\right)$ and an initial hydrogen pressure of $1800 \mathrm{psi}$ (cold). After heatup, pressure was maintairied at no less than 3000 psig during the course of the reaction by addition of hydrogen as required.

\footnotetext{
*Underlined numbers in parentheses refer to items in the references at the end of this report.
} 
The only variation in run conditions was in the ratio of coal to resid in the autoclave charge. Runs were conducted with coal concentrations of $2,20,30$ and 40 weight percent.

A simplified diagram of the workup procedure is provided in Figure 1; a detailed description is provided in Appendix A. A filtration step was included so that the insoluble organic matter (IOM) and soluble resid could be analyzed independently. At the end of the filtration, the filter cake was found to contain a viscous material which differed from the bulk filtrate. Thus the filter cake was washed with tetrahydrofuran (THF) to provide a THF soluble fraction in addition to the THF insolubles (ash and insoluble organic matter [IOM]). As the THF soluble fraction was found to contain significantly more nondistillable material than the filtrate, the filtrate and THF solubles were analyzed independently.

Yields of the gaseous products on the basis of petroleum resid plus moisture and ash free (MAF) coal are shown in Figure 2. The yields of gaseous products increase with increasing coal content for the coal levels of 20-40 percent. Except for carbon dioxide, the results for the 2 percent coal run are not consistent with this trend. A possible explanation of this divergence may be that the catalyst was less effective because it was loaded on a relatively small quantity of coal. Carbon dioxide levels are related to the coal content indicating direct formation of $\mathrm{CO}_{2}$ from the coal.

Yields of the gross reactor products (except gas) are shown in Figure 3. Filtrate is, of course, the predominant reactor product and its extensive separation and analysis is discussed in later sections. At this point, discussion of trends with changing coal concentration will be limited to the THF insolubles (or insoluble organic matter [IOM] since results are presented on an ash-free basis). IOM increases with increasing coal content for the 20, 30 and 40 percent coal runs inci.ating coal as the primary source of this product. However, the highest IOM yield was obtained with the 2 percent coal run. The original Maya vacuum resid is free of THF insolubles so the IOM in the 2 percent coal run was formed via retrogressive runs. Such reactions may have been promoted by a poorer catalyst distribution with the low coal concentration as mentioned in the above discussion on gas yielús.

Both the filtrate and THF solubles were analyzed by simulated distillation (Appendix A). The THF solubles were shown to contain a significantly higher level of $>538^{\circ} \mathrm{C}\left(1000^{\circ} \mathrm{F}\right)$ material than 


\section{WORKUP PROCEDURE}

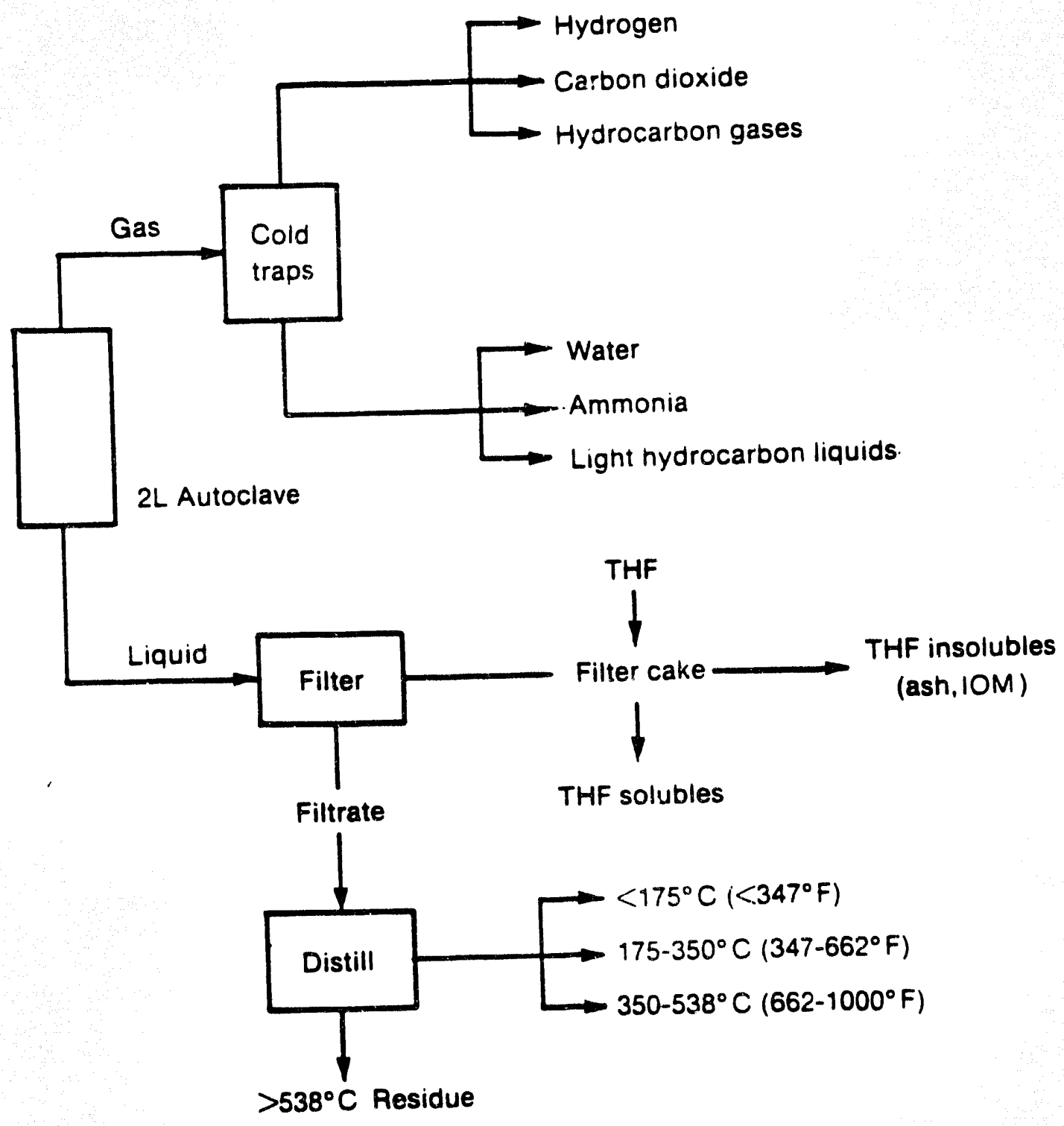

FIGURE 1. - Workup procedure for coprocessing runs. 


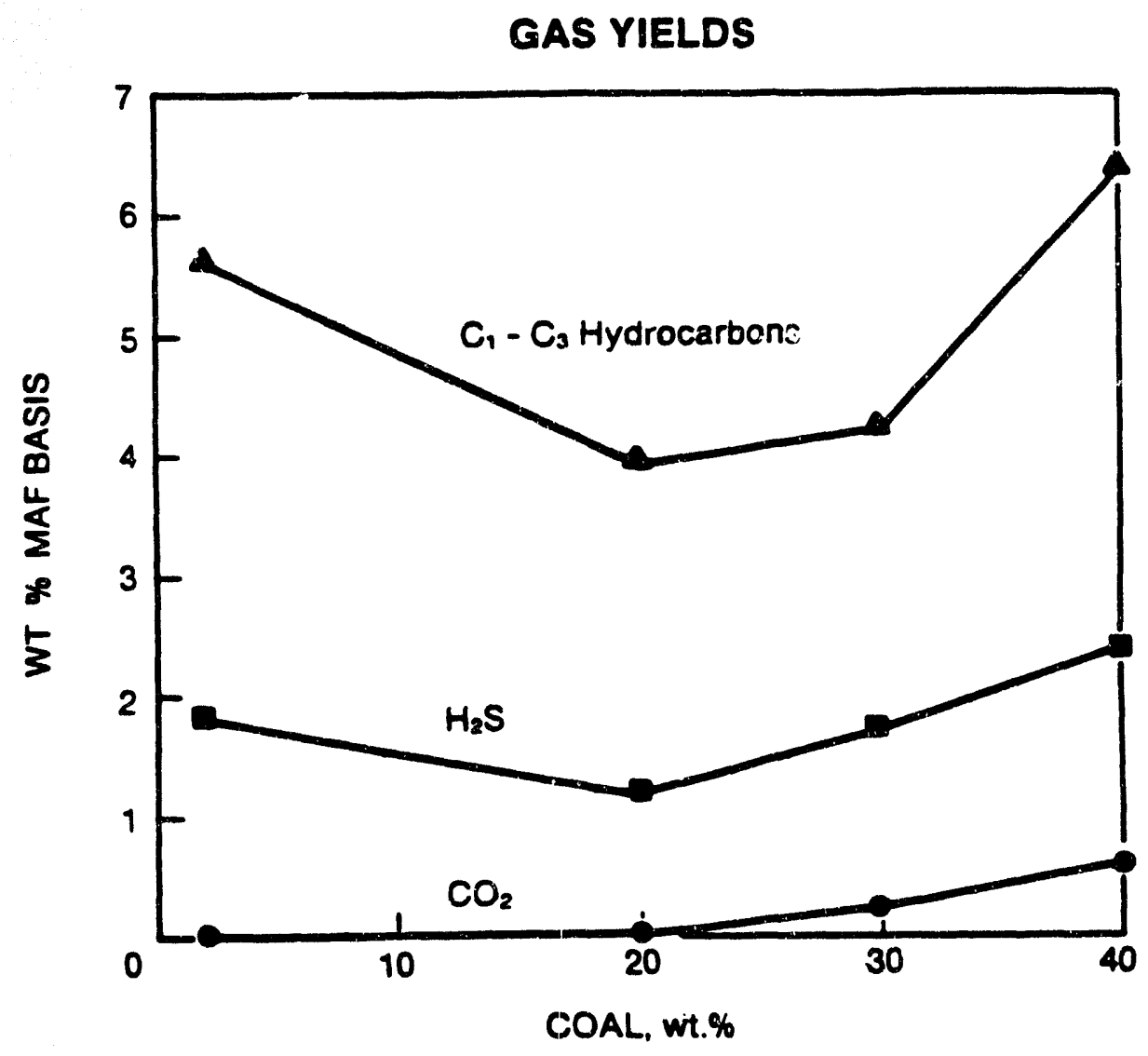

FIGURE 2. - Yields of gaseous products versus coal concentration. 
LIQUID AND SOLID PRODUCT YIELDS

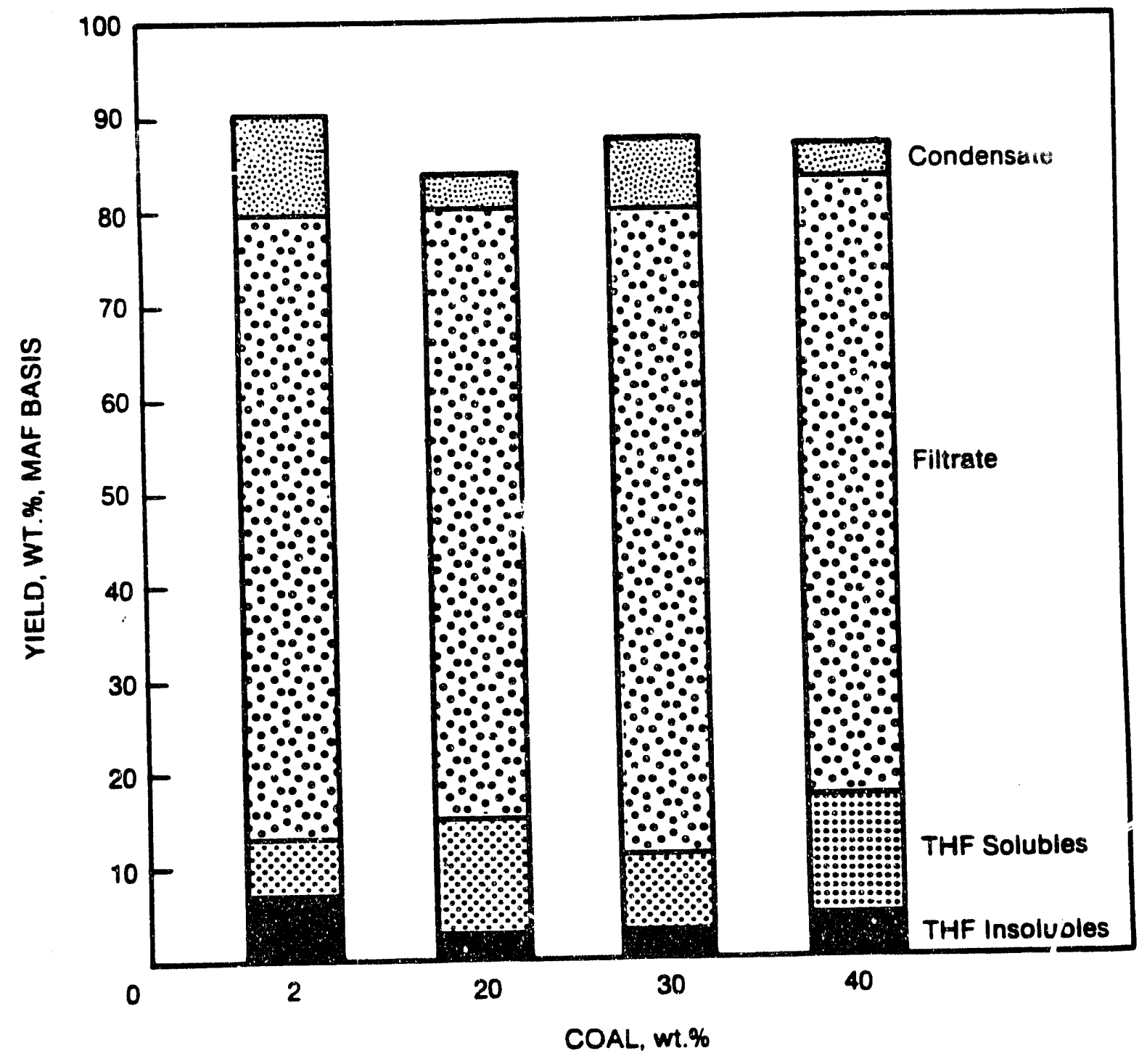

FIGURE 3. - Yields of reactor products versus coal concentration. 
the filtrate. It was decided not to combine these fractions but to analyze them separately. Table 1 shows the H/C molar ratios for the reactants, filtrate, THF solubles, and THF insolubles (IOM). As anticipated, the filtrate is enriched in hydrogen compared to the reactants. The H/C ratios of the filtrate samples show only a small decline with increasing coal content. The THF solubles fractions are quite hydrogen deficient compared to the filtrate. A fraction comparable to this THF soluble fraction, which is distinctly different from the filtrate, is not found in conventional coal liquefaction. This fraction, soluble in THF but insoluble in the coprocessing filtrate, presumably results from the lower solvency of the petroleum coprocessing product compared to more aromatic coal liquefaction products. As anticipated, the THF insolubles (IOM) are quite deficient in hydrogen compared to the other products.

TABLE 1. - Hydrogen/carbon ratios for coprocessing products

\begin{tabular}{|c|c|c|c|c|}
\hline \multirow[b]{2}{*}{ Coal, Percent } & \multicolumn{4}{|c|}{$\mathrm{H} / \mathrm{C}$ Ratios } \\
\hline & 2 & 20 & 30 & 40 \\
\hline Reactants & 1.5 & 1.39 & 1.33 & 1.26 \\
\hline Filtrate & 1.55 & 1.55 & 1.50 & 1.51 \\
\hline THF Solubles & 0.92 & 0.97 & 0.97 & 1.03 \\
\hline THF Insolubles & 0.62 & 0.66 & 0.64 & 0.62 \\
\hline
\end{tabular}

Overall coprocessing yields, based on distillation of filtrate as described in Appendix A, are summarized in Table 2. Yields of selected products versus coal concentration are shown in Figure 4. Overall yields are relatively consistent over the range of coal concentrations investigated; the largest changes in yields occurred between 30 and 40 percent coal. Conversion to $-538^{\circ} \mathrm{C}$ $\left(1000^{\circ} \mathrm{F}\right)$ products $\left[100-\left(>538^{\circ} \mathrm{C}\right.\right.$ resid $\left.\left.+\mathrm{IOM}\right)\right]$ range from 76 to 69 percent with the lowest conversion obtained at the highest coal concentration. The decreased conversion is, of course, reflected in a decreased total distillate yield and increased $>538^{\circ} \mathrm{C}\left(1000^{\circ} \mathrm{F}\right)$ resid yield. The yield of light distillate $\left(<175^{\circ} \mathrm{C}, 347^{\circ} \mathrm{F}\right)$ decreased with increasing coal concentration while the yields of middle $\left(175-350^{\circ} \mathrm{C}, 347-662^{\circ} \mathrm{F}\right)$ and heavy $\left(350-538^{\circ} \mathrm{C}, 662-1000^{\circ} \mathrm{F}\right)$ distillates remained relatively constant. 
TABLE 2. - Overall coprocessing yields

\begin{tabular}{|c|c|c|c|c|}
\hline Coal, Percent & 2 & 20 & 30 & 40 \\
\hline \multicolumn{5}{|c|}{ Normalized Yields, Weight Percent* } \\
\hline Gases $\left(\mathrm{C}_{1}-\mathrm{C}_{7}, \mathrm{CO}_{2}, \mathrm{H}_{2} \mathrm{~S}\right)$ & 8.5 & 6.2 & 7.2 & 10.7 \\
\hline \multicolumn{5}{|l|}{ Distillates } \\
\hline$<175^{\circ} \mathrm{C}\left(347^{\circ} \mathrm{F}\right)$ & 20.5 & 15.5 & 15.8 & 7.9 \\
\hline $175-350^{\circ} \mathrm{C}\left(347-662^{\circ} \mathrm{F}\right)$ & 27.0 & 28.3 & 26.4 & 27.6 \\
\hline $350-538^{\circ} \mathrm{C}\left(662-1000^{\circ} \mathrm{F}\right)$ & 20.1 & 22.2 & 25.5 & 22.8 \\
\hline Total & 67.6 & 66.0 & 67.7 & 58.3 \\
\hline \multicolumn{5}{|l|}{ Nondistillable } \\
\hline$>538^{\circ} \mathrm{C}\left(1000^{\circ} \mathrm{F}\right)$ resid & 17.8 & 24.9 & 22.2 & 26.7 \\
\hline THF Insolubles (IOM) & 6.9 & 2.9 & 2.9 & 4.3 \\
\hline Total & 23.6 & 27.8 & 25.1 & 31.0 \\
\hline Total & 100.0 & 100.0 & 100.0 & 100.0 \\
\hline $538^{\circ} \mathrm{C}+\left(1000^{\circ} \mathrm{F}\right)$ conversion & 76.4 & 72.2 & 74.9 & 69.0 \\
\hline
\end{tabular}

* Based on petroleum resid plus MAF coal. Yields are normalized to 100 percent; raw yields are provided in Table A-8. 


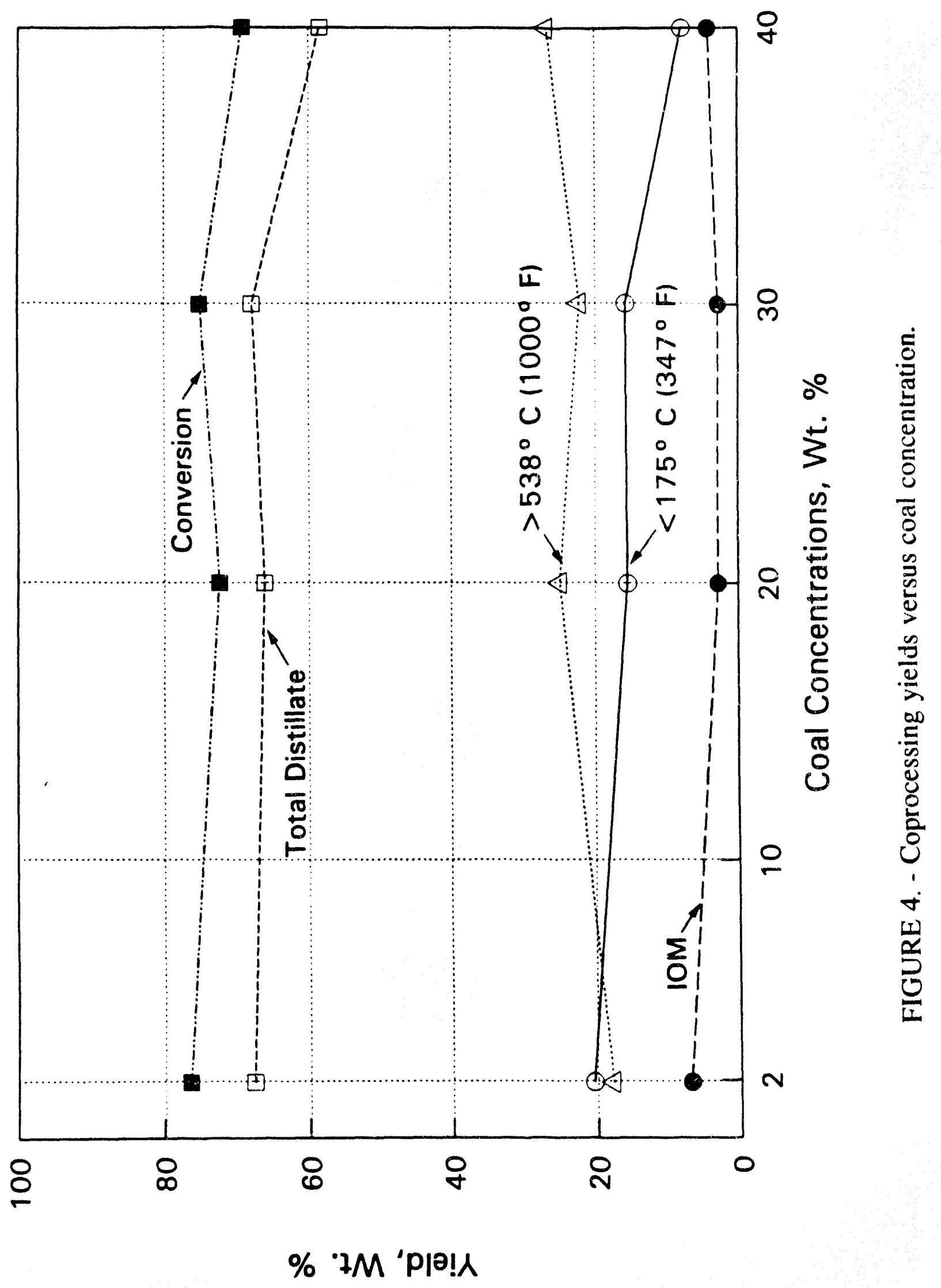




\section{II.B. CARBON ISOTOPE STUDIES}

\section{II.B.1. Summary}

Section II.B. reviews the use of isotope ratios to determine the source of compound classes (e.g., acids, bases, neutrals, aromatics, saturates, etc.) in coprocessing products. Selective isotope fractionation is a complicating factor in the use of carbon isotope ratios to determine the source of coprocessing products. Other researchers have shown that through the use of appiopriate correction factors to correct for this isotope selectivity, isotope ratios can be used to quantitatively determine the source of coprocessing fractions obtained by distillation. It is concluded in this section that although isotope ratios may provide qualitative information on the source of coprocessing compound classes, that the high degree of isotope selectivity in compound classes originating from a single feed prohibits the quantitative determination of the origin of such compound classes.

\section{II.B.2. Introduction}

In this project, two approaches were evaluated as potential methods to distinguish between products originating from coal and those originating from petroleum resid. One is based on the use of carbon isotope ratios and the other is based on variations in compound classes in the coprocessing products in response to changes in the rutio of coal to resid in the coprocessing feed. The use of isotope ratios is discussed in this section and the other approach is discussed in Section II.C.

Other researchers using carbon isotope ratios to determine the origin of products have typically examined distillation fractions. This project involves determination of the origin of specific chemical classes (e.g., saturates, neutral-aromatics, acids, bases, etc.) within each boiling range rather than calculation of coal versus resid contributions based on global examination of whole distillation fractions.

Maya resid and Illinois No. 6 coal (with coal feed varying from 2 to 40 percent) were coprocessed in a batch autoclave to obtain products for detailed analysis. Reaction products were separated into a number of fractions--first by distillation and then by a comprehensive chromatographic separation scheme developed at NIPER (3). The batch autoclave runs are discussed in Section II.A and the chromatographic separations are ciscussed in Section II.C. 
In the absence of complications such as isotope fractionation (discussed below), the application of isotope ratios to determine the source of products is simple and straightforward. If the carbon isoiope ratios, represented by $\delta^{13} \mathrm{C}^{1}$, of two components differ adequately, the amount of each component in a mixture can be determined from $\delta^{13} \mathrm{C}$ for the mixture. Where a product is made up of components $\mathrm{A}$ and $\mathrm{B}$, the amount of each component in the product (more strictly, the amount of carbon in the product arising from each component) can be calculated from the relationship

$$
\text { (1-x) } \delta^{13} C_{A}+x \delta^{13} C_{B}=\delta^{13} C_{\text {Product }}
$$

where $\mathrm{x}=$ the fraction of the carbon in the product arising from component $\mathrm{B}$.

With mixtures. application of the method is straight forward and has been successfully used, for example, with mixtures of natural gas (4).

For determining the contribution of coal carbon and resid carbon to a coprocessing product, the above relationship (in the absence of necessary corrections) becomes

$$
(1-x) \delta^{13} C_{\text {resid }}+x \delta^{13} C_{\text {coal }}=\delta^{13} C_{\text {product }} \quad \text { Eq. } 2
$$

where $\mathrm{x}=$ the fraction of the product carbon arising from the coal.

This equation may be rearranged to the following by which the percentage of coal carbon ( $x$ ) in the priduct may be conveniently calculated. This equation is equivalent to the uncorrected versions of those of Steer et al. (5) or of Burke et al. (6).

$$
x=\frac{\delta^{13} C_{\text {resid }}-\delta^{13} C_{\text {product }}}{\delta^{13} C_{\text {resid }}-\delta^{13} C_{\text {coal }}} \times 100
$$

Carbon-13 isotope ratios of coal are typically on the order of -25 per mil $(-24.56$ for the Illinois No. 6 coal used in this work) and petroleum resids, while more variable, are generally

\footnotetext{
1 Carbon isotope ratios in this work are represented by $\delta^{13} \mathrm{C}$ which by conve:tion is the difference between the sample and a reference material, Peedee Belemnite (PDB), in parts per thousand or parts per mil. Carton isotope ratio values $\left(\delta^{13} \mathrm{C}\right)$ are deternined by the relation $\delta^{13} \mathrm{C}=1000\left(\mathrm{R}\right.$ samp $\left.-R_{\text {ref }}\right) / R_{\text {ref }}$ where $R$ is the ratio ${ }^{13} \mathrm{C} /{ }^{12} \mathrm{C}$ in the sample and reference materials.
} 
isotopically lighter; i.e., more negative $\delta^{13} \mathrm{C}(-27.56$ for the Maya vacuum resid used in this work). Repeatability of the $\delta^{13} \mathrm{C}$ measurement is generally better than 0.1 per mil allowing for good accuracy in the cietermination of the source of carbon in coprocessing products for properly selected pairs of reactants in the absence of complicating factors.

It is now well established that complicating factors require that various corrections be made in order to use isotope ratios to determine the source of products of coprocessing. Corrections have been used by Steer et al. (5), and by Ohio Ontario Clean Fuels, inc. (isotope methods credited to Alberta Research Council and the University of Alberta) (7). Corrections required for the accurate carbon sourcing of coprocessing products have been studied most extensively by Winschel et al. at Consolidation Coal Co. (8).

The complications in application of isotope ratios to determine the source of coprocessing products arises from the facts that neither coal nor petroleum are isotopically homogeneous and, more importantly, to isotopic fractionation during coprocessing. Carbon-13 heterogeneity has been reported for both coal (2), and petroleum. Carbon isotope ratios for petroleum vary with boiling range (10), and by compound class (11).

Selective isotopic fractionation results from the kiretic isotope effect. Due to differences in bond energies, there is a tendency for certain fractions to become enriched in one of the two stable carbon isotopes during molecular weight reduction. This is most evident in the formation of hydrocarbon gas formed from the decomposition of higher molecular weight hydrocarbons. For example, in the pyrolysis of n-octadecane, there is a substantial enrichmeni of the methane in ${ }^{12} \mathrm{C}(12)$.

To correct for isotopic fractionation, Winschel et al. (8) developed a correction procedure based on the following three assumptions:

1. the carbon in the gas is formed from the two feedstocks in proportion to the carbon fed to the unit from each feedstock,

2. the difference between $\delta^{13} \mathrm{C}$ for each feedstock and $5^{13} \mathrm{C}$ for the gas produced from that feedstork is the same for the coal ard the petroleum, and

3. the non-gas producing carbon undergoes no further selective isotopic fractionation. 
Although the assumptions are not strictly true, Winschel et al. (8) argued that the likely errors in the assumptions do not dramatically effect results of carbon sourcing based on isotope ratios with corrections based on these assumptions. Note that the primary use of these corrections was in the application of carbon isotope ratios to determine the source of distillation fractions. Discussion of assumptions necessary to determine the source of compound classes through the use of isotope ratios is included in the following section.

\section{II.B.3 Results and Discusaion}

The application of isotope ratios for determining the source of coprocessing products separated by distillation was discussed in the prior section. This section will critically review the findings of this project related to the use of isotope ratios for determination of the origin of compound class fractions obtained in coprocessing.

The batch autoclave procedures used in this study were discussed in Section II.A and experimental details are provided in Appendix A. Carbon isotope ratios were first determined on reactor products with minimal prior separation. Results are summarized in Table 3 and partial results are plotted in Figure 5. The $\delta^{13} \mathrm{C}$ values for the feed materials are included as is the calculated $\delta^{13} \mathrm{C}$ for the feed blend (based on the $\delta^{13} \mathrm{C}$ values for the resid and coal, the fractional amounts of coal and resid used, and the carbon analyses of 84.6 weight percent for the resid and 69.8 weight percent for the coal).

Gaseous products were examined in more detail than has typically been done in isotope studies in coprocessing; in particular, carbon dioxide was separated from the hydrocarbon gases and analyzed separately. The $\delta^{13} \mathrm{C}$ values for carbon dioxide from the various runs are nearly identical as would be expected since it is derived almost exclusively from the coal. The origin of carbon dioxide from coal is, of course, already established and is consistent with the variation of carbon dioxide yields with coal concentration shown in this project. The $\delta^{13} \mathrm{C}$ value for carbon dioxide is significantly different from coal or the reaction mix and may indicate that it is formed, at least in part. from mineral decomposition rather than decarboxylation of organic coal components. Carbon dioxide produced by the treatmeni of coal with hydrochloric acid and trapped as barium carbonate had a $\delta^{13} \mathrm{C}$ of -2.62 . The anount of barium carbonate recovered indicated a carbonate content of 0.58 percent $\mathrm{CaCO}_{3}$ or 0.255 percent $\mathrm{CO}_{2}$. If all of the carbonate decornposed during coprocessing, and it is assumed that the balance of the $\mathrm{CO}_{2}$ was supplied by coal at $\delta^{13} \mathrm{C}=-24.56$, abuut 25 percent of the carbon dioxide originated from the coal mineral and the remainder from the organic content of the coal. 
TABLE 3. - Carbon isotope ratios for reactor products

\begin{tabular}{|c|c|c|c|c|}
\hline \multirow[b]{2}{*}{ Coal, perceni } & \multicolumn{4}{|c|}{$8^{13} \mathrm{C}$} \\
\hline & 2 & 20 & 30 & 40 \\
\hline Feed blend & -27.51 & -27.05 & -2.6 .79 & -26.51 \\
\hline $\mathrm{CO}_{2}$ & ND & -18.87 & -18.88 & -19.13 \\
\hline Hydrocarbon gas & -36.32 & -37.60 & -34.31 & -34.46 \\
\hline Filtrate & -26.44 & -26.17 & -26.18 & -26.00 \\
\hline THF solubles & -27.53 & -26.89 & -26.50 & -26.05 \\
\hline THF insolubles & -27.50 & -26.38 & -25.58 & 25.70 \\
\hline Feed components & \multicolumn{4}{|c|}{$\delta^{13} \mathrm{C}$} \\
\hline Maya resid & \multicolumn{4}{|c|}{-27.56} \\
\hline Illinois No. $6 \mathrm{coal}$ & \multicolumn{4}{|c|}{-24.56} \\
\hline
\end{tabular}




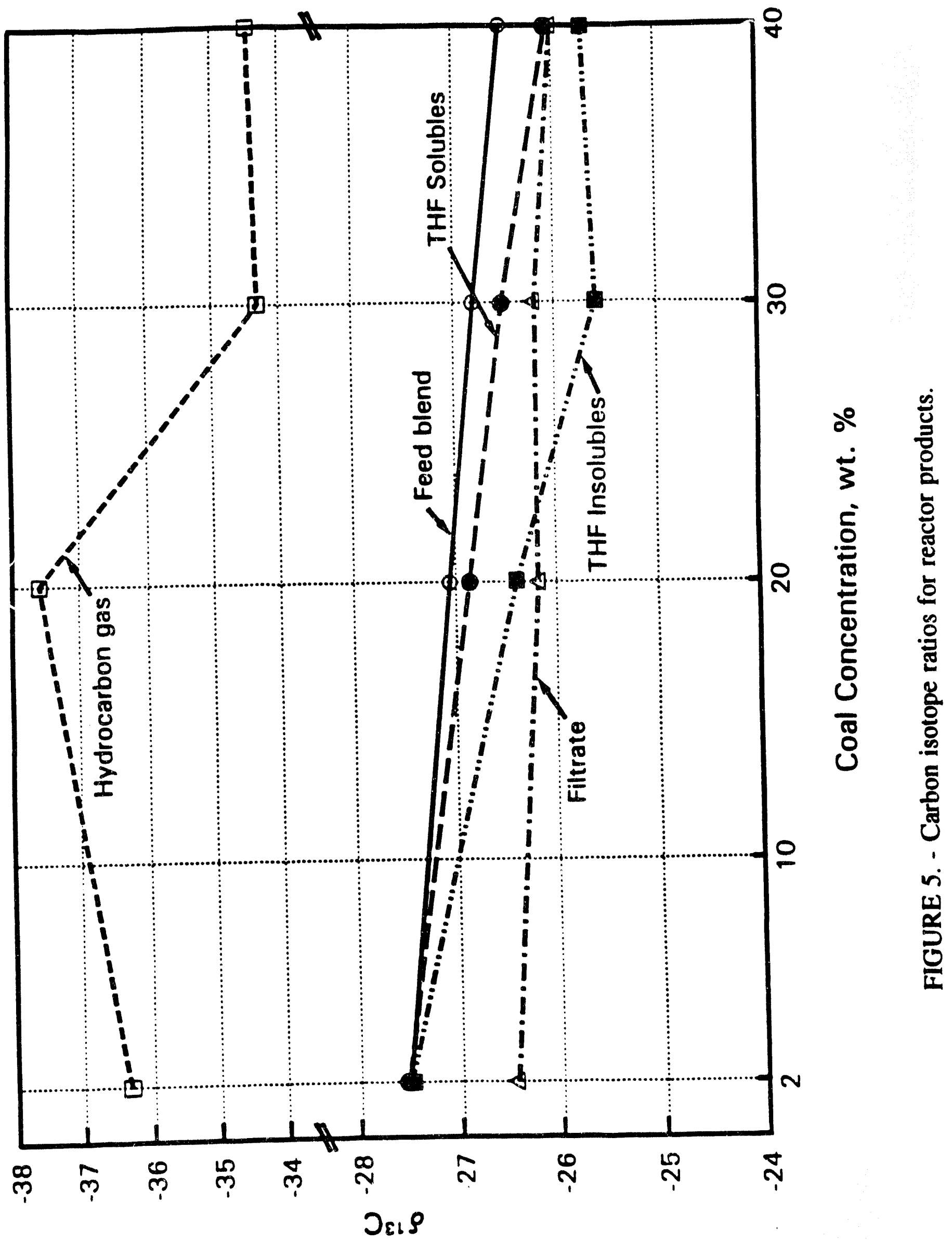


As noted in Section II.B.2, any isotope fractionation complicates interpretation of isotope ratio data. The severity of isotope fractionation which can occur in coprocessing is evident even in these initial results (Figure 5). The hydrocarbon gas samples were much lighter isotopically (more negative $\delta^{13} \mathrm{C}$ values) than the feed or the condensed products. Differences in $\delta^{13} \mathrm{C}$ between the hydrocarbon gas and the feed were 7.5 to 10.5 per mil. This is true even at the lowest coal concentration ( 2 weight percent) where nearly all of the gas must have arisen from the petroleum resid. This difference is similar to that reported by other workers. For example, Winschel et al. (8) reported that forced isotope balances indicated that the gases from petroleum pyrolysis must have isotope ratios 6 to 8 per mil lighter than the respective feedstocks (although analysis indicated that the gases were isotopically heavier than the respective feedstocks). The separation of carbon dioxide in this work directionally contributes to a larger difference between the gas and the feedstock but this effect, although measurable, is minor (due to the low carbon dioxide yield) compared to the overall isotope fractionation.

As is evident in Figure 5, there is not a regular trend in $\delta^{13} \mathrm{C}$ for the hydrocarbon gases with varying coal concentration in the feed. The random variations in $\delta^{13} \mathrm{C}$ for the hydrocarbon gases reported in this work are likely to be related to difficulties in transfer of $\mathrm{C}_{2}-\mathrm{C}_{5}$ from the charcoal trap to the pressurized sample vessel. At the two higher coal concentrations, $\delta^{13} \mathrm{C}$ for the hydrocarbon gases is less negative (more coal like) but the very large isotope fractionation effect negates any possibility of determining the source of the hydrocarbon gases by isotope ratios.

The more negative $\delta^{13} \mathrm{C}$ values for the hydrocarbon gases (depleted in ${ }^{13} \mathrm{C}$ ) are balanced by the sum of the liquid and solid products having $\delta^{13} \mathrm{C}$ values less negative (enriched in ${ }^{13} \mathrm{C}$ ) than the feed. In contrast to the hydrocarbon gases, trends in carbon isotope ratios for the remainder of the reactor products more or less paralleled those of the reactor feed (Figure 5).

The $\delta^{13} \mathrm{C}$ for the filtrate (the primary reactor product) tended to follow that of the reactor feed but the overall range in $\delta^{13} \mathrm{C}$ was quite small--varying only from -26.4 to -26.0 . Due to isotope fractionation leaving the condensed products enriched in carbon-13, the filtrate appears to be more coal-like than the feed blend. The obvious need for correction for isotope fractionation can be shown by application of Eq. 3 to the 2 percent coal run without an isotope fractionation correction. The uncorrected application of Eq. 3 indicates that 37 percent of the filtrate arose from coal--a meaningless conclusion since the feed contained only 2 percent coal. With an increase in coal concentration from 2 to 40 percent, the contribution of coal to the filtrate has to have increased substantially based on mass balance considerations; this magnitude of increase is not shown by the small change in $\delta^{13} \mathrm{C}$. 
Significant isotopic fractionation also occurred between the filtrate and THF soluble phase. The largest difference was in the run with 2 percent coal--an unexpected difference since both of these fractions must be derived almost entirely from the petroleum resid. The difference decreased with increasing coal concentration to almost nil in the 40 percent coal run. $\delta^{13} \mathrm{C}$ for the THF solubles followed that of the feed--becoming more coal-like with increasing coal concentration.

The most pronounced increase (becoming less negative) in $\delta^{13} \mathrm{C}$ with changing coal concentration occurred in the THF insolubles which qualitatively indicated coal to be the primary source of this fraction.

Each filtrate was distilled to produce three distillate cuts and a resid. Isotope ratio data for the distillatior fractions are summarized in Table 4 and are plotted in Figure 6. Isotope fractionation is apparent in the 2 percent coal run with the light distillate $\left(<175^{\circ} \mathrm{C}\right)$ isotopically lighter than the filtrate $\left(-27.08\right.$ per mil for the $<175^{\circ} \mathrm{C}$ distillate versus -26.44 for the fiitrate). This trend holds for the other runs also with $\delta^{13} \mathrm{C}$ for the $<175^{\circ} \mathrm{C}$ distillate $1.08,1.22$, and 1.05 per mil lighter than the corresponding filtrate for the 20,30 and 40 percent coal runs, respectively. As is apparent in Figure 6 , there is not a regular trend in $\delta^{13} \mathrm{C}$ for the $<175^{\circ} \mathrm{C}$ distiilate with both the 2 and 40 percent coal runs having essentually identical $\delta^{13} \mathrm{C}$ values $(-27.08$ and -27.05 , respectively). Similarly, the range in $\delta^{13} \mathrm{C}$ for the $175-350^{\circ} \mathrm{C}$ distillate is small and the trend is irregular varying only from -26.16 to -26.45 . Except for the $<175^{\circ} \mathrm{C}$ distillate, there is a general correlation between $\delta^{13} \mathrm{C}$ for the feed blend and the distillation products for the 20,30 and 40 percent coal runs.

Table 4 includes a comparison of the measured values of $\delta^{13} \mathrm{C}$ for the filtrate with those recalculated from the yields of the distillation fractions and their measured $\delta^{13} \mathrm{C}$ values. The average absolute difference between the measured and calculated values is 0.10 per mil indicating good accuracy for the carbon isotope measurements and distillation mass balance.

Each of the distillates were separated into acid, base and neutral fractions by standard NIPER methods (Section II.C.3) and isotope ratios were determined for each fraction. Results are summarized in Table 5 and are plotted in Figures 7 and 8 . Isotopic fractionation is apparent throughout including the run with only 2 percent coal. The neutral materials show depletion in 
TABLE 4. - Carbon isotope ratios values for distillation fractions

\begin{tabular}{|lrrrr|}
\hline & \multicolumn{4}{c}{$\delta^{13} \mathrm{C}$} \\
\cline { 2 - 5 } Coal, percent & \multicolumn{1}{c|}{20} & \multicolumn{1}{c|}{30} & \multicolumn{1}{c|}{40} \\
\hline & & & & \\
Total filtrate, measured & -26.44 & -26.17 & -26.18 & -26.00 \\
Total filtrate, recalculated & -26.55 & -26.38 & -26.22 & -25.96 \\
Difference $^{\mathrm{a}}$ & 0.11 & 0.21 & 0.04 & -0.04 \\
& & & & \\
$>175^{\circ} \mathrm{C}\left(<347^{\circ} \mathrm{F}\right)$ & -27.08 & -27.25 & -27.40 & -27.05 \\
$175-350^{\circ} \mathrm{C}\left(347-662^{\circ} \mathrm{F}\right)$ & -26.38 & -26.45 & -26.38 & -26.16 \\
$350-538^{\circ} \mathrm{C}\left(662-1000^{\circ} \mathrm{F}\right)$ & -26.24 & -26.05 & 25.92 & 25.75 \\
$>538^{\circ} \mathrm{C}\left(>1000^{\circ} \mathrm{F}\right)$ & -26.94 & 26.14 & -25.92 & 25.71 \\
\hline
\end{tabular}

a measured-recalculated 
TABLE 5. - Carbon isotope ratios for distillate acid-base-neutral fractions

\begin{tabular}{|c|c|c|c|c|}
\hline \multirow[b]{2}{*}{ Coal, percent } & \multicolumn{4}{|c|}{$\delta^{13} \mathrm{C}$} \\
\hline & 2 & 20 & 30 & 40 \\
\hline \multicolumn{5}{|l|}{$175-350^{\circ} \mathrm{C}$ fractions } \\
\hline Whole distillate, measured & -26.38 & -26.45 & -26.38 & -26.16 \\
\hline Whole distillate, recalculated & -26.37 & -26.48 & -26.42 & -26.09 \\
\hline Difference ${ }^{a}$ & -0.01 & 0.02 & 0.04 & -0.07 \\
\hline Acids & -25.88 & -24.51 & -24.83 & -24.33 \\
\hline Bases & -24.80 & -24.19 & -24.84 & -23.94 \\
\hline Neutrals & -26.41 & -26.68 & -26.67 & -26.39 \\
\hline \multicolumn{5}{|l|}{$350-538^{\circ} \mathrm{C}$ fractions } \\
\hline Whole distillate, measured & -26.24 & -26.05 & -25.92 & -25.75 \\
\hline Whole distillate, recalculated & -26.30 & -26.15 & -26.07 & -25.79 \\
\hline Difference $^{a}$ & 0.06 & 0.10 & 0.15 & -0.04 \\
\hline Acids & -25.64 & -25.54 & -25.15 & -24.50 \\
\hline Bases & -25.42 & -24.77 & -24.74 & -24.41 \\
\hline Neutrals & -26.43 & -26.34 & -26.39 & -26.19 \\
\hline
\end{tabular}

a measured-recalculated 


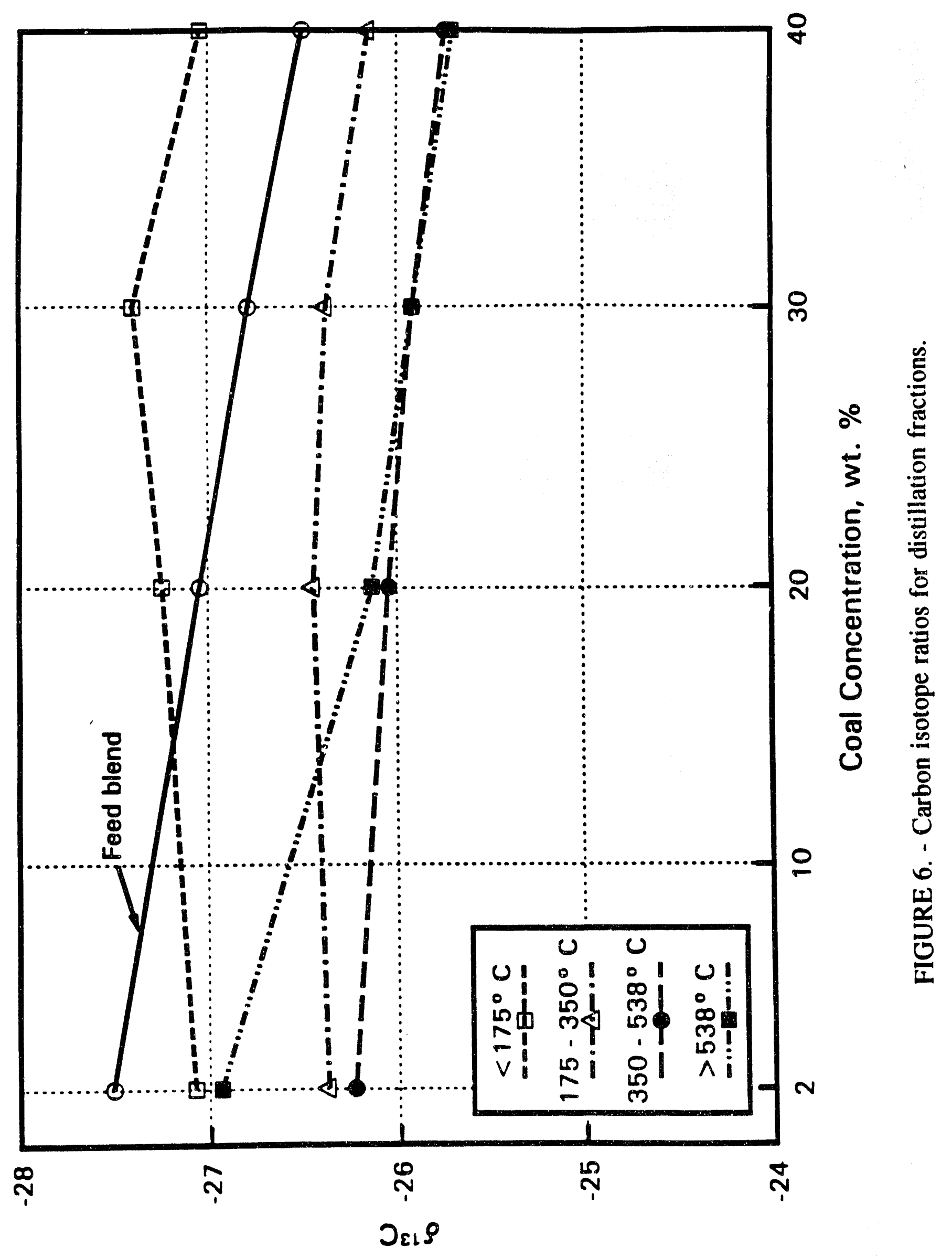




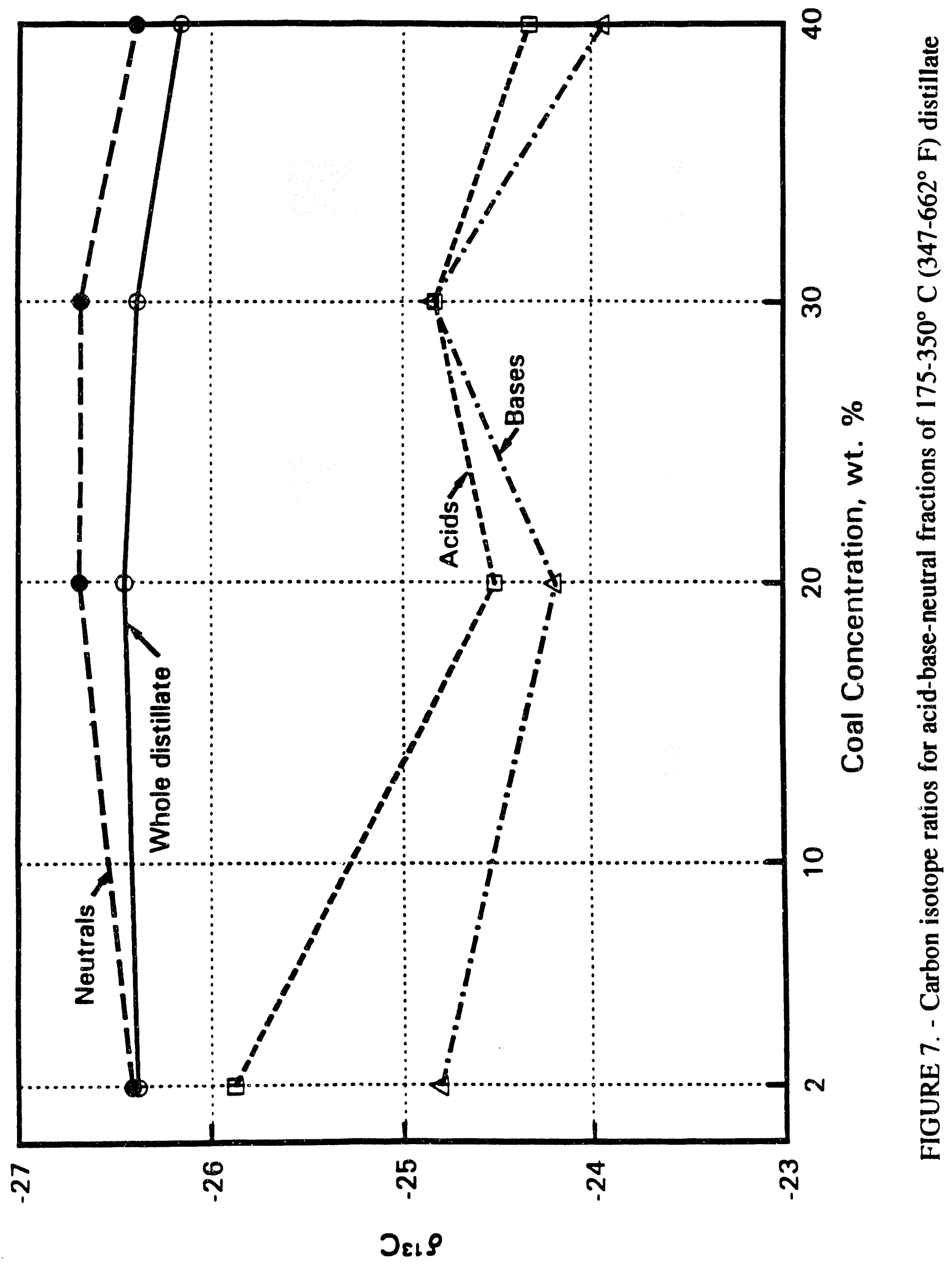




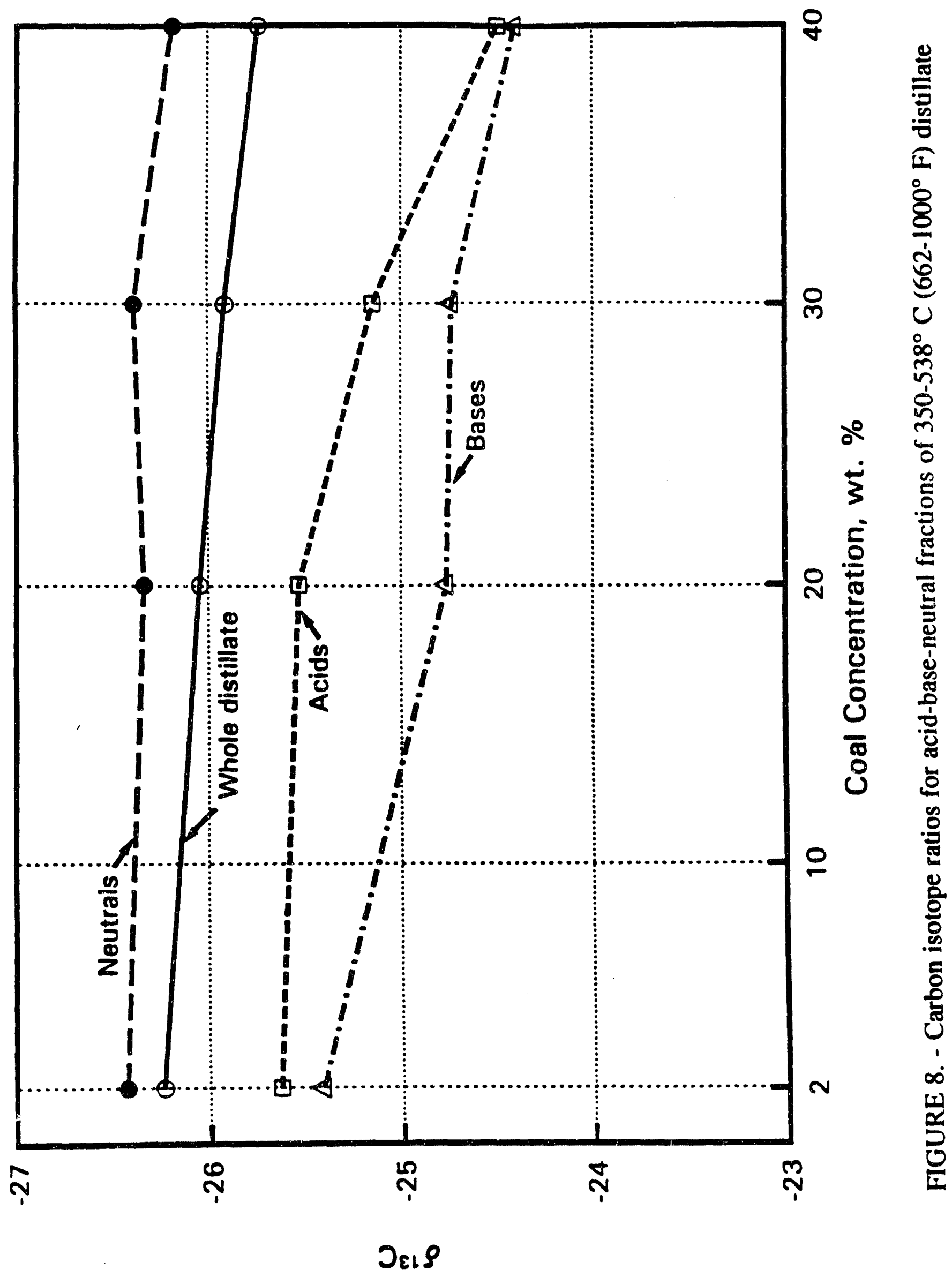


${ }^{13} \mathrm{C}$ while polar materials are enriched (less negative $\delta^{13} \mathrm{C}$ ). The significant range of isotope ratios in products from the 2 percent coal run demonstrates the substantial isotope fractionation occurring during reaction of petroleum resid itself. For example, in the $175-350^{\circ} \mathrm{C}$ distillate, the base fraction is 1.61 per mil isotopically heavier than the neutral fraction while in the $350-538^{\circ} \mathrm{C}$ distillate, the difference is 1.01 per mil. The $\delta^{13} \mathrm{C}$ value for the base fraction from the 2 percent coal run $175-350^{\circ} \mathrm{C}$ distillate approaches the value for coal $(-24.56)$.

The acids and bases from the runs with higher coal concentrations are more coal-like (less negative $\delta^{13} \mathrm{C}$. This is qualitatively in agreement with studies of changes in product composition with changing coal concentration which indicated that coal was the primary source of acid and base fractions. However, the large isotope fractionation seen in the 2 percent coal run makes a quantitative assessment of the source of the acids or bases in coprocessing problematic.

The $\delta^{13} \mathrm{C}$ values for the whole distillates can be recalculated from the $\delta^{13} \mathrm{C}$ values for the separated components and the yields of the fractions. The recalculated values and the differences between the measured and recalculated values are included in Table 5 . The excellent agreement between the measured and calculated values confirms the quality of the product fractions and the quality of the $\delta^{13} \mathrm{C}$ measurements. Significant contamination of the fractions with solvents used in the separations would result in poor ${ }^{13} \mathrm{C}$ balances. Average absolute variations between the measured and calculated values are 0.04 per mil for the $175-350^{\circ} \mathrm{C}$ distillate and 0.09 per mil for the $350-538^{\circ} \mathrm{C}$ distillates.

Neútral fractions were separated by NIPER techniques (Section II.C.3) into saturate and aromatic fractions. Isotope ratios for the whole neutrals and saturate and aromatic subfractions are included in Table 6 and are plotted in Figures 9 and 10. Again, measured $\delta^{13} \mathrm{C}$ values for the whole fraction are compared with that recalculated from the yields and $\delta^{13} \mathrm{C}$ values for the subfractions. The calculated $\delta^{13} \mathrm{C}$ values would include effects of errors in yield determination, isotope ratio measurement, solvent content of the fractions and any other contamination. Agreement is again excellent with the average absolute differences being 0.05 per mil for the 175 $350^{\circ} \mathrm{C}$ fractions and 0.02 for the $350-538^{\circ} \mathrm{C}$ fractions.

Differences between $\delta^{13} \mathrm{C}$ for the saturate and aromatic fractions are included in Table 6 . The largest differences were observed for 2 percent coal run. As noted previously, essentially all of the neutral compounds in this product must have originated from the Maya resid alone; thus, the difference in $\delta^{13} \mathrm{C}\left(0.98 \mathrm{per}\right.$ mil for the $175-350^{\circ} \mathrm{C}$ fraction and 1.13 for the $350-538^{\circ} \mathrm{C}$ fraction) is reflecting the selective nature of isotope distribution in products originating from the petroleum resid. 
TABLE 6. - Carbon isotope ratios for neutral subfractions

\begin{tabular}{|c|c|c|c|c|}
\hline \multirow[b]{2}{*}{ Coal, percent } & \multicolumn{4}{|c|}{$\delta^{13} \mathrm{C}$} \\
\hline & 2 & 20 & 30 & 40 \\
\hline \multicolumn{5}{|l|}{$175-350^{\circ} \mathrm{C}$} \\
\hline Neutrals, measured & -26.41 & -26.68 & -26.67 & -26.39 \\
\hline Neutrals, recalculated & -26.47 & -26.67 & -26.70 & -26.50 \\
\hline Difference ${ }^{a}$ & 0.06 & -0.01 & 0.03 & 0.11 \\
\hline Saturate subfraction & -25.95 & -26.40 & -26.54 & -26.32 \\
\hline Aromatic subfraction & -26.93 & -27.05 & -26.82 & -26.59 \\
\hline Difference (sat-aromatic) & 0.98 & 0.65 & 0.28 & 0.27 \\
\hline \multicolumn{5}{|l|}{$350-538^{\circ} \mathrm{C}$} \\
\hline Neutrals, measured & -26.43 & -26.34 & -26.39 & -26.19 \\
\hline Neutrals, recalculated & -26.44 & -26.39 & -26.37 & -26.19 \\
\hline Difference ${ }^{a}$ & 0.01 & 0.05 & -0.02 & 0.00 \\
\hline Saturate suhfraction & -25.61 & -26.11 & -26.28 & -26.01 \\
\hline Aromatic subfraction & -26.74 & -26.52 & -26.40 & -26.27 \\
\hline Difference (sat-aromatic) & 1.13 & 0.41 & 0.12 & 0.26 \\
\hline
\end{tabular}

Interestingly, carbon isotope ratios for saturate fractions from products where 20 to 40 percent coal was added are more negative than those from the corresponding 2 percent coal run. The trend opposes that of the acid and base fractions as well as that for the coal versus resid. This may result from isotopic fractionation within the oal or a shift in isotopic fractionation within saturates from the resid in the presence of coal. Furthermore, differences between $\delta^{13} \mathrm{C}$ for the aromatic and distillate fractions decreases strongly although somewhat erratically with increasing coal content.

a measured-recalculated 


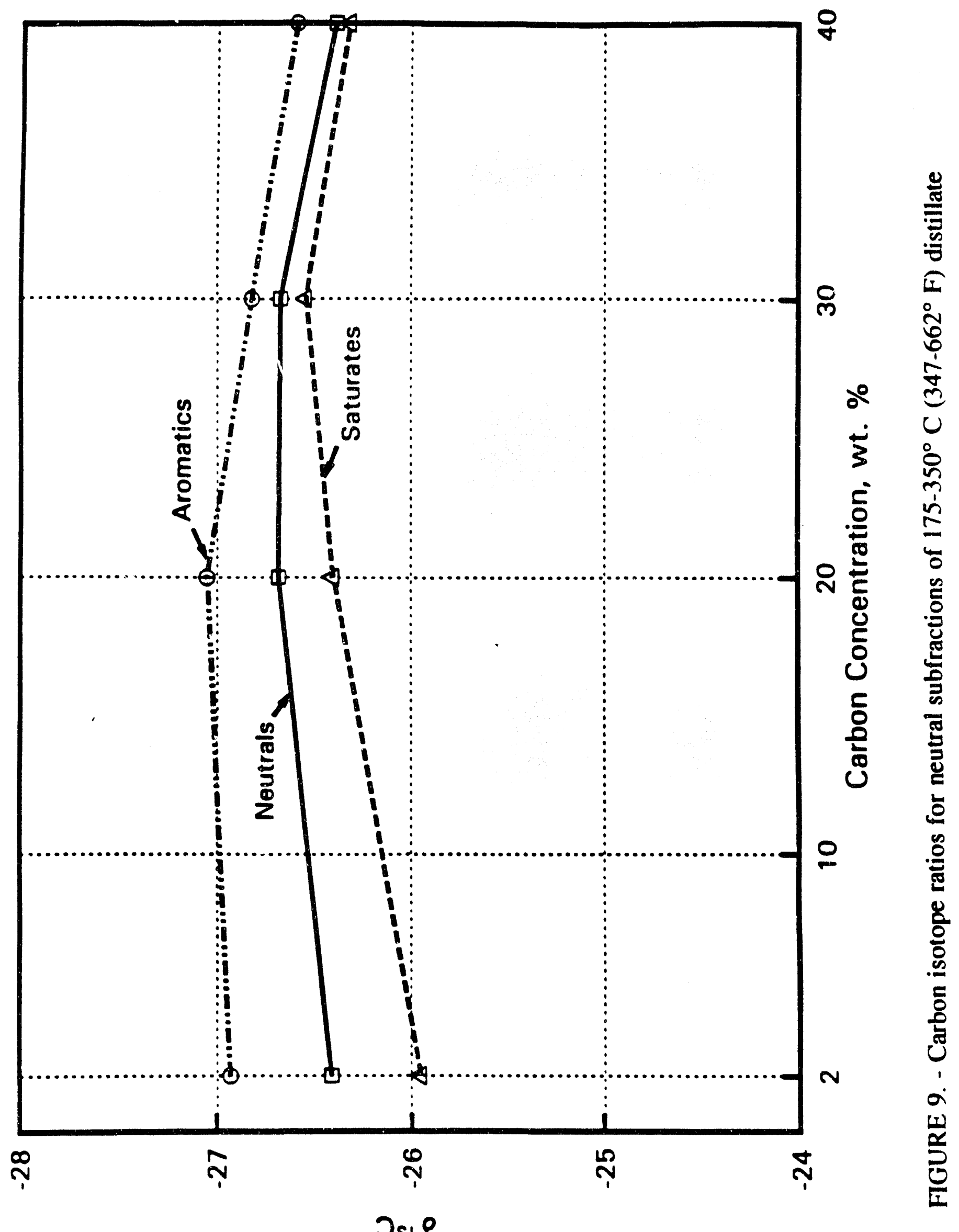




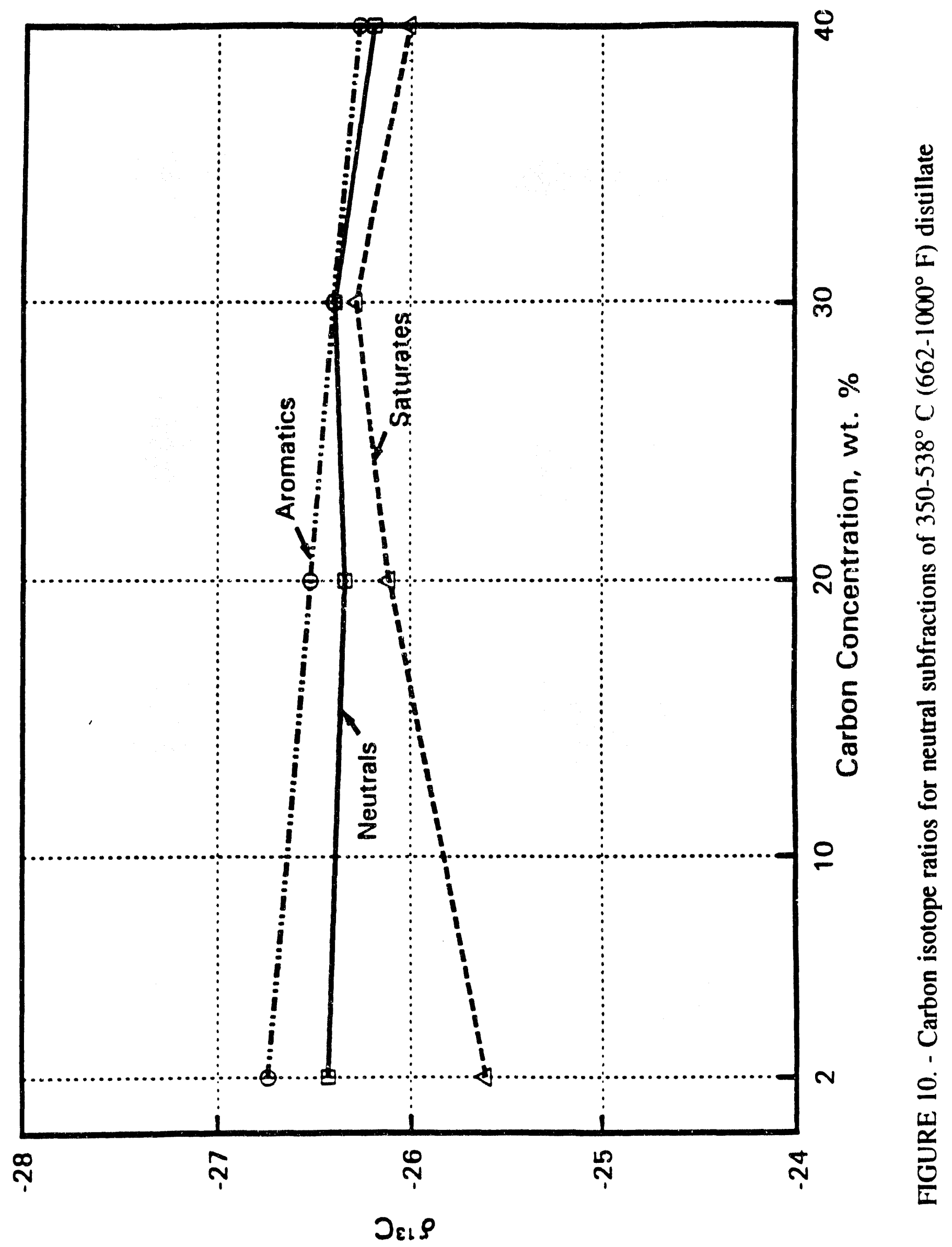


This suggests that coal-derived neutral prnducts differ from petroleum resid-derived materials in selective isotope distribution. A possible explanation consistent with this observation is that saturates derived from coal may be more naphthenic, having been derived from aromatics by hydrogenation.

Resid fractions were separated into five fractions (strong acids, weak acids, strong bases, weak bases and neutrals) rather than the three fractions produced from the distillates. The samples showed poorer solubility in the solvents used in the LC separation than is typical for petroleum samples and recoveries fell in the range of 82 to 90 percent. Results for the carbon isotope ratio measurements for the resid fractions are shown in Table 7 . Again, a comparison of the measured values for the whole resids with the values recalculated from the fraction yields and the fraction $\delta^{13} \mathrm{C}$ measurements are included. In contrast to all of the earlier results, the recalculated values are significantly more negative (isotopically lighter) by 0.3 to 0.5 per mil relative to the measured values for the whole resid. The differences are probably caused by retention of solvent in the subfractions.

Isotope fractionation in resid from the 2 percent coal run is apparent, but it differs from that of the distillate fractions. For the distillate fractions, $\delta^{13} \mathrm{C}$ for the acids was 0.5 to 0.6 less negative than for the neutrals while for the resid, $\delta^{13} \mathrm{C}$ for the weak and strong acid fractions were slightly more negative (probably within experimental error considering the poorer ${ }^{13} \mathrm{C}$ balance for the resid fractionation) than $\delta^{13} \mathrm{C}$ for the neutrals. The bases in the resid fractions were isotopically heavier (less negative $\delta^{13} \mathrm{C}$ ) than the neutrals as was observed for the distillates but the effect was less pronounced. The difference between $\delta^{13} \mathrm{C}$ for the neutrals and bases decline with increasing boiling point as shown below:

$$
\begin{aligned}
& 175-350^{\circ} \mathrm{C} \text { distillate } \\
& 350-538^{\circ} \mathrm{C} \text { distillate } \\
& >538^{\circ} \mathrm{C} \text { resid }
\end{aligned}
$$

$\Delta \delta^{13} \mathrm{C}^{*}$

$-1.61$

$-1.01$

$-0.24$

* $\delta^{13} C_{\text {neutrals }}-\delta^{13} C_{\text {bases }}$; used average of strong and weak bases for the resid fractions

As boiling point is increased, the polar fraction of the molecule which caused it to segregate into the acid or base fraction becomes a smaller part of the overall molecule. As the carbon isotope heterogeneity is presumably associated with the polar segment of the molecule, this is probably the reason for the decreased difference in $\delta^{13} \mathrm{C}$ values between polar and neutral fractions with increasing boiling point. 


\section{TABLE 7. - Carbon isotope ratios for coprocessing resid subfractions}

\begin{tabular}{|lccc|}
\hline & \multicolumn{3}{c|}{$\delta^{13} \mathrm{C}$} \\
\cline { 2 - 4 } Coal, percent & 2 & 20 & 40 \\
\hline & & & \\
Whole resid, measured & -26.90 & -26.13 & -25.76 \\
Whole resid, recalculated & -27.22 & -26.64 & -26.14 \\
Difference & 0.32 & 0.51 & 0.38 \\
& & & \\
Neutrals & -27.19 & -26.64 & -26.51 \\
Strong acids & -27.37 & -26.88 & -25.90 \\
Weak acids & -27.46 & -26.75 & -26.49 \\
Strong bases & -26.94 & -26.07 & -25.65 \\
Weak bases & -26.96 & -26.22 & -26.39 \\
\hline
\end{tabular}

Figure 11 shows the carbon isotope ratios of the resid fractions from the various coprocessing runs. Although there are some irregularities, $\delta^{13} \mathrm{C}$ for all of the fractions tend to follow that of the feed blend qualitatively indicating the expected increase in coal-like character with increasing feed level of coal.

Bécause of the variations in $\delta^{13} \mathrm{C}$ for the various fractions from the 2 percent coal run demonstrating isotope fractionation, an analogous set of measurements was made on Maya crude. These fractions were prepared directly from the crude oil without application of hydrogenation or any other processing chemistry. Carbon isotope ratios for the Maya crude fractions are provided in Table 8. Differences in $\delta^{13} \mathrm{C}$ for the various boiling range fractions are much smaller than for the coprocessing products from the 2 percent coal run. For example, in the 2 percent coal run the difference between the $<175^{\circ} \mathrm{C}$ distillate and the whole filtrate was 0.64 per mil while for the unprocessed crude, the difference between the $<175^{\circ} \mathrm{F}$ fraction and the whole crude was only 0.05 per mil. In fact, the whole range in distillation cuts for the Maya crude was only 0.12 per mil.

a measured-recalculated 


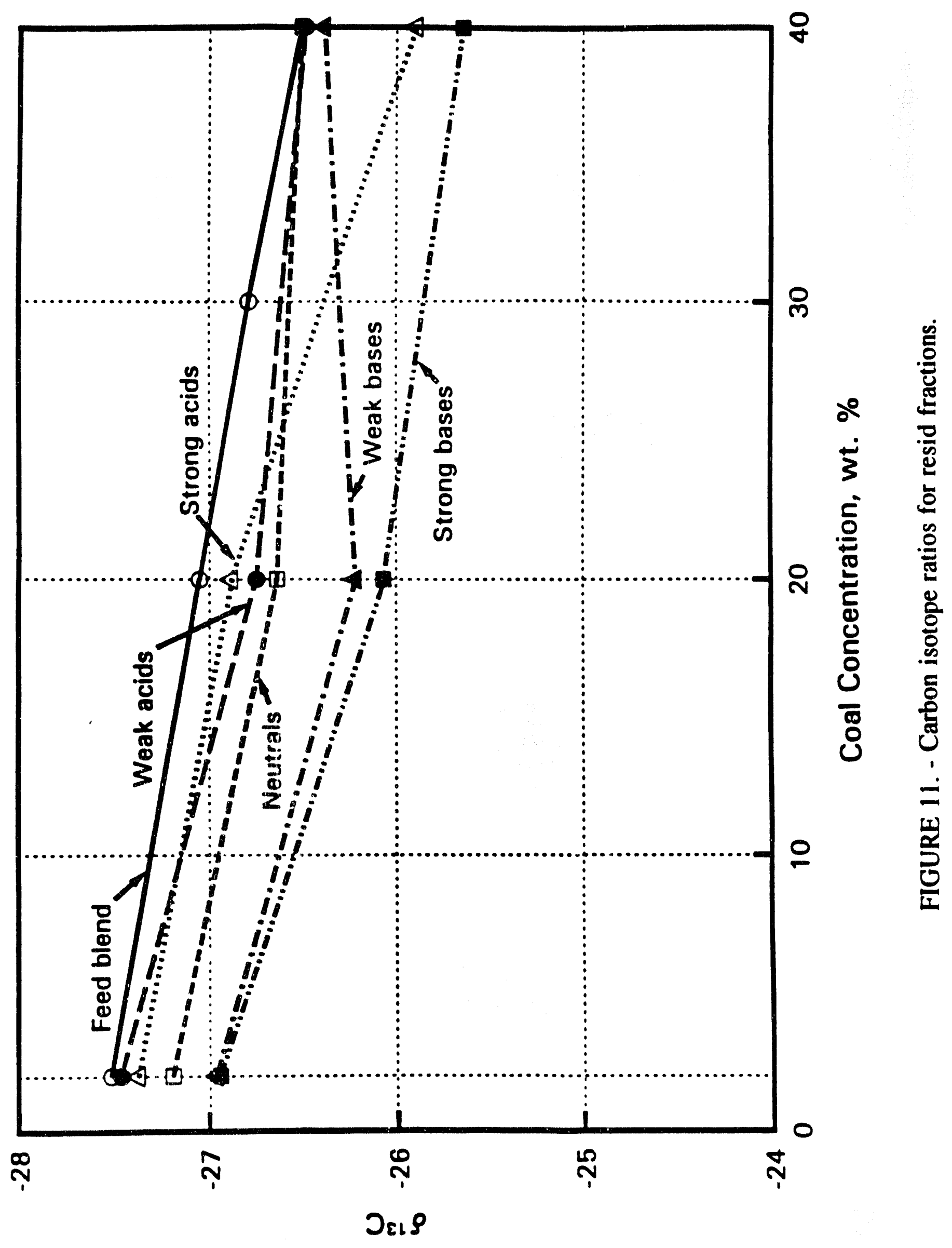


TABLE 8. - Carbon isotope ratios for Maya crude fractions

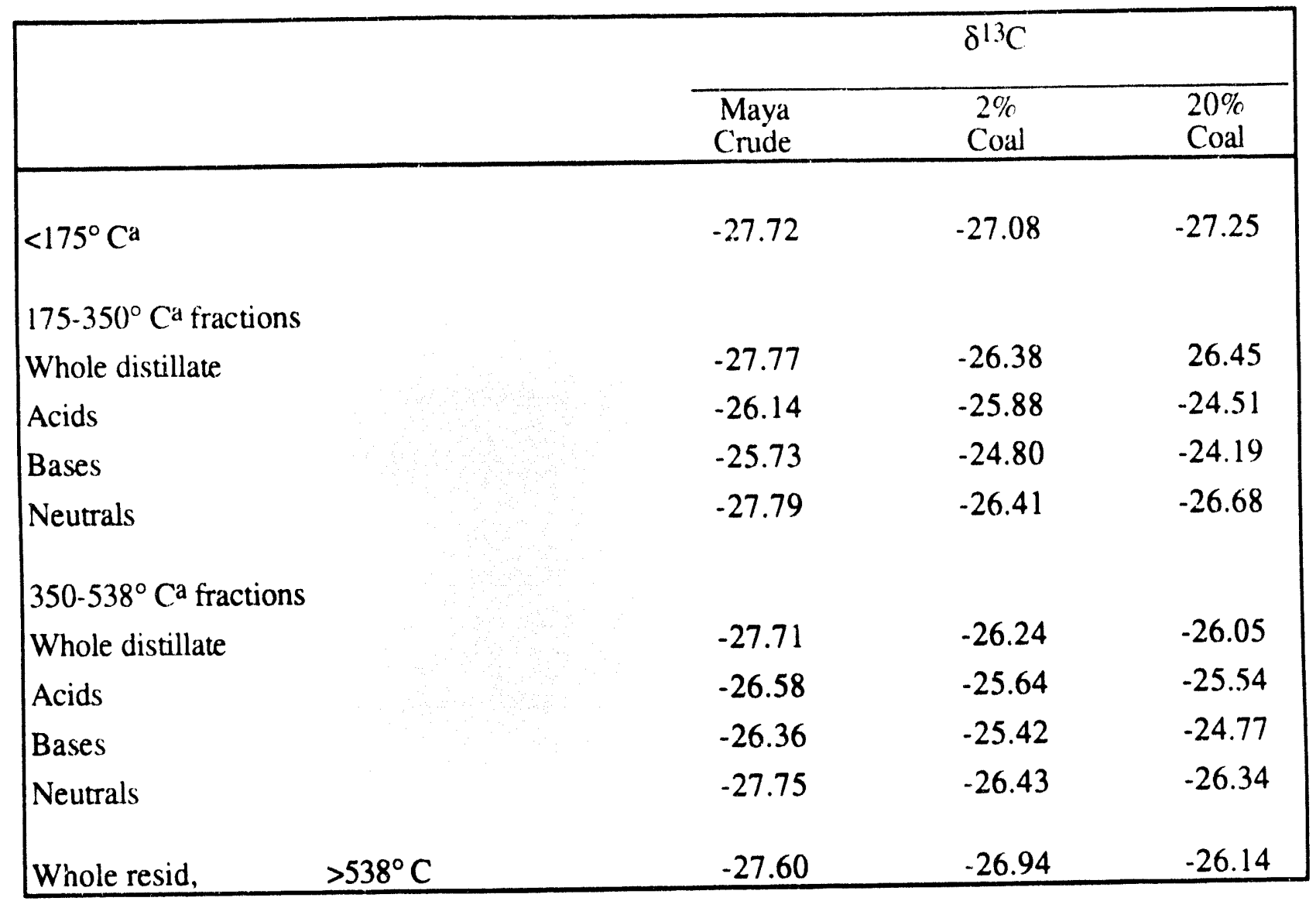

a Nominal boiling point ranges. 
TABLE 9. - Carbon isotope ratios for Maya resid fractions

\begin{tabular}{|lr|}
\hline & $\delta^{13} \mathrm{C}$ \\
\hline Whole resid, measured & -27.60 \\
Whole resid, recalculated & -27.64 \\
Difference & 0.04 \\
& \\
Neutrals & -27.68 \\
Strong Acids & -27.75 \\
Weak Acids & -27.36 \\
Strong Bases & -27.58 \\
Weak Bases & -27.53 \\
\hline
\end{tabular}

Differences in fractions separated by polarity were much larger than differences in the fractions separated by boiling point. The carbon isotope ratios for the Maya crude acid-baseneutral fractions for the distillate fractions generally paralleled those of the coprocessing products. These comparisons are shown in Table 8. In comparison to a range in $\delta^{13} \mathrm{C}$ of only 0.12 for the boiling point range fractions, the difference between the neutrals and bases in the $175-350^{\circ} \mathrm{C}$ distillate was 2.06 per mil or 1.39 per mil for the $350-538^{\circ} \mathrm{C}$ distillate. The products from the coprocessing runs are enriched in ${ }^{13} \mathrm{C}\left(\delta^{13} \mathrm{C}\right.$ is less negative) due to the loss of gas which is depleted in ${ }^{13} \mathrm{C}$.

The initial results for the acid-base-neutral fractions of the resid were inconsistent with the trends for the distillate fractions. It was suspected that the problem was due to contamination from the solvents used in the separation so an additional separation of Maya $+538^{\circ} \mathrm{C}$ resid was carried out with rigorous drying to eliminate solvent. The severe conditions may degrade the samples so such vigorous conditions were not used with the coprocessing fractions. Carbon isotope measurements for these fractions are shown in Table 9. The calculated $\delta^{13} \mathrm{C}$ for the whole resid based on the fraction yields and their $\delta^{13} \mathrm{C}$ differed by only 0.04 per mil. In this case, there is only a minimal range in $\delta^{13} \mathrm{C}$ for the various fractions. 


\section{II.B.4. Conclusions}

The isotope measurements were shown to be of high quality and generally consistent trends were observed. Isotope ratios can be used to provide qualitative indications of the source of various coprocessing compound class fractions. Isotope fractionation during coprocessing is significant with lighter materials (notably hydrocarbon gases but also, to a lesser extent, $<175^{\circ} \mathrm{C}$ distillate) being depleted in ${ }^{13} \mathrm{C}$. Polar materials are significantly enriched in ${ }^{13} \mathrm{C}$--to such an extent that $\delta^{13} \mathrm{C}$ for one of the polar fractions from the 2 percent coal run (where the contribution from coal would be nearly insignificant) approached that of coal.

There appears to be no solid basis for making corrections to allow accurate determination of the origin of compound classes in coprocessing products through the use of carbon isotope ratios. Even within whole distillate classes from the 2 percent coal run, isotopic fractionation makes the light distillate appear more petroleum-like and the heavier distillate appear more coal-like. Selective isotopic fractionation between compound classes all derived primarily from a single feed ( 2 percent coal run) was substantial (e.g., difference in $\delta^{13} C^{\prime}$ of 1.6 per mil for bases versus neutrals in the $175-350^{\circ} \mathrm{C}$ distillate). The difference in $\delta^{13} \mathrm{C}$ for similar classes varies with boiling range of the fraction. There is no basis to assume that this isotopic fractionation would be constant for variable feeds (resid versus coal or even for different resids or different coals). Although isotope ratios are qualitatively useful for determining the source of compound classes and for understanding other facets of coprocessing chemistry, the use of isotope ratios for accurate and quantitative determination of the source of compound classes dies not appear feasible. If the difference between isotope ratios for the coal and resid were $\mathrm{k}$ ased significantly, the situation could be improved.

\section{II.B.5 Elemental Compositions and Carbon Isotope Ratios}

Data collected for the evaluation of the use of isotope ratios for determination of the origin of compound classes in coprocessing showed some interesting correlations between elemental compositions and carbon isotope ratios which are presented in this section. Elemental analyses of the coprocessing distillates, resids, and class fractions are shown in Table 10. Direct analysis was carried out for carbon, hydrogen, nitrogen, and sulfur with all results given in weight percent. Oxygen was estimated by difference, that is, 100 minus the sum of the yzed elements. The elemental data show fairly consistent trends with sample type. Nitrogen and oxygen are most concentrated in the acid and base samples with nitrogen being most prominent in the bases and oxygen in the acids. Sulfur appears to be concentrated in the neutral fractions somewhat preferentially over the acid and base fractions. 
The distribution and amounts of heteroatoms (nitrogen, sulfur, oxygen) somewhat parallel the trends in carbon isotope ratio values reported in the prior section. It was shown that acid and base fractions are strongly enriched in the ${ }^{13} \mathrm{C}$ isotope (i.e., $\delta^{13} \mathrm{C}$ is less negative). The extent of enrichment in some cases was greater than the isotope ratio of the coal reactant and it was impossible to determine reactant contributions to these fractions based $r n$ the carbon isotope ratios. Enrichment of those fractions at about the same magnitude was also observed for the 2 percent coal product and for the unprocessed Maya crude fractions.

Elemental analysis data for the 20,30 , and 40 percent coal products selected from Table 10 were related to carbon isotope ratios by a multivariate regression procedure. The relation fitted to the data has the form:

$$
\delta^{13} \mathrm{C}=\mathrm{a}+\mathrm{b}(\operatorname{coal} \%)+\mathrm{c}(\mathrm{N} \%)+\mathrm{d}(\mathrm{S} \%)+\mathrm{e}(\mathrm{O} \%) . \quad \text { Eq. } 4
$$

The values $a, b, c, d$, and e were determined in the regression procedure. Other terms in Eq. 4 are $\delta^{13} \mathrm{C}$-calculated carbon isotope ratio; coal percent - percent reactant coal; $\mathrm{N}$ percent, $\mathrm{S}$ percent, $O$ percent - weight percent nitrogen, sulfur, ard oxygen. Values for elemental analysis and isotope ratios of the resid fractions were not included in this calculation. Data values for the 2 percent coal products did not fit well with the other values in the regression procedure and were processed in a separate regression analysis. The values determined are:

$\begin{array}{ll}\mathrm{a} & -28.02 \\ \mathrm{~b} & +0.0 ! 83 \\ \mathrm{c} & +0.3376 \\ \mathrm{~d} & +0.4630 \\ \mathrm{e} & +0.1744\end{array}$

Observed and calculated values are shown in Table 11.

The agreement of the observed and calculated values is reasonably good. The average difference between the observed and calculated values is $0.22 \delta^{13} \mathrm{C}$ units. Figure 12 shows the plot of observed against calculated values. The line shown on the plot represents equivalence values; that is, $\delta^{13} \mathrm{C}(\mathrm{Calc})=\delta^{13} \mathrm{C}(\mathrm{Obs})$. The scatter shown in this plot appears to be somewhat greater in the region representing acid and base samples ( $\delta$ below 26) than in the remainder $c$ the plot. However, the overall fit of calculated and observed values is sufficient to indicate that a relationship between isoinpic composition and heteroatom content is probable. The failure of the regression method to inciude values from the 2 percent coal products in a satisfactory manner and 
TABLE 10. - Elemental composition of coprocessing fractions

\begin{tabular}{|c|c|c|c|c|c|}
\hline & $\mathrm{C}$ & $\mathrm{H}$ & $\mathrm{N}$ & $\mathrm{S}$ & 0 \\
\hline \multicolumn{6}{|l|}{$2 \%$ Coal Products } \\
\hline Distillate, $<175^{\circ} \mathrm{C}$ & 85.10 & 14.66 & 0.050 & 0.212 & -0.47 \\
\hline Distillate, $175-350^{\circ} \mathrm{C}$ & 83.92 & 12.10 & 0.210 & 2.083 & 1.69 \\
\hline Neutral & 84.01 & 12.28 & $<0.01$ & 1.999 & 1.71 \\
\hline Acid & 72.49 & 7.76 & 3.171 & 2.996 & 1.358 \\
\hline Base & 78.58 & 8.22 & 6.691 & 1.370 & 5.14 \\
\hline Distillate, $350-538^{\circ} \mathrm{C}$ & 85.10 & 9.81 & 0.734 & 2.759 & 1.60 \\
\hline Neutral & 84.78 & 10.32 & 0.080 & 2.768 & 2.05 \\
\hline Acid & 82.51 & 7.14 & 3.163 & 1.748 & 5.44 \\
\hline Base & 82.56 & 7.55 & 3.830 & 2.373 & 3.69 \\
\hline Residue, $>538^{\circ} \mathrm{C}$ & 86.01 & 6.24 & 1.400 & 3.926 & 2.42 \\
\hline Neutral & 85.64 & 7.48 & 0.134 & 4.831 & 1.92 \\
\hline Strong Acid & 82.68 & 5.88 & 1.674 & 2.952 & 6.81 \\
\hline Weak Acid & 82.74 & 6.30 & 1.072 & 3.054 & 6.83 \\
\hline Strong Base & 78.84 & 5.93 & 1.194 & 3.725 & 10.31 \\
\hline \multicolumn{6}{|l|}{$20 \%$ Coal Products } \\
\hline Distillate, $<175^{\circ} \mathrm{C}$ & 85.16 & 14.00 & 0.084 & 0.063 & 0.69 \\
\hline Distillate, $175-350^{\circ} \mathrm{C}$ & 84.38 & 11.64 & 0.260 & 1.396 & 2.32 \\
\hline Neutral & 84.08 & 11.96 & $<0.01$ & 1.452 & 2.51 \\
\hline Acid & 78.24 & 8.21 & 1.362 & 0.548 & 11.64 \\
\hline Base & 80.14 & 8.34 & 6.898 & 0.769 & 3.85 \\
\hline Distillate, $350-538^{\circ} \mathrm{C}$ & 85.77 & 10.22 & 0.692 & 1.782 & 1.54 \\
\hline Neutral & 86.06 & 10.85 & 0.064 & 1.873 & 1.15 \\
\hline Acid & 81.98 & 7.32 & 2.301 & 0.758 & 7.64 \\
\hline Base & 84.20 & 7.80 & 4.186 & 1.231 & 2.58 \\
\hline Residue, $>538^{\circ} \mathrm{C}$ & 87.11 & 7.24 & 1.224 & 2.662 & 1.76 \\
\hline Neutral & 86.66 & 8.83 & 0.132 & 3.102 & 1.28 \\
\hline Strong Acid & 81.39 & 6.29 & 0.997 & 1.565 & 9.76 \\
\hline Weak Acid & 83.60 & 6.62 & 1.068 & 2.133 & 6.58 \\
\hline Strong Base & 80.32 & 6.30 & 2.802 & 2.323 & 8.26 \\
\hline
\end{tabular}


TABLE 10. - Elemental composition of coprocessing fractions (Continued)

\begin{tabular}{|c|c|c|c|c|c|}
\hline & $\mathrm{C}$ & $\mathrm{H}$ & $\mathrm{N}$ & $\mathrm{S}$ & $\mathrm{O}$ \\
\hline \multicolumn{6}{|l|}{$30 \%$ Coal Products } \\
\hline Distillate, $<175^{\circ} \mathrm{C}$ & 83.09 & 13.50 & 0.080 & 0.125 & 3.21 \\
\hline Distillate, $175-350^{\circ} \mathrm{C}$ & 84.60 & 11.72 & 0.448 & 1.230 & 2.00 \\
\hline Neutral & 84.86 & 12.14 & 0.026 & 1.343 & 1.63 \\
\hline Acid & 76.74 & 8.43 & 0.572 & 0.299 & 13.96 \\
\hline Base & 77.70 & 9.02 & 5.074 & 0.267 & 7.94 \\
\hline Distillate $350-538^{\circ} \mathrm{C}$ & 85.30 & 10.10 & 0.724 & 1.449 & 2.43 \\
\hline Neutral & 85.18 & 10.84 & 0.073 & 1.667 & 2.24 \\
\hline Acid & 80.48 & 7.54 & 2.200 & 0.606 & 9.17 \\
\hline Base & 82.63 & 7.83 & 3.888 & 0.971 & 4.68 \\
\hline Residue, $>538^{\circ} \mathrm{C}$ & 87.58 & 6.72 & 0.856 & 2.138 & 2.71 \\
\hline \multicolumn{6}{|l|}{$40 \%$ Coal Products } \\
\hline Distillate, $<175^{\circ} \mathrm{C}$ & 85.26 & 13.42 & 0.102 & 0.082 & 1.14 \\
\hline Distillate, $175-350^{\circ} \mathrm{C}$ & 84.92 & 11.36 & 0.477 & 1.350 & 1.89 \\
\hline Neutral & 85.35 & 11.76 & 0.026 & 1.494 & 1.37 \\
\hline Acid & 78.12 & 8.12 & 0.532 & 0.480 & 12.75 \\
\hline Base & 79.22 & 8.08 & 6.278 & 0.622 & 5.80 \\
\hline Distillate, $350-538^{\circ} \mathrm{C}$ & 86.25 & 9.93 & 0.842 & 1.598 & 1.38 \\
\hline Neutral & 85.82 & 10.68 & 0.084 & 1.771 & 1.65 \\
\hline Acid & 82.85 & 7.12 & 2.222 & 0.674 & 7.13 \\
\hline Base & 82.59 & 7.34 & 4.660 & 1.031 & 4.38 \\
\hline Residue, $>538^{\circ} \mathrm{C}$ & 87.98 & 6.48 & 1.030 & 2.061 & 2.45 \\
\hline Neutral & 86.26 & 8.46 & 0.084 & 3.049 & 2.15 \\
\hline Strong Acid & 83.92 & 5.89 & 1.256 & 0.976 & 7.96 \\
\hline Weak Acid & 84.61 & 6.34 & 0.798 & 2.148 & 6.10 \\
\hline Strong Base & 85.00 & 5.93 & 1.642 & 1.590 & 5.84 \\
\hline
\end{tabular}


TABLE 11. - Observed and calculated carbon isotope ratios $(20,30$, and $40 \%$ coal $)$

\begin{tabular}{|lcccccc|}
\hline & \multicolumn{2}{c}{$20 \%$ Coal } & \multicolumn{2}{c|}{$30 \%$ Coal } & \multicolumn{2}{c|}{ 40\% Coal } \\
& Obs & Calc & Obs & Calc & Obs & Calc \\
\hline Distillate, $<175^{\circ} \mathrm{C}$ & -27.25 & -27.47 & -27.40 & -26.83 & -27.05 & -27.02 \\
Distillate, $175-350^{\circ} \mathrm{C}$ & -26.45 & -26.51 & -26.38 & 26.40 & -26.16 & -26.17 \\
Neutral & -26.68 & -26.54 & -26.67 & -26.56 & -26.39 & -26.35 \\
Acid & -24.51 & -24.91 & -24.83 & -24.70 & -24.33 & -24.66 \\
Base & -24.19 & -24.30 & -24.84 & -24.25 & -23.94 & -23.87 \\
Distillate, 350-538 ${ }^{\circ} \mathrm{C}$ & -26.05 & -26.33 & -25.92 & -26.13 & -25.75 & -26.02 \\
Neutral & -26.34 & -26.56 & -26.39 & -26.28 & -26.19 & -26.15 \\
Acid & -25.54 & -25.19 & -25.15 & -24.85 & -24.50 & -24.98 \\
Base & -24.77 & -25.22 & -24.74 & -24.89 & -24.41 & -24.47 \\
Residue, $>538^{\circ} \mathrm{C}$ & -26.14 & -25.70 & -25.92 & -25.72 & -25.71 & -25.56 \\
\hline
\end{tabular}




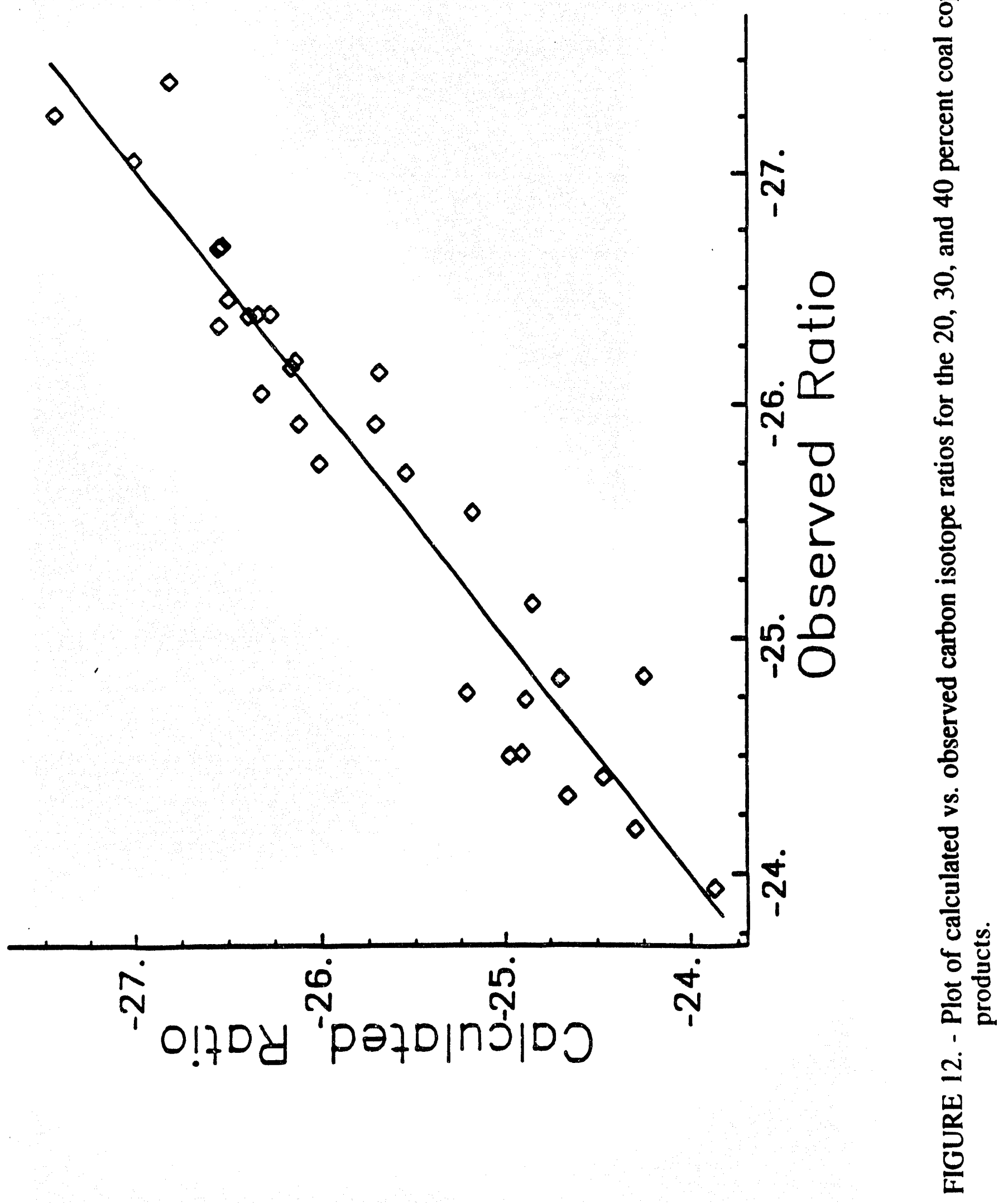


some of the scatter shown in the data and plot may be related to the limitation of equation 4 in not including the effect of reaction selectivity of resid and coal contributions to isotopic shifts. In this circumstance, the agreement shown in the data and plot would indicate that heteroatom content may have as much or more importance in isotopic shift as reaction selectivity.

The $c, d$, and e terms listed above all show positive values which indicate that the nitrogen, sulfur, and oxygen are all associated with enriched ${ }^{13} \mathrm{C}$ levels. If the relation of isotopic enrichment to heteroatom content is correct, it is likely that the ${ }^{13} \mathrm{C}$ atoms are adjacent to or directly bonded to the heteroatoms since an effect of this type at a distance is improbable. This effect may have originated in the biochemistry of the algae and plant matter from which the petroleum and coal were formed. Although molecular rearrangements and other processes during maturation would have diminished the association, the effect could still be present. The fact that similar isotopic fractionation is found in the Maya crude fractions indicate that the effect is not related to the hydroprocessing conditions of the coprocessing procedure.

A similar regression procedure was applied to the data of the 2 percent coal reaction product. In this procedure, equation 4 was modified by the elimination of the $b$ (coal percent) term. The values determined are:

$\begin{array}{ll}\mathrm{a} & -26.59 \\ \mathrm{c} & +0.2726 \\ \mathrm{~d} & -0.0338 \\ \mathrm{e} & +0.0055\end{array}$

Observed and calculated values are shown in Table 12. Figure 13 shows a plot of observed and calculated values. Agreement of these values is somewhat poorer than that for the previous set with an average difference of $0.25 \delta^{13} \mathrm{C}$ units.

No strong significance can be assigned to the values of $c, d$, and e other than that they are the result of the best fit determinations in the least squares procedure. Evaluation of the standard errors of coefficients showed the errors for d, the term related to sulfur content, was substantially greater than the errors for the other coefficients. This may indicate that inclusion of the sulfur values in equation 4 may do little for the overall fit of the isotope ratio values. The value for a should represent the carbon isotope ratio for carbon not associated with heteroatoms for the Maya residue products in the coprocessing product. The combination $a+b$ (coal percent) represents this same carbon for the 20,30 , and 40 percent coal products. If the coal contributed to polar and 
TABLE 12. - Observed and calculated carbon isotope ratios, $2 \%$ coal

\begin{tabular}{|lcc|}
\hline & Observed & Calculated \\
\hline Distillate, $<175^{\circ} \mathrm{C}$ & -27.08 & -26.59 \\
Distillate, $175-350^{\circ} \mathrm{C}$ & -26.38 & -26.60 \\
Neutral & -26.41 & -26.65 \\
Acid & -25.88 & -25.76 \\
Base & -24.80 & -24.79 \\
& & \\
Distillate, $350-538^{\circ} \mathrm{C}$ & -26.24 & -26.48 \\
Neutral & -26.43 & -26.65 \\
Acid & -25.64 & -25.76 \\
Base & -25.42 & -25.61 \\
Residue, $>538^{\circ} \mathrm{C}$ & -26.94 & -26.33 \\
\hline
\end{tabular}

non-polar products in the same proportion as the residue, the value of $b$ would be expected to be 0.03 . However, since relatively more of the carbon of coal goes to polar fractions and less to nonpolar, the value $b=0.0183$ is reasonable.

Several sources of error may be considered in relation to the calculated carbon isotope ratio values. The observed isotope ratio values are considered to be quite reliable and are not expected to contribute any significant error in the regression procedure. Calculated values for isotope ratio values of the distillates based on yields and isotope ratios of the fractions have shown good agreement. This agreement has established the validity of the carbon isotope ratio values. Somewhat greater error is thought to be present in the elemental analysis data. This error is mostly in the oxygen values since thes^ are actually net difference numbers. As such, they contain the error cf carbon, hydrogen, nitrogen, and sulfur analyses.

The greatest source of error is contained in the model used for relating isotope ratios to composition. Equation 4 contains a minimum number of factors that can be expected to account for the effect, and each of them is included only as a first-order term. No interaction or higher 


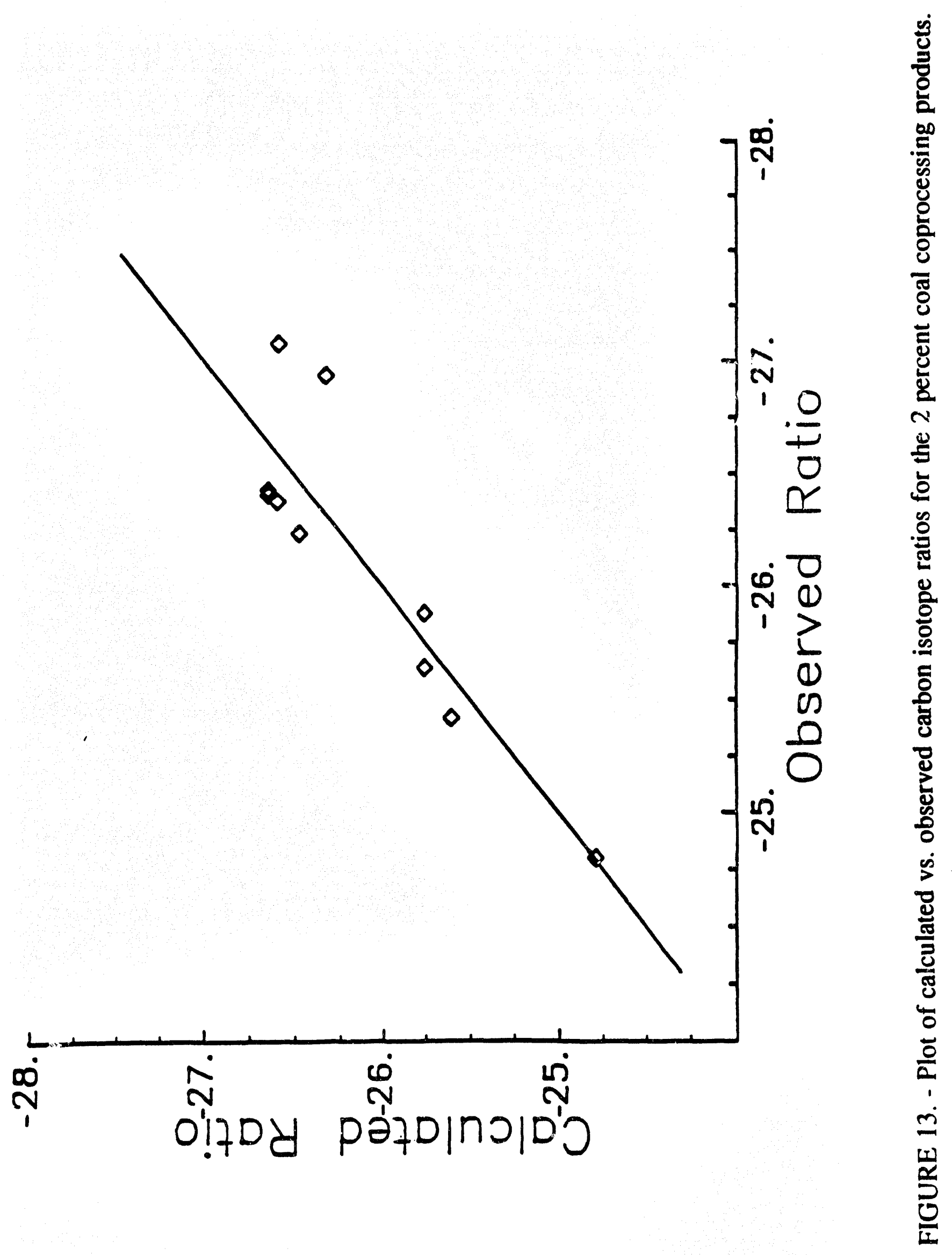


order terms are included. However, without a better understanding of the possible relationship of elemental composition to isotopic fractionation, no other terms are justified. The most important error is the lack of any terms relating selectivity of residue and coal in contributions to the various fractions. Yield based selectivities (Section II.C.3) show the significance of contributions of both reactants. Unfortunately, the heteroatom related calculation of isotope ratios does not seem to provide corrected values by which selectivity values may be determined from carbon isotope ratios.

\section{II.C. DETAILED COMPOSITION STUDIES}

\section{II.C.1. Introduction}

Methods for the exhaustive analysis of complex petroleum products have been developed at NIPER and described in detail in a two-volume report (3). The reader is referred to this reference for detailed descriptions of the analytical procedures. An overall schematic of the methods which are available for application to a wide variety of fossil fuel products is shown in Figure 14. While some elements of the scheme consist of conventional techniques (e.g., distillation), others encompass significantly improved versions of earlier methods (e.g., nonaqueous ion exchange liquid chromatography) or novel procedures (e.g., schemes 1-4).

Emphasis was placed on analysis of polar compounds. These types of compounds are typically present in significantly higher concentrations in coal liquefaction products than in conventional petroleum products. Particular emphasis was placed on analysis of acid fractions; acid compounds have been found to be particularly troublesome with regard to both upgrading and product quality.

For all distillation cuts except the resid, the neutral fraction was the dominant fraction. This material was further analyzed by separation into saturates and aromatics with further analysis by mass spectrometric techniques.

Where possible, concentrations of various compound types were related to concentration of coal in the feed. This included the determination of selectivity factors which provide a numerical estimation of the contributions of coal or resid to the compound class of interest. 

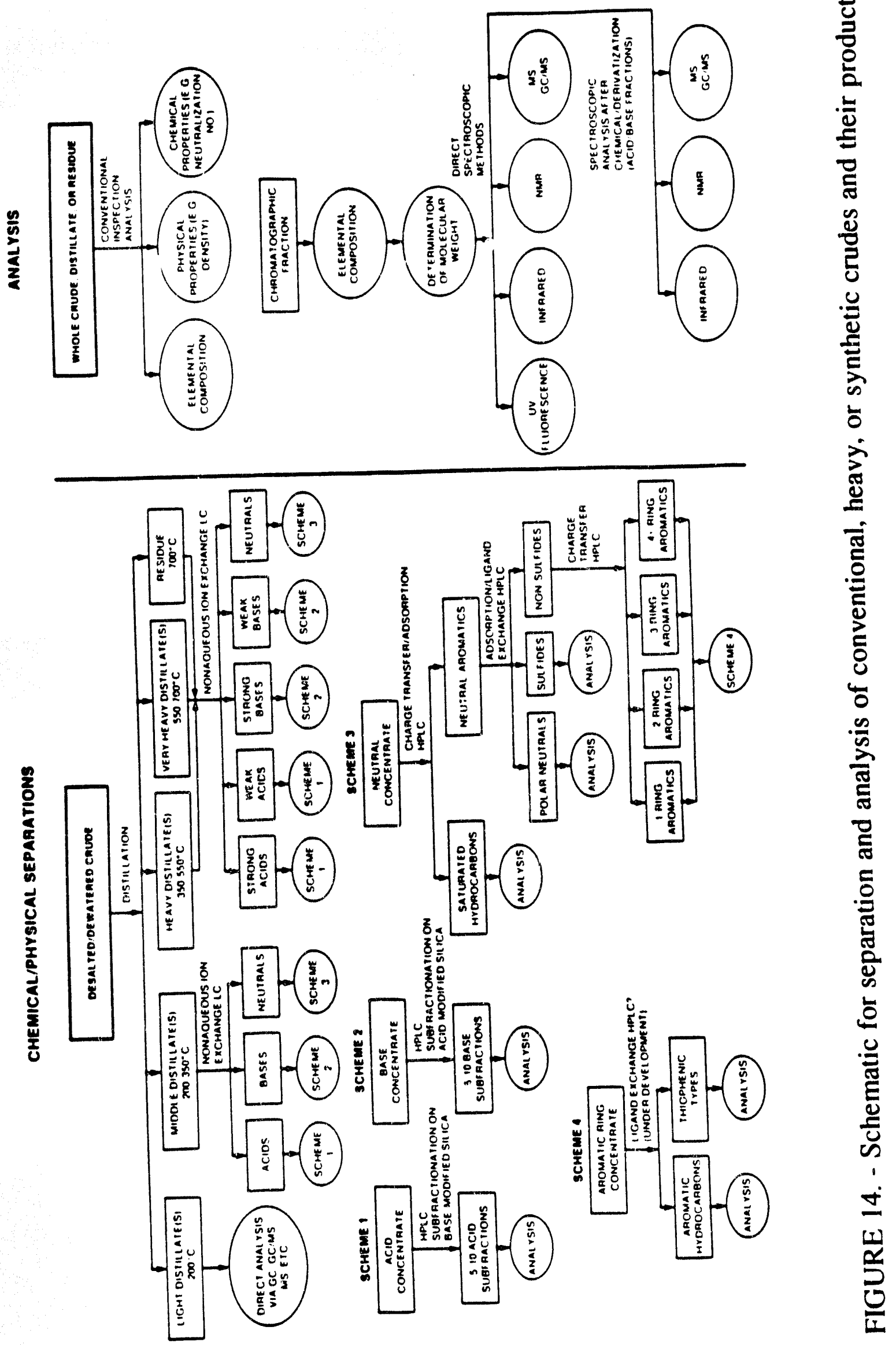


\section{II.C.2. Analysis Light Distillates}

Analysis of light distillates (boiling below $175^{\circ} \mathrm{C}, 347^{\circ} \mathrm{F}$ ) was limited to a high resolution gas chromatographic method known as PIANO analysis. In this method, individual hydrocarbons up to about C-12 are quantitated. Cornpound classes (paraffins, isoparaffins, aromatics, naphthenes, olefins) are reported based on the summation of the individual compounds. Table 13 summarizes results ${ }^{f}$ ) the light distillate samples from the four batch autoclave runs.

\section{TABLE 13. - PIANO analysis of light distillates $\left(<175^{\circ} \mathrm{C}\right)\left(347^{\circ} \mathrm{F}\right)$}

\begin{tabular}{|lrrrr|}
\hline Coal, Percent & 2 & 20 & 30 & 40 \\
\hline & & & & \\
Paraffins & 25.60 & 22.94 & 21.13 & 20.50 \\
Isoparaffins & 31.28 & 31.30 & 31.63 & 34.60 \\
Aromatics & 15.72 & 15.61 & 16.93 & 22.26 \\
Naphthenes & 21.85 & 23.42 & 23.96 & 16.92 \\
Olefins & 4.90 & 4.51 & 4.11 & 3.28 \\
Unknown & 0.66 & 2.21 & 2.24 & 2.45 \\
\hline
\end{tabular}

Correlations between compound classes and coal concentration, although not strong, are evident for paraffins, isoparaffins and aromatics (Figure 15). Normal paraffins decrease with increasing coal concentration while isoparaffins and aromatics increase with increasing coal content.

The PIANO analysis provides substantially more information than summarized above. A representative analysis with the quantitation of 217 peaks is provided in Appendix C. The reporting procedure is based on a large library of retention times of identified hydrocarbons and produces a report showing detailed composition of the sample as well as summary by class and carbon numbers. This analytical procedure was developed for petroleum products but it appears to produce good results with little unidentified material for the coprocessing products. Also provided in Appendix $\mathrm{C}$ are figures showing the distributions of the major hydrocarbon classes by molecular weight for the light distillates from the four coprocessing runs. An increase in isoparaffins at high molecular weight is the most obvious change with molecular weight. 


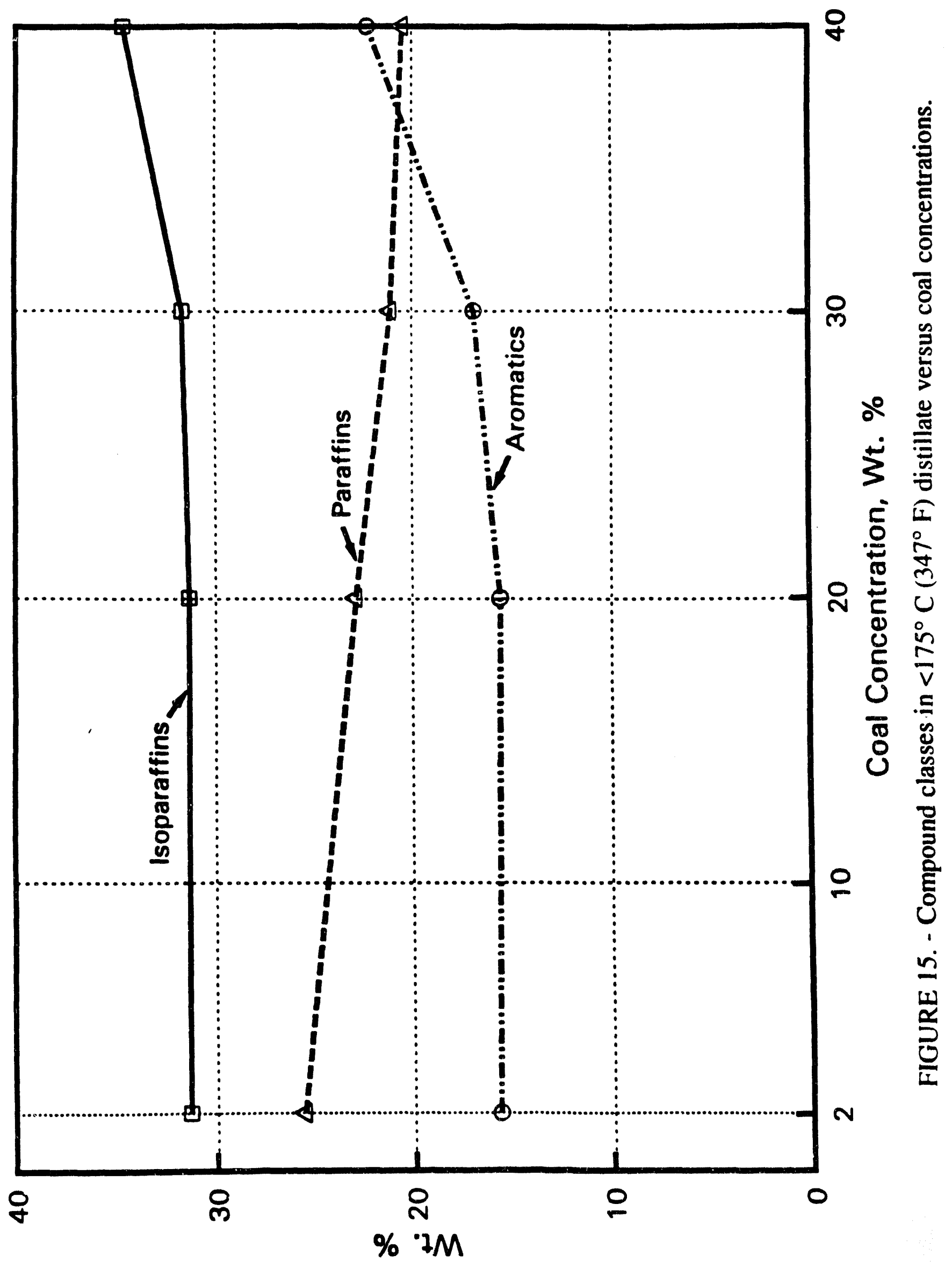




\section{II.C.3. Analysis of $175-350^{\circ} \mathrm{C}\left(347-662^{\circ} \mathrm{F}\right)$ and $350.538^{\circ} \mathrm{C}\left(662-1000^{\circ} \mathrm{F}\right)$ Distillates}

\section{II.C.3.a. Separation into Acid, Base and Neutral Fractions}

The $175-350^{\circ}$ and $350-538^{\circ} \mathrm{C}$ distillates were processed by nonaqueous ion exchange chromatography to produce acid, base and neutral fractions. This procedure, briefly described in Appendix B, was developed at NIPER for application to high-boiling and residual materials (3). Figures 16 and 17 show the percentage yields of these fractions from the distillates.

Both acid and base levels show a relationship to coal content of the coprocessing feed. The formation of product classes from the coprocessing feed may be represented by a relation for the linear combination of petroleum residuum and coal products.

$$
\text { Prod }=a * \text { Res }+b * \text { Coal }
$$

The terms $a$ and $b$ represent the fraction of residuum and coal converted to the particular component or product class. If Res and Coal are the weight fractions of residuum and coal in the reaction feed and Prod is the percentage of a product class in a distillate class, the values of $a$ and $b$ may be determined by graphical means as intercepts at Res and Coal $=0$. This is illustrated in Figure 18 in which the concentrations of a hypothetical product are plotted against the coprocessing feed composition. The four points represent concentrations of the product at coal concentrations of $2,20,30$ and 40 weight percent. However, more reliable determinations may be made by the least squares method. The a and $\mathrm{b}$ values may be converted to terms for selectivity in residue and coal formation of products by the relations:

$$
S_{R}=a /(a+b) ; S_{C}=b /(a+b)
$$

The yield of a product class may be represented as relative product yield (RPY) by the relation:

$$
\text { RPY }=(a+b) / 2 .
$$




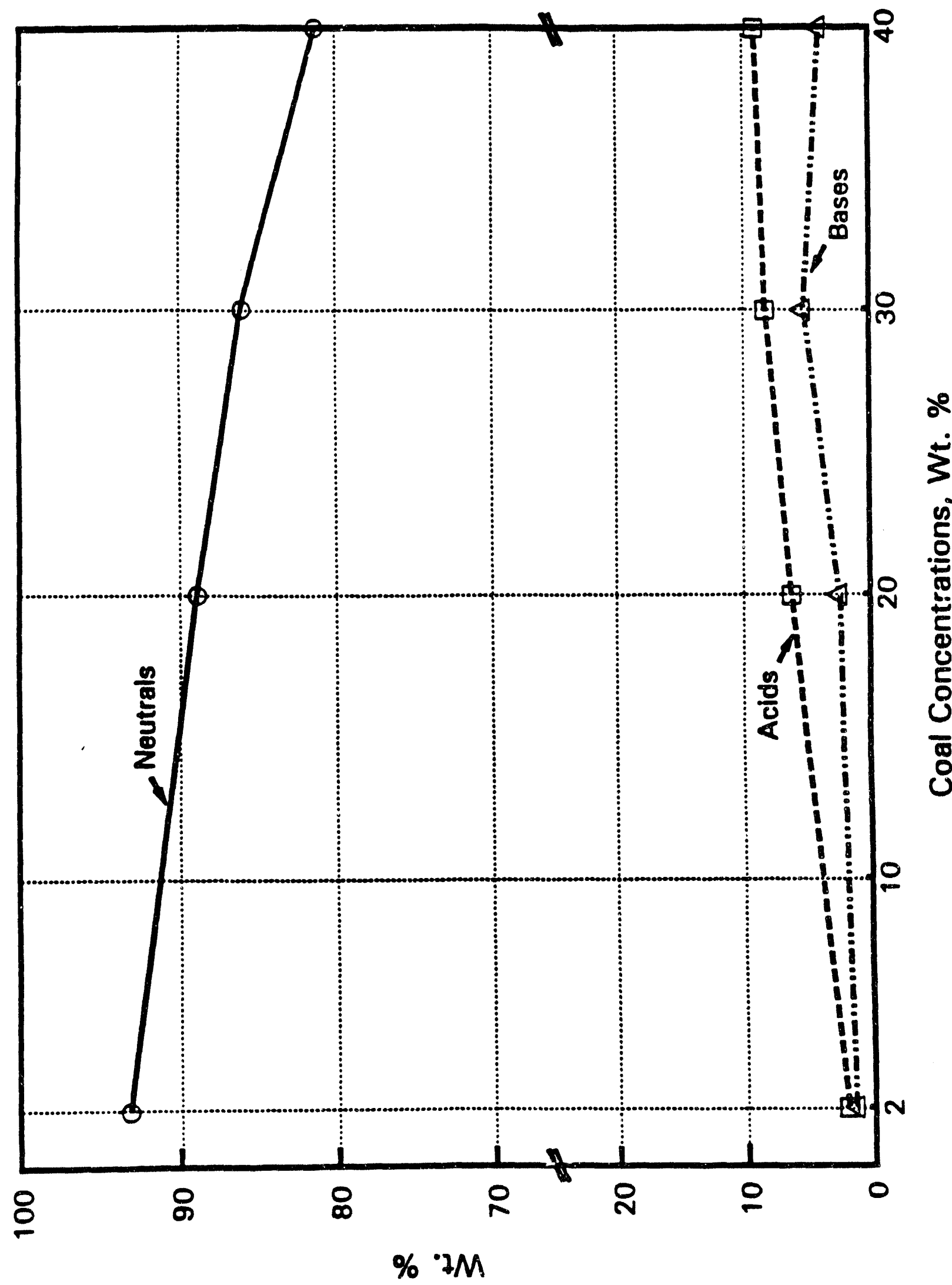

ปే 


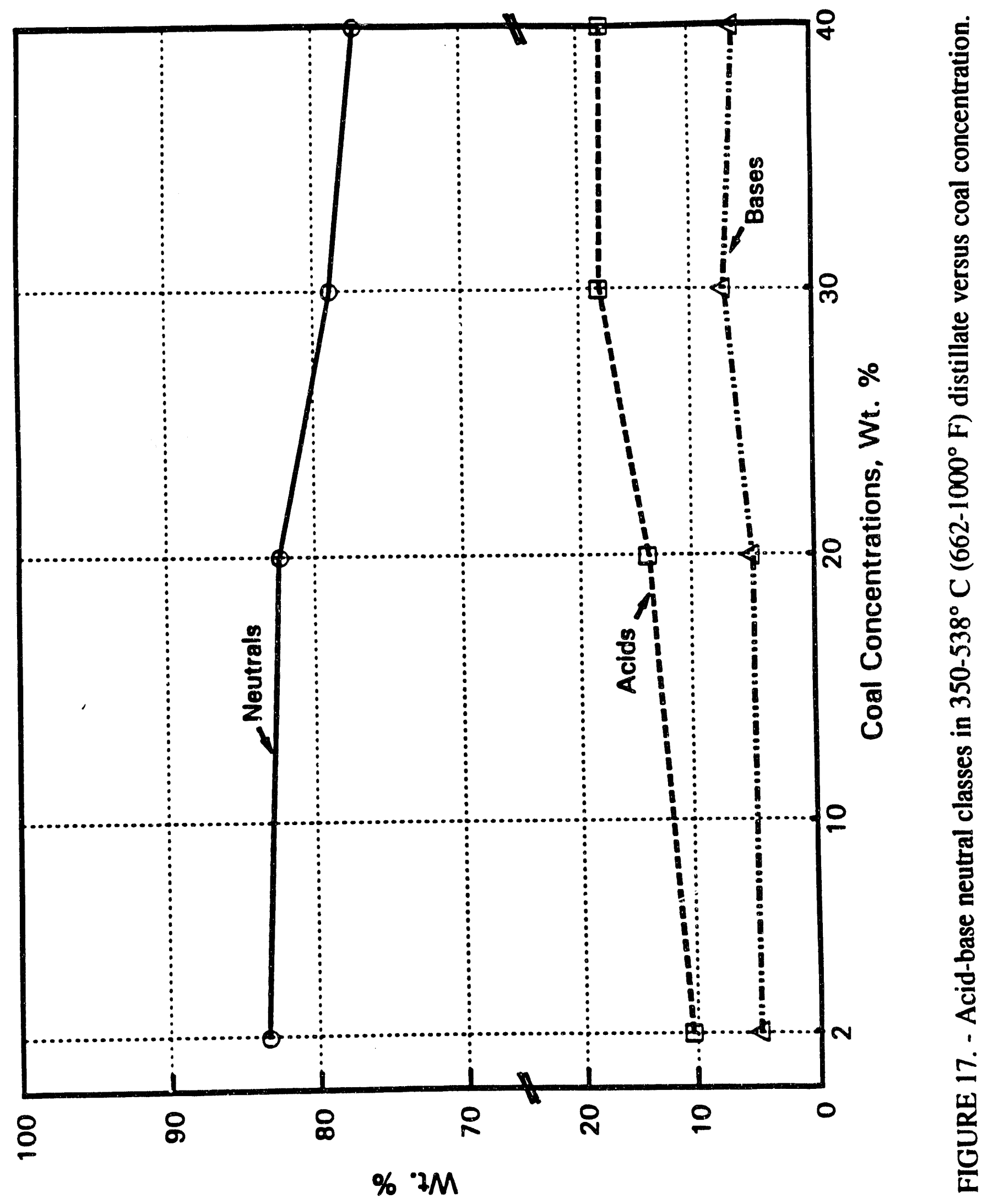




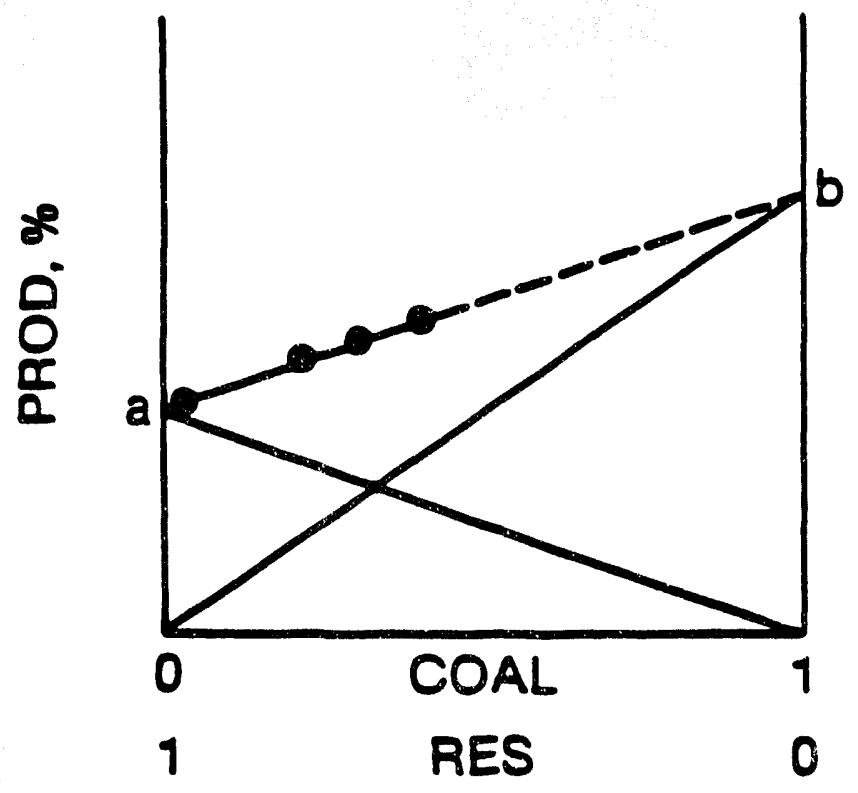

FIGURE 18 - Hypothetical yield structure for coprocessing. 
Table 14 shows values of selectivities $\mathrm{S}_{\mathrm{R}}$ and $\mathrm{S}_{\mathrm{C}}$ and $\mathrm{RPY}$ for the product classes contained in the distillates. The selectivities may be considered to show the relative contributions of resid and coal to the product in a reaction mix of equal amounts of residue and coal. Data in Table 14 indicate that for a coprocessing run in which the feed consisted of equal concentrations of coal and petroleum resid, 9 percent of the acids in the $175-350^{\circ} \mathrm{C}$ distillate would have arisen from the petroleum resid and 91 percent from the coal. Similarly, 59 percent of the neutral fraction would have arisen from the resid and 41 percent from the coal. The selectivity values show that coal is clearly the dominant source of acid and base components in the products. The selectivity tor these classes to be formed from coal is less pronounced in the higher boiling distillate. In a similar manner, RPY is the magnitude of that product in the distillate from the same reaction mix. The RPY values show the higher concentrations of acids and bases in the higher boiling fraction.

\section{TABLE 14. - Selectivity and RPY values of distillate subfractions}

\begin{tabular}{|lrrr|} 
& $S_{R}$ & $S_{C}$ & $R P Y$ \\
\hline $175-350^{\circ} \mathrm{C}$ & & & \\
Acids & & & \\
Bases & 0.09 & 0.91 & 11.58 \\
Neutral & 0.12 & 0.88 & 5.67 \\
& 0.59 & 0.41 & 79.18 \\
$350-538^{\circ} \mathrm{C}$ & & & \\
Acids & & & \\
Bases & 0.25 & 0.75 & 20.07 \\
Neutral & 0.32 & 0.68 & 7.24 \\
& 0.56 & 0.44 & 75.82 \\
\hline
\end{tabular}

\section{II.C.3.b. Acids Analysis}

\section{II.C.3.b.1. Nonaqueous Titrations}

Nonaqueous titration was used in the analysis of the acid fractions. Table 15 shows the results of these titrations in terms of milliequivalents per gram (meg/g) and estimated mean equivalent molecular weight (EW). Inflection values of the titration curves showed half neutralization potentials in the range of -200 to $-560 \mathrm{mv}$. This range is consistent with such acid components as phenols and carbazoles. 
TABLE 15. - Acid fraction titrations

\begin{tabular}{|lcccc|}
\hline Coal, percent & 2 & 20 & 30 & 40 \\
\hline & & & & \\
$175-350^{\circ} \mathrm{C}$ & & & & \\
meq/g & 5.43 & 5.79 & 6.00 & 6.34 \\
EW & 184 & 173 & 167 & 158 \\
350-538 ${ }^{\circ} \mathrm{C}$ & & & & \\
meq $/ \mathrm{g}$ & 3.42 & 4.00 & 4.04 & 3.86 \\
EW & 292 & 250 & 248 & 259 \\
\hline
\end{tabular}

\section{II.C.3.b.2. Chemical Derivatization/Gas Chromatography/Mass Spectrometry of the Acid Fraction}

Detailed analysis of the acids of the $175-350^{\circ} \mathrm{C}$ distillate of the 20 percent coal processing product was conducted by derivatization with methyl iodide followed by gas chromatography/mass spectrometry (GC/MS). The alkylation procedure for derivatizing acid fractions is described in Appendix B. Two portions of each sample were reacted separately with ${ }^{12} \mathrm{CH}_{3} \mathrm{I}$ and ${ }^{13} \mathrm{CH}_{3} \mathrm{I}$ to prepare material for NMR analysis. Figure 19 shows the total ion current chromatogram produced for the ${ }^{13} \mathrm{CH}_{3}$ derivatized sample. The ${ }^{12} \mathrm{CH}_{3}$ derivatized sample produced a chromatogram identical in appearance and retention times. Ion spectra from the two samples were used together to identify the components.

Table 16 shows a list of the compound classes identified and the amount of each class present. It is clear that the phenols predominate with all classes of phenols summing to 82.9 percent. These amounts are approximate only since it was necessary to assume uniform ionization yield of the parent ions. The column labeled First M.W. shows the lowest molecular weight at which the class was detected while the column labeled Max. M.W. shows the maximum molecular weight.

Figure 20 shows the molecular weight distribution of the three phenol classes present in the largest amount. It is likely that the alkylphenols are almost all contained in the $175-350^{\circ} \mathrm{C}$ distillate fraction. However, the other two classes shown in the figure may lap over into the $350-538^{\circ} \mathrm{C}$ distillate. The alkyl and phenyl phenols show the form for a smooth single distribution of species but the cycloalkylphenols may show a bimodal distribution. It is not evident from the mass spectra what this might be. 


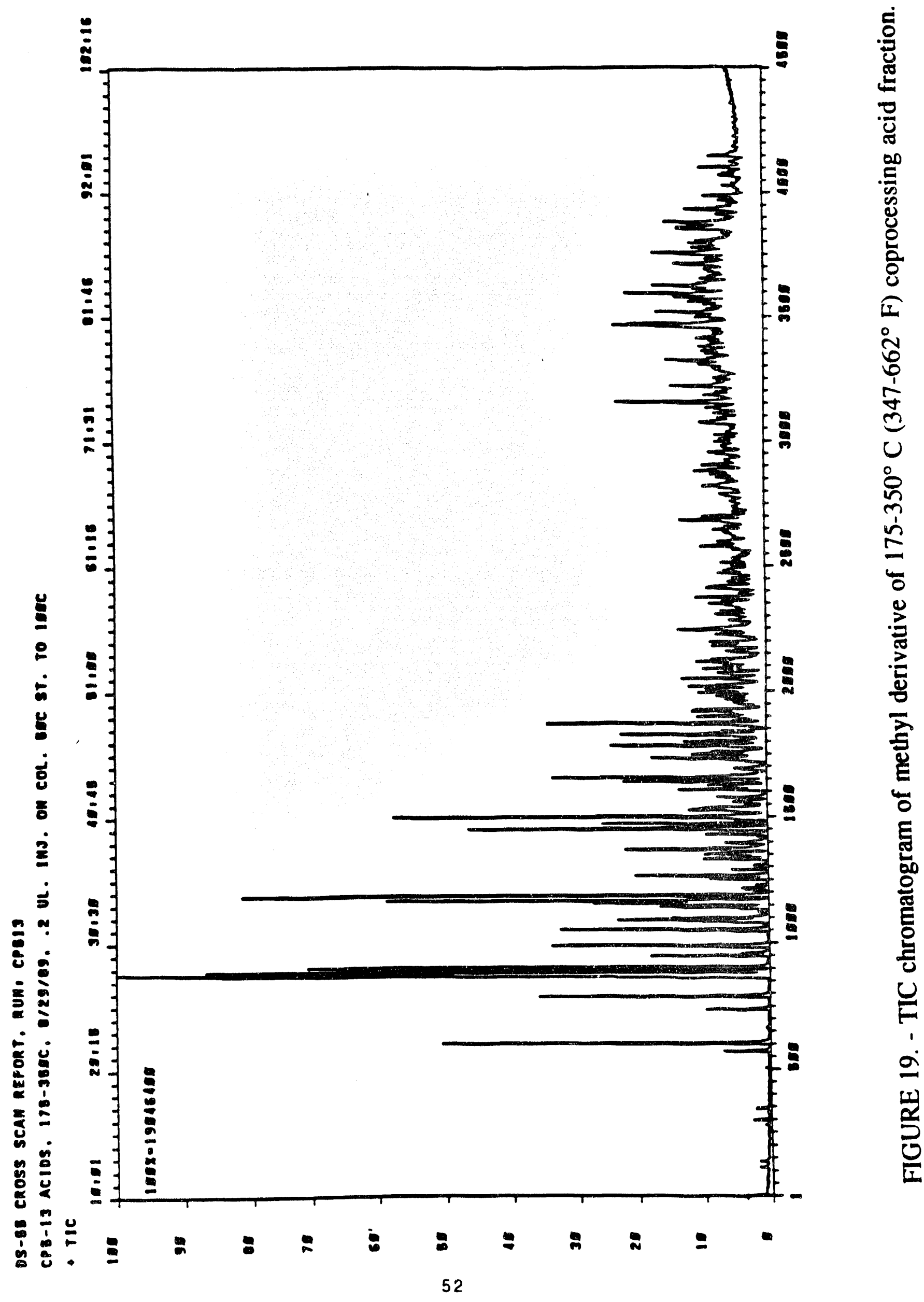




\section{TABLE 16. - Acids of $175-350^{\circ} \mathrm{C}\left(347-662^{\circ} \mathrm{F}\right), 20 \%$ coal product, analyzed by GC/MS}

\begin{tabular}{|lccc|}
\hline Compound Class & Amount, \% & First M.W. & Max. M.W. \\
\hline Alkylphenols & & & \\
Cycloalkylphenols & 43.9 & 108 & 122 \\
Bis(cycloalkyl)phenols & 21.9 & 134 & 162 \\
Phenylphenols & 3.2 & 174 & 188 \\
Cycloalkylphenylphenols & 10.6 & 170 & 198 \\
Bisphenols & 1.0 & 196 & 224 \\
Indoles & 2.4 & 186 & 200 \\
Carbazoles/benzoindoles & 2.2 & 117 & 145 \\
\hline
\end{tabular}

The molecular weight distributions of the remaining classes are shown in Figure 21. Note that the vertical scales of the two figures are different. The amounts of the nitrogen acids (indoles and carbazoles) may be over estimated by the assumption of uniform parent ion formation. Only trace amounts of naphthols could be identified. No carboxylic acids or acidic hydrocarbons (e.g., fluorene) could be found.

Several interesting structural details were determined in this study. The molecular weight of the first cycloalkylphenols (M.W. $=134$, two isomers) clearly indicates the hydroxyindane (cyclopenta) form. In addition, of the nine isorners at M.W. $=148$, only one lacked a distinct methyl loss peak further indicating cyclopenta form. It should be noted that hydroxytetralin (M.W. $=148$, cyclohexa) would have only two isomers. In addition, the bis(cycloalkyl)phenols at M.W. $=174$ should have two cyclopenta groups and at M.W. $=188$ should have at least one. From this it may be assumed that a large part of the cycloalkyl function in coprocessing acids must be cyclopenta.

The dihydroxybiphenyls (bisphenols) fall in the same molecular weight series as naphthols. However, examination of the ${ }^{13} \mathrm{CH}_{3}$ derivatized sample showed the parent ion to occur at two units higher, supporting the difunctional compound class. 


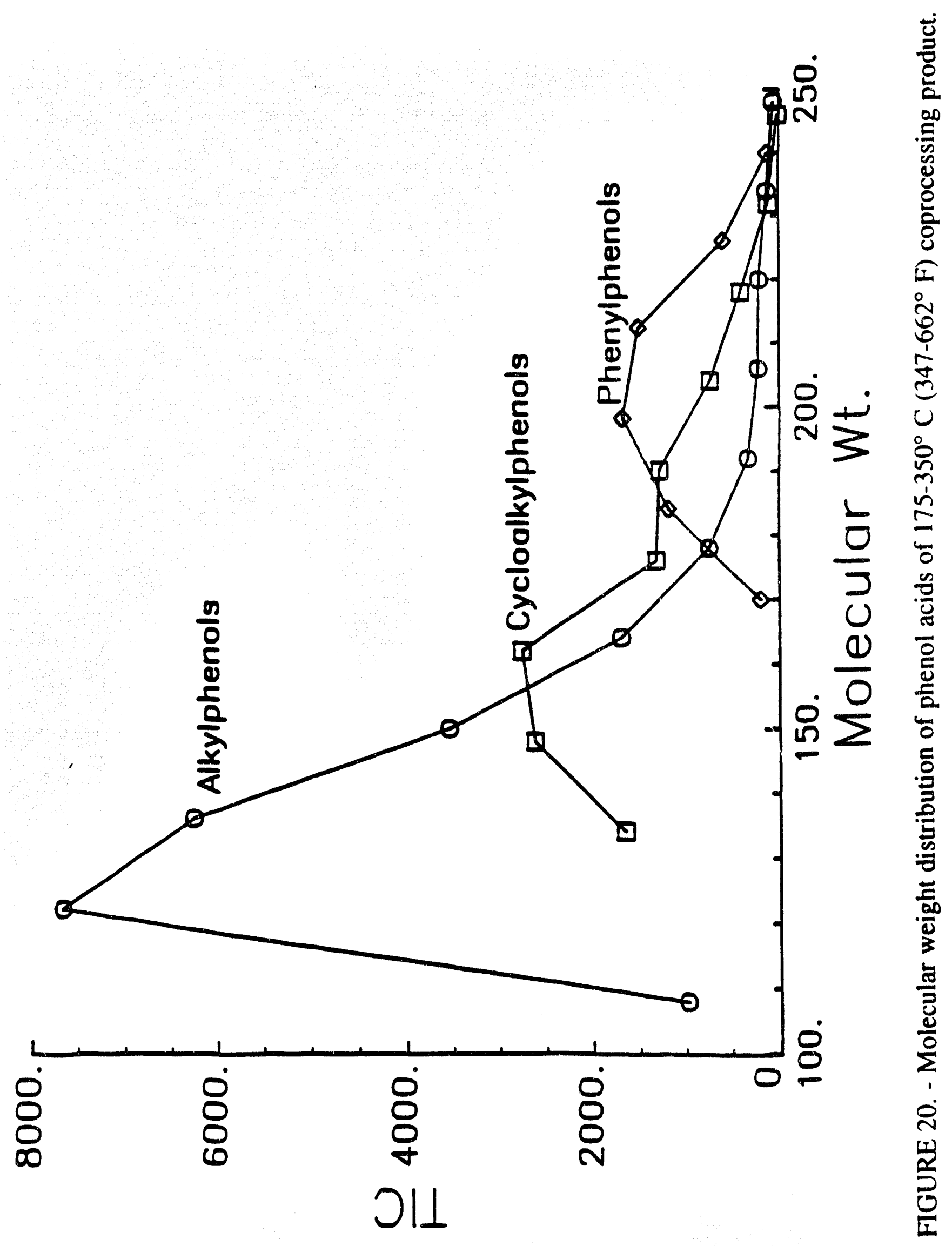




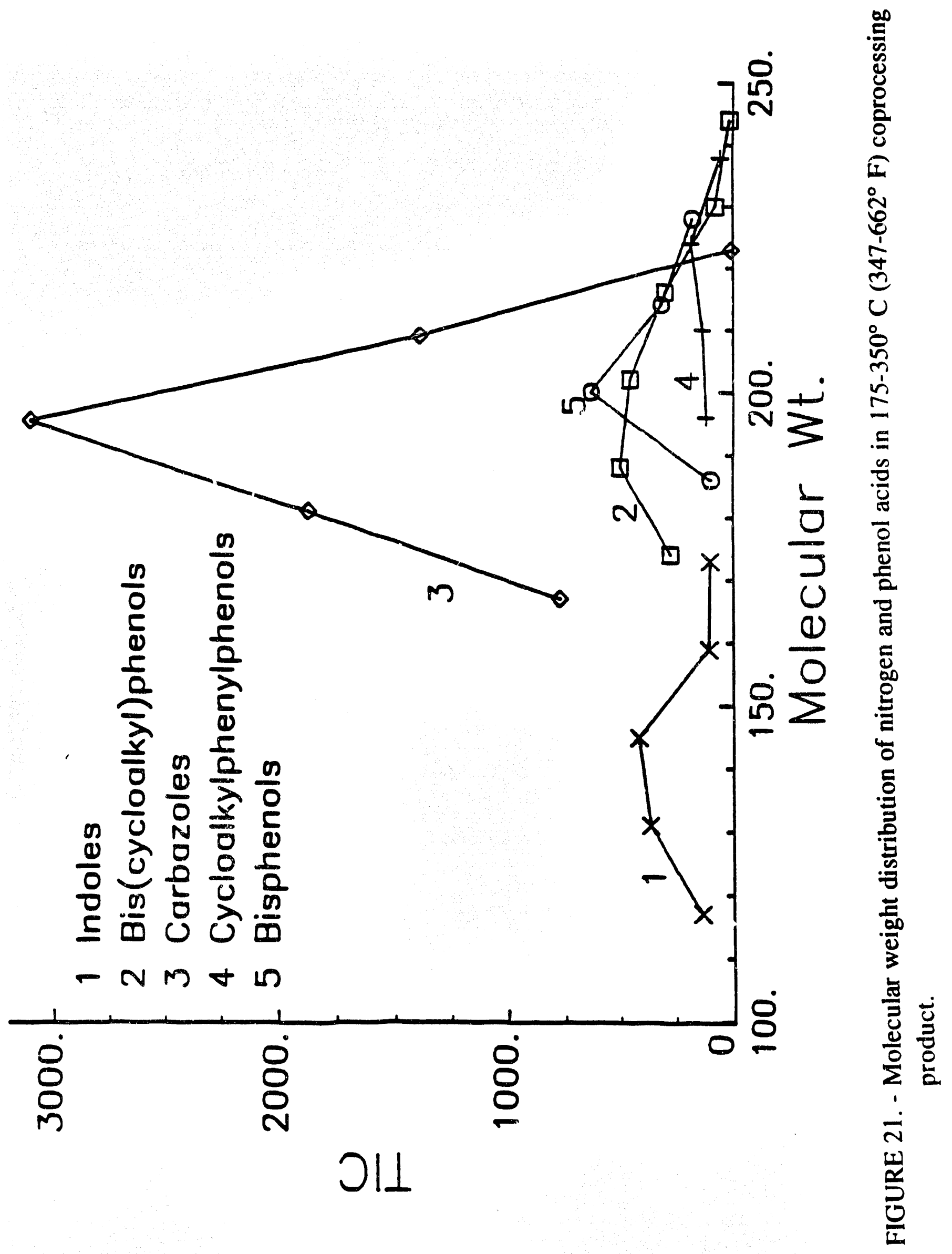


The acidic nitrogen compounds are a minor but significant part of the coprocessing acids. The three-ring system labeled carbazoles/benzoindoles is the dominant type in this class. The chromatographic pattern of the M.W. $=167$ species shows four isomers, one well separated from the other three. It is possible that the group of three are the isomers of benzoindole, in which case they would amount to about two-thirds of the M.W. $=167$ nitrogen compound species.

\section{II.C.3.b.3. Nuclear Magnetic Resonance (NMR) Analysis of Methylated Acid Fractions}

The acid fractions were derivatized with ${ }^{12} \mathrm{CH}_{3} \mathrm{I}$ and ${ }^{13} \mathrm{CH}_{3} \mathrm{I}$ and the methylated acids were an alyzed by two-dimensional NMR and other NMR techniques which are described in detail in Appendix B.

Three general types of acids are present in the coprocessing products--all of which are determired by the NMR techniques. These include oxygen acids (phenols, hindered phenols, and much less prominently, carboxylic acids), nitrogen acids (indoles and carbazoles), and benzylic or sulfur containing acids. Figures 22 and 23 show graphically the number of functional groups of each type (oxygen acids, nitrogen acids and benzylic/sulfur acids) in the $175-350^{\circ}$ and $350-538^{\circ} \mathrm{C}$ acid fractions, respectively.

Figure 22 and 23 show that phenols increase in prominence with increasing coal concentration while nitrogen acids are much more prominent in the run with 98 percent petroleum resid; generally, nitrogen acids diminish with increasing coal reactant content. Benzylic/sulfur acids are minor contributors in all cases but are also much more prominent in the 98 percent petroleum resid run. Both nitrogen acids and benzylic/sulfur acids are more prominent in the higher boiling distillates.

Figures 24 and 25 and illustrate the change in prominence of the three oxygen classes (carboxylic acids, phenols and hindered phenols) across the fractions. [In Figures 24 and 25, the hindered phenols are designated by the symbol $-\mathrm{OCH}_{3}(\mathrm{H})$ ]. Carboxylic acids make only a very minor contribution. Figures 24 and 25 confirm the observations made previously that phenols are the dominant oxygen class in all cases. 


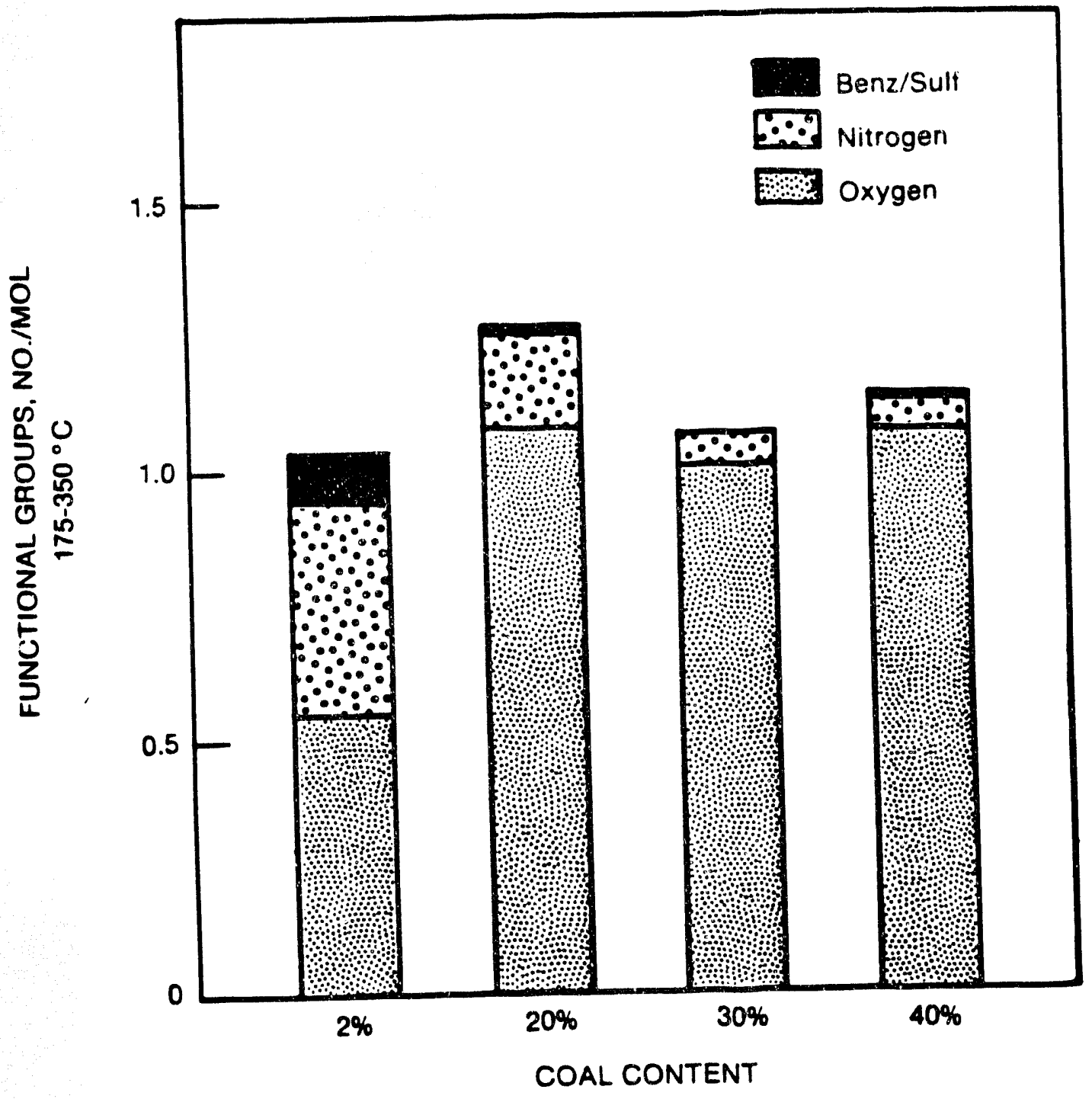

FIGURE 22. - Number of functional groups per molecule for the $175-350^{\circ} \mathrm{C}$ (347-662 F) products. 


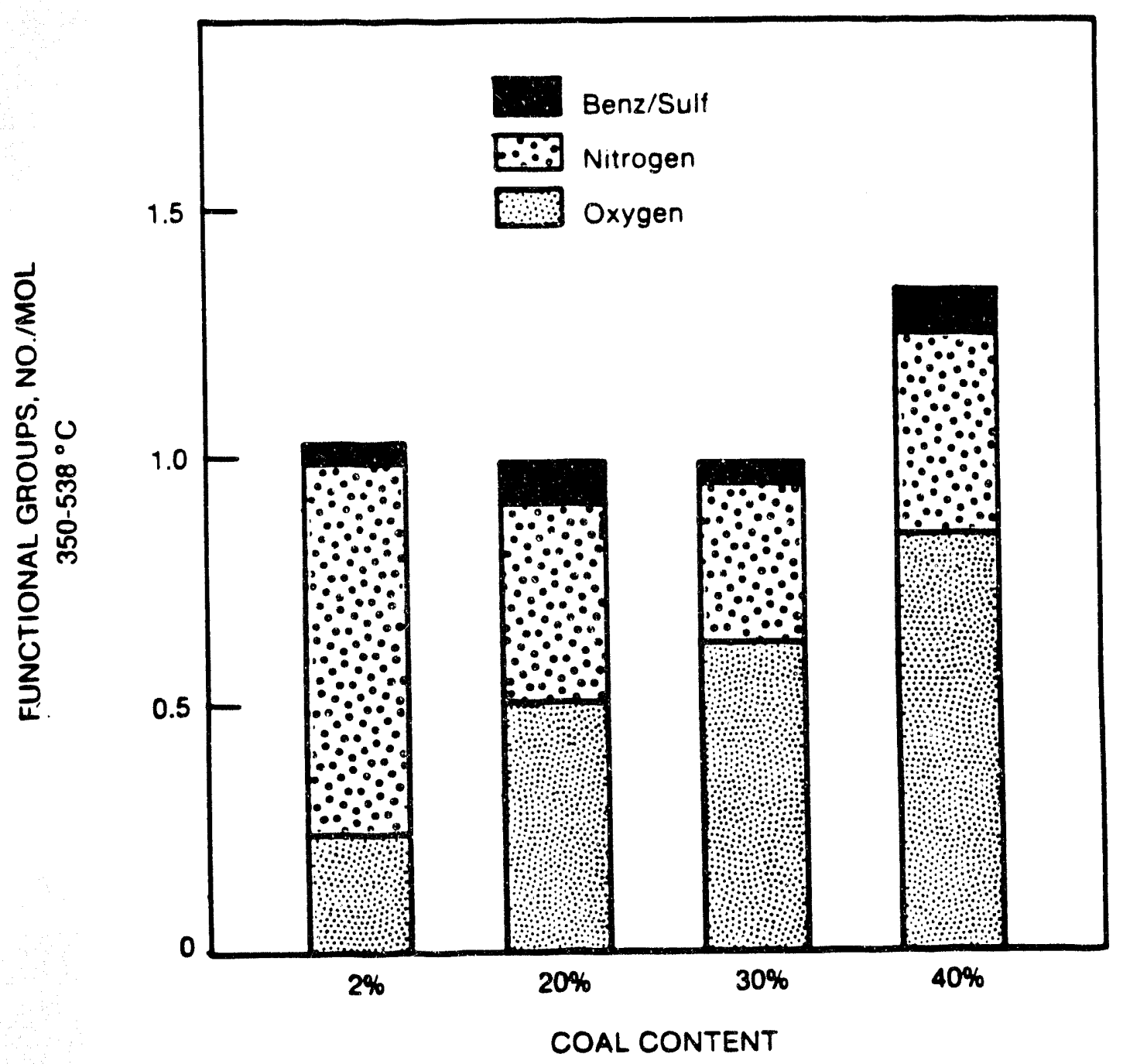

FIGURE 23. - Number of functional groups per molecule for the $350-558^{\circ} \mathrm{C}$ $\left(662-1000^{\circ} \mathrm{F}\right)$ products. 


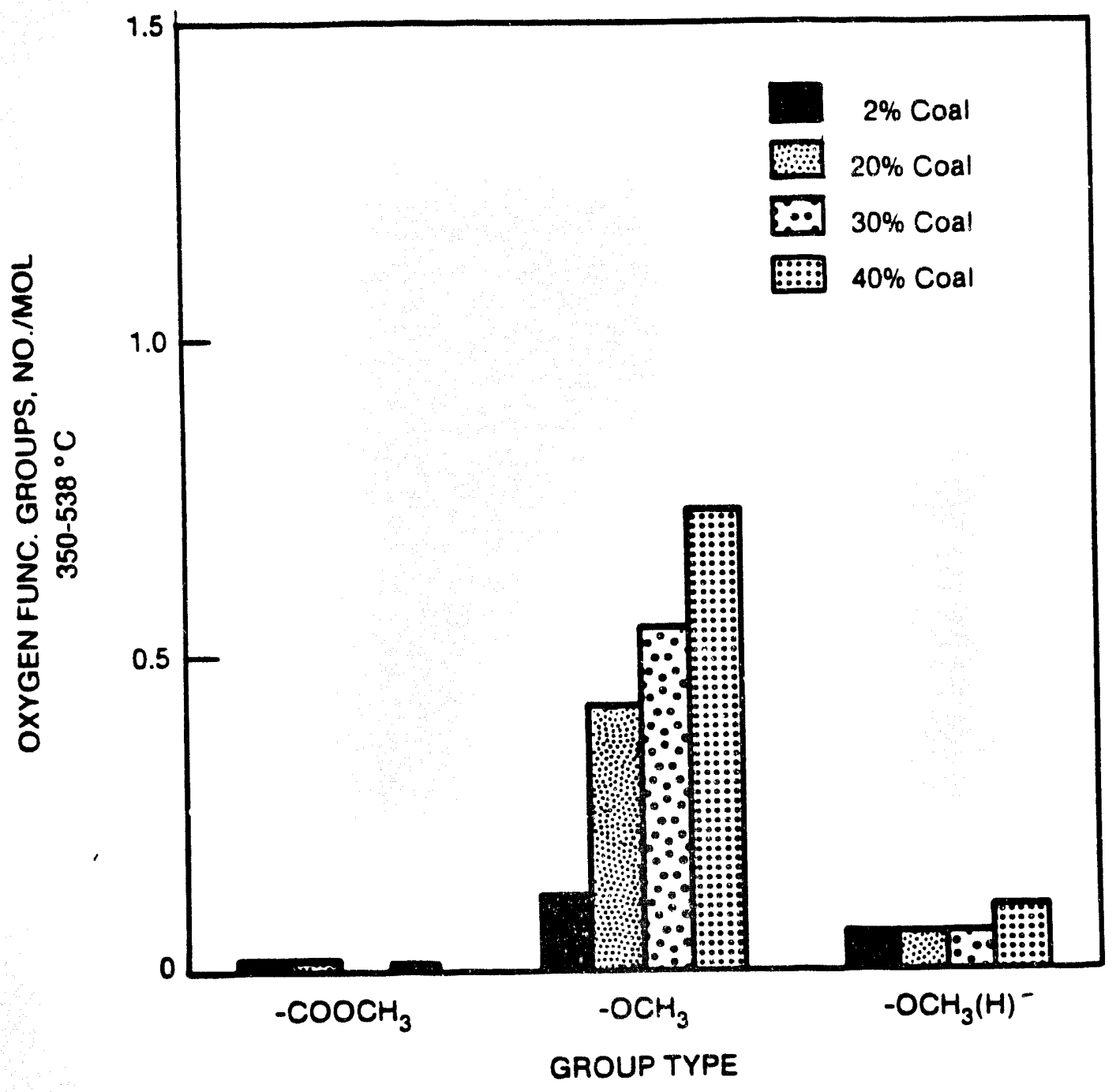

FIGURE 24. - Distribution of oxygen functional groups in the $175-350^{\circ}$ $\left(347-662^{\circ} \mathrm{F}\right)$ products. 


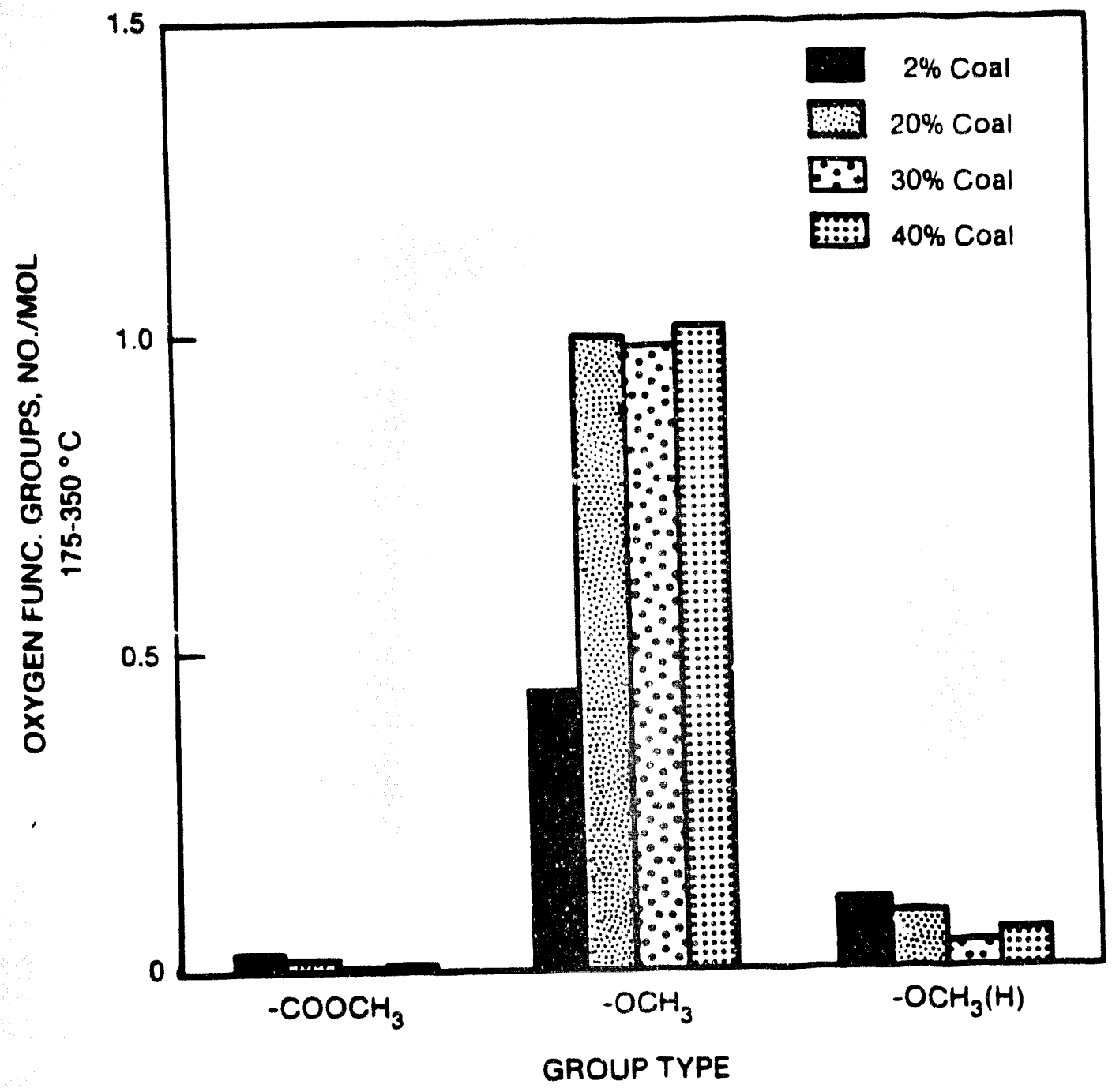

FIGURE 25. - Distribution of oxygen functional groups in the $350-558^{\circ} \mathrm{C}$ $\left(662-1000^{\circ} \mathrm{F}\right)$ products. 


\section{II.C.3.c. Analysis Base Fractions}

The base fractions isolated from the coprocessing distillates were analyzed by nonaqueous titration. The solvents used were acetonitrile and acetic anhydride and the titrations were monitored by special glass electrodes. This procedure determines bases in sirong and weak basic strength. classes. Strong bases include azaarenes (e.g., pyridine, quinoline, etc.) and arylamines (e.g., aniline, etc.). Titration in $\mathrm{CH}_{3} \mathrm{CN}$ determines both of these together while titration in acetic anhydride detects azaarenes alone because arylamines are acetylated in this solvent. Weak bases determined by this procedure include sulfoxides, diarylamines, amides, and carbonyl classes.

No wean bases were detected in any of the coprocessing base samples. This contrasts with the composition of petroleum fiactions in which weak bases are often significant. It is possible that the coprocessing reaction converts these componen" to neutral or strong base materials. Table 17 shows titration results. The content of the components in the base fractions is reported in terms of milliequivalents per gram of sample. The estimated mean molecular weight of each base fraction is shown. The values shown for the $175-350^{\circ} \mathrm{C}, 30$ percent coal fraction may indicate solvent residue in the sample.

\section{TABLE 17. - Titration analysis of base fractions}

\begin{tabular}{|ccccc|}
\hline Coal, percent & 2 & 20 & 30 & 40 \\
\hline $175-350^{\circ} \mathrm{C}$ & & & & \\
Azaarenes, meq/g & 3.79 & 3.39 & 1.95 & 2.86 \\
Arylamines, meq/g & 1.02 & 1.58 & 1.26 & 1.46 \\
Equivalent M.W. & 208 & 201 & 312 & 231 \\
& & & & \\
$350-538^{\circ} \mathrm{C}$ & 2.49 & 2.60 & 2.22 & 2.66 \\
Azaarenes, meq/g & 0.36 & 0.50 & 0.48 & 0.53 \\
Arylamines, meq/g & 351 & 323 & 370 & 313 \\
Equivalent M.W. & & & & \\
\hline
\end{tabular}


Table 18 shows the results converted to the whole distillate basis. For reference, the values for the amount of base in the distillates are included. The yields are shown in terms of milliequivalents per gram of distillate. Trends in content of both azaarenes and arylamines with coal content are similar to that of yields of base fractions described previously. It appears that the levels of azaarenes increase and arylamines decrease in the higher boiling distillates.

TABLE 18. - Base class composition of coprocessing distillates

\begin{tabular}{|lllll|}
\hline Coal, percent & \multicolumn{1}{c}{2} & \multicolumn{1}{c}{20} & 30 & 40 \\
\hline $175-350^{\circ} \mathrm{C}$ & & & & \\
$\quad$ Base Content, \% & 1.5 & 2.5 & 5.3 & 4.0 \\
Azaarenes* & 0.0563 & 0.0848 & 0.1034 & 0.1144 \\
Arylamines* & 0.0153 & 0.0395 & 0.0668 & 0.0584 \\
& & & & \\
$350-538^{\circ} \mathrm{C}$ & & & & \\
Base Content, \% & 4.8 & 5.0 & 7.2 & 6.3 \\
Azaarenes* & 0.1195 & 0.1300 & 0.1598 & 0.1676 \\
Arylamines* & 0.0173 & 0.0250 & 0.0346 & 0.0334 \\
\hline
\end{tabular}

*Meq per gram of distillate

\section{II.C.3.d. Neutral Class Analysis}

\section{II.C.3.d.1. Neutral Class Subfractionation}

The neutral class fractions were further separated into saturate and aromatic subfractions; results are summarized in Table 19. Separations were carried out on charge transfer and adsorption-type liquid chromatography columns (Appendix B). Yields of $175-350^{\circ} \mathrm{C}$ subfractions were less satisfactory than those of higher boiling range because of volatility of some of the components. To avoid excess loss of sample, the solvent content was left at about 5 to 7 percent in each sample, as determined by gas chromatographic analysis.

The trends in saturate and aromatic composition of the $175-350^{\circ} \mathrm{C}$ neutral fraction appear somewhat erratic, possibly because of the effect of loss of sample in the 20 and 30 percent coal products. In both distillate ranges, the 2 percent coal product appears to have less saturate and more aromatic content than might be expected from the trends shown by the other samples. This 
TABLE 19. - Neutral class fractionation

\begin{tabular}{|crrrr|}
\hline Coal, percent & 2 & 20 & 30 & 40 \\
\hline & & & & \\
$175-350^{\circ} \mathrm{C}$ & & & & \\
Saturates & 48.0 & 55.3 & 38.9 & 30.0 \\
Aromatics & 53.2 & 39.6 & 55.5 & 68.0 \\
Recovery & 101.2 & 94.9 & 94.4 & 98.0 \\
& & & & \\
$350-538^{\circ} \mathrm{C}$ & & & & \\
Saturates & 26.8 & 31.2 & 29.4 & 29.9 \\
Aromatics & 74.0 & 70.7 & 69.8 & 69.8 \\
Recovery & 100.7 & 101.8 & 99.2 & 99.8 \\
\hline
\end{tabular}

may indicate that the reaction mechanisms controlling product distribution may differ somewhat in the absence of substantial amounts of coal. The distribution of saturate and aromatic products in the $350-538^{\circ} \mathrm{C}$ fractions for $20-40$ percent coal appears quite constant.

The values in Table 19 are the yields obtained from the neutral fraction. Table 20 shows the yields of neutral saturates and aromatics on the basis of the whole liquid filtrate. The values for $175-350^{\circ} \mathrm{C}, 20$ percent coal sample seem rather inconsistent with the trends of the other samples.

Section II.C.3.a, on separation of distillates into acid, base and neutral fractions, presented a procedure for estimation of source selectivity and relative product yield determination. These values obtained from the yields of Table 20 are shown in Table 21 . The values for $175-350^{\circ} \mathrm{C}$, 20 percent coal were excluded from these calculations. 
TABLE 20. - Yields of neutral saturate and aromatic fractions. Whole filtrate basis

\begin{tabular}{|crrrr|}
\hline Coal, percent & 2 & 20 & 30 & 40 \\
\hline 175-350 $\mathrm{C}$ & & & & \\
Saturates & 16.0 & 17.7 & 11.5 & 8.6 \\
Aromatics & 17.7 & 12.7 & 16.4 & 20.3 \\
& & & & \\
$350-538^{\circ} \mathrm{C}$ & & & & \\
Saturates & 6.1 & 6.7 & 7.4 & 6.2 \\
Aromatics & 16.9 & 15.1 & 17.5 & 14.5 \\
Total & 56.7 & 52.1 & 52.8 & 49.6 \\
\hline
\end{tabular}

TABLE 21. - Selectivity and RPY values for saturates and aromatics

\begin{tabular}{|llrr|}
\hline & $\mathrm{S}_{\mathrm{R}}$ & $\mathrm{S}_{\mathrm{C}}$ & $\mathrm{RPY}$ \\
\hline $175-350^{\circ} \mathrm{C}$ & & & \\
Saturate & & & \\
Aromatic & 1.16 & -0.16 & 7.15 \\
& 0.45 & 0.55 & 19.24 \\
$350-538^{\circ} \mathrm{C}$ & & & \\
Saturate & & & \\
Aromatic & 0.46 & 0.54 & 6.90 \\
\hline
\end{tabular}

The selectivity values for the $175-350^{\circ} \mathrm{C}$ fractions are probably not correct. The negative value for saturate $S_{C}$ is meaningless, and the best interpretation of the $S_{R}$ and $S_{C}$ values would suggest that the $175-350^{\circ} \mathrm{C}$ saturates are produced solely by the Maya residue. This is not reasonable, and the values calculated for selectivities were presumably affected by the loss of volatile components, errors in yield determinations, and solvent contamination. Selectivity values determined for the $350-538^{\circ} \mathrm{C}$ fractions are probably reliable, however, and should be similar to the correct values for the $175-350^{\circ} \mathrm{C}$ fractions. Despite the greater complexity of the $350-538^{\circ} \mathrm{C}$ sample, it is processed more satisfactorily in the separation procedures as shown by the recoveries 
in Table 19. The contribution of aromatic-related materials by coal is greater than indicated by the selectivity values in Table 21. Much the larger part of the acid and base fractions, which are almosi entirely aromatic related, are produced from the coal. Yields and selectivity values demonstrating this were included in section II.C.2.a.

\section{II.C.3.d.2. Mass Spectral Analysis Neutral Fractions}

The detailed analysis of the $350-538^{\circ} \mathrm{C}$ saturate samples was carried out by the ASTM D 2786 low resolution mass spectrometric method developed for petroleum samples. This method is commonly applied to petroleum distillates in which aromatic hydrocarbons and polar compounds are low or absent. The carbon number range is about 12-37. Since the method was developed for petroleum, the results may be somewhat less accurate for the samples containing substantial amounts of coal products. However, studies of coal products have yielded good results. The results of this analysis are shown in Table 22.

TABLE 22. - MS analysis of $350-538^{\circ} \mathrm{C}\left(662-1000^{\circ} \mathrm{F}\right)$ saturates

\begin{tabular}{|lrrrr|}
\hline Coal, percent & 2 & 20 & 30 & 40 \\
\hline & & & & \\
O-Ring & 36.3 & 35.9 & 36.3 & 36.4 \\
1-Ring & 25.8 & 25.1 & 24.9 & 26.0 \\
2-Ring & 13.4 & 13.9 & 13.9 & 13.7 \\
3-Ring & 7.5 & 8.5 & 8.6 & 8.3 \\
4-Ring & 7.7 & 8.0 & 8.2 & 7.5 \\
5-Ring & 5.0 & 4.4 & 4.2 & 4.1 \\
6-Ring & 2.2 & 1.6 & 1.4 & 1.4 \\
Monoaromatic & 2.1 & 2.6 & 2.5 & 2.7 \\
Average Carbon No. & 25 & 27 & 27 & 27 \\
\hline
\end{tabular}

The composition of the $350-538^{\circ} \mathrm{C}$ saturates appears to be remarkably constant with varying residue-coal reactant compositions. In terms of selectivity values shown in Table 21 , the $\mathrm{S}_{\mathrm{R}}$ and $\mathrm{S}_{\mathrm{C}}$ numbers shown for the $350-538^{\circ} \mathrm{C}$ saturate fraction may be assumed to be the same for all of the saturate component classes. The average carbon numbers showri at the bottom of Table 22 were determined by simulated distillation. 
The subfraction from the $175-350^{\circ} \mathrm{C}$ coprocessing neutral materials proved to be somewhat unsatisfactory for compositional analysis because of loss of volatile components and contamination by residual solvent. Because of this, the MS analysis was repeated for determination of the hydrocarbon composition in the original neutral fractions. The Teeter mass spectrometry method determines the major saturate and aromatic hydrocarbons as well as several sulfur classes commonly present in petroleum products. These include a series of cycloalkyl saturates and aromatics and di-and poly-aromatic hydrocarbons. It is suitable for olefin-free distillates boiling in the range $120-566^{\circ} \mathrm{C}$ containing less than 5 percent oxygen, nitrogen, or sulfur. It is based on high-resolution electron impact spectra.

Table 23 shows the results of analysis for the $175-350^{\circ} \mathrm{C}$ neutral samples. No composition trends with coal content are evident for the saturate and monoaromatic compounds. The diaromatics and triaromatics as well as total aromatics show increased levels with increasing coal content. The sulfur compounds are higher in the 2 percent coal product than in the other samples. The reduced effectiveness of the coprocessing procedure in removing sulfur from the 2 percent coal reaction product was noted in Appendix A (Table A-10). This may have been due to poorer dispersion of the catalyst. The calculated elemental compositions of the neutral samples are shown at the bottom of the table.

The analysis of the $350-538^{\circ} \mathrm{C}$ neutral aromatic subfractions by the Teeter method is shown in Table 24. The polynuclear aromatic species $Z=-22$ and the total aromatic hydrocarbon content show an increasing trend with increasing coal content. The $Z=-22$ group is also the largest single species in these samples. Compound types with $Z=-22$ include dinaphthenophenanthrenes, dinaphthenoanthracenes, pyrenes, and fluoranthenes. Sulfur compounds (particularly the dibenzothiophenes and naphthobenzothiophenes) are again high in the 2 percent coal sample. 
TABLE 23. - MS Analysis of neutral fractions, $175-350^{\circ} \mathrm{C}\left(347-662^{\circ} \mathrm{F}\right)$, weight percent

\begin{tabular}{|c|c|c|c|c|}
\hline Coal, percent & 2 & 20 & 30 & 40 \\
\hline \multicolumn{5}{|l|}{ Saturates } \\
\hline Paraffins & 18.5 & 20.2 & 20.1 & 18.7 \\
\hline Monocyclo & 13.7 & 14.5 & 13.8 & 12.8 \\
\hline Dicyclo & 7.6 & 7.5 & 7.8 & 6.2 \\
\hline Tricyclo & 4.6 & 5.4 & 4.9 & 4.7 \\
\hline Tetracyclo & 0.0 & 0.0 & 0.0 & 0.0 \\
\hline Total Saturates & 44.4 & 47.6 & 46.6 & 42.3 \\
\hline \multicolumn{5}{|l|}{ Monoaromatics } \\
\hline Alkylbenzenes & 6.1 & 6.3 & 6.6 & 5.3 \\
\hline Benzocycloparaffins & 7.8 & 8.6 & 9.1 & 7.1 \\
\hline Benzodicycloparaffins & 1.5 & 1.9 & 1.9 & 1.9 \\
\hline \multicolumn{5}{|l|}{ Diaromatics } \\
\hline Naphthalenes $(\mathrm{Z}=-12)$ & 6.6 & 6.8 & 8.3 & 9.5 \\
\hline$(Z=-14)$ & 3.6 & 4.5 & 5.0 & 6.2 \\
\hline$(Z=-16)$ & 4.4 & 4.9 & 5.3 & 6.3 \\
\hline \multicolumn{5}{|l|}{ Polynucleararomatics } \\
\hline$(Z=-18)$ & 2.1 & 2.4 & 2.5 & 3.2 \\
\hline$(\mathrm{Z}=-22)$ & 0.8 & 0.7 & 0.5 & 0.5 \\
\hline Total Aromatics & 32.8 & 36.3 & 39.2 & 40.1 \\
\hline \multicolumn{5}{|l|}{ Sulfur Compounds } \\
\hline Thiophenes & 0.2 & 0.0 & 0.0 & 0.0 \\
\hline Benzothiophenes & 20.6 & 13.9 & 12.4 & 16.0 \\
\hline Dibenzothiophenes & 2.0 & 2.2 & 1.7 & 1.7 \\
\hline Naphthobenzothiophenes & 0.0 & 0.0 & 0.0 & 0.0 \\
\hline Total Sulfur Compounds & 22.8 & 16.1 & 14.1 & 17.7 \\
\hline Calculated, percent C & 85.2 & 85.9 & 86.2 & 86.0 \\
\hline percent $\mathrm{H}$ & 11.7 & 12.0 & 12.0 & 11.6 \\
\hline percent S & 3.07 & 2.08 & 1.84 & 2.32 \\
\hline
\end{tabular}


TABLE 24. - MS Analysis of aromatic neutral subfractions, $350-538^{\circ} \mathrm{C}$ $\left(662-1000^{\circ} \mathrm{F}\right)$, weight percent

\begin{tabular}{|c|c|c|c|c|}
\hline Coal, percent & 2 & 20 & 30 & 40 \\
\hline $\begin{array}{l}\text { Saturates } \\
\text { Paraffins } \\
\text { Monocyclo } \\
\text { Dicyclo } \\
\text { Tricyclo }\end{array}$ & $\begin{array}{l}1.3 \\
2.1 \\
1.0 \\
1.1\end{array}$ & $\begin{array}{l}1.8 \\
2.8 \\
2.0 \\
1.5\end{array}$ & $\begin{array}{l}1.5 \\
2.7 \\
1.7 \\
1.0\end{array}$ & $\begin{array}{l}0.2 \\
0.8 \\
0.7 \\
0.6\end{array}$ \\
\hline Total Saturates & 5.5 & 8.1 & 6.8 & 2.4 \\
\hline $\begin{array}{l}\text { Monoaromatics } \\
\text { Alkylbenzenes } \\
\text { Benzocycloparaffins } \\
\text { Benzodicycloparaffins }\end{array}$ & $\begin{array}{l}2.7 \\
2.4 \\
1.7\end{array}$ & $\begin{array}{l}3.5 \\
3.4 \\
1.7\end{array}$ & $\begin{array}{l}3.5 \\
3.5 \\
1.5\end{array}$ & $\begin{array}{l}2.7 \\
2.4 \\
1.4\end{array}$ \\
\hline $\begin{array}{l}\text { Diaromatics } \\
\text { Naphthalenes }(Z=-12) \\
(Z=-14) \\
(Z=-16)\end{array}$ & $\begin{array}{l}2.1 \\
2.3 \\
6.9\end{array}$ & $\begin{array}{l}2.8 \\
2.6 \\
6.6\end{array}$ & $\begin{array}{l}2.7 \\
3.0 \\
7.8\end{array}$ & $\begin{array}{l}2.3 \\
2.3 \\
6.7\end{array}$ \\
\hline $\begin{array}{l}\text { Polynucleararomatics } \\
\left(\begin{array}{l}\mathrm{Z}=-18) \\
(\mathrm{Z}=-22) \\
(\mathrm{Z}=-24) \\
(\mathrm{Z}=-28)\end{array}\right.\end{array}$ & $\begin{array}{r}6.8 \\
14.9 \\
9.5 \\
11.1\end{array}$ & $\begin{array}{r}8.2 \\
16.1 \\
9.1 \\
9.2\end{array}$ & $\begin{array}{r}7.9 \\
18.7 \\
9.4 \\
9.1\end{array}$ & $\begin{array}{r}7.1 \\
25.4 \\
10.0 \\
9.9\end{array}$ \\
\hline Total Aromatics & 60.4 & 63.3 & 67.1 & 70.3 \\
\hline $\begin{array}{l}\text { Sulfur Compounds } \\
\text { Thiophenes } \\
\text { Benzothiophenes } \\
\text { Dibenzothiophenes } \\
\text { Naphthobenzothiophenes }\end{array}$ & $\begin{array}{r}0.4 \\
7.6 \\
18.1 \\
8.0\end{array}$ & $\begin{array}{r}0.8 \\
7.5 \\
13.7 \\
6.6\end{array}$ & $\begin{array}{r}0.6 \\
7.9 \\
12.0 \\
5.6\end{array}$ & $\begin{array}{r}0.8 \\
7.6 \\
12.6 \\
6.4\end{array}$ \\
\hline Total Sulfur Comps. & 34.1 & 28.6 & 26.1 & 27.3 \\
\hline $\begin{array}{l}\text { Calculated percent } \mathrm{C} \\
\text { percent } \mathrm{H} \\
\text { percent } \mathrm{S}\end{array}$ & $\begin{array}{l}87.2 \\
9.6 \\
3.18\end{array}$ & $\begin{array}{c}87.5 \\
9.8 \\
2.71\end{array}$ & $\begin{array}{c}87.8 \\
9.8 \\
2.43\end{array}$ & $\begin{array}{c}88.1 \\
9.2 \\
2.65\end{array}$ \\
\hline
\end{tabular}




\section{II.C.4. Resid Fractionation and Analysis}

Samples of the 2 percent, 20 percent, and 40 percent coal coprocessing resids (bp $>1000^{\circ} \mathrm{F}$ ) were separated into neutral, acid, and base class fractions. Separation is based on nonaqueous ion exchange techniques. The procedure developed for separation of resid samples further resolves the acid and base materials into strong and weak subfractions.

Table 25 shows the yields of fractions obtained from the coprocessing resid samples. These samples showed poorer solubility in the solvent system than do the petroleum resids for which the procedure was developed. This caused total recovery to fall in the range $82-90$ percent. Strong correlations between coal concentration and resid compositions were not apparent. The strong acid content was lower in the resid from the 2 percent coal run.

TABLE 25. - Separation of coprocessing resid $>538^{\circ} \mathrm{C}\left(>1000^{\circ} \mathrm{F}\right)$ fractions

\begin{tabular}{|lrrr|}
\hline Coal, percent & 2 & 20 & \multicolumn{1}{c|}{40} \\
\hline Neutral & 32.18 & 39.32 & 27.52 \\
Strong Acid & 20.28 & 27.04 & 28.28 \\
Weak Acid & 11.68 & 9.73 & 9.87 \\
Strong Base & 15.43 & 12.31 & 14.54 \\
Weak Base & 1.94 & 1.72 & 1.73 \\
Total & 81.51 & 90.12 & 82.82 \\
\hline
\end{tabular}

In a similar separation procedure, a set of fractions were prepared from Maya $>1000^{\circ} \mathrm{F}$ resid. Special effort was made to remove traces of solvent from these fractions for the carbon isotope measurements. Table 26 shows the $\mathrm{ABN}$ yields.

TABLE 26.- Separation of Maya resid $>538^{\circ} \mathrm{C}\left(>1000^{\circ} \mathrm{F}\right)$

\begin{tabular}{|lc|}
\hline & Yield, \% \\
\hline Neutral & 54.3 \\
Strong Acid & 17.8 \\
Weak Acid & 8.1 \\
Strong Base & 10.3 \\
Weak Base & 8.4 \\
Total Yield & 98.9 \\
\hline
\end{tabular}


Comparison of fraction yields in Tables 25 and 26 show the coprocessing residues to contain less neutral and more polar compound classes. However, the coprocessing resids contain much less of the weak bases which are usually prominent in petroleum distillates and residues. Results of base titrations reported in Section II.C.3.c showed that weak bases could not be detected in the coprocessing distillates. Weak bases that may be found in petroleum products include such compounds as sulfoxides, diarylamines, amides, and carbonyl classes. It is possible that the weak bases most prominent in petroleum fractions are destroyed in the coprocessing reactions.

\section{II.C.5. Conclusions}

Coprocessing products made under constant conditions with the exception of ratio of coal to resid in the feed were subjected to extensive separation and analysis. Changes in product compositions with changing feed ratio have allowed a determination of the source of particular compound classes.

In the light distillates (boiling below $175^{\circ} \mathrm{C}, 347^{\circ} \mathrm{F}$ ), correlations between compound classes and coal concentration, although not strong, are evident. Normal paraffins decrease with increasing coal concentration while isoparaffins and aromatics increase.

In the middle $\left(175-350^{\circ} \mathrm{C}, 347-662^{\circ} \mathrm{F}\right)$ and heavy $\left(350-538^{\circ} \mathrm{C}, 662-1000^{\circ} \mathrm{F}\right)$ distillates, both acids and bases increase with increasing coal concentration. Selectivity factors, which are an expression showing the fraction of a particular compound class which is derived from coal or resid, were determined. These factors indicate that coal is clearly the dominant source of both acids and bases. For example, with equal concentrations of coal and resid in the feed, 9 percent of the acids in the $175-350^{\circ} \mathrm{C}$ distillate would have arisen from the petroleum and 91 percent from the coal. Similarly, 12 percent of the bases would have arisen from the resid and 88 percent from coal. In the higher boiling distillates, where concentrations of the polar constituents are higher, coal continues to be the dominant scurce of acids and bases--although to a lesser extent.

Two-dimensional NMR analysis of the middle and heavy distillates showed that phenols increase in concentration with increasing coal content while nitrogen acids are much more prominent in the run with 98 percent petroleum resid. Generally, nitrogen acids decreased in concentration with increasing coal content. Benzylic or sulfur acids were minor contributors in all cases but were much more prominent in the run with 98 percent petroleum resid. Nitrogen acids and benzylic or sulfur acids were more prominent in the higher boiling distillates. 
Analysis of basic fractions by nonaqueous titration techniques showed increases in both azaarenes (e.g., pyridines, quinolines, etc.) and arylamines (e.g., anilines, etc.) with increasing coal content. Compared to middle distillates $\left(175-350^{\circ} \mathrm{C}\right)$, heavy distillates $\left(350-538^{\circ} \mathrm{C}\right)$ contain increased levels of azaarenes and decreased levels of arylamines.

Subfractionation of the middle distillate $\left(175-350^{\circ} \mathrm{C}\right)$ neutrals into saturates and aromatics showed a general trend for an increase in aromatics with increasing coal content. However, the run with 98 percent resid was hign in aromatics. This may indicate somewhat differing reaction mechanisms in the absence of substantial amounts of coal. In the heavy distillate, saturate/aromatic ratios were relatively independent of coal concentration. Selectivity values indicate that in the heavy distillate, 56 percent of the aromatics would originate from the coal and 44 percent from the petroleum resid (with a 1:1 ratio of coal:resid in the feed). The contribution of aromatic materials by coal is greater than that indicated by the selectivity values since the larger part of the acids and bases (almost entirely aromatic) arise from the coal.

Mass spectral analyses of the middle and heavy distillates showed that compositions of the saturate fractions were remarkably constant with varying resid:coal feed ratios. For the middle distillate, mass spectral analyses showed increases in diaromatics and triaromatics as well as total aromatics with increasing coal content. The only prominent trend in the heavy distillate aromatics was an increase in the $Z=-22$ series with increasing coal content. Compound types with $Z=-22$ include dinaphthenophenanthrenes, dinaphthenoanthracenes, pyrenes, and fluoranthenes.

\section{II.D. ANALYSIS HRI SAMPLES}

\section{II.D.1 Introduction}

A set of eight coprocessing samples was received from HRI, Inc. Based on run conditions and preliminary analyses, a set of vacuum still bottoms samples was selected for detailed analysis. The samples were selected so that processing conditions were constant except for variations in feed composition. The samples selected allowed a determination of the effect of changing coal concentration and a comparison of results with subbituminous coal versus lignite.

Samples were selected from run 238; in all cases reaction temperature was $810^{\circ} \mathrm{F}$, relative space velocity was 1 and the petroleum resid was Hondo. Variable conditions are as follows: 


\begin{tabular}{|llcc|}
\hline Sample.wt \% & Coal & Coal Concentration. \% & Resid Conversion \\
& & & \\
$238-8-5$ & New Mexico* & 33 & 93 \\
$238-8-9$ & New Mexico & 50 & 90 \\
$238-10-8$ & Texas Lignite & 33 & 93 \\
\hline
\end{tabular}

*Subbituminous coal from the McKinley Mine

Thus, 238-8-5 and 238-8 $\rightarrow$ vary only in coal concentration and 238-8-5 and 238-10-8 vary only in the coal feedstock. In all cases the samples further analyzed were vacuum still bottoms (VSB). Elementai: and solubility analyses of the samples provided by HRI are shown in Table 27.

TABLE 27. - Elemental and solubility analyses of vacuum still bottoms samples (HRI, Inc.)

\begin{tabular}{|lccc|}
\hline & $238-8-5$ & $238-8-9$ & $238-10-8$ \\
\hline & $\ldots$ & & \\
& & & \\
$\mathrm{C}$ & 13.8 & 10.9 & 16.2 \\
$\mathrm{C}$ & 64.26 & 63.62 & 61.02 \\
$\mathrm{H}$ & 6.43 & 5.84 & 6.05 \\
$\mathrm{~N}$ & 0.48 & 0.65 & 0.56 \\
$\mathrm{~S}$ & 0.71 & 0.47 & 1.07 \\
Ash & 27.63 & 28.56 & 30.04 \\
Quinoline Insolubles & 43.09 & 44.41 & 50.99 \\
Toluene Insolubles & 44.10 & 46.15 & 51.14 \\
Cyclohexane Insolubles & 48.92 & 48.68 & 56.55 \\
\hline
\end{tabular}

Note from these data that the difference between the quinoline insolubles and the toluene insolubles is quite small ( 0.2 to 1.7 weight percent); thus the amount of material in the "preasphaltene" category is quite small. The difference between the toluene insolubles and the cyclohexane insolubles is larger but also small ( 2.5 to 5.4 weight percent). 


\section{II.D.2 Separation into Acids, Bases and Neutrals}

The vacuum still bottoms samples were separated by nonaqueous ion exchange liquid chromatography into five fractions: strong acids, weak acids, strong bases, weak bases, and neutrals; results are summarized in Table 28. The separation scheme is applicable only to soluble materials so the samples ( $\sim 35 \mathrm{~g}$ samples) were first Soxhlet extracted with benzene. As noted above, there is a relatively small difference in quinoline versus toluene or cyclohexane insolubles. The quinoline insolubles (including ash ano what is typically termed "IOM" or insoluble organic matter) would typically not be material which would be capable of undergoing further reaction and thus its composition is of limited information anyway. The benzene solubles/insolubles are shown on the first two rows of Table 28. Benzene insolubles were determined by difference; i.e., 100 benzene solubles. This preparative extraction indicates a higher percentage of benzene insolubles than anticipated from Table 27. Note that recovery from the acid-base-neutral separation is greater than 100 weight percent by 6 to 10 percent. This is due to retention of some of the separation solvents by the resid fractions.

The predominant fraction (67-81 percent) from the ABN separation is the neutral fraction. Unless there is a predominance of highly condensed aromatics, this type of material would be expected to be relatively easily converted into distillate range materials. Separation of the neutral fraction into saturates and neutral aromatics is discussed later.

Comparing runs 238-8-5 and 238-8-9, all of the polar fractions increase with increasing coal concentration. This is not wholly consistent with the earlier work at NIPER in which only the strong acids (in the resid fraction) showed a strong increase with an increase in coal concentration. This variaticn may be due to differences in composition of the resids used (Maya at NIPER versus Hondo at $\mathrm{HRI}$ ), the coal used (bituminous at NIPER versus subbituminous at HRI), or the more effective heteroatom removal at HRI.

Comparing runs 238-8-5 and 238-10-8, (subbituminous coal versus lignite), there is a significantly larger strong acid fraction from the lignite run. Weak acids (generally indole/ carbazole-type structures) are also significantly higher in the resid from the lignite. The are however, only relatively small differences in the concentrations of the basic fractions from the two different coals. Further analyses of the acid and base fractions are discussed later. 
TABLE 28. Liquid chromatographic fractionation of HRI resids

\begin{tabular}{|c|c|c|c|}
\hline Fraction & $238-8-5$ & $238-8-9$ & $238-10-8$ \\
\hline & \multicolumn{3}{|c|}{--Vacuum Still Bottoms Basis, wt \%-- } \\
\hline \multicolumn{4}{|c|}{ A. Separation of Benzene Solubles } \\
\hline Benzene Solubles & 47.2 & 44.7 & 29.8 \\
\hline \multirow[t]{2}{*}{ Benzene Insolubles } & 53.8 & 55.3 & 70.2 \\
\hline & \multicolumn{3}{|c|}{---Benzene Solubles Basis, wt \%--- } \\
\hline \multicolumn{4}{|l|}{ B. ABN Separation } \\
\hline Strong Acids & 12.2 & 17.4 & 21.0 \\
\hline Weak Acids & 7.0 & 13.2 & 14.2 \\
\hline Total Acids & 19.2 & 30.6 & 35.2 \\
\hline Strong Bases & 5.5 & 9.3 & 6.8 \\
\hline Weak Bases & 0.8 & 1.2 & 1.0 \\
\hline Total Bases & 6.3 & 10.5 & 7.8 \\
\hline Neutrals & 80.8 & 67.3 & 67.4 \\
\hline Total & 106.3 & 108.4 & 110.4 \\
\hline
\end{tabular}

\section{II.D.3. Analysis of Neutral Fractions}

As noted above, the predominant fraction in the resid in all cases is the neutrals. Results for separation of the neutral fraction into saturates and neutral aromatics are presented in Table 29. Recoveries were 97.5 to 100.4 percent. The concentration of saturates is high ( 70 percent) in the neutrals from run 238-8-5 (33 percent subbituminous coal, 67 percent Hondo resid) and drops markedly (to 26 percent) with an increase in coal concentration to 50 percent (238-8-9). This suggests that the resid is the source of the saturates--not a surprising suggestion. However, the run with 33 percent lignite and 67 percent Hondo resid (238-10-8) contains a much lower level of saturates ( 32 percent) than the run with the same level of subbituminous coal indicating a role of the coal (or an unrecognized variable) in controlling the level of saturates in the neutral resid fraction. 


\section{TABLE 29. - Liquid chromatographic separation of neutrals into saturates and neutral aromatics}

\begin{tabular}{|c|c|c|c|}
\hline Fraction & $238-8-5$ & $238-8-9$ & $238-10-8$ \\
\hline & \multicolumn{3}{|c|}{-....-VSB Benzene Solubles Basisa , wt \% } \\
\hline Saturates & $55.5(69.8)$ & $17.4(25.7)$ & $20.8(31.7)$ \\
\hline Neutral Aromatics & $24.0(30.2)$ & $50.2(74.3)$ & $44.9(68.3)$ \\
\hline Total & 79.5 & 67.6 & 65.7 \\
\hline Recovery, \% & 98.4 & 100.4 & 97.5 \\
\hline
\end{tabular}

a Values within parentheses are on a normalized neutrals basis

Both the saturates and neutral aromatic fractions were analyzed by high temperature gas chromatography. While normal simulated distillation techniques can determine boiling-point distributions up to only about $1000^{\circ} \mathrm{F}$, high temperature simulated distillation can determine distributions to over $1300^{\circ} \mathrm{F}$ or up to a carbon number of about $\mathrm{C}-120$. By use of an internal standard, the amount of material not eluted from the column is also determined. Chromatograms of the saturate fractions are shown in Figure 26. The regularly spaced sharp peaks represent n-paraffins. Chromatograms of the two runs with 33 or 50 percent subbituminous coal are virtually indistinguishable, while the run with lignite is similar with a slightly higher boiling range distribution. Similarly, the chromatograms for the aromatic fractions (Figure 27) for the 33 and 50 percent subbiturninous runs are nearly indistinguishable. The chromatogram for the lignite shows some differences but many of the same major peaks predominate. Figures 28 and 29 show the cumulative percent of saturates and aromatics eluted as a function of apparent carbon number with the carbon number scale based on n-paraffin elution times. In all cases, the saturates are essentially completely eluted with a maximum apparent carbon number of just over 80 . Nearly all of the aromatics (95-97 percent) were also eluted from the column. Boiling-point distributions are summarized in Table 30.

The neutral-aromatics fraction from each sample was further characterized by highperformance liquid chromatography (HPLC) using a separation system that gives an aromatic ringnumber distribution. An analytical-size column packed with a charge-transfer bonded phase (dinitroanilinopropyl silica or DNAP) was used to study the ring number distribution. Figure 30 is a chromatogram of a mixture of 1 through 5-ring unsubstituted aromatic hydrocarbons separated on the DNAP column. These compounds are benzene, naphthalene, phenarthrene, benz(a)anthracene and dibenz(a,c)anthracene. 

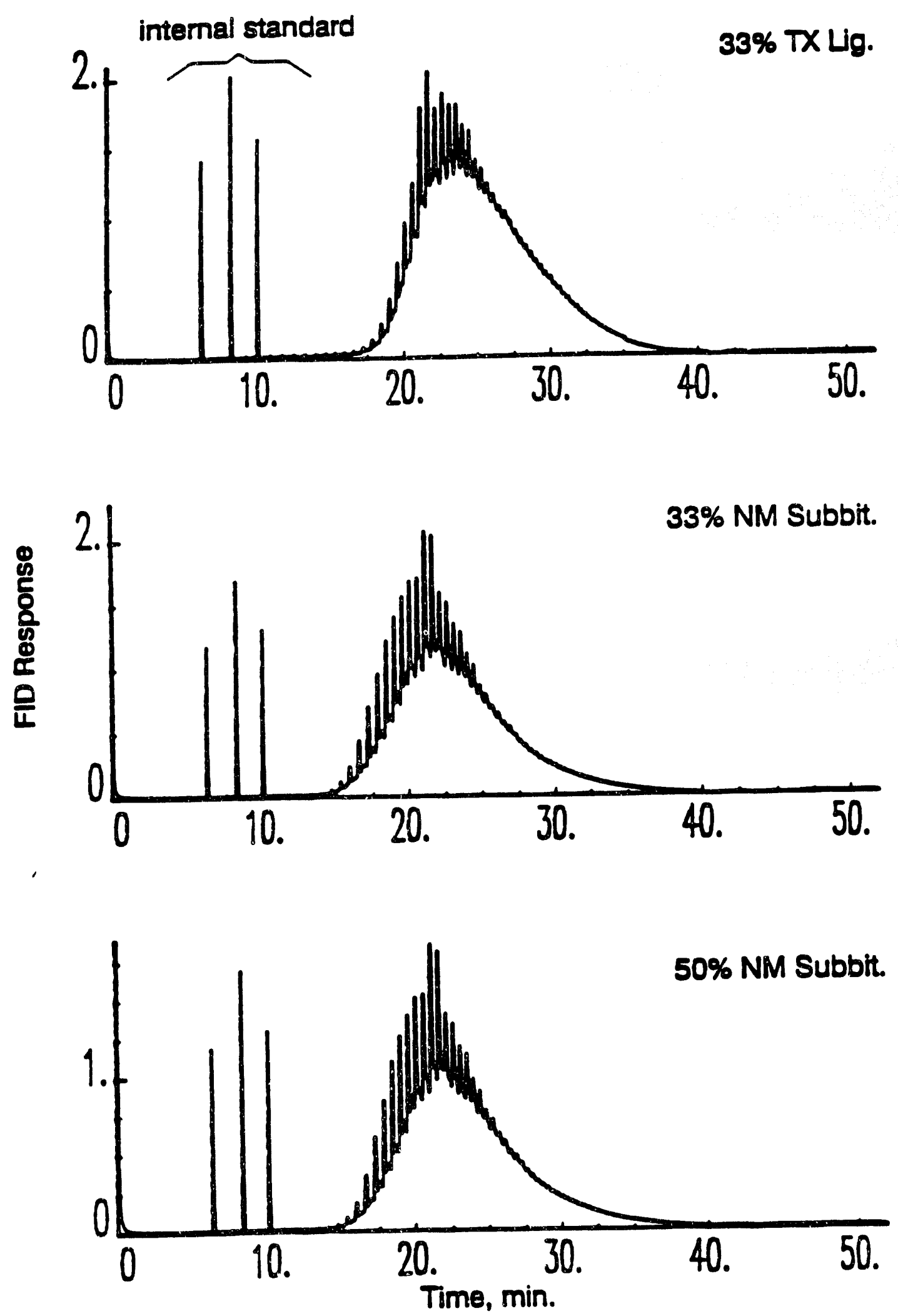

FIGURE 26. - HTGC chromatograms of saturate fractions from HRI coprocessing resids. 

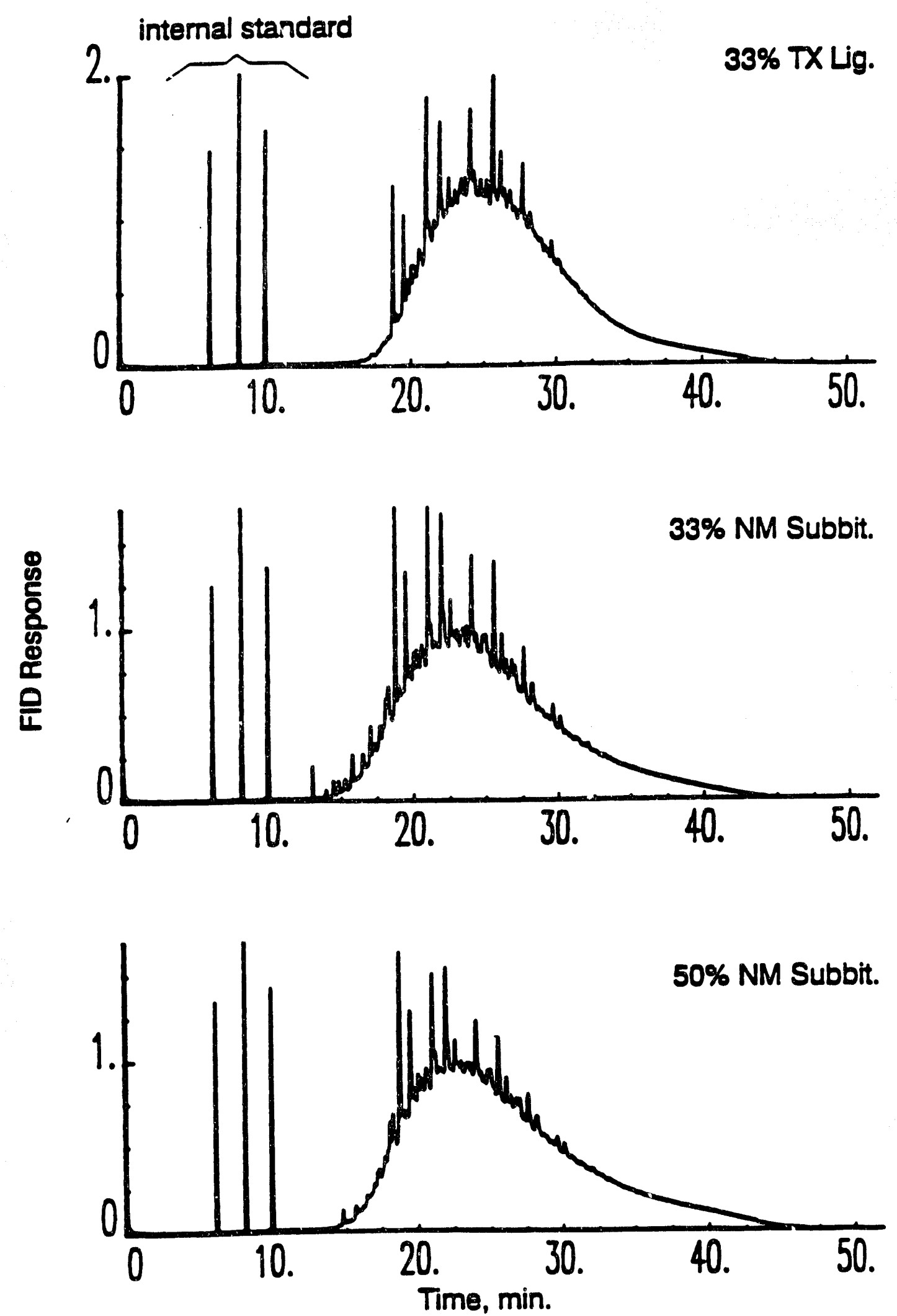

FIGURE 27. - HTGC chromatograms of neutral-aromatic fractions from HRI coprocessing res ds. 

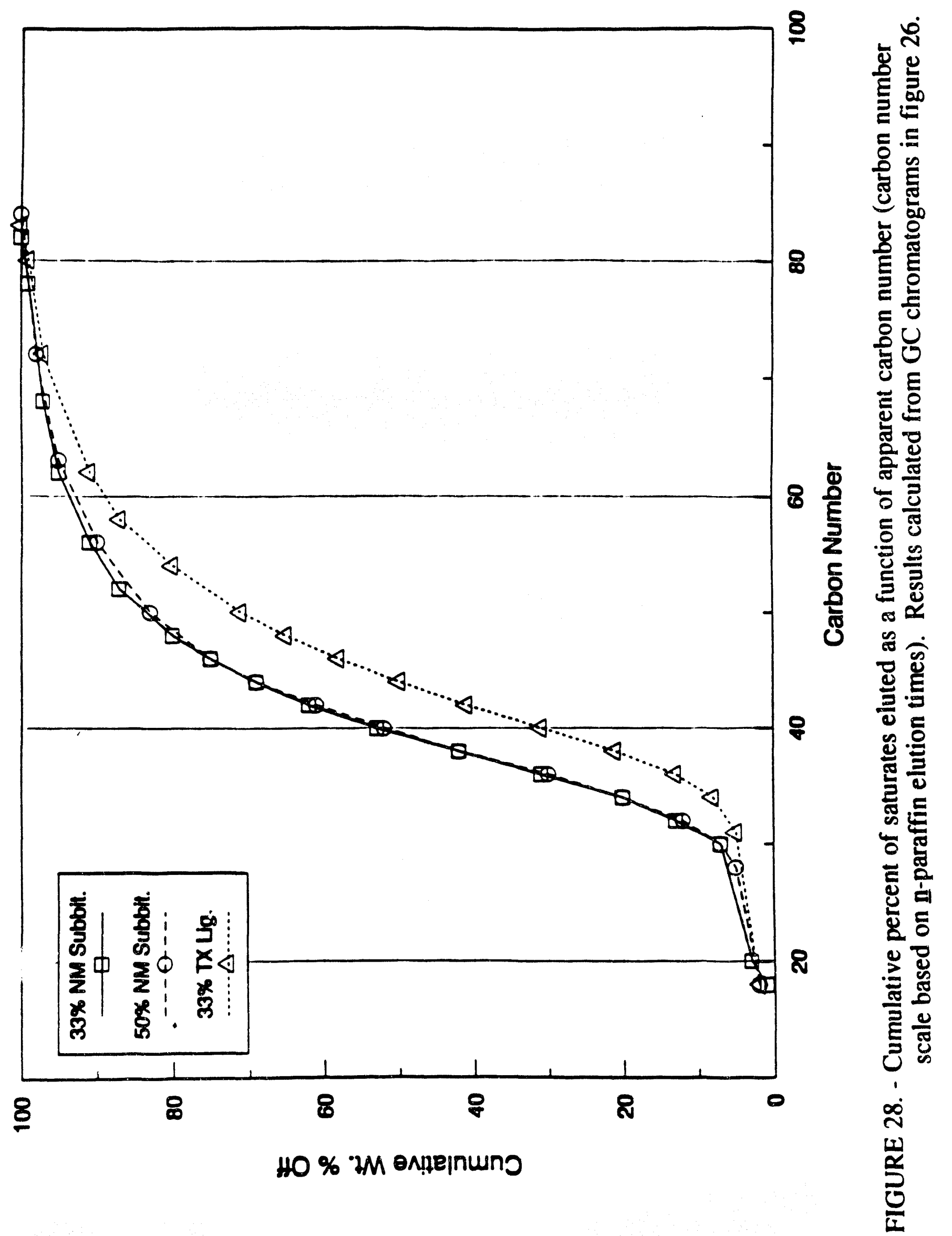


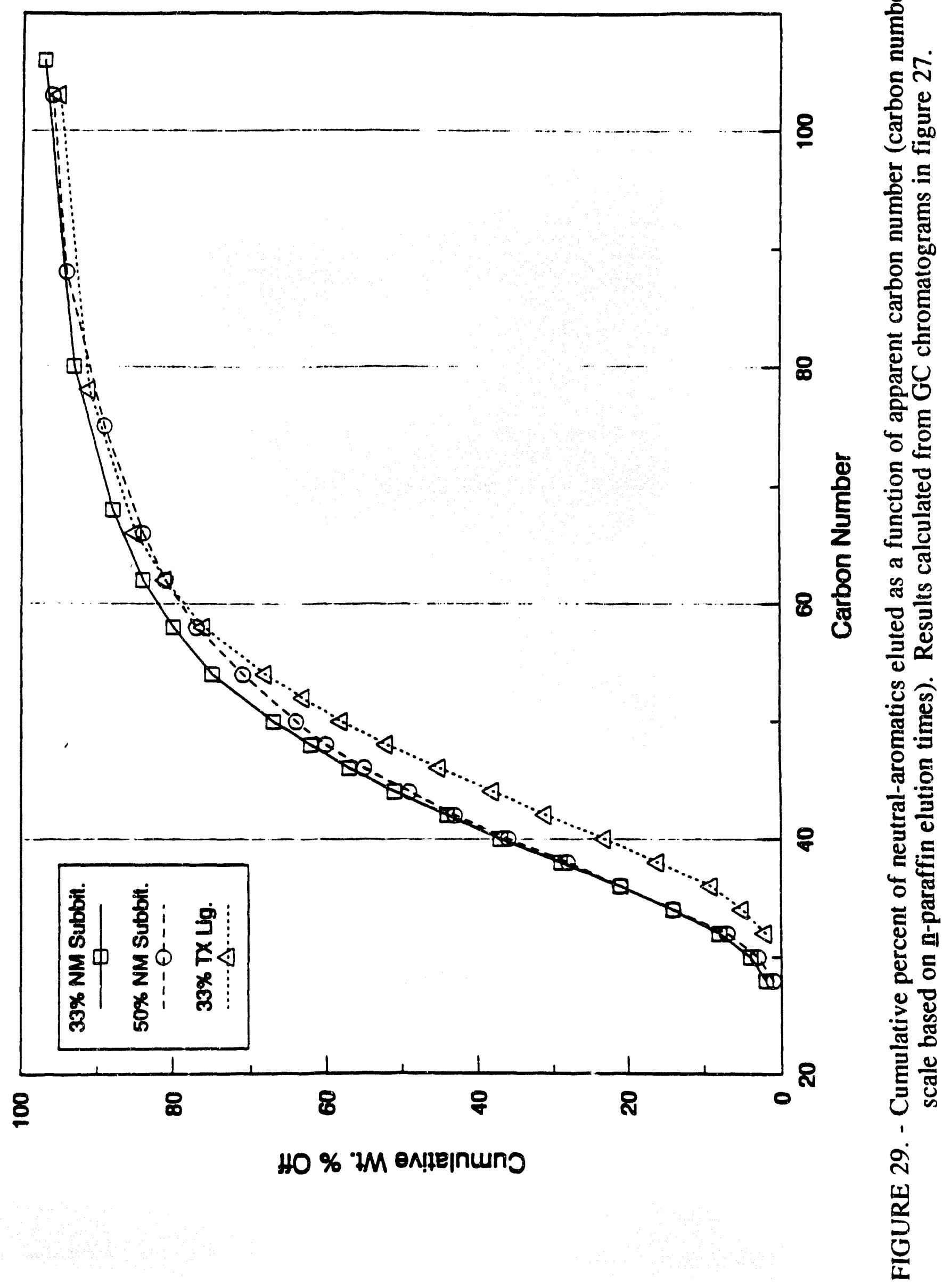


TABLE 30. - High temperature simulated distillation

\% Distilled

1
5
10
20
30
40
50
60
70
80
90
95
99

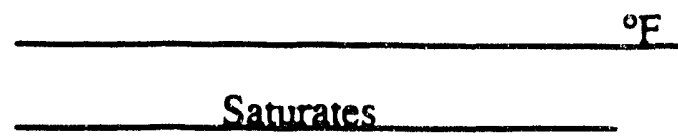

\section{8-8-5} $33 \%$ sub. $50 \%$ sub. $33 \%$ lig.

238-8-9

238-10-8

598

598

812

859

900

926

950

971

995

1020

1052

1104

1154

1234

552
807
860
901
927
951
972
996
1021
1053
1108
1157
1233

552
807

860

901

927

951

972

996

1021

1108

1233
${ }^{\circ} \mathrm{F}$

Aromarics

238-8-5 238-8-9 238-10-8

$33 \%$ sub. $50 \%$ sub. $33 \%$ lig.

$\begin{array}{llr}795 & 808 & 853 \\ 854 & 860 & 901 \\ 882 & 885 & 931 \\ 923 & 926 & 966 \\ 957 & 959 & 998 \\ 986 & 990 & 1022 \\ 1015 & 1021 & 1046 \\ 1042 & 1052 & 1073 \\ 1079 & 1092 & 1104 \\ 1127 & 1147 & 1147 \\ 1204 & 1235 & 1219 \\ 1281 & 1299 & 1308 \\ 1321(97 \%) & 1329(97 \%) & -\end{array}$




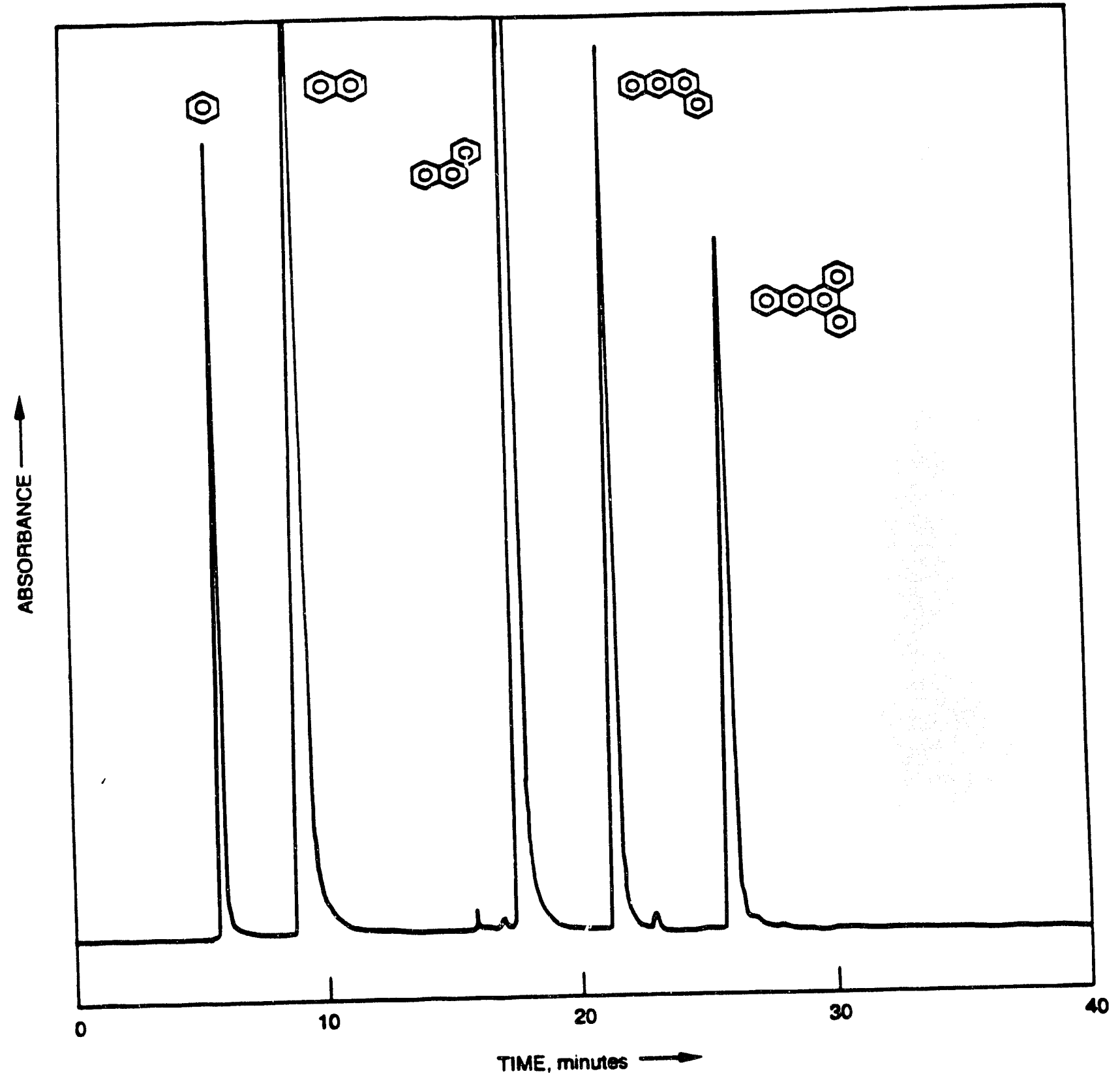

FIGURE 30. - Chromatogram of known compounds on DNAP-silica. 
Figures 31-33 are chromatograms of the neutral-aromatic fractions of samples 238-8-5 (33 percent New Mexico subbituminous coal), 238-8-9 (50 percent New Mexico subbituminous coal) and 238-10-8 (33 percent Texas lignite) run under the same conditions. The sharp spike at $5.5 \mathrm{~min}$. is due to benzene from the acid-base-neutral fractionation procedure. Then there is a low level of mono and diaromatic compounds, and at $15 \mathrm{~min}$. a large broad mass begins to elute. The front of this mass coincides with the retention time of the 3 fused-ring compound in the calibration run.

The broad mass elutes for $30 \mathrm{~min}$. or more before returning completely to the baseline. At approximately $30 \mathrm{~min}$. each sample has a peak that rises significantly above the baseline. Based on its retention time, it is probably a six fused-ring aromatic compound.

The concentration of neutral-aromatics increased with increasing coal concentration suggesting coal as the primary source of this fraction. The chromatograms are remarkably similar indicating the production of very similar materials (even in the resid fraction) from either subbituminous coal or lignite. 


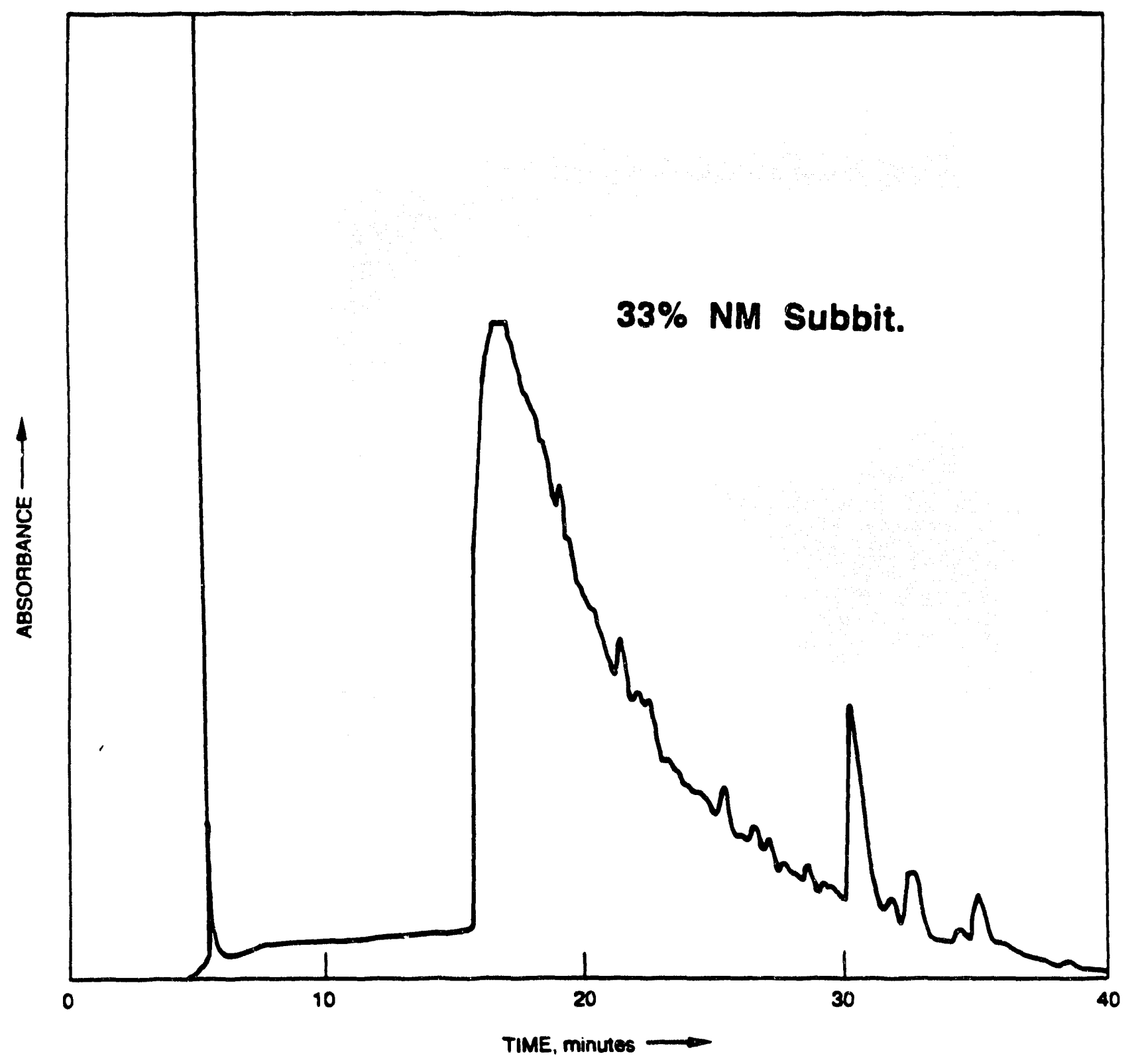

FIGURE 31. - Chromatogram of 238-8-5 neutral aromatics on DNAP-silica. 


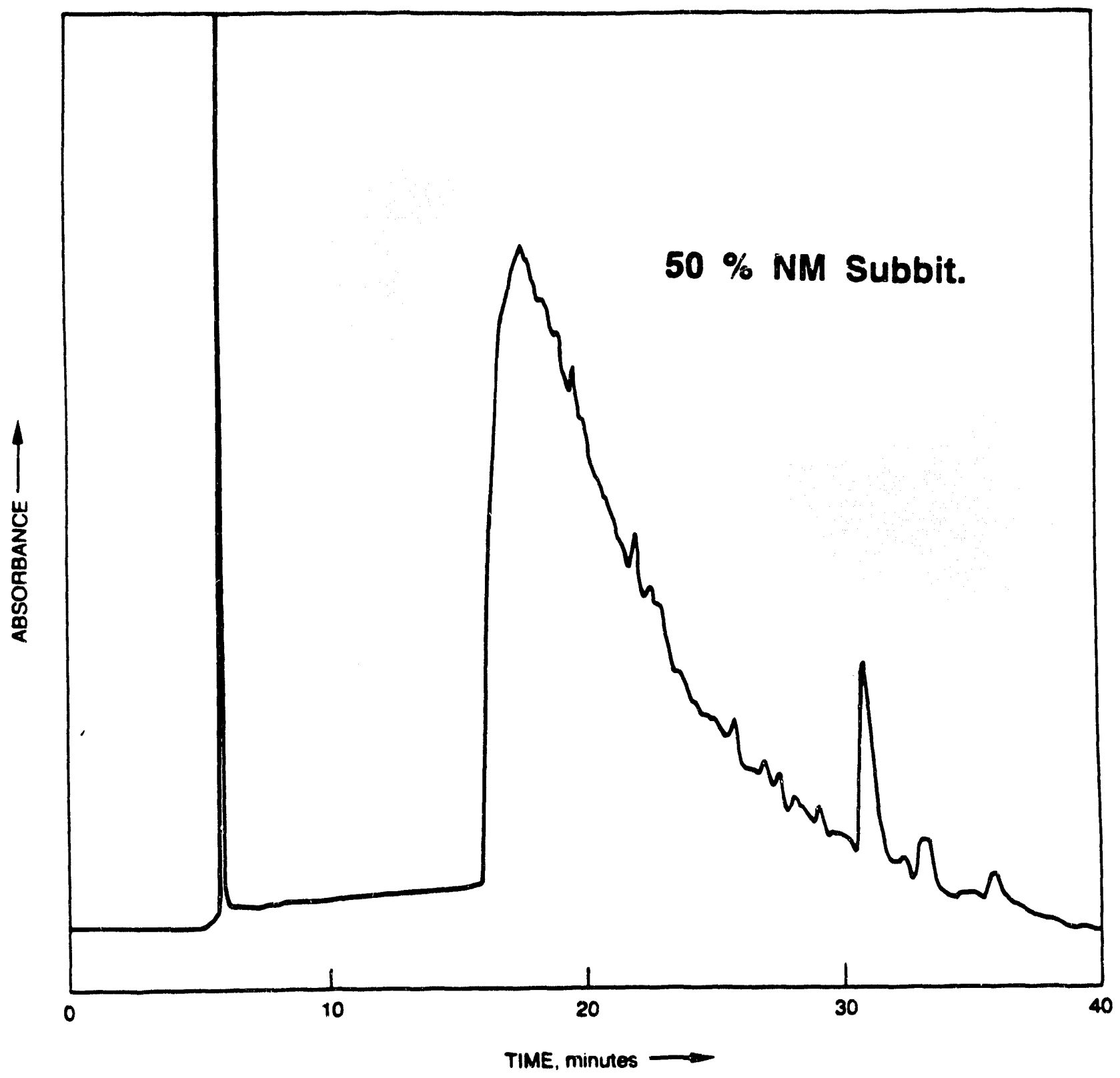

FIGURE 32. - Chromatogram of 238-8-9 neutral aromatics on DNAP-silica. 


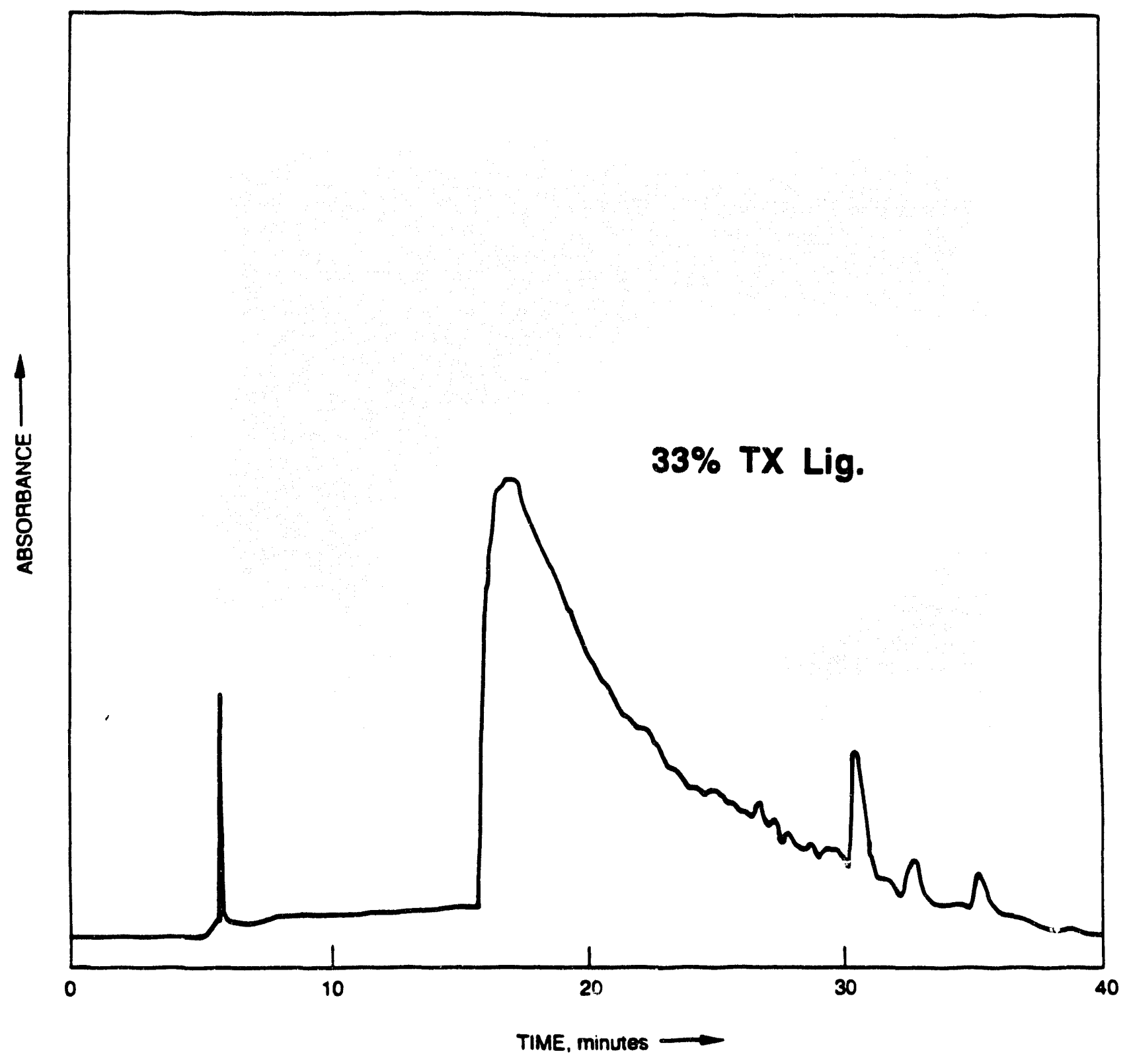

FIGURE 33. - Chromatogram of 238-10-8 neutral aromatics on DNAP-silica. 
Table 31 summarizes results for elemental analyses of all fractions. In general, the elemental content of a given fraction, e.g. saturates, over each of the resids is relatively constant. Thus, differences in elemental analyses for each of the whole resids indicate differences in their fraction distributions to a much greater extent than variations in elemental content for the fractions themselves.

Approximately one-third of the benzene insolubles obtained is comprised of carbon. The H/C ratio of these materials is extremely low, near that of petroleum coke, which accounts for the insolubility of the organic matter present. Some or all of the sulfur and nitrogen present in the insolubles may exist in inorganic forms.

The combination of $\mathrm{H} / \mathrm{C}$ ratios, average molecular weights estimated from $\mathrm{GC}$ data and, in the case of neutral-aromatic fractions, LC profiles for ring-number distributions may be used to derive average carbon skeletons for saturate and neutral-aromatic fractions from the HRI coprocessing resids.

Table 32 lists $\mathrm{H} / \mathrm{C}$ ratio as a function of naphthene ring number for saturated hydrocarbon homologs with molecular weights approximately equal to those determined for the coprocessing saturate fractions. Comparison of the $\mathrm{H} / \mathrm{C}$ ratios of saturate fractions from the Hondo: subbituminous coal products (average molecular weight $=550$ ) with those in Table 32 indicates that saturates from either fraction contain, on the average, only 1-2 naphthene rings per molecule. Of course, this is only an average parameter and, in reality, a range of naphthene ring-number species are present. The analogous comparison of the Hondo: lignite saturates (average molecular weight $=620$ ) reveals an average ring number of $1-2$ for that fraction as well.

The analogous comparison for neutral-aromatic compounds was initially based on the assumption that aliphatic carbons were present solely in acyclic forms. Matching experimental $\mathrm{H} / \mathrm{C}$ ratios in Table 1 with those of $\mathbf{n}$-alkyl-substituted aromatics in Table 33 resulted in estimates of average aromatic ring numbers near 6 for all three resids. However, reexamination of actual ring number distributions determined by HPLC revealed that this estimate was erroneousiy high. All three fractions showed very similar HPLC chromatograms indicating distributions from approximately 3 to 6 aromatic rings per molecule with an average near 4 rings per molecule.

Feconciliation of the HPLC versus $\mathrm{H} / \mathrm{C}$ data is possible if one considers naphthenic forms of aliphatic carbon. For example, the observed $\mathrm{H} / \mathrm{C}$ ratios of neutral-aromatic fractions match those listed in Table 34 for 4-ring aromatics containing from 5-7 naphthenic rings. 
TABLE 31. - Elemental analyses of LC fractions and benzene insolubles from HRI coprocessing resids

\begin{tabular}{|c|c|c|c|c|c|c|c|}
\hline \multirow[b]{2}{*}{ Sample No. } & \multirow[b]{2}{*}{ Fraction } & \multicolumn{5}{|c|}{ Weight Percent } & \multirow{2}{*}{$\begin{array}{c}\mathrm{H} / \mathrm{C} \\
\text { atomic } \\
\text { Ratio }\end{array}$} \\
\hline & & $\mathrm{C}$ & $\mathrm{H}$ & $\mathrm{N}$ & $\mathrm{S}$ & Total & \\
\hline $238-8-5$ & saturates & 86.46 & 14.48 & $<0.01$ & $<0.01$ & 100.94 & 1.996 \\
\hline (67\% Hondo: & neutral-aromatics & 89.72 & 9.07 & 0.116 & 0.143 & 99.05 & 1.205 \\
\hline $33 \%$ New & strong acids & 74.22 & 6.49 & 1.20 & 0.121 & 82.03 & 1.042 \\
\hline Mexico & weak acids & 82.22 & 7.81 & 1.46 & 0.157 & 91.65 & 1.132 \\
\hline \multirow[t]{3}{*}{ subbituminous) $^{1}$} & 1 strong bases & 84.18 & 8.50 & 2.25 & 0.414 & 95.34 & 1.203 \\
\hline & weak bases & 86.64 & 8.86 & 1.45 & 0.56 & 97.51 & 1.219 \\
\hline & insolubles & 32.36 & 1.96 & 0.39 & 1.11 & 35.82 & 0.722 \\
\hline $238-8-9$ & saturates & 85.77 & 14.27 & $<0.01$ & $<0.01$ & 100.04 & 1.983 \\
\hline (50\% Hondo: & neutral-aromatics & 90.15 & 8.76 & 0.122 & 0.206 & 99.24 & 1.158 \\
\hline $50 \%$ New & strong acids & 79.91 & 7.01 & 1.25 & 0.180 & 88.35 & 1.045 \\
\hline Mexico & weak acids & 83.24 & 8.32 & 1.00 & 0.150 & 92.71 & 1.190 \\
\hline \multirow[t]{3}{*}{ subbituminous) ${ }^{1}$} & 1 strong bases & 79.85 & 7.74 & 3.33 & 0.419 & 91.34 & 1.155 \\
\hline & weak bases & 85.76 & 8.56 & 1.75 & 0.74 & 96.81 & 1.189 \\
\hline & insolubles & 35.92 & 2.20 & 0.39 & 0.70 & 39.21 & 0.305 \\
\hline $238-10-8$ & saturates & 86.32 & 14.38 & $<0.01$ & $<0.01$ & 100.70 & $1.98 E$ \\
\hline (67\% Hondo: & neutral-aromatics & 89.86 & 9.43 & C. 126 & 0.323 & 99.74 & 1.250 \\
\hline $33 \%$ Texas & strong acids & 80.99 & 6.84 & 1.16 & 0.217 & 89.21 & 1.006 \\
\hline \multirow[t]{4}{*}{ Lignite) ${ }^{1}$} & weak acids & 82.49 & 8.22 & 1.31 & 0.262 & 92.28 & 1.187 \\
\hline & strong bases & 86.24 & 8.02 & 2.06 & 0.379 & 96.70 & 1.108 \\
\hline & weak bases & 83.30 & 8.62 & 1.53 & 0.90 & 94.85 & 1.226 \\
\hline & insolubles & 27.33 & 1.46 & 0.35 & 1.87 & 31.01 & 0.637 \\
\hline
\end{tabular}

${ }^{1}$ Feedstocks for coprocessing run. 
TABLE 32. - H/C ratios of saturated hydrocarbon homologs with molecular weights near 550 and 620

\begin{tabular}{|cllllll|}
\hline $\begin{array}{l}\text { Number of } \\
\text { Naphthenic } \\
\text { Rings }\end{array}$ & $\begin{array}{l}\text { Empirical } \\
\text { Formula }\end{array}$ & MW & $\begin{array}{c}\mathrm{H} / \mathrm{C} \\
\text { Ratio }\end{array}$ & $\begin{array}{c}\text { Empirical } \\
\text { Formula }\end{array}$ & MW & $\begin{array}{r}\mathrm{H} / \mathrm{C} \\
\text { Ratio }\end{array}$ \\
\hline & & & & & & \\
0 & $\mathrm{C}_{39} \mathrm{H}_{80}$ & 548 & 2.051 & $\mathrm{C}_{44} \mathrm{H}_{90}$ & 618 & 2.046 \\
1 & $\mathrm{C}_{39} \mathrm{H}_{78}$ & 546 & 2.000 & $\mathrm{C}_{44} \mathrm{H}_{88}$ & 616 & 2.000 \\
2 & $\mathrm{C}_{39} \mathrm{H}_{76}$ & 544 & 1.949 & $\mathrm{C}_{44} \mathrm{H}_{86}$ & 614 & 1.955 \\
3 & $\mathrm{C}_{39} \mathrm{H}_{74}$ & 542 & 1.897 & $\mathrm{C}_{44} \mathrm{H}_{84}$ & 612 & 1.909 \\
4 & $\mathrm{C}_{39 H} \mathrm{H}_{72}$ & 540 & 1.846 & $\mathrm{C}_{45} \mathrm{H}_{84}$ & 624 & 1.867 \\
5 & $\mathrm{C}_{40} \mathrm{H}_{72}$ & 552 & 1.800 & $\mathrm{C}_{45} \mathrm{H}_{82}$ & 622 & 1.822 \\
6 & $\mathrm{C}_{40} \mathrm{H}_{70}$ & 550 & 1.750 & $\mathrm{C}_{45} \mathrm{H}_{80}$ & 620 & 1.778 \\
\hline
\end{tabular}

TABLE 33. - H/C ratios of n-alkyl-substituted aromatic hydrocarbons with molecular weights near 600

\begin{tabular}{|cccc|}
\hline $\begin{array}{l}\text { Number of } \\
\text { Aromatic } \\
\text { Rings }\end{array}$ & $\begin{array}{l}\text { Empirical } \\
\text { Formula }\end{array}$ & MW & $\begin{array}{c}\text { H/C } \\
\text { Ratio }\end{array}$ \\
\hline & & & \\
0 & $\mathrm{C}_{43} \mathrm{H}_{88}$ & 604 & 2.047 \\
1 & $\mathrm{C}_{43} \mathrm{H}_{80}$ & 596 & 1.861 \\
2 & $\mathrm{C}_{44} \mathrm{H}_{76}$ & 604 & 1.727 \\
3 & $\mathrm{C}_{44} \mathrm{H}_{70}$ & 598 & 1.591 \\
4 & $\mathrm{C}_{44} \mathrm{H}_{64}$ & 592 & 1.454 \\
5 & $\mathrm{C}_{45} \mathrm{H}_{60}$ & 600 & 1.333 \\
6 & $\mathrm{C}_{45} \mathrm{H}_{54}$ & 594 & 1.200 \\
7 & $\mathrm{C}_{46} \mathrm{H}_{50}$ & 602 & 1.087 \\
8 & $\mathrm{C}_{46} \mathrm{H}_{44}$ & 596 & 0.957 \\
\hline
\end{tabular}


TABLE 34. - H/C ratios of 4-ring aromatic hydrocarbons, ca. 600 molecular weight, with varying numbers of naphthenic rings

\begin{tabular}{|clcc|}
\hline $\begin{array}{l}\text { Number of } \\
\text { Naphthenic } \\
\text { Rings }\end{array}$ & $\begin{array}{l}\text { Empirical } \\
\text { Formula }\end{array}$ & MW & $\begin{array}{c}\text { H/C } \\
\text { Ratio }\end{array}$ \\
\hline 0 & $\mathrm{C}_{45} \mathrm{H}_{66}$ & 606 & 1.467 \\
1 & $\mathrm{C}_{45} \mathrm{H}_{64}$ & 604 & 1.422 \\
2 & $\mathrm{C}_{45} \mathrm{H}_{62}$ & 602 & 1.378 \\
3 & $\mathrm{C}_{45} \mathrm{H}_{60}$ & 600 & 1.333 \\
4 & $\mathrm{C}_{45} \mathrm{H}_{58}$ & 598 & 1.289 \\
5 & $\mathrm{C}_{45} \mathrm{H}_{56}$ & 596 & 1.244 \\
6 & $\mathrm{C}_{45} \mathrm{H}_{54}$ & 594 & 1.200 \\
7 & $\mathrm{C}_{45} \mathrm{H}_{52}$ & 592 & 1.156 \\
8 & $\mathrm{C}_{45} \mathrm{H}_{50}$ & 590 & 0.111 \\
\hline
\end{tabular}

The appreciably different carbon skeletons for saturated (1-2 naphthene rings) versus neutralaromatic (ca. 10 rings, 4 of which are aromatic) hydrocarbons points to: 1) a different origin for each type and 2) little interconversion between saturates and aromatics during coprocessing. Furthermore, if significant hydrogenation of aromatics to saturates occurred, one would expect much more prominent concentrations of one and two arorratic-ring molecules than actually observed in HPLC chromatograms.

Based on their $\mathrm{H} / \mathrm{C}$ ratius, the carbon skeletons of acid and base fractions are probably similar to those of neutral-aromatics. For example, the $\mathrm{H} / \mathrm{C}$ ratios of 238-8-5 strong and weak bases are quite similar to that of the corresponding neutral-aromatic fraction, while those of the strong and weak acids are somewhat lower, indicating slightly greater aromaticity (approximately one more aromatic ring) for those fractions.

\section{II.D.4 Analysis of Acid and Base Fractions}

Table 35 provides a summary of the nonaqueous titration data for strong and weak base fractions. The distribution of basic types measured by titration depends significantly on the type and amount of coal used during coprocessing. For example, aninoaromatics (compounds 
TABLE 35. - Results from nonaqueous titration of base fractions

\begin{tabular}{|c|c|c|c|c|c|c|}
\hline \multirow[b]{2}{*}{ Sample No. } & \multirow[b]{2}{*}{ Fraction } & \multirow{2}{*}{$\begin{array}{c}\text { Equivalent } \\
\text { Weight } \\
\text { (g/EQ) }\end{array}$} & \multirow[b]{2}{*}{ Azaarenes } & \multicolumn{2}{|c|}{ L mole percent } & \multirow[b]{2}{*}{$\begin{array}{l}\text { Nontitratable } \\
\begin{array}{c}4 \\
\text { s }\end{array} \\
\end{array}$} \\
\hline & & & & $\begin{array}{c}\text { Amino- } \\
\text { aromatics }\end{array}$ & $\begin{array}{c}\text { Very } \\
\text { Weak Bases } \\
\end{array}$ & \\
\hline $238-8-5$ & strong bases & 554 & 54.6 & 21.4 & 24.0 & - \\
\hline ( $67 \%$ Hondo: & weak bases & - & 12.3 & 7.0 & 19.7 & 61.0 \\
\hline $\begin{array}{l}33 \% \mathrm{NM} \\
\text { subbit.) } 1\end{array}$ & total bases ${ }^{2}$ & 554 & 49.2 & 19.6 & 23.5 & 7.7 \\
\hline $238-8-9$ & strong bases & 521 & 29.1 & 27.3 & 43.6 & - \\
\hline (50\% Hondo: & weak bases & - & 14.4 & $\mathrm{nd}^{3}$ & 32.7 & 52.9 \\
\hline $\begin{array}{l}50 \% \mathrm{NM} \\
\text { subbit.) }\end{array}$ & total bases ${ }^{2}$ & 521 & 27.4 & 24.2 & 42.4 & 6.0 \\
\hline $238-10-8$ & strong bases & 654 & 87.2 & 3.8 & 9.0 & - \\
\hline (67\% Hondo: & weak bases & - & 8.9 & 2.6 & 42.0 & 46.5 \\
\hline $\begin{array}{l}33 \% \text { TX } \\
\text { Lignite) }\end{array}$ & total bases ${ }^{2}$ & 654 & 77.2 & 3.6 & 13.2 & 6.0 \\
\hline
\end{tabular}

${ }^{1}$ Feedstócks for coprocessing nun.

2 Calculated from the yields of strong and weak base fractions.

3 None detected.

${ }^{4}$ Estimated assuming the equivalent weight for the corresponding strong base fraction.

analogous to aniline) are present in significant amounts in the two products made from New Mexico subbituminous coal, but are nearly absent in the Texas lignite product. Also, the product from 50 percent subbituminous coal contains more aminoaromatics than that from 33 percent subbituminous coal. The trend for very weak bases closely follows that of aminoaromatics, but the pattern for azaarenes (compounds analogous to pyridine) opposes that of the other two types.

Each sample contains 6-8 percent of bases too weak to be detected by the titration system employed. Those types partition into the weak base fraction exclusively. 
Equivalent weights for strong base fractions are also listed in the table. Equivalent weights can normally be used as estimates of average molecular weights for base fractions free of nontitratable species. As shown in Table 36 , the equivalent weights thus determined compare favorably with average molecular weights for saturate and neutral-aromatic fractions estimated from boiling point distributions as discussed above. Fractions from the two resids produced from subbituminous coal have slightly lower average molecular weights than those from the lignite coal product. The variation in molecular weight between compound types in a given resid is relatively small.

TABLE 36. - Estimated average molecular weights for selected LC fractions

\begin{tabular}{|llc|}
\hline Sample No. & Fraction & MW (g/mole) \\
\hline $238-8-5$ & saturates $^{2}$ & 550 \\
$(67 \%$ Hondo: & neutral-aromatics $^{2}$ & 600 \\
$33 \%$ NM & strong bases $^{3}$ & 554 \\
subbit. $)^{1}$ & & \\
& & 550 \\
$238-8-9$ & saturates & 620 \\
$(50 \%$ Hondo: & neutral-aromatics & 521 \\
$50 \%$ NM & strong bases & \\
subbit. $)^{1}$ & & 620 \\
$238-10-8$ & & 650 \\
$(67 \%$ Hondo: & saturates & 654 \\
$33 \%$ TX & neutral-aromatics & \\
Lignite $)^{1}$ & strong bases & \\
\hline
\end{tabular}

1 Feedstocks for coprocessing run.

2 Estimated from midboiling point determined via high temperature GC simulated distillation.

3 Enguivalent weight determined from nonaqueous titration in acetic anhydride.

Infrared (IR) spectra of base fractions exhibited bands consistent with nitrogen present only in aromatic systems, e.g., azaarenes, and, in the case of the two subbituminous coal products, primary aromatic amine groups. Other heteroatoms present are probably also contained in aromatic systems based on the lack of IR bands indicating other functional groups. Thus, the very weak base class determined by nonaqueous titration is most likely made up of azaarene species with additional heteroatoms nearby that reduce the overall basicity of the nitrogen (3). 
The elemental nitrogen content of strong base fractions (Table 31 ) coupled with their average molecular weights in Table 36 indicate $0.89,1.24$, and $0.96 \mathrm{~N}$ atoms per molecule for 238-8-5, 238-8-9, and 238-10-8 resids, respectively. Thus, strong base fractions are predominantly comprised of nitrogen-containing species. On the other hand, weak base fractions contain only $0.57,0.65$, and $0.71 \mathrm{~N}$ atoms per molecule, respectively, for 238-8-5, 238-8-9 and 239-10-8 resids. The lack of infrared evidence for other basic types and appreciable proportions of nontitratable species indicated by titration indicate that the weak base fractions, which comprise only 0.8-1.2 weight percent of the benzene solubles from each resid, also contain 30-40 percent of neutral-aromatic species present as contaminants.

Free $\mathrm{OH}$ bands, characteristic of phenolic-type compounds, were of very weak to negligible intensity in infrared spectra of strong and weak acid fractions. This apparent lack of free hydroxyl in groups in partially coal-derived products is quite unexpected. A very broad band, typical of hydrogen-bonded $\mathrm{OH}$, was apparent, however. Strong acid and, to a somewhat less extent, weak acid fractions exhibited strong carbonyl absorptions at 1780 and $1730 \mathrm{~cm}^{-1}$. Assignment of these bands to a specific functional group is not possible with the available data. The only unequivocal band observed in acid fraction spectra was that of NH groups present in pyrrolic-type structures.

Table 37 compares the proportion of nitrogen present in pyrrolic-type compounds in acid fractions versus other forms of nitrogen. Virtually all of the nitrogen in strong acid fractions is present as pyrrolic-type compounds. Up to about one-third of the nitrogen in weak acid fractions is presént in some other form.

The overall percentage of nitrogen and its speciation in acidic fractions is relatively insensitive to the type and quantity of coal used, unlike the situation for basic fractions. However, since the overall yield of acids is affected by feedstock parameters, it follows that the quantity of acidic nitrogen compounds produced is proportionally related to the amount and type of coal used. 
TABLE 37. - Speciation of nitrogen in acid fractions (weight percent $\mathbf{N}$ )

\begin{tabular}{|c|c|c|c|c|}
\hline Sample No. & Fraction & Total $\mathrm{N}^{2}$ & $\mathrm{~N}$ as $\mathrm{NH}^{3}$ & $\begin{array}{c}\text { Other } \\
N \text { types }\end{array}$ \\
\hline $238-8-5$ & strong acids & 1.20 & 1.26 & - \\
\hline (67\% Hondo: & weak acids & 1.46 & 1.04 & 0.42 \\
\hline $\begin{array}{l}33 \% \text { NM } \\
\text { subbit.) } 1\end{array}$ & total acids 5 & 1.29 & 1.18 & 0.11 \\
\hline $238-8-9$ & strong acids & 1.25 & 1.22 & 0.03 \\
\hline (50\% Hondo: & weak acids & 1.00 & 0.80 & 0.20 \\
\hline $\begin{array}{l}50 \% \text { NM } \\
\text { subbit.) } 1\end{array}$ & total acids & 1.14 & 1.04 & 0.10 \\
\hline $238-10-8$ & strong acids & 1.16 & 1.17 & - \\
\hline (67\% Hondo: & weak acids & 1.31 & 0.83 & 0.48 \\
\hline $33 \% \mathrm{TX}$ & total acids & 1.22 & 1.03 & 0.19 \\
\hline \multicolumn{5}{|l|}{ Lignite) ${ }^{1}$} \\
\hline $\begin{array}{l}1 \text { Feedstocks for } \\
2 \text { From Table } 1 . \\
{ }^{3} \text { From IR. NH f } \\
4 \text { Total N-N(NH). } \\
{ }^{5} \text { Calculated from }\end{array}$ & hal groups are & in pyrro & & \\
\hline
\end{tabular}

\section{II.D.5 Conclusions}

The predominant fraction from the $\mathrm{ABN}$ separations was the neutral fraction (67-81 percent). All of the polar fractions increase with increasing coal concentration. The concentration of saturates in the neutrals is high in a run with 33 percent subbituminous coal but drops substantially with either increasing coal concentration or the substitution of lignite for subbituminous coal. High temperature gas chromatography showed that both the neutral aromatics fractions and saturates fractions from all of the runs are extremely similar regardless of the coal concentration or coal type. The reutral aromatics fractions were further separated by ring number separation. Chromatograms were again very similar regardless of the initial coal concentration or coal type with most material eluting in the 3-ring to 6 -ring region. 
The concentration of aminoaromatics in base fractions appear to be a sensitive indicator of the amount and type of coal used in coprocessing. The hydrocarbon skeletons of saturated hydrocarbons in the HRI coprocessing resids appears to be fundamentally different than those of aromatic species. The average molecular weights of various compound types in a given resid are similar to one another; the overall average molecular weights for Hondo: subbituminous coal products are somewhat lower than those for the Hondo: lignite product. The average molecular weights determined for these resids ( $\geq 650$ ) are well below those of typical straight-run petroleum $>1000^{\circ} \mathrm{F}$ resids $(\geq 900)(3)$. Base fractions contain predominantly single nitrogen compounds of azaarene or aminoaromatic type. Acid fractions contain appreciable quantities of pyrrolic benzologs, but surprisingly low concentrations of compounds with a free $\mathrm{OH}$ group. Neutralaromatic fractions contain minor levels of sulfur compounds, an unknown proportion of ether or other oxygen-containing species, and major concentrations of aromatic hydrocarbons containing from three to six aromatic rings.

\section{ACKNOWLEDGMENT}

The financial assistance of the U.S. Department of Energy, Pittsburgh Energy Technology Center is gratefully acknowledged as is the assistance of PETC technical monitors including William E. McKinstry, Nand Narain, Swenam R. Lee, and Casimiro A. Izquierdo. PDU samples, analyses, and run conditions were supplied by John Duddy and Sudhir Panvelker of HRI, Inc. Carbon isotope ratio determinations were conducted under the direction of Michael Engle at the School of Geology and Geophysics, Energy Center, University of Oklahoma. Finally, special thanks are extended to Ms. Susan Steele for final manuscript preparation. 


\section{REFERENCES}

1. Cugini, A. V., J. A. Ruether, D. L. Cillo, D. Krastman, P. N. Smith, and V. Balsone, Novel Dispersed-Phase Catalytic Approach to Coprocessing. Preprints ACS Division of Fuel Chemistry, vol. 33(1), June 1988, pp. 6-19.

2. Derbyshire, F. J., A. Davis, R. Lin, P. G. Stansberry, M. T. Terrer. Coal Liquefaction by Molybdenum Catalyzed Hydrogenation in the Absence of Solvent. Fuel Proc. Tech., v. 12, 1986, pp. 127-41.

3. Green, J. A., J. B. Green, R. D. Grigsby, C. D. Pearson, J. W. Reynolds, J. Y. Shay, G. P. Sturm, Jr. J. S. Thomson, J. W. Vogh, R. P. Vrana, S. K.-T. Yu, B. H. Diehl, P. L. Grizzle, D. E. Hirsch, K. W. Hornung. S. - Y. Tang, L. Carbognani, M. Hazos, V. Sanchez. Analysis of Heavy Oils: Method Development and Application to Cerro Negro Heavy Petroleum. Final Technical Report NIPER-452, v. 1 and 2 (NTIS Report Nos. DE90000200 and DE90000201, December 1989).

4. Coleman, D. D. Gas Identification by Geochemical Fingerprinting, American Gas Association Operating Section Meeting, Las Vegas, 1987.

5. Steer, J. G., T. Ohuchi, and K. Muehlenbachs. Efficacy of Coal-Bitumen Co-Processing as Determined by Isotopic Mass Balance Calculations, Fuel Processing Technology, v. 15., 1987 , p. 429.

6. Burke, F.P., R. A. Winschel, and M. S. Lancet. Stable Isotope Analysis of Coprocessing Materials. Quarterly Technical Progress Report, DOE/PC 88800-6, July-September, 1988.

7. Anonymous. Prototype Commercial Coal/Oil Coprocessing Plant Project, v. 1, November 1989, DOE/PC/79797-T4.

8. Winschel, R. A., M. S. Lancet, and F. P. Burke. Stable Carbon Isotope Analysis of Coprocessing Materials. Final Technical Report, DOE/PC 88800-43, April 1991.

9. Chung, H. M. Isotope Fractionation During the Maturation of Organic Matter, Ph.D. Thesis, Texas A\&M University, 1976.

10. Silverman, S. R., and Epstein. Carbon Isotopic Compositions of Petroleums and Other Sedimentary Materials, Bull. Am. Assoc. Pet. Geol., v. 42, 1958, p. 998.

11. Stahl, W. J.. Source Rock-Crude Oil Correlation by Isotopic-Type Curves, Geochimica et Cosmochimica Acta, v. 42, 1978, pp. 1573.

12. Sackett, W. M. Carbon and Hydrogen Isotope Effects During the Thermocatalytic Production of Hydrocarbons in Laboratory Simulation Experiments, Geochimica et Cosmochimica Acta, v. 42, 1978, p. 571. 
APPENDIX A

DETAILED DESCRIPTION BATCH AUTOCLAVE COPROCESSING RUNS 


\section{A.1 Materials}

The reactants used were a petroleum resid and coal which have been used in other coprocessing studies (1). Maya vacuum resid (boiling above ca $1000^{\circ} \mathrm{F}$ ) and Illinois No. 6 coal (Burning Star Mine) were used in all reactions. The petroleum resid was available in NIPER stocks from previous programs and the coal was obtained from the Advanced Coal Liquefaction Facility of Wilsonville, AL. Elemental analyses for the Maya resid are provided in Table A-1. The coal was analyzed by the Commercial Testing \& Engineering Co., South Holland, IL; results are summarized in Table A-2. Ammonium tetrathiomolytydate (Aldrich) was added to form the catalyst and dimethyl disulfide (Aldrich) added to insure complete sulfiding of the molybdenum.

TABLE A-1. - Maya crude resid $>1000^{\circ} \mathrm{F}\left(>538^{\circ} \mathrm{C}\right)$, elemental composition

\begin{tabular}{|lc|}
\hline $\mathrm{C}$ & 84.6 \\
$\mathrm{H}$ & 10.64 \\
$\mathrm{~S}$ & 4.85 \\
$\mathrm{~N}$ & 0.57 \\
\hline
\end{tabular}

In each coprocessing run 666.7 grams of combined resid and coal were used. The composition of the reaction mixtures were made up to contain $2,20,30$, and 40 weight percent loadings of coal. Each reaction mixture contained 1.81 grams of $\left(\mathrm{NH}_{4}\right)_{2} \mathrm{MoS}_{4}$, equivalent to 0.1 weight percent molybdenum on the total reaction mix basis. Table A-3 shows the reaction composition used in each of the runs. In determining the amount of coal to be used, no allowance was made for the ash and moisture content. The ash and moisture contents of each impregnated coal preparation are included. The last row shows the combined weights of the residue and the moisture and ash free coal.

The molybdenum precatalyst was added by impregnating the coal with an aqueous solution. An excess of coal and $\left(\mathrm{NH}_{4}\right)_{2} \mathrm{MoS}_{4}$ were mixed in the proper ratio for the reactant mix. The slurry was partially dried in a porcelain pan on a hot plate at minimum setting. The mix was stirred often to avoid any overheating, and the drying continued until the material was in a near-dry granular siate. The drying was completed in a rotary vacuum evaporator at about $60^{\circ} \mathrm{C}$ and 100 torr vacuum. This procedure for impregnation of the coal with solubic catalyst agent is similar to that used in coal liquefaction studies (2). The residual moisture content of the impregnated coal was determined by weight loss on drying at $105^{\circ} \mathrm{C}$ for 30 minutes. When the reactants were loaded into the autoclave, $0.5 \mathrm{~mL}(0.52 \mathrm{~g})$ of dimethyl disulfide was added. 
TABLE A-2. - Analysis of Illinois No. 6 coal

COMMERCIAL TESTING \& ENGINEERING CO.

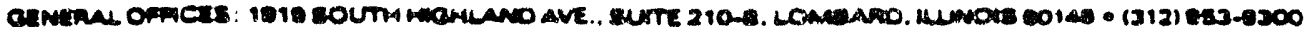

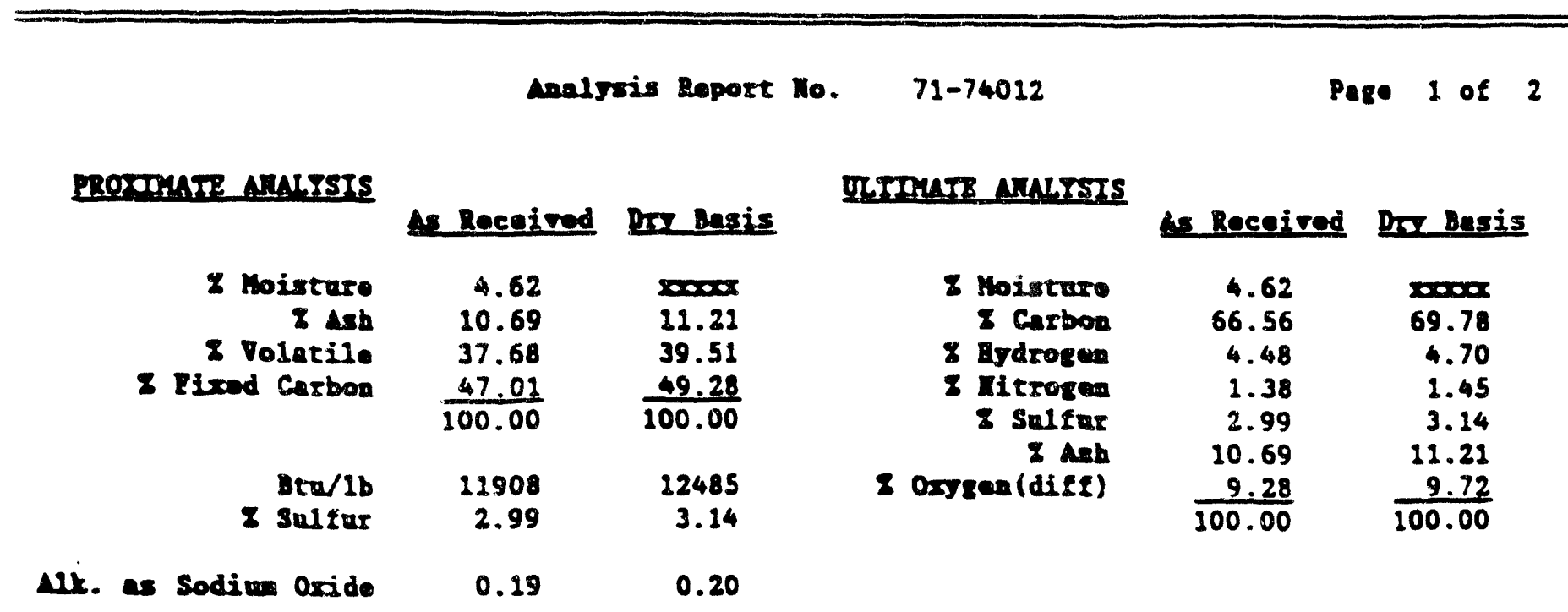

Andrais Report to. 71-74022

Page 2 of 2

MITSTS OF_ASI

SLiean diard to

Mratina exida

I1taxio diecido

Irea aride

Caleion acido

Mncesie acide

Potansin arido

sodim aside

Sulfur trioride

Phosphoras pancorid

strontie axide

Bariva aride

Henganese axide

Dedetermined

silice Veleo $=66.08$

Bese 1 cid Ratio $=0.41$

Isen Ieqperetere a $2403 \cdot I$
DTRT 8. IGIYAM RASTS

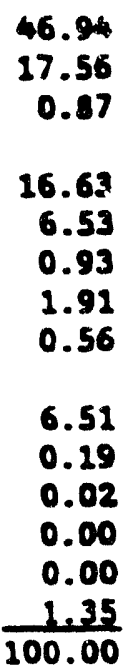

46.94

7.56

16.63

6.53

0.93

1.91

56

6.51

0.29

0.00

0.00

$\frac{1.35}{100.00}$

Fouline Index $=0.23$

SIacring Indax $=1.29$

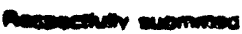

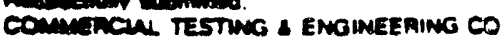

Soter w

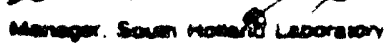

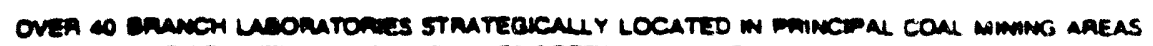

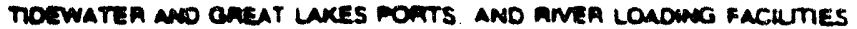

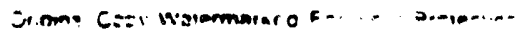


TABLE A-3. - Composition of coprocessing reactants, grams

\begin{tabular}{|lcccc|}
\hline & Run \#8 & Run \#5 & Run \#7 & Run \#6 \\
& $2 \%$ Coal & $20 \%$ Coal & $30 \%$ Coal & $40 \%$ Coal \\
\hline Residue reacted & 653.3 & 533.3 & 466.7 & 400.0 \\
Coal reacted & 13.3 & 133.3 & 200.0 & 266.7 \\
$\left(\mathrm{NH}_{4}\right)_{2} \mathrm{MoS}_{4}$ & 1.81 & 1.81 & 1.81 & 1.81 \\
Coal ash & 1.45 & 14.51 & 22.10 & 29.31 \\
Coal moisture & 0.38 & 3.88 & 2.94 & 5.23 \\
Residue plus & 664.8 & 648.3 & 641.6 & 632.1 \\
MAF coal & & & & \\
\hline
\end{tabular}

\section{A.2 Reaction Procedures}

The coprocessing reaction was carried out in a 2-liter Hastalloy $\mathrm{C}$ autoclave (Autoclave Engineering). It utilized a magnetically coupled stirrer and was equipped with temperature and pressure monitors and a temperature controller. A stirrer impeller was constructed to provide narrow wall and bottom clearance in order to minimize sedimentation of solids. A second 2-liter autoclave used is a high-pressure hydrogen reservoir was connected to the coprocessing reactor through a pressure regulator.

After the reactants were sealed in the autoclave, air was removed by repeated flushing with hydrogen. Hydrogen pressure was then raised to $1800 \mathrm{psi}$ at room temperature. The autoclave was brought to the reaction temperature of $445^{\circ} \mathrm{C}\left(833^{\circ} \mathrm{F}\right)$ under manual control in such manner as to avoid exceeding that temperature. The heating rate in this procedure was about $4^{\circ} \mathrm{C} / \mathrm{min}$. Some reaction occurred and hydrogen was consumed during this heating period. However, the start of the reaction period was taken as the time at which the temperature reached $445^{\circ} \mathrm{C}$.

At the beginning of the reaction period the hydrogen pressure was substantially above 3000 psi. As hydrogen was consumed during the reaction, the pressure was preventer from falling below $3000 \mathrm{psi}$ by addition of hydrogen from a second autoclave. The reaction temperature and pressure were maintained for a one hour reaction period. The hydrogen supply was then shut off and the heating terminated to end the reaction. 


\section{A.3 Coprocessing Product Workup}

After the reactor temperature had fallen to $20-30^{\circ} \mathrm{C}$, the first of the gas samples was collected in an evacuated 0.5 -liter steel cylinder. The samples were analyzed by gas chromatography for hydrogen, the $C_{1}$ through $C_{7}$ hydrocarbons, carbon dioxide, and hydrogen sulfide. Gas from the autoclave was then metered through a wet test meter until the pressure had fallen to 300 psi, when the second gas sample was collected in another steel cylinder. Gas analysis was repeated and the two gas cylinders set aside for later workup to collect samples for carbon isotope ratio determination. The gas was again passed through the wet test meter and two more gas samples were collected at autoclave pressures of 75 and 3 psi. These two samples were collected in $40-\mathrm{mL}$ glass flow through vessels placed in the line to the wet test meter. Gas analysis was repeated as before.

The total amount of gas liberated at the end of the coprocessing reaction was determined by combination of the metered quantities with that estimated from the PVT values of the two large gas samples. The mean composition of the gas was estimated by trapezoidal integration of the analytical composition of each component on the pressure coordinate, divided by initial pressure. Gas product compositions are summarized in Table A-4.

A pair of liquid cold traps were then attached to the autoclave vent valve, the first held at $0^{\circ} \mathrm{C}$ and the second at $-80^{\circ} \mathrm{C}$. The autoclave was heated to $75^{\circ} \mathrm{C}$ to promote vaporization of the condensate material. The autoclave was evacuated through the cold traps to a final pressure of about 100 torr. The material collected in the two cold traps was combined and stored in septum sealed viaus under refrigeration.

The remaining liquid and solid contents of the autoclave were then transferred to a filter unit. This was a pressure filter (Fisher, Catalog No. 09-753-25G) of 1.5-liter capacity. A glass fiber filter membrane was used. The body of the filter unit was heated to about $80^{\circ} \mathrm{C}$ with electrical heating tape and the filtration carried out under a nitrogen pressure of 15-20 psi. The complete filtration required 2-3 hours and the last filtrate delivered was quite viscous and pitch-like. After filtration was completed, the wet solids remaining were dispersed in tetrahydrofuran (THF), agitated for about an hour to insure solution ef soluble material, and filtered through Whatman No. 40 paper in a Buchner funnel. The THF soluble material was recovered by solvent stripping in a rotary vacuum evaporator. The THF insolubles were air dried to complete recovery of the coprocessing products. 
TABLE A-4. - Gas product composition, percent

\begin{tabular}{|lccc|}
\hline & $20 \%$ Coal & $30 \%$ Coal & $40 \%$ Coal \\
\hline Hydrogen & 61.27 & 54.22 & 30.28 \\
Methane & 21.54 & 21.05 & 30.41 \\
Ethane & 5.38 & 6.81 & 10.42 \\
Propane & 2.03 & 3.22 & 5.03 \\
Butanes & 0.55 & 0.99 & 1.60 \\
Pentanes & 0.15 & 0.28 & 0.47 \\
Hexanes & 0.04 & 0.09 & 0.14 \\
Heptanes & 0.01 & 0.02 & 0.03 \\
$\mathrm{CO}_{2}$ & 0.44 & 0.95 & 2.23 \\
$\mathrm{H}_{2} \mathrm{~S}$ & 5.37 & 8.35 & 11.25 \\
\hline
\end{tabular}

The yields of fractions obtained in the workup of the coprocessing products are shown in Table A-5. These values are calculated on the basis of moisture and ash-iree coal plus petroleum resid. However, the THF insolubles fractions will contain both the original ash and the $\mathrm{MoS}_{2}$ catalyst. Therefore, the THF insolubles values are shown as the organic content excluding the calculated ash and catalyst.

TABLE A-5. - Yields of coprocessing products, percentage of residue and MAF coal

\begin{tabular}{|lcccc|}
\hline & $\begin{array}{c}\text { Run \#8 } \\
2 \% \text { Coal }\end{array}$ & $\begin{array}{c}\text { Kun \#5 } \\
20 \% \text { Coal }\end{array}$ & $\begin{array}{c}\text { Run \#7 } \\
30 \% \text { Coal }\end{array}$ & $\begin{array}{c}\text { Run \#6 } \\
40 \% \text { Coal }\end{array}$ \\
\hline Methane & & & & \\
$\mathrm{C}_{2}-\mathrm{C}_{7}$ & 2.57 & 2.30 & 2.10 & 3.07 \\
$\mathrm{CO}_{2}$ & 3.99 & 1.98 & 2.70 & 4.27 \\
$\mathrm{H}_{2} \mathrm{~S}$ & 0.04 & 0.13 & 0.26 & 0.62 \\
Condensate & 1.83 & 1.22 & 1.77 & 2.42 \\
Filtrate & 10.29 & 3.42 & 7.59 & 3.15 \\
THF Solubles & 66.52 & 65.42 & 68.73 & 65.67 \\
THF Insolubles* & 6.60 & 12.65 & 8.40 & 13.38 \\
Total & $\underline{6.83}$ & $\underline{2.55}$ & $\underline{2.73}$ & $\underline{4.16}$ \\
\hline
\end{tabular}

*Excluding ash and catalyst. 


\section{A.4 Preparation Gas Samples for Isotope Ratio Analysis}

The gas samples that had been collected from the autoclave in steel cylinders were processed in a scrubber and condensation train to co!lect components for carbon isotope analysis. Hydrogen sulfide was first removed in a scrubber containing copper acetate solution buffered to $\mathrm{pH} 5$ with sodium acetate and acetic acid. Carbon dicxide was then collected in potassium hydroxide solution. The $\mathrm{KOH}$ solution was treated in advance with a small amount of $\mathrm{Ba}(\mathrm{OH})_{2}$ solution to precipitate any carbonate impurity and then centrifuged to remove solids. Following the $\mathrm{KOH}$ scrubber was a silica gel drying tube and a pair of metal cold traps for collection of the light hydrocarbons. The first of the cold traps was open and the second contained activated carbon. Both were cooled with Squid nitrogen. The exit gas (hydrogen) was collected in a Tedlar gas bag and passage of the gas was continued until roughly 5-10 liters of sample had been processed as indicated by the volume in the gas bag. When the collection process was completed the cold traps were attached to vacuum manifold containing a gas sample cylinder and the gas transferred by heating the traps. The $\mathrm{KOH}$ solution was guarded against contact with air and the carbonate was precipitated by injection of $\mathrm{BaCl}_{2}$ solution through a septum port. The precipitate was then washed with freshly boiled water introduced through the septum and the washings forced out under helium pressure through the sparger frit. This was continued until the washings were nearly neutral. The $\mathrm{BaCO}_{3}$ was then transferred to a filter, washed and dried.

\section{A.5 Distillation and Simulated Distillation}

Simulated distillation of the filtrate and THF soluble fractions was carried out by the proposed ASTM crude oil method developed for high boiling samples. Figures A-1 - A-4 show the results of simulated distillation analysis in graphic form. In each case, the upper trace represents the filtrate product while the lower is the THF soluble material. While there is some difference in conversion to distillate below $1000^{\circ} \mathrm{F}$ among the samples, the plots show little difference in overall character. In every case, the THF soluble product shows the lack of material below $\mathrm{C}_{9}$ $\mathrm{C}_{10}$, probably because of vaporization loss in the solvent stripping operation. Also, all THF soluble products contain 1.5-2 percent tetrahydrofuran, showing the difficulty of removal of this solvent from high-boiling and residue materials. 


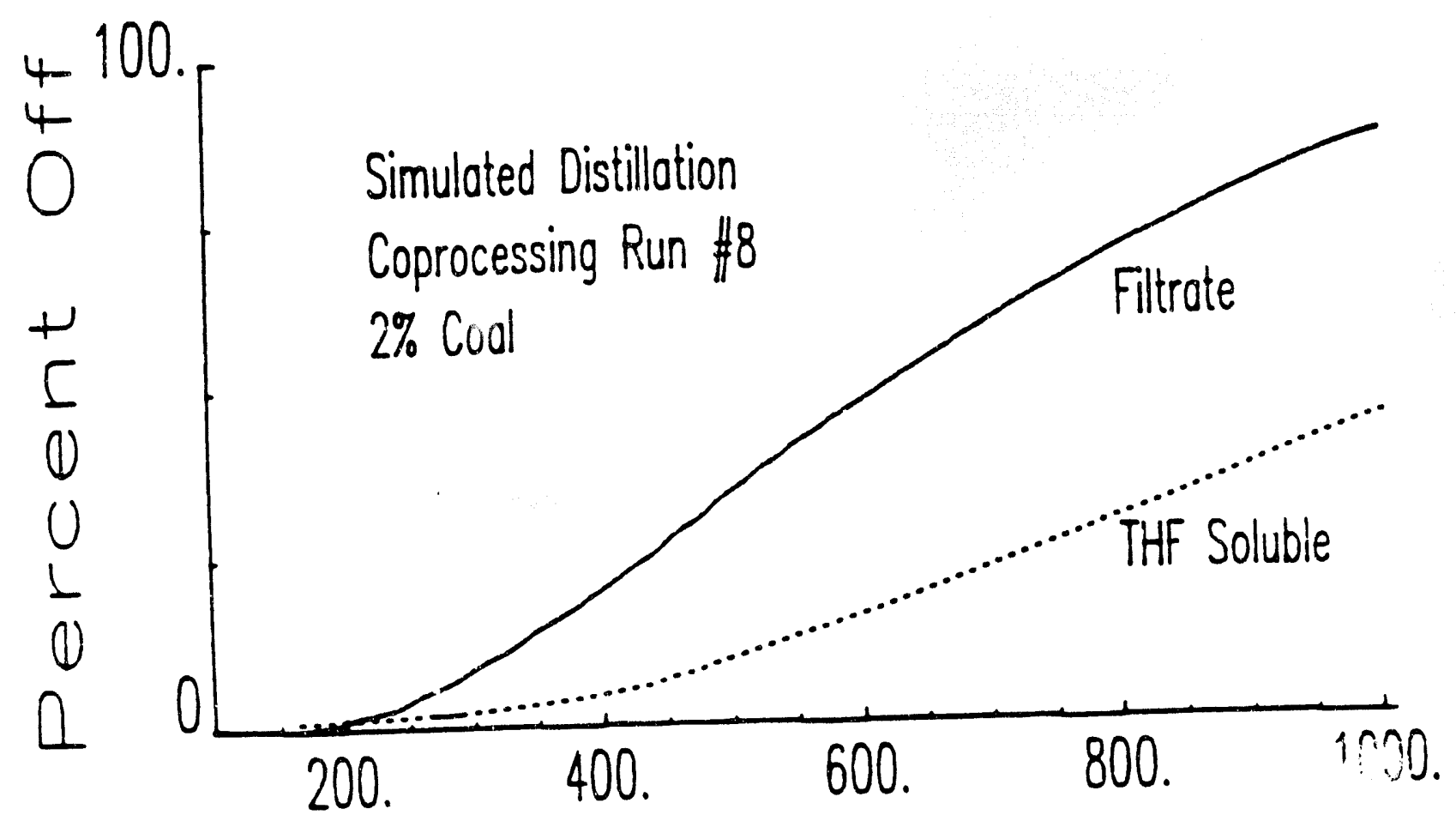

FIGURE A-1 - Simulated distillation of filtrate and THF solubles, $2 \%$ coal run

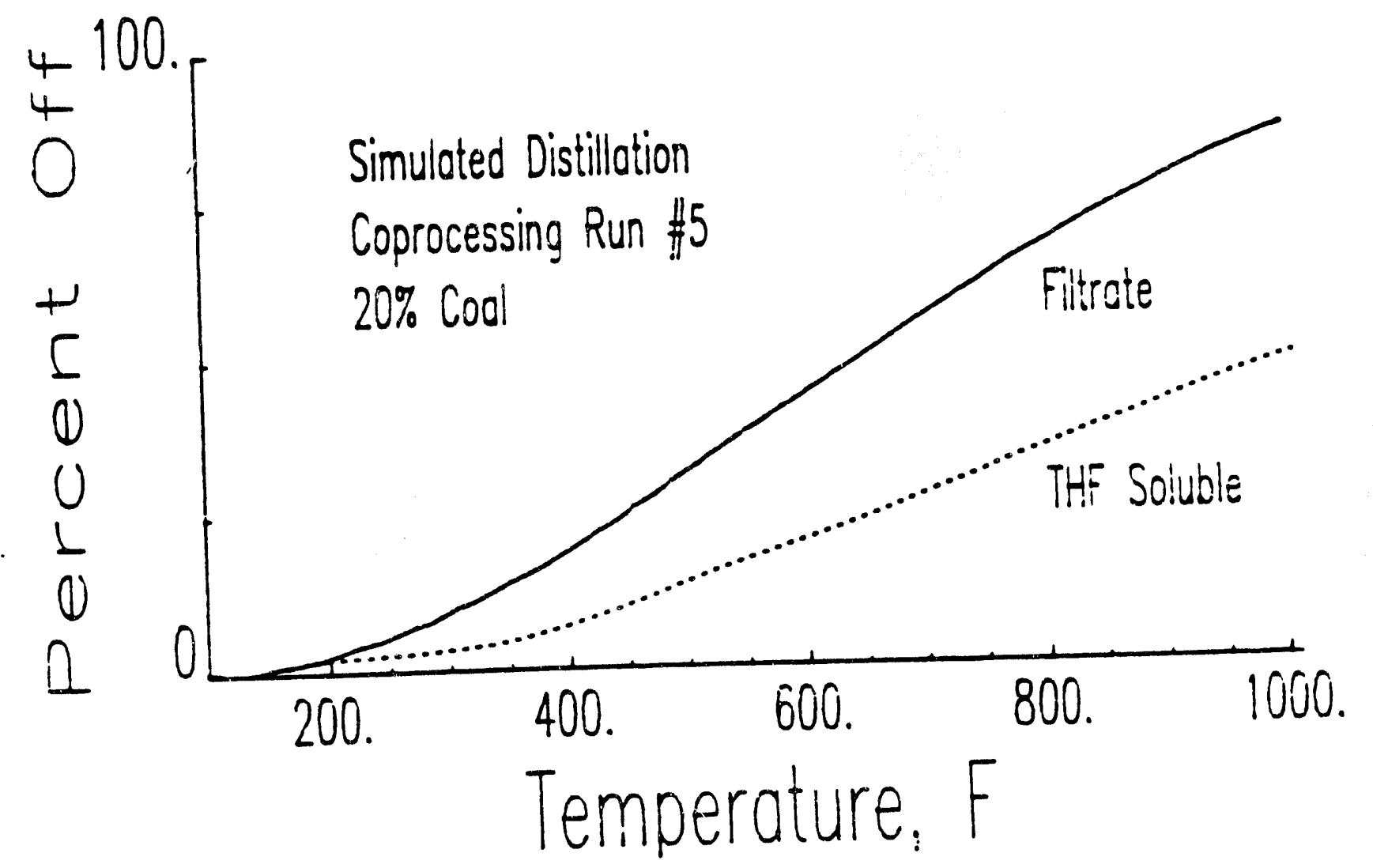

FIGURE A-2. - Simulated distillation of filtrate and THF solubles, $20 \%$ coal run 


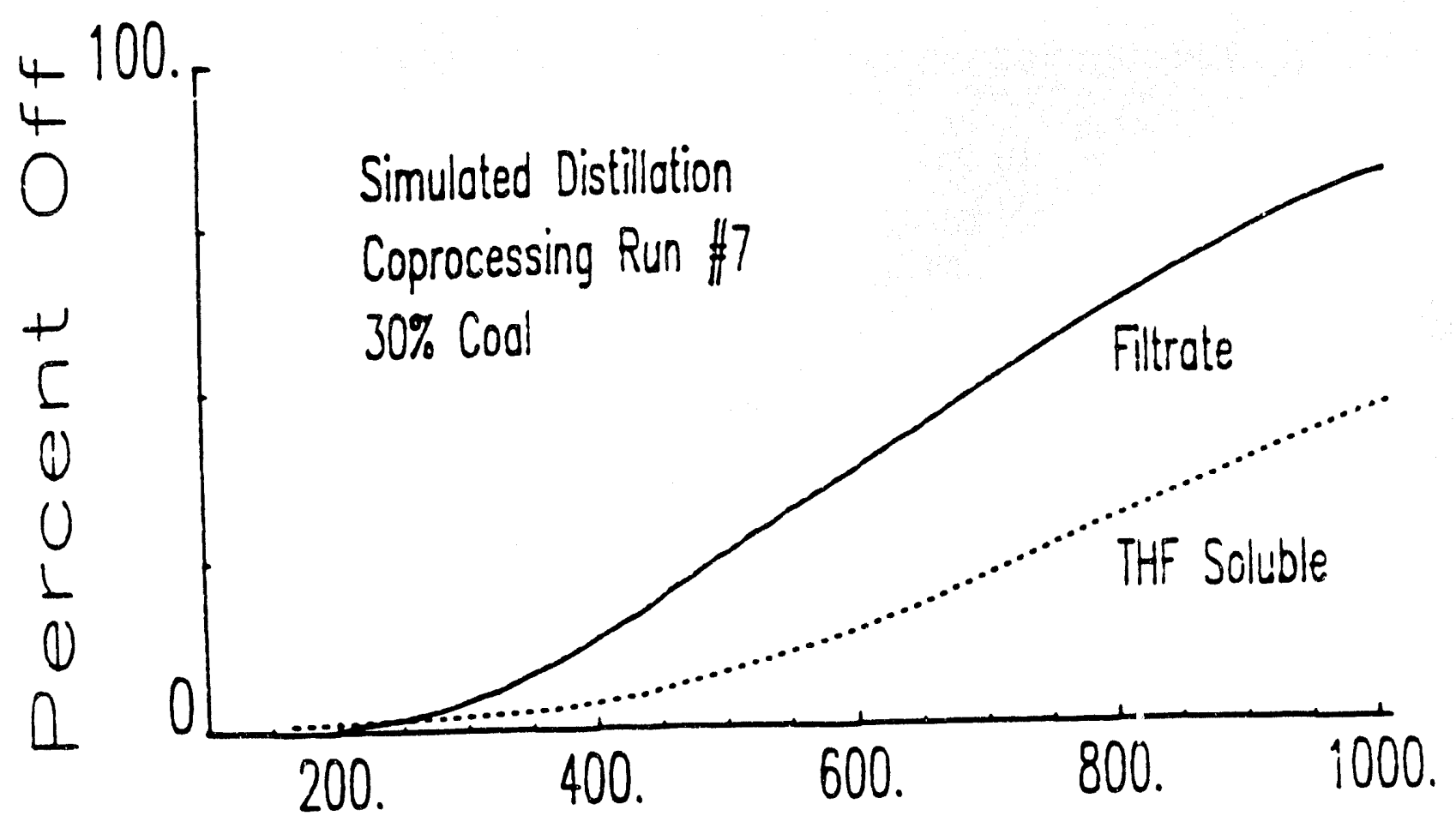

FIGURE A-3 . - Simulated distillation of filtrate and THF solubles, $30 \%$ coal run

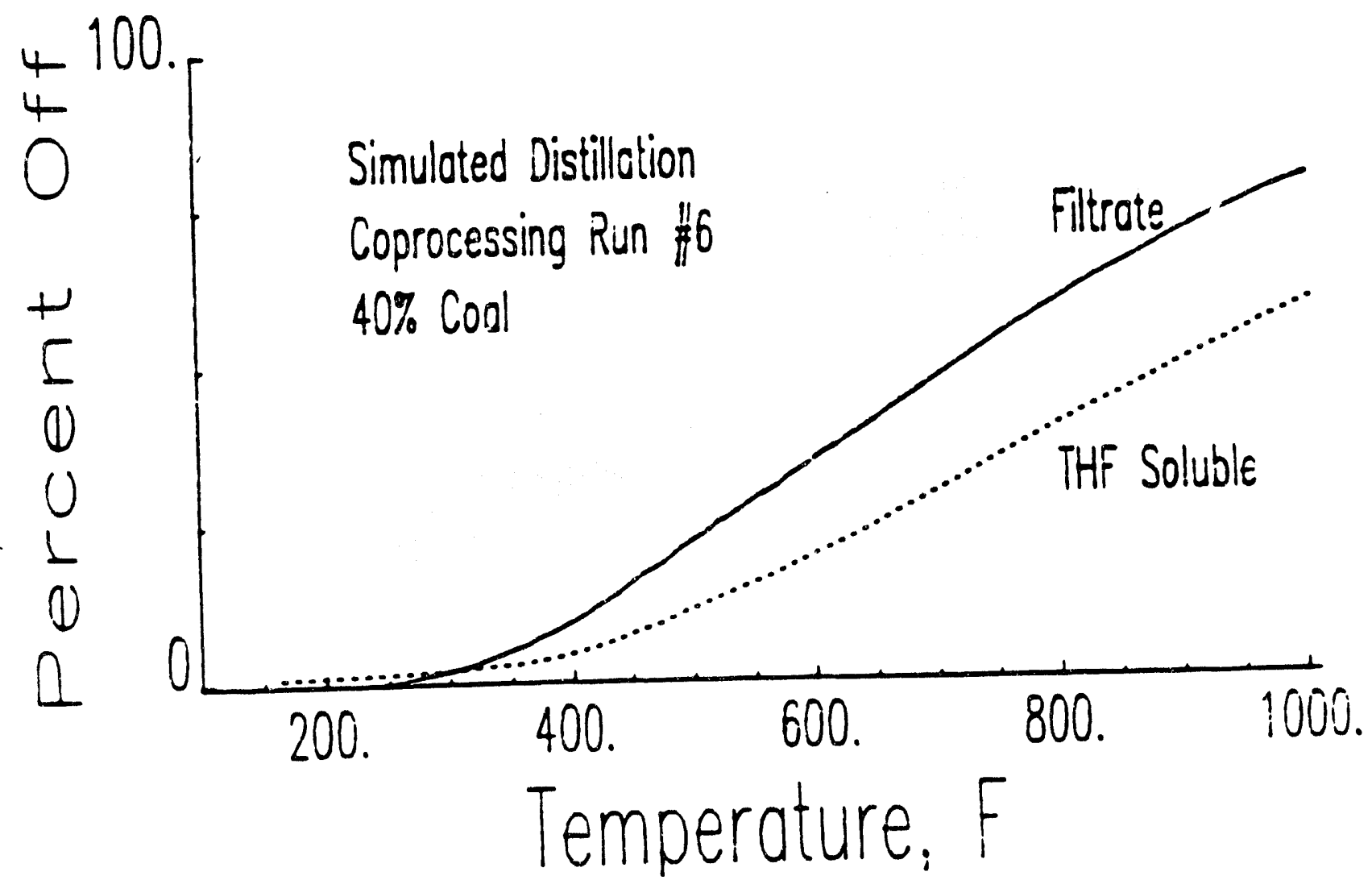

FIGURE A-4. - Simulated distillation of filuate and THF solubles, $40 \%$ coal run 
The following summarizes the weighted mean percentage of $<1000^{\circ} \mathrm{F}$ material for the filtrate and THF soluble products taken together (based on simulated distillation data). These data could be used to calculate conversions to distillate but the results based on actual distillation are of greater interest.

Products Distilling below $1000^{\circ} \mathrm{F}\left(538^{\circ} \mathrm{C}\right)$, Percent

$\begin{array}{cccc}2 \% \text { Coal } & 20 \% \text { Coal } & 30 \% \text { Coal } & 40 \% \text { Coal } \\ 83.0 & 79.5 & 77.6 & 75.1\end{array}$

The filtrate liquids were distilled to produce suitable cuts for separation and analysis. A Perkin-Elmer spinning band still was used to prepare cuts at initial boiling point (IBP)-175 and $175-350^{\circ} \mathrm{C}\left(347-662^{\circ} \mathrm{F}\right.$, corrected to atmospheric pressure). These distillation cuts were made at 100 torr and 1 torr, respectively. The final cut to $538^{\circ} \mathrm{C}\left(1000^{\circ} \mathrm{F}\right)$ was made in a short-path, high-vacuum still that is used in the D- 1160 method for crude oil analysis.

The quantities of distillates obtained in the fractional and high-vacuum distillations of the filtrate products are shown in Table A-6. The THF soluble products were not included in this distillation procedure because of the unremovable content of tetrahydrofuran. It appeared that this THF might introduce errors in the the carbon isotope ratio determination that could not be estimated. The lowest boiling fraction (IBP- $175^{\circ} \mathrm{C}$ ) diminishes with increasing coal level while the residue increases with coal content. The intermediate fractions show relatively uniform yield at ail coal contents. The residue levels are about 3-6 percent greater than indicated by simulated distillation, presumably because of condensation or polymerization at pot temperatures during distillation.

TABLE A-6. - Filtrate distillation

\begin{tabular}{|lccrr|}
\hline & \multicolumn{4}{c|}{ Percent Distilled. Wt* } \\
\cline { 2 - 5 } Coal, percent & 2 & 20 & 30 & 40 \\
\hline & & & & \\
Distillation Range & 14.2 & 14.0 & 9.9 & 5.5 \\
IBP- $175^{\circ} \mathrm{C}\left(3.77^{\circ} \mathrm{F}\right)$ & 38.6 & 36.0 & 34.3 & 36.7 \\
$175-350^{\circ} \mathrm{C}\left(347-662^{\circ} \mathrm{F}\right)$ & 27.3 & 25.9 & 31.8 & 26.9 \\
$350-538^{\circ} \mathrm{C}\left(662-1000^{\circ} \mathrm{F}\right)$ & 19.9 & 24.1 & 24.0 & 30.9 \\
Residue $>538^{\circ} \mathrm{C}\left(1000^{\circ} \mathrm{F}\right)$ & & & & \\
\hline
\end{tabular}

*Normalized to $100 \%$. 
Since the THF solubles fractions were not distilled, yields corresponding to the above cuts were determinec' from simulated distillation results; these yields are summarized in Table A-7. Since there is only a small difference between actual distillation yields and simulated distillation results and since the yields of the THF fractions are relatively small, use of simulated distillation data in place of actual distillation of the THF solubles fractions has only a very minor effect on overall distillate yields.

TABLE A-7. - Distillation cuts of THF solubles (by simulated distillation)

\begin{tabular}{|lrlrr|}
\hline & \multicolumn{4}{c|}{ Percent Distilled. Wt* } \\
\cline { 2 - 5 } Coal, percent & 2 & 20 & 30 & 40 \\
\hline Distillation Range & & & & \\
IBP- $175^{\circ} \mathrm{C}\left(347^{\circ} \mathrm{F}\right)$ & 7 & 10 & 6 & 7 \\
$175-350^{\circ} \mathrm{C}\left(347-662^{\circ} \mathrm{F}\right)$ & 13 & 15 & 15 & 19 \\
$350-538^{\circ} \mathrm{C}\left(662-1000^{\circ} \mathrm{F}\right)$ & 25 & 24 & 26 & 33 \\
Residue $>538^{\circ} \mathrm{C}\left(1000^{\circ} \mathrm{F}\right)$ & 55 & 51 & 53 & 41 \\
\hline
\end{tabular}

\section{A.6. Yield Summary}

Overall coprocessing yields based on petroleum resid and MAF coal were determined by combining yields of the gross reactor products (Table A-5), yields from the filtrate distillation (Table A-6), and yields for distillation cuts for the THF solubles based on simulated distillation data (Table A-7). Raw yields are summarized in Table A-8. Conversions (conversion to $-538^{\circ} \mathrm{C}$, $1000^{\circ} \mathrm{F}$ products), which are simply 100 minus the yields of $+538^{\circ} \mathrm{C}$ organic products $(>538 \mathrm{C}$ soluble resid and IOM), are included. Variation in yields with changing coal concentration are discussed in Section II.A. Due to variations in recoveries between the various runs, yields normalized to 100 percent (Table 2 in Section II.A) are used as the basis for discussion of changes in yields with changing coal concentration.

\section{A.7 Elemental Compositions}

Elemental compositions of the filtrate, THF solubles, and THF insolubles are shown in Table A-9. The totals of the carbon, hydrogen, nitrogen, and sulfur for each sample are also shown. The difference of this total from 100 percent may be attributable to oxygen and ash. The last column shows the ratio of hydrogen to carbon on a molar basis for each sample. 
TABLE A-8. - Overall coprocessing yields

\begin{tabular}{|lcccc|}
\hline & \multicolumn{4}{c|}{ Raw Yields. Weight Percent } \\
\cline { 2 - 5 } Coal.percent & 2 & 20 & 30 & 40 \\
\hline Gases $\left(\mathrm{C}_{1}-\mathrm{C}_{7}, \mathrm{CO}_{2}, \mathrm{H}_{2} \mathrm{~S}\right)$ & 8.4 & 5.6 & 6.8 & 10.4 \\
& & & & \\
Distillation Range & & & & \\
$<-175^{\circ} \mathrm{C}\left(347^{\circ} \mathrm{F}\right)$ & 20.2 & 13.9 & 14.9 & 7.6 \\
$175-350^{\circ} \mathrm{C}\left(347-662^{\circ} \mathrm{F}\right)$ & 26.6 & 25.4 & 24.9 & 26.7 \\
$350-538^{\circ} \mathrm{C}\left(662-1000^{\circ} \mathrm{F}\right)$ & 19.8 & 19.9 & 24.0 & 22.1 \\
Total & 66.6 & 59.2 & 63.8 & 56.4 \\
Nondistillable & & & & \\
$>538^{\circ}\left(1000^{\circ} \mathrm{F}\right)$ resid & 16.8 & 22.3 & 20.9 & 25.8 \\
THF Insolubles $(\mathrm{IOM})$ & 6.8 & 2.6 & 2.7 & 4.2 \\
Total & 23.6 & 24.9 & 23.6 & 30.0 \\
Total & 98.6 & 89.7 & 94.2 & 96.8 \\
$538^{\circ} \mathrm{C}+\left(1000^{\circ} \mathrm{F}\right)$ conversion & 76.4 & 75.1 & 76.4 & 70.0 \\
\hline
\end{tabular}


TABLE A-9. - Coprocessing fractions, elemental composition

\begin{tabular}{|lrrrrr|}
\hline & $\mathrm{C}$ & $\mathrm{H}$ & $\mathrm{N}$ & $\mathrm{S}$ & $\mathrm{H} / \mathrm{C}$ \\
\hline 2\% Coal & & & & & \\
Reactants & 84.26 & 10.52 & 0.59 & 4.81 & 1.498 \\
Filtrate & 84.55 & 10.95 & 0.47 & 2.81 & 1.554 \\
THF Solubles & 82.20 & 6.30 & 1.14 & 4.73 & 0.920 \\
THF Insolubles & 80.05 & 4.10 & 0.16 & 5.97 & 0.615 \\
20\% Coal & & & & & \\
Reactants & 81.23 & 9.42 & 0.74 & 4.49 & 1.392 \\
Filtrate & 84.36 & 10.87 & 0.54 & 1.69 & 1.546 \\
THF Solubles & 80.42 & 6.51 & 1.28 & 2.87 & 0.971 \\
THF Insolubles & 82.18 & 4.53 & 0.54 & 6.74 & 0.661 \\
$30 \%$ Coal & & & & & \\
Reactants & 79.75 & 8.84 & 0.83 & 4.32 & 1.330 \\
Filtrate & 85.22 & 10.64 & 0.61 & 1.67 & 1.498 \\
THF Solubles & 84.03 & 6.78 & 1.02 & 2.56 & 0.968 \\
THF Insolubles & 33.18 & 1.78 & 0.66 & 6.52 & 0.644 \\
40\% Coal & & & & & \\
Reactants & 78.13 & 8.22 & 0.91 & 4.14 & 1.263 \\
Filtrate & 86.04 & 10.83 & 0.55 & 1.67 & 1.510 \\
THF Solubles & 82.24 & 7.08 & 1.02 & 2.40 & 1.033 \\
THF Insolubles & 39.52 & 2.03 & 0.57 & 6.22 & 0.616 \\
\hline
\end{tabular}

The coprocessing hydrogenations produce moderate reductions in nitrogen and sulfur levels. If $\mathrm{N}$ and $\mathrm{S}$ are assumed to be absent from the light hydrocarbons of the gases and condensate, Table A-10 shows the amount of each removed in each run. It appears that $\mathrm{N}$ and $\mathrm{S}$ are somewhat more effectively removed in runs containing the higher levels of coal. It is not clear whether this may be related to influence of coal on $\mathrm{N}$ and $\mathrm{S}$ removal, differing composition of $\mathrm{N}$ and $\mathrm{S}$ compounds in resid and coal, or a more active catalyst because of better dispersion. The enhanced $\mathrm{N}$ and $\mathrm{S}$ removal is minor. 
TABLE A-10. - Nitrogen and sulfur removal in coprocessing reactions

\begin{tabular}{|lcccc|}
\hline & \multicolumn{4}{c|}{ Percent Reduction } \\
\cline { 2 - 5 } Coal, percent & 2 & 20 & 30 & 40 \\
\hline & 31 & 20 & 33 & 41 \\
Nitrogen & 45 & 59 & 62 & 58 \\
Sulfur & & & \\
\hline
\end{tabular}

\section{A.8 References}

1. Cugini, A. V., J. A. Ruether, D. L. Cillo, D. Krastman, P. N. Smith, and V. Balsone, Novel Dispersed-Phase Catalytic Approach to Coprocessing. ACS Preprints, Division of Fuel Chemistry, v. 33 (1), June 1988, pp. 6-19.

2. Derbyshire, F. J., A. Davis, R. Lin, P. G. Stansberry, M. T. Terrer. Coal Liquefaction by Molybdenum Catalyzed Hydrogenation in the Absence of Solvent. Fuel Proc. Tech., v. 12, 1986, pp. 127-41. 
APPENDIX B

ANALYTICAL PROCEDURES 
The lowing sections provide general information on the analytical procedures used in this project as well as unformation of conditions, solvents, etc., which are specific to this work. For detailed informetion on the procedures, the reader is referred to an exhaustive two-volume report on the development of methods used for the detailed separation and analysis of complex petroleum products (1).

\section{B.1 Separation of Distillates into Acid, Base and Neutral Fractions}

The $175-350^{\circ}$ and $350-538^{\circ} \mathrm{C}$ distillates were processed by nonaqueous ion exchange chromatography in produce acid, base, and neutral fractions. This procedure was developed at NIPER for application to high boiling and residual materials (1). The acid and base fractions were separated on the resins MP-1 and MP-50 (BioRad Laboratories) from 1:3 benzene-cyclohexane solution. The unretained material is the neutral class fraction. Acids are recovered by washing the anion resin in a Soxhlet extractor with formic acid in methanol-benzene mixture. Bases were collected in a similar manner from the cation resin with 1-aminopropane in methanol-benzene solvent. Yields are summarized in Tábie $\bar{B}-1$.

TABLE B-1. - Class composition of distillates

\begin{tabular}{|lrrrr|}
\hline & \multicolumn{4}{c|}{ Weight Percent } \\
\cline { 2 - 5 } Coal, percent & 2 & 20 & 30 & 40 \\
\hline & & & & \\
Distil. 175-350 & & & \\
Acids & 2.1 & 6.3 & 8.3 & 4.1 \\
Bases & 1.5 & 2.5 & 5.3 & 81.3 \\
Neutral & 93.1 & 88.9 & 86.1 & \\
Distil. 350-538 $\mathrm{C}$ & & & & 17.2 \\
Acids & 10.3 & 13.5 & 17.4 & 6.3 \\
Bases & 4.8 & 5.0 & 7.2 & 77.2 \\
Neutral & 83.5 & 82.5 & 78.9 & \\
\hline
\end{tabular}

\section{B.2 Separation of Resids into Strong and Weak Acid, Strong and Weak Base, and Neutral Fractions}

Samples of coprocessing resids were separated into neutrai, acid, and base fractions by preparative liquid chromatographic methods. Both the acid and base fractions were further resolved to strong and weak subfractions. The procedure is based on nonaqueous ion exchange chromatography and is similar to the procedure described for the distillate classes. However, 
solubility limitations of the resid samples require that a first pass of these samples through the ion exchange columns be carried out in a mixture of ethanol, tetrahydrofuran, and benzene $(1: 4.5: 4.5)$. In this solvent mixture only the strong acids and bases are retained. Acids are recovered by Soxhlet extraction of the arion resin with benzene containing formic acid while bases are recovered by Soxhlet extraction of the cation resin with I-propylamine in benzene. The eluant from the first pass of the residue samples contains neutrals, weak acids, and weak bases. It is soluble in less polar solvents than the original residue and therefore is redissolved in a mixture of benzene and cyclohexane $(1: 3)$ for a second pass through the column system. Acids and bases are recovered as before. The ion exchange column system consists of the BioRad Laboratories resins MP-1 (anion) in the first position, followed by MP-50 (cation). Because of this arrangement, amphoteric components are retained in the acid fractions.

\section{B.3 Separation of Neutral Fractions into Saturate and Aromatic Fractions}

The neutral fractions of the $175-350^{\circ}$ and $350-538^{\circ} \mathrm{C}$ distillates were separated into saturate and aromatic fractions. This was accomplished in a two-stage liquid chromatographic procedure in which the saturate and monoaromatic hydrocarbons are separated from other aromatics on a charge transfer (2,4-dinitroanilinopropylsilica, DNAP) column and the saturates then separated from the monoaromatics on an adsorption (silica) column. The aromatic fractions from the two columns are recombined. Pentane and dichloromethane are used as solvents in these separations. In reconcentration of the fractions of the $175-350^{\circ} \mathrm{C}$ distillate after the chromatographic separations, excessive loss of the more volatile portion of the samples occurred if attempts were made to remove all solvent. Because of this, the solvent content was left at about 5 to 7 percent level in each of the lower boiling range samples, based on gas chromatographic determinations. However, the portions of these samples submitted to carbon isotope ratio analysis were further stripped of solvent with the luss of a small amount of volatile sample components.

\section{B.4 Titration of Acid and Base Fractions}

The base fractions isolated from all of the $175-350^{\circ}$ and $350-538^{\circ} \mathrm{C}$ distillates have were analyzed by nonaqueous titration. Samples of each base fraction were titrated in both acetonitrile and acetic anhydride with $0.01 \mathrm{~N}$ perchloric acid in dioxane as the titrant. The titrations were monitored by a glass electrode and an $\mathrm{Ag} / \mathrm{AgCl}$ electrode that was modified for this procedure. Further details of the method and calculation of the various types of bases from results obtained in the two solvents are described elsewhere $(12)$. 
The acid fractions obtained from both distillates were titrated by a nonaqueous titration procedure. In this method, the titrant is potassium dimsyl, formed by reaction of potassium hydride with dimethylsulfoxide (DMSO). The samples were dissolved in DMSO and titrated under a dry argon atmosphere. The apparatus was constructed of Teflon and stainless steel and the electrodes were specifically prepared for this procedure. This titration procedure was developed at NIPER for study of petroleum residue composition.

\section{B.5 Derivatization of Acids}

A procedure was developed for the specific alkylation of acidic functional groups present in petroleum and related products. Samples (weighed to provide about 0.2 gram of product) were

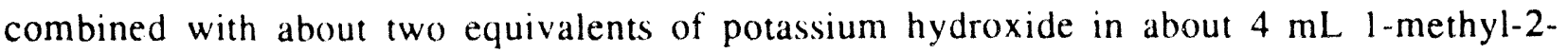
pyrrolidinone. To this, about 20 percent excess of iodomethane was added. After mixing, it was held at $45^{\circ} \mathrm{C}$ for one hour. It was then poured into water and extracted with ethyl ether to obtain the product. This method provided a standard procedure for $\mathrm{N}$ and $\mathrm{O}$ methylation of a wide variety of acidic compounds. Nearly quantitative conversion was obtained for compounds such as indole, carbazole, phenols, (including 2-naphthol and 2,6-di-tert-butyl-4-methylphenol), thiols and aromatic amides. Also, compounds with benzylic hydrogen activated by neighboring groups, such as fluorene, and oxindole, were completely converted to the methylated form.

\section{B.6 GC/MS Analysis of Acids}

Derivatized acid samples of the $175-350^{\circ} \mathrm{C}, 20$ percent coal distillate were analyzed by a gas chromatography - mass spectrometry procedure. Analysis was on a 100-meter capillary column (007 methyl silicone, Quadrex) in a Carlo Erba instrument. MS determination was in a Kratos MS80 instrument with column effluent introduced directly to the source.

\section{B.7 NMR Analysis of Derivatized Acids}

The methylation procedure using $13 \mathrm{C}$ enriched iodomethane $\left(99\right.$ percent $\left.+{ }^{13} \mathrm{CH}_{3} \mathrm{I}\right)$ was applied to the 175-350 and $350-538^{\circ} \mathrm{C}$ acid fractions of the coprocessing products. Samples of the acid fractions were also reacted using normal iodomethane (1.1 percent ${ }^{1}{ }^{3} \mathrm{CH}_{3}$ I, 98.9 percent $\left.{ }^{12} \mathrm{CH}_{3} \mathrm{I}\right)$. Each sample was dissolved in deuterochloroform $\left(\mathrm{CDCl}_{3} ; 99.6\right.$ percent $\left.\mathrm{D}\right)$ using tetramethylsilane (TMS) as the internal chemical shift reference. Four types of NMR experiments were run on each of the ${ }^{13} \mathrm{CH}_{3}$ derivatized samples using a JEOL GX-270 FT-NMR spectrometer operating at $270.15 \mathrm{MHz}$ for ${ }^{1} \mathrm{H}$ and $67.94 \mathrm{MHz}$ for ${ }^{13} \mathrm{C}$; a proton NMR experiment $\left(45^{\circ}\right.$ pulse, 
5-sec pulse delay, 64-pulse summation); a quantitative ${ }^{13} \mathrm{C}$ NMR experiment (gated-decoupling of protons during signal acquisition, $30^{\circ}$ pulse, 20-sec pulse delay, 3200-pulse summation); a DEPTD experiment (Distortionless Enhancement by Polarizatun Transfer with proton Decoupling) to differentiate the methyl carbon signals $\left(135^{\circ}\right.$ pulse $(R), 5$-sec pulse delay, 600 -pulse summation); a CHSHF (Carbon Hydrogen SHift correlation) experiment correlating the ${ }^{1} \mathrm{H}$ chemical shift with the ${ }^{13} \mathrm{C}$ chemical shift $\left({ }^{1} \mathrm{H}: 1500 \mathrm{~Hz}, 128\right.$ points; ${ }^{13} \mathrm{C}: 4800 \mathrm{~Hz}, 1024$ points; 192-pulse summation each ${ }^{1} \mathrm{H}$ point, $1.893-\mathrm{sec}$ pulse delay). The first three experiments were also run on each of the ${ }^{12} \mathrm{CH}_{3}$ derivatized samples.

Table B-2 shows the ${ }^{1} \mathrm{H}$ and $13 \mathrm{C}$ chemical shifts of the ${ }^{13} \mathrm{CH}_{3}$ group for nine model compounds methylated using ${ }^{13} \mathrm{C}$ enriched iodomethane together with the methylation yield based on ${ }^{13} \mathrm{C}$ peak integrals. The uncertainty in the yields is aboui +7 percent. Several of the methylated compounds contain methyl peaks from side products apparent y formed during methylation. These have been identified where possible. These were chosen because they represent possible functional structures present in petroleum acidic classes.

TABLE B-2. - Proton $\left({ }^{1} \mathrm{H}\right)$ and carbon-13 $\left({ }^{13} \mathrm{C}\right)$ chemical shifts of methylated model compounds

\begin{tabular}{|c|c|c|c|}
\hline Compound & $w\left({ }^{13} C\right)^{a} \cdot g p m$ & $\begin{array}{l}\text { Methylation } \\
w\left({ }^{l} H\right)^{a}, p p: n\end{array}$ & Yield, \% \\
\hline \multirow[t]{2}{*}{ Methyl tolyl sulfide } & 16.5 & 2.40 & 95 \\
\hline & $43.5(4 \%)$ & 2.63 (DMSO Imp.) & \\
\hline 9-Hydroxyfluorene (9-methyl) & 26.5 & $1.67\left(-\mathrm{CCH}_{3}\right)$ & 95 \\
\hline (9-methoxy) & 51.5 & $2.73\left(-\mathrm{OCH}_{3}\right)$ & \\
\hline \multirow[t]{2}{*}{ Fluorene (9.9-dimethyl) } & 27.0 & 1.46 & 84 \\
\hline & $18.0(6.5 \%)$ & 1.48 (Imp.) & \\
\hline N-methylcarbazole & 28.5 & 3.75 & 96 \\
\hline$N$-methylindole & 32.5 & 3.48 & 96 \\
\hline $\mathrm{N}$-methyl-N-phenylvaleramide & 37.5 & 3.22 & 95 \\
\hline$N$-methylindazole $(1-N)$ & $35.0(80 \%)$ & 3.95 & 100 \\
\hline$(2-N)$ & $39.7(20 \%)$ & 4.05 (rearrange) & \\
\hline Myristic acid (methyl ester) & 51.5 & 3.62 & 90 \\
\hline 2-Naphthyl methyl ester & 55.2 & 3.85 & 96 \\
\hline
\end{tabular}

a Chemical shifts referenced to internal TMS, $w($ TMS $)=0.00$. 
Table B-3 shows the estimated mean equivalent molecular weights (EW) obtained for the coprocessing sample acid fractions using nonaqueous titration. Assuming an average carbon:hydrogen ratio of $1: 1.5$ for these acid fractions, the estimated number of carbons per average molecule was calculated assuming that the compounds are monofunctional in oxygen or nitrogen content. These average carbon numbers are also shown in Table B-3 for each acid fraction.

TABLE B-3. - Acid fraction equivalent weights and carbon number

\begin{tabular}{|ccccc|}
\hline Coal, percent & 2 & 20 & 30 & 40 \\
\hline $175-350^{\circ} \mathrm{C}$ & & & & \\
EW & 184 & 173 & 167 & 158 \\
Carbon No. & 12.5 & 11.7 & 11.3 & 10.6 \\
$350-538^{\circ} \mathrm{C}$ & & & & \\
EW & 292 & 250 & 248 & 259 \\
Carbon No. & 20.5 & 17.4 & 17.3 & 18.1 \\
\hline
\end{tabular}

The carbon number will be used later to calculate the average number of functional groups per molecule for the acid fractions.

Figures B-1 - B-8 show the CHSHF two-dimensional contour plots of the acid fractions. In these figures the individual peaks are shown as closed contours oi signal height (intensity) plotted at the coordinates of the ${ }^{13} \mathrm{C} / 1 \mathrm{H}$ chemical shifts referenced to the TMS signal in the upper right corner. The ${ }^{13} \mathrm{C}$ chemical shift is the horizontal axis, and the ${ }^{1} \mathrm{H}$ chemical shift is the vertical axis. Also shown in each figure are horizontal and vertical projections of the peak intensity which represent the proton and carbon-13 spectra, respectively, plotted as chemical shift relative to the TMS peak used as internal chemical shift reference. In Figure B-1, the three regions of interest for methylated oxygen, nitrogen and benzylic/sulfur functional groups present in the acid subfractions are labeled. Based in part on results for pure compounds in Table B-2, the oxygen region was defined as the region from 49-65 ppm $\left({ }^{13} \mathrm{C}\right)$ and $2.7-4.2 \mathrm{ppm}\left({ }^{1} \mathrm{H}\right)$. Similarly, the nitrogen region was found to extend from $28-49 \mathrm{ppm}\left({ }^{13} \mathrm{C}\right)$ and $3.0-4.4 \mathrm{ppm}\left({ }^{1} \mathrm{H}\right)$. The benzylic/sulfur region extends from $5.28 \mathrm{ppm}\left({ }^{13} \mathrm{C}\right)$ and $1.4-3.0 \mathrm{ppm}\left({ }^{1} \mathrm{H}\right)$. Above the benzylic/sulfur region is the region from $10-38 \mathrm{ppm}\left({ }^{13} \mathrm{C}\right)$ and $0.5-1.4 \mathrm{ppm}\left({ }^{1} \mathrm{H}\right)$ which contains peaks typical of alkyl carbons. The peaks of alkyl carbons alpha to aromatic structures can have ${ }^{1} \mathrm{H}$ shifts up to $3.0 \mathrm{ppm}$; so peaks from these components could interfere with benzylic/sulfur assignments. These same regions apply to the other Figures B-2 - B-8. 


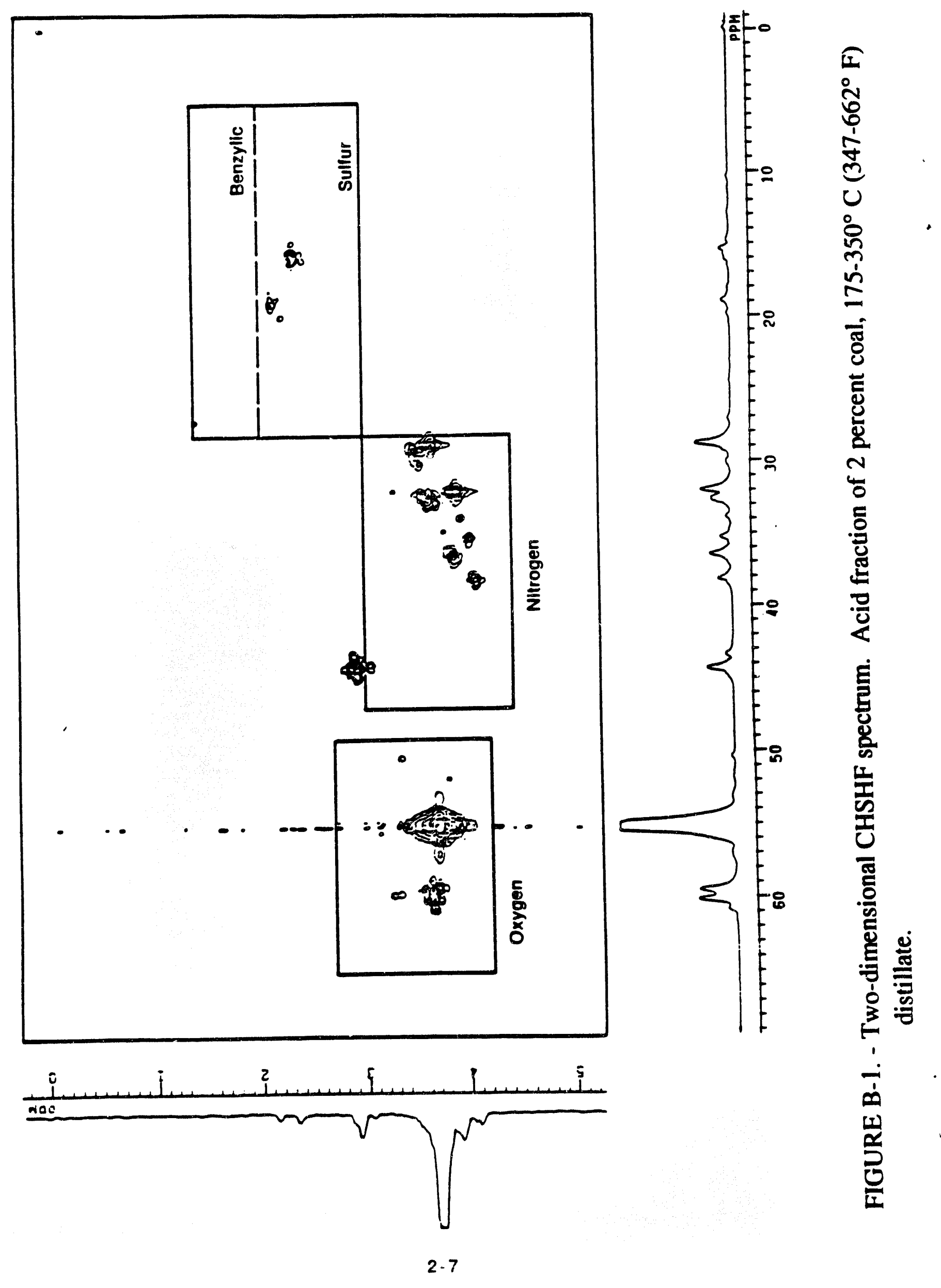




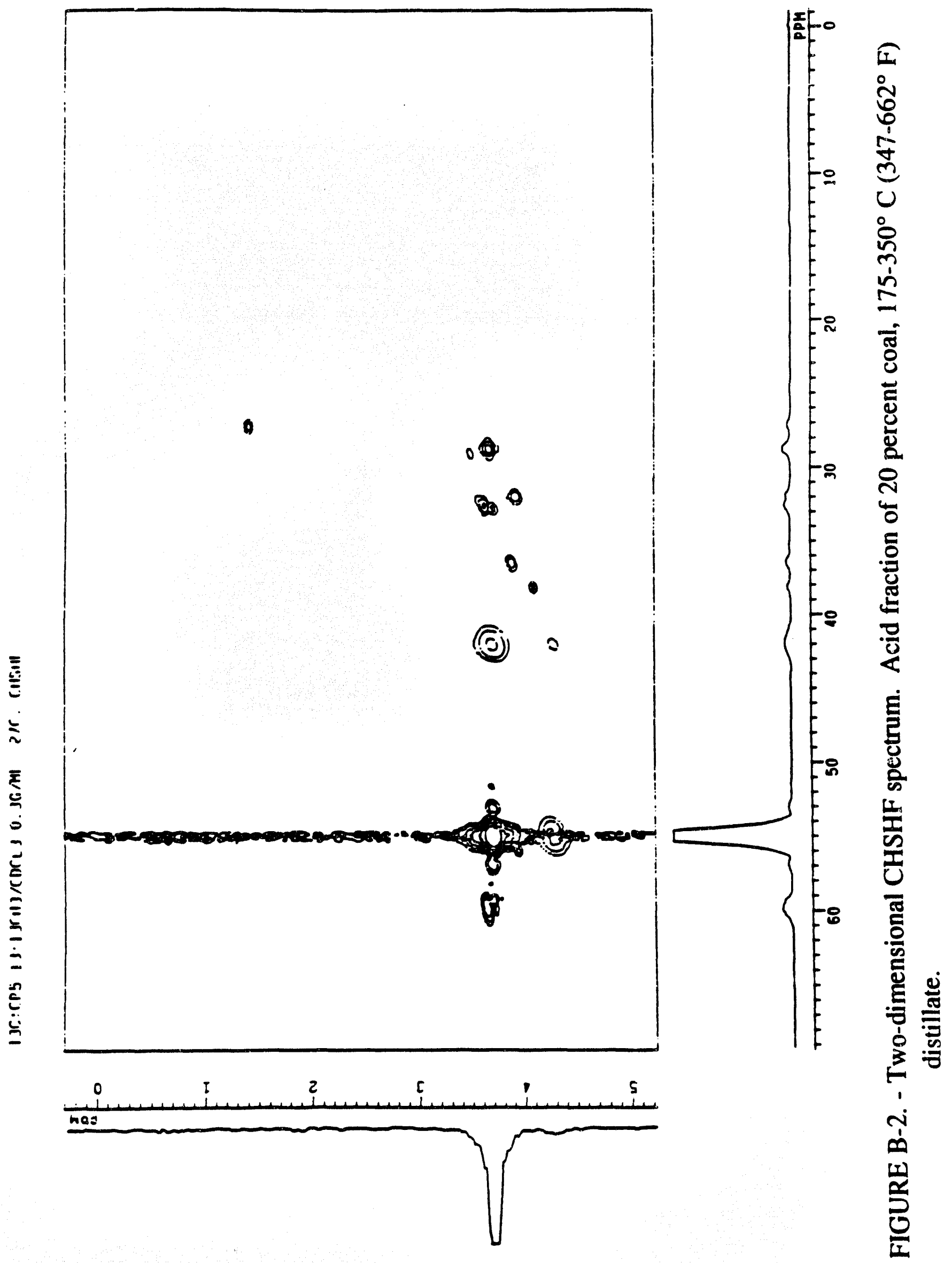




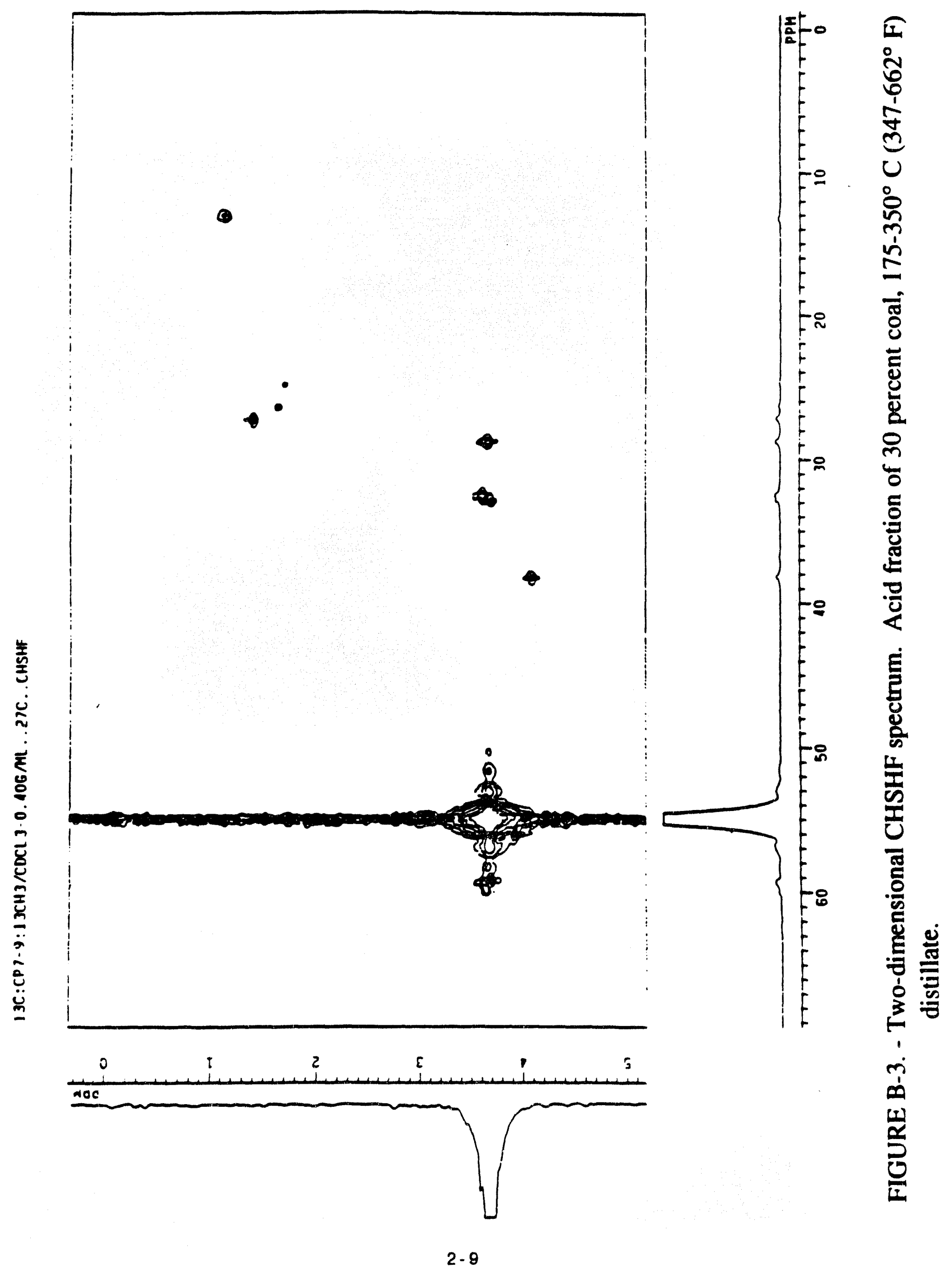




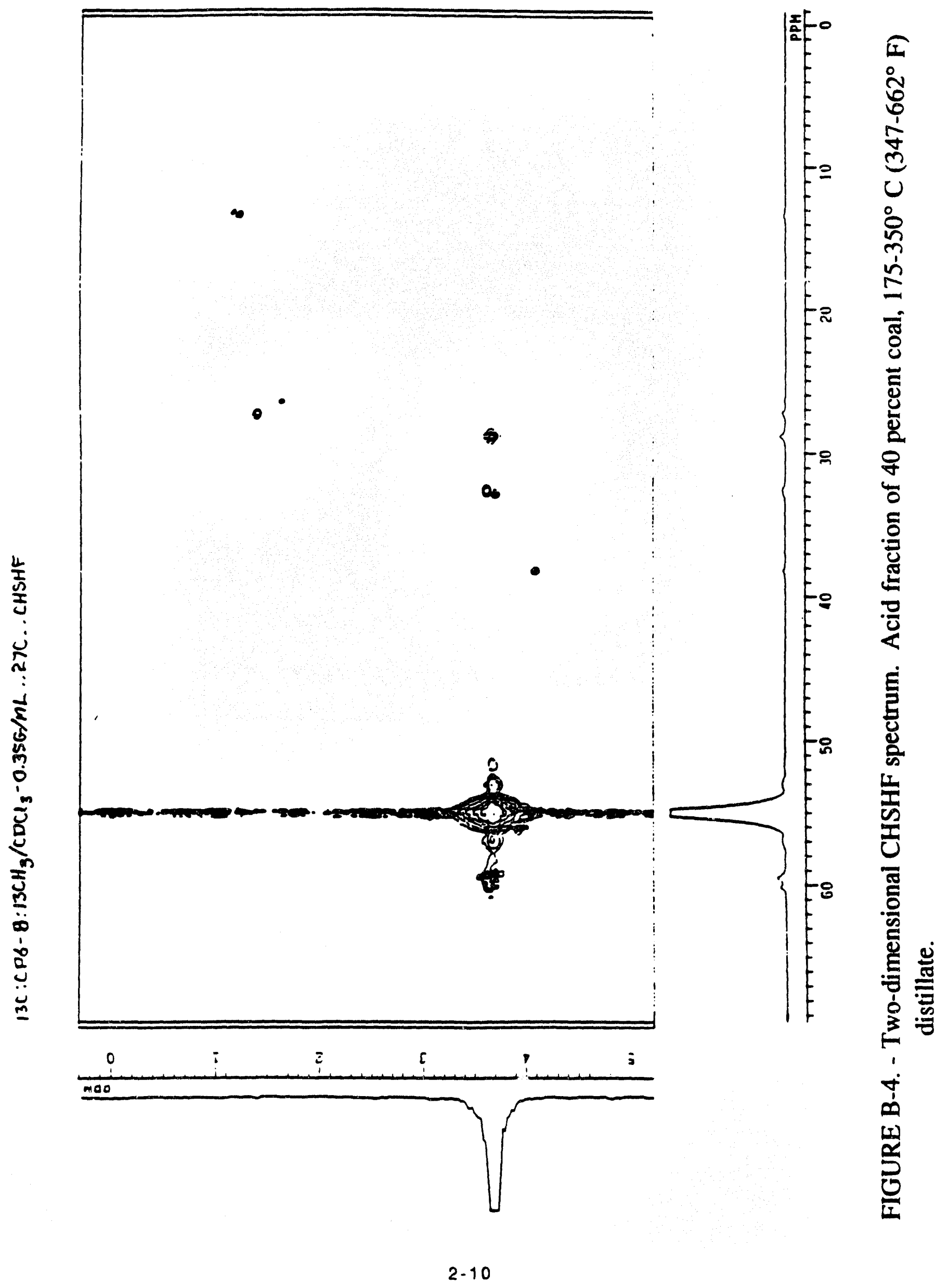



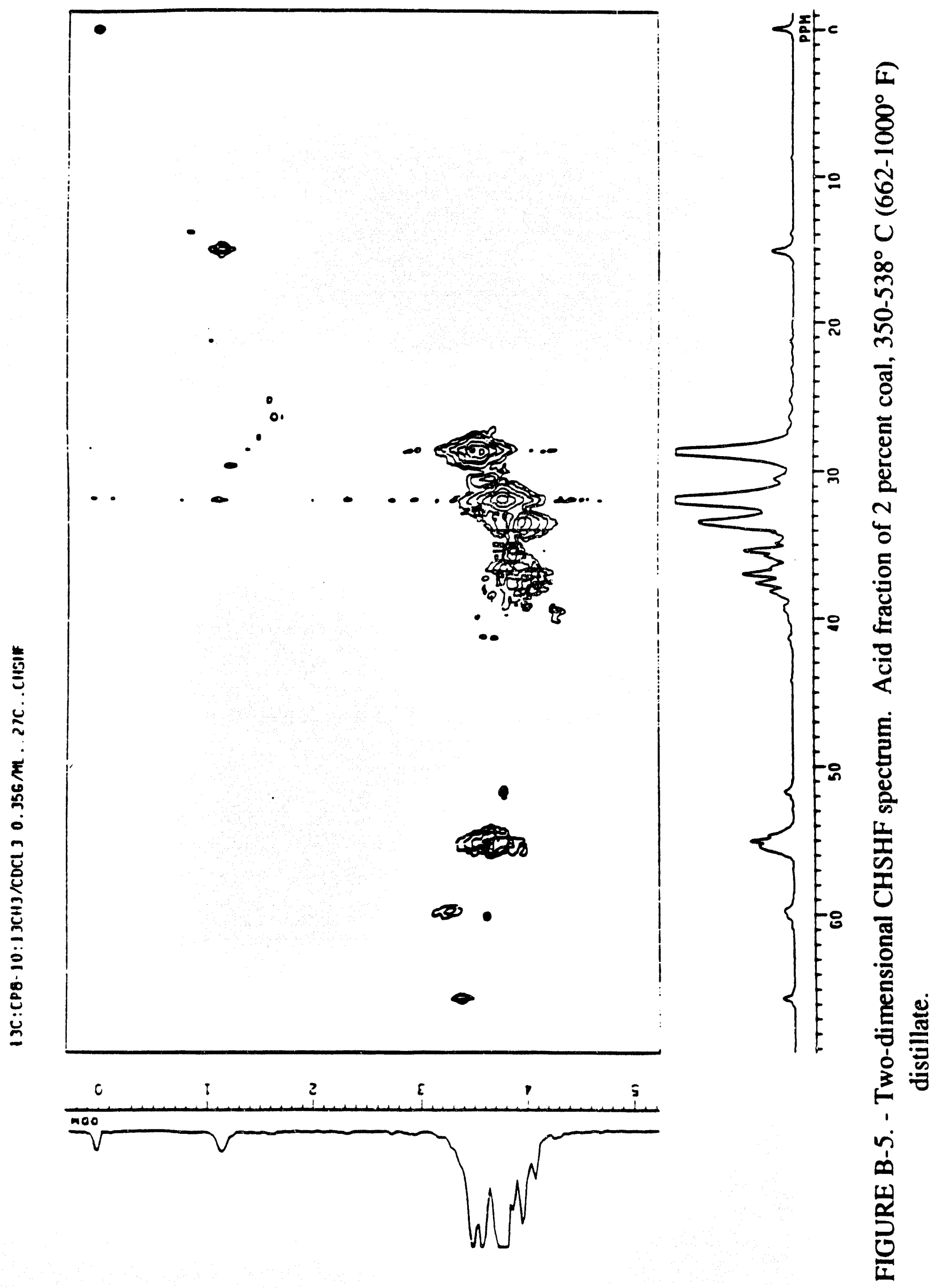

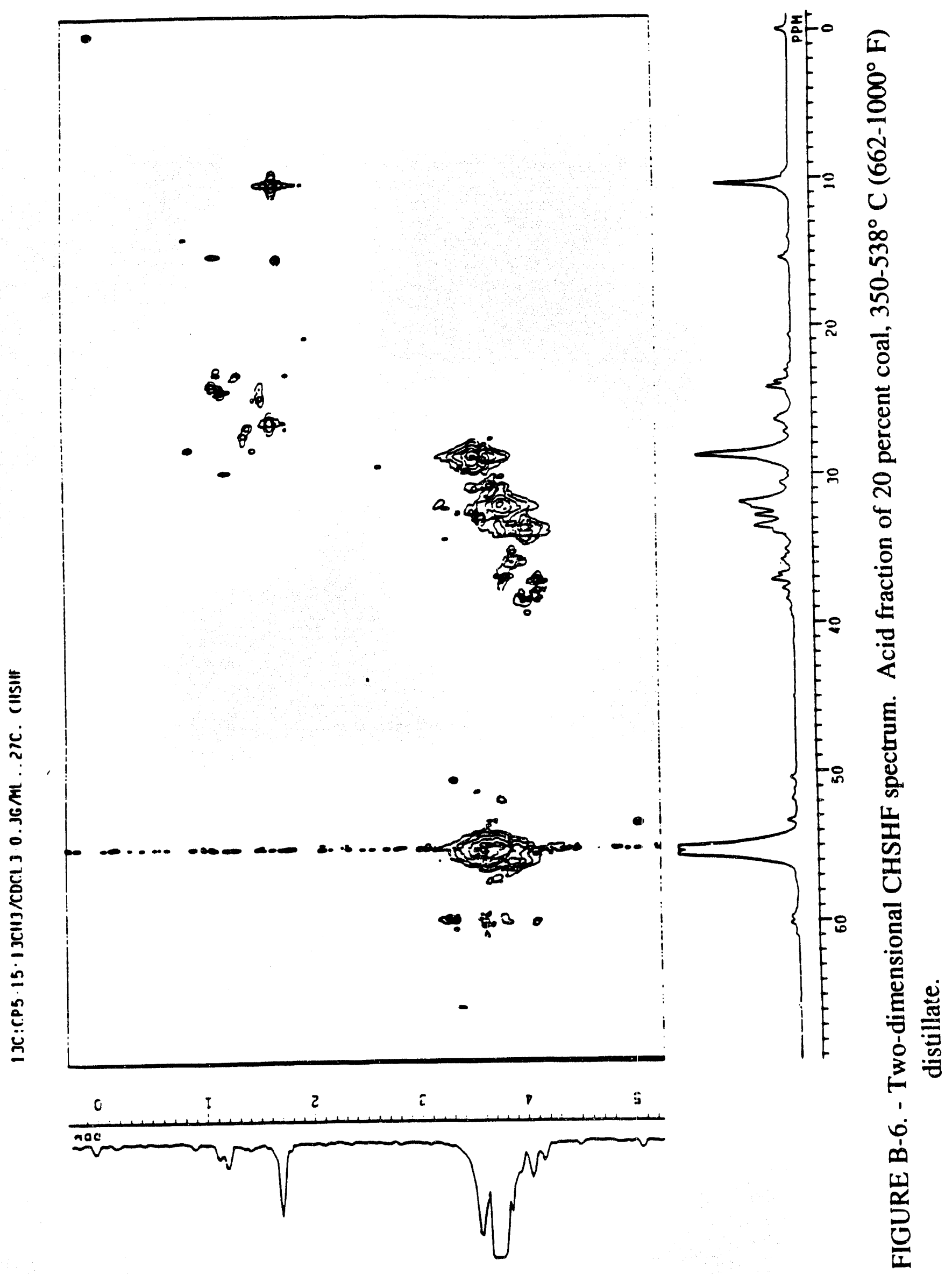


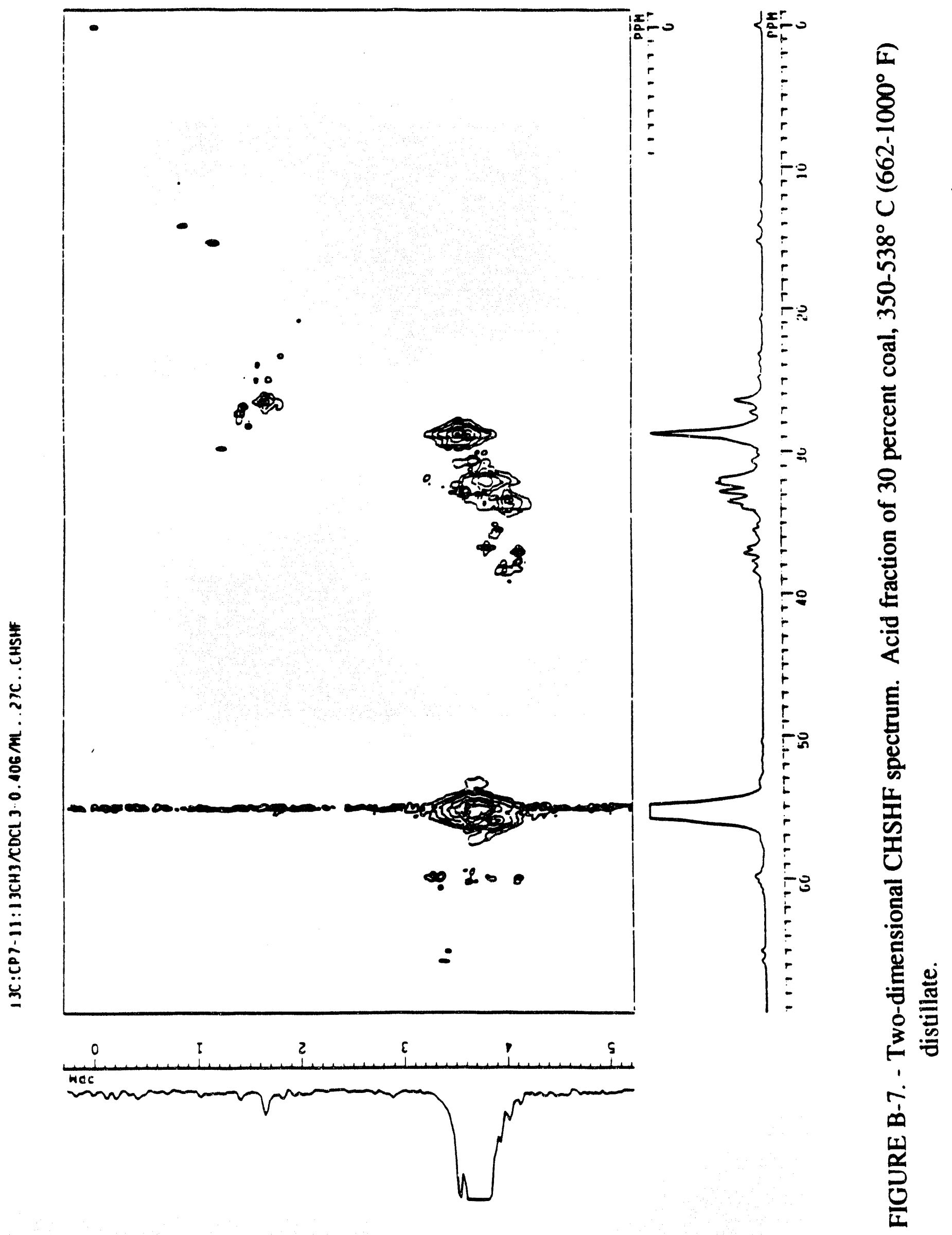




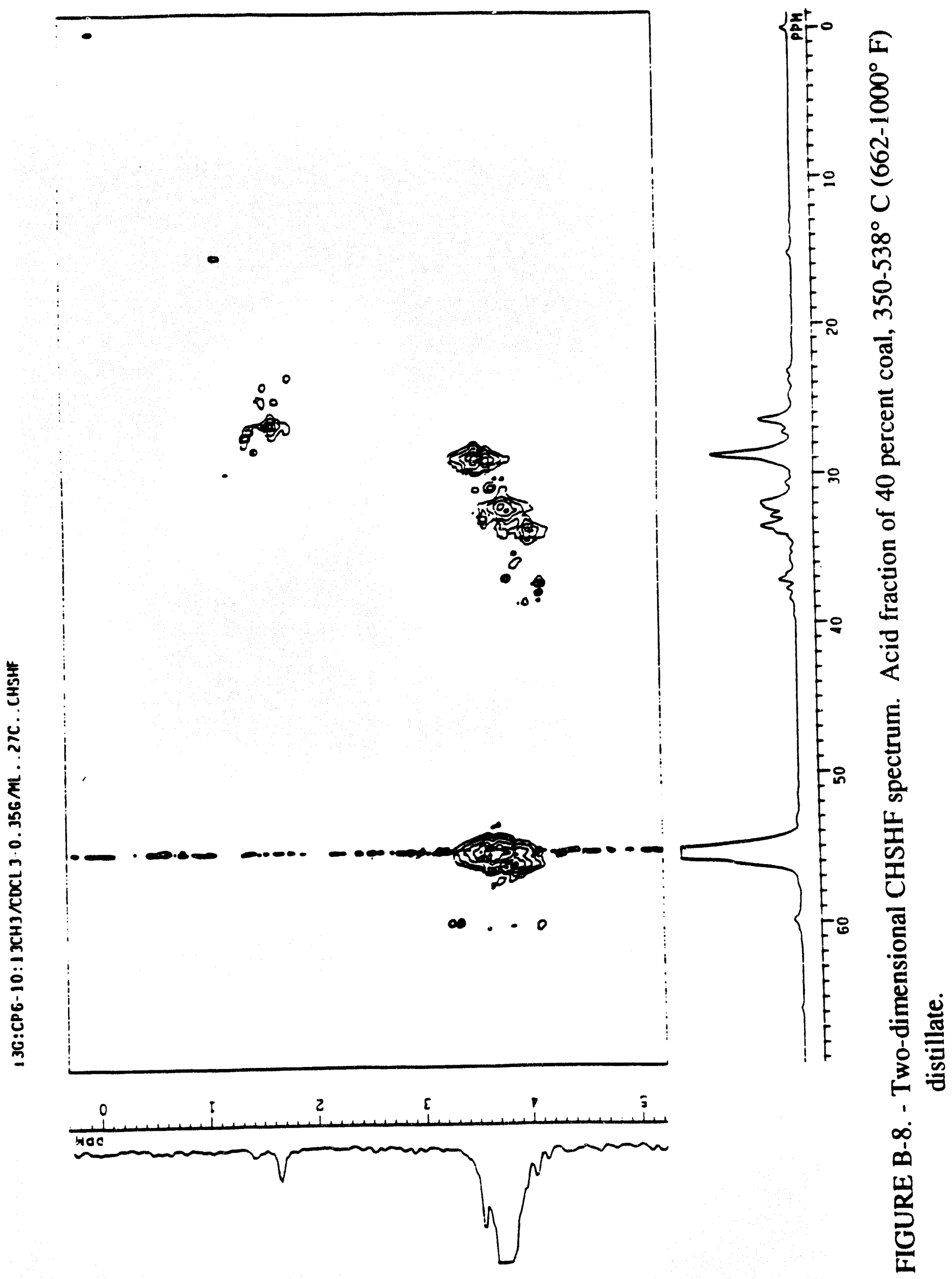


The oxygen region may be further subdiviod into three subregions based on the ${ }^{13} \mathrm{C}$ chemical shift. The methyl esters of carboxylic acids $\left(-\mathrm{COOCH}_{3}\right)$ have ${ }^{13} \mathrm{C}$ shifts from 49 $54 \mathrm{ppm}$ with the primary position being $51-52 \mathrm{ppm}\left({ }^{1} \mathrm{H}\right.$ chemical shifts are typically $3.6-4.0$ $\mathrm{ppm})$. The methylated phenols or hydroxyl groups $\left(-\mathrm{CCH}_{3}\right)$ have ${ }^{13} \mathrm{C}$ shifts from $54-59 \mathrm{ppm}\left({ }^{1} \mathrm{H}\right.$ shifts are typically $3.5-4.2 \mathrm{ppm}$ for aromatic methoxy groups and $3.2-3.5 \mathrm{ppm}$ for aliphatic methoxy groups). However, hindered phenolic groups $\left(-\mathrm{OCH}_{3}(\mathrm{H})\right)$ that have two orthosubstituents exhibit ${ }^{13} \mathrm{C}$ shifts from $59-63 \mathrm{ppm}\left({ }^{1} \mathrm{H}\right.$ shifts are similar to those of other methoxy groups). These three subregions seem to be well defined with essentially no overlap based on the ${ }^{13} \mathrm{C}$ chemical shifts of many compounds. However, the methylated model compound 9-hydroxy. fluorene had a ${ }^{13} \mathrm{C}$ shift for the $-\mathrm{OCH}_{3}$ group of $51.5 \mathrm{ppm}$ with a ${ }^{1} \mathrm{H}$ shift of $2.75 \mathrm{ppm}$, both outside the typical ranges for the $-\mathrm{OCH}_{3}$ groups. A series of 9-n-alkyl-fluorene-9-ols has previously been identified in petroleum, but may not be present in these coprocessing samples.

Within the nitrogen region those methyls attached to amine-type nitrogens have ${ }^{1} \mathrm{H}$ shifts around 3.0-3.2 ppm while methyls attached to nitrogen in aromatic rings or condensed ring systems have ${ }^{1} \mathrm{H}$ shifts from $3.4-4.4 \mathrm{ppm}$. For example, the methylated model compound carbazole has a ${ }^{13} \mathrm{CH}_{3}$ shift of $28.5 \mathrm{ppm}\left({ }^{13} \mathrm{C}\right)$ and $3.75 \mathrm{ppm}\left({ }^{1} \mathrm{H}\right)$. If the ring system has several nearby nitrogens, the ${ }^{1} \mathrm{H}$ shift of the $\mathrm{N}$-methyls is generally toward the higher end of the range.

Within the benzylic/sulfur region, methyl sulfides generally have ${ }^{1} \mathrm{H}$ shifts from $2.0-2.5 \mathrm{ppm}$ with aromatic methyl sulfides around $2.4-2.5 \mathrm{ppm}$. The ${ }^{13} \mathrm{C}$ shifts of methyl sulfides are generally from 10-20 ppm. Benzylic methyls have ${ }^{1} \mathrm{H}$ shifts sypically from $1.4-2.0 \mathrm{ppm}$.

Figure B-1 shows that the 2 percent coal, $175-350^{\circ} \mathrm{C}$ acid fraction contains substantial oxygen and nitrogen methylated classes with some peaks in the benzylic/sulfur region. Within the oxygen region the most prominent peak is that typical of methylated phenolic groups at $55.0 \mathrm{ppm} /$ $3.70 \mathrm{ppm}\left({ }^{13} \mathrm{C} /{ }^{1} \mathrm{H}\right)$, with a smaller group of peaks typical of hindered methylated phenols at $60 \mathrm{ppm} / 3.65 \mathrm{ppm}$, with several smaller peaks from other methylated oxygen classes of intermediate nature.

There is a substantial group of methylated nitrogen classes with carbazole prominent as the peak at the right edge of this region at $28.7 \mathrm{ppm} / 3.71 \mathrm{ppm}$. N-methyl indole would appear to be outside this group based on the ${ }^{1} \mathrm{H}$ shift of $3.48 \mathrm{ppm}$, but $\mathrm{N}$-methylindazole would appear to be a good representative at $35.0 \mathrm{ppm} / 3.95 \mathrm{ppm}(39.7 \mathrm{ppm} / 4.05 \mathrm{ppm}$ for the rearrangement product). 
$\mathrm{N}$-methyl-N-phenylvaleramide also appears to be an unlikely candidate based on the ${ }^{1} \mathrm{H}$ shift of $3.22 \mathrm{ppm}$ for the methyl protons. The group of peaks at $44 \mathrm{ppm} / 2.9 \mathrm{ppm}$ is atypical but might be an amine derivative.

The two groups of peaks in the benzylic/sulfur region at $15.5 \mathrm{ppm} / 2.35 \mathrm{ppm}$ and $19.0 \mathrm{ppm} /$ $2.2 \mathrm{ppm}$ have ${ }^{13} \mathrm{C}$ and ${ }^{1} \mathrm{H}$ shifts that are representative of methylated sulfur functional groups. This is the only sample that shows the probable presence of sulfur functional groups; the others have some peaks in this region more typical of benzylic derivatives.

For the rest of the $175-350^{\circ} \mathrm{C}$ acid fraction CHSHF spectra in Figures B-2 - B-4, the trends are the increasing prominence of the methylated phenolic group peak at $55 \mathrm{ppm} / 3.7 \mathrm{ppm}$ and the decreasing presence of methylated nitrogen or benzylic/sulfur peaks. Figure B-22 contains two strange broad low intensity signals at $42 \mathrm{ppm} / 3.7 \mathrm{pp}: n$ and at $55 \mathrm{ppm} / 4.3 \mathrm{ppm}$. The appearance of these peaks is not characteristic of peaks displayed in CHSHF spectra and they are probably artifacts of some type. A common artifact of the CHSHF experiment are the "tails" extending vertically in the ${ }^{1} \mathrm{H}$ shift direction for prominent peaks when low contours are used to show weaker peaks. These artifacts are evident in Figure B-1 and strongly in Figures B-2 - B-4 for the phenolic derivative peaks.

Comparing the $350-538^{\circ} \mathrm{C}$ acid fraction CHSHF spectra shown in Figures B-5 - B-8 with the lower temperature spectra reveals that nitrogen functional groups are much more prominent in these higher temperature fractions. The carbazole derivative peak at $28.7 \mathrm{ppm} / 3.6 \mathrm{ppm}$ is prominent in all the Figures B-5 - B-8. The phenolic derivative peak at $55 \mathrm{ppm} / 3.7 \mathrm{ppm}$ is present in Figure B-5 and increases strongly in intensity in Figures B-6 - B-8. This peak also appears to have several overlapping components while the corresponding peak in the lower temperature fractions was indicative of mostly one component. There is no evidence of sulfur derivatives in these fractions and possible benzylic derivatives are most prominent in Figure B-6 for the 20 percent coal acids.

The CHSHF experiment is inherently not quantitative; so the intensities or integrals of peaks in Figures B-1 - B-8 cannot be used as a measure of the exact proportions of each acid class present in each sample. Thus the following treatment is used to obtain quantitative results. Tables B-4 - B-8 show the functional class integrals, the intermediate values used in determination of relative abundance of the classes, and finally the number of functional groups per average molecule. In Table $\mathrm{B}-4$ are shown the ${ }^{13} \mathrm{C}$ peak integrals from the quantitative $13 \mathrm{C}$ NMR experiments for both the ${ }^{13} \mathrm{CH}_{3}$ and $12 \mathrm{CH}_{3}$ methylated samples of each fraction. The integrals 
are shown for four regions: the aromatic region (110-160 ppm) and the oxygen, nitrogen, and benzylic/sulfur regions previously identified. The aromatic carbon structure has been assumed to be unaltered by the methylation process; so all integrals have been scaled to give the same result for the aromatic region.

The integral values of Table B-4 provide the information required to determine the amounts of the acid functional groups present in the samples. In combination with the titration values shown in Table B-3, the number of functional groups of each acid type for the average molecule can be determined as well as the total number of acid groups. Table B-5 contains intermediate values required in calculation of the number of functional groups. The values $1{ }^{3} \mathrm{R}$ and $12 \mathrm{R}$ represent the sum of integrals over all ${ }^{13} \mathrm{C}$ response areas and are obtained from the last columns of each distillate section of Table B-4. These $R$ values may be represented by equations 1 and 2 as the sum of functional and non-functional ${ }^{13} \mathrm{C}$.

$$
\begin{array}{lll}
0.011 \mathrm{~N}_{\mathrm{C}} \mathrm{I}+0.011 \mathrm{~N}_{\mathrm{d}} \mathrm{I}=12 \mathrm{R} & \left({ }^{12} \mathrm{CH}_{3} \text { derivative }\right) & \text { Eq. } 1 \\
0.011 \mathrm{~N}_{\mathrm{c}} \mathrm{I}+0.99 \mathrm{~N}_{\mathrm{d}} \mathrm{I}={ }^{13} \mathrm{R} & \left(13 \mathrm{CH}_{3} \text { derivative }\right) & \text { Eq. } 2
\end{array}
$$


TABLE B-4. - Quantitative carbon-13 NMR peak integrals

\begin{tabular}{|c|c|c|c|c|c|}
\hline Sample. \% Coal & Arom. & $\begin{array}{c}O \\
110-160 \mathrm{ppm}\end{array}$ & $\begin{array}{c}N \\
49-65 \mathrm{ppm}\end{array}$ & $\begin{array}{c}\mathrm{B} / \mathrm{S} \\
28-49 \mathrm{pm}\end{array}$ & $\begin{array}{c}\text { Total } \\
5-28 \mathrm{ppm}\end{array}$ \\
\hline \multicolumn{6}{|l|}{$175-350^{\circ} \mathrm{C}$} \\
\hline $2 \%,\left({ }^{13} \mathrm{CH}_{3}\right)$ & $82.08^{*}$ & 520.27 & 312.32 & 108.14 & 1022.81 \\
\hline$\left({ }^{12} \mathrm{CH}_{3}\right)$ & 82.08 & 5.57 & 15.42 & 30.11 & 133.18 \\
\hline $20 \%,\left({ }^{13} \mathrm{CH}_{3}\right)$ & 82.08 & 1048.78 & 178.89 & 45.01 & 1354.76 \\
\hline$\left({ }^{12} \mathrm{CH}_{3}\right)$ & 82.08 & 8.35 & 19.07 & 27.03 & 136.53 \\
\hline $30 \%,\left({ }^{13} \mathrm{CH}_{3}\right)$ & 82.08 & 1015.19 & 57.84 & 29.91 & 1185.74 \\
\hline$\left({ }^{12} \mathrm{CH}_{3}\right)$ & 82.08 & 10.69 & 18.18 & 25.91 & 136.86 \\
\hline $40 \%,\left({ }^{13} \mathrm{CH}_{3}\right)$ & 82.08 & 1122.85 & 69.57 & 39.92 & 1314.42 \\
\hline$\left({ }^{12} \mathrm{CH}_{3}\right)$ & 82.08 & 11.63 & 17.68 & 25.13 & 136.52 \\
\hline \multicolumn{6}{|l|}{$350-538^{\circ} \mathrm{C}$} \\
\hline $2 \% \cdot\left({ }^{13} \mathrm{CH}_{3}\right)$ & 82.08 & 103.69 & 405.51 & 48.33 & 639.61 \\
\hline$\left({ }^{12} \mathrm{CH}_{3}\right)$ & 82.08 & 0.82 & 16.82 & 21.00 & 120.58 \\
\hline $20 \%,\left({ }^{13} \mathrm{CH}_{3}\right)$ & 82.08 & 322.41 & 261.61 & 76.96 & 743.06 \\
\hline$\left(12 \mathrm{CH}_{3}\right)$ & 82.08 & 7.14 & 21.26 & 16.90 & 127.38 \\
\hline $30 \%,\left({ }^{13} \mathrm{CH}_{3}\right)$ & 82.08 & 360.18 & 209.09 & 42.45 & 693.80 \\
\hline$\left({ }^{12} \mathrm{CH}_{3}\right)$ & 82.08 & 3.11 & 15.88 & 17.73 & 118.80 \\
\hline $40 \%,\left({ }^{13} \mathrm{CH}_{3}\right)$ & 82.08 & 439.72 & 23898 & 62.59 & 823.37 \\
\hline$\left(12 \mathrm{CH}_{3}\right)$ & 82.08 & 3.14 & 14.84 & 15.33 & 115.39 \\
\hline
\end{tabular}

* The integrals for each sample were scaled to make the aromatic integral the same. The aromatic region was assumed to be invariant during methylation. 
TABLE B-5. - Intermediate values (see text)

\begin{tabular}{|lcccc|}
\hline Coal, percent & 2 & 20 & 30 & 40 \\
\hline & & & & \\
$175-350^{\circ} \mathrm{C}$ & & & & \\
$13 \mathrm{R}_{\mathrm{R}}$ & 1022.81 & 1354.76 & 1185.74 & 1314.42 \\
$12 \mathrm{R}$ & 133.18 & 136.53 & 136.86 & 136.52 \\
$\mathrm{X}$ & 12.52 & 11.70 & 11.26 & 10.59 \\
$\mathrm{~N}_{\mathrm{c}} \mathrm{I}$ & 11198.6 & 11167.5 & 11370.4 & 11207.7 \\
$\mathrm{~N}_{\mathrm{d}} \mathrm{I}$ & 908.7 & 1244.4 & 1071.4 & 1203.2 \\
$\mathrm{~N}_{\mathrm{d}} / \mathrm{N}_{\mathrm{c}}\left({ }^{*} 10^{4}\right)$ & 811.4 & 1114.3 & 942.3 & 1073.5 \\
$\mathrm{X} \mathrm{N}_{\mathrm{d}} / \mathrm{N}_{\mathrm{c}}$ & 1.016 & 1.304 & 1.061 & 1.137 \\
$350-538^{\circ} \mathrm{C}$ & & & & \\
$133_{\mathrm{R}}$ & & & & \\
$12 \mathrm{R}$ & 639.61 & 743.06 & 693.80 & 823.37 \\
$\mathrm{X}$ & 120.58 & 127.38 & 118.80 & 115.39 \\
$\mathrm{~N}_{\mathrm{c}} \mathrm{I}$ & 20.52 & 17.41 & 17.26 & 18.07 \\
$\mathrm{~N}_{\mathrm{d}} \mathrm{I}$ & 10431.7 & 10951.1 & 10212.7 & 9766.8 \\
$\mathrm{~N}_{\mathrm{d}} / \mathrm{N}_{\mathrm{c}}\left({ }^{*} 10^{4}\right)$ & 530.2 & 628.9 & 587.3 & 723.2 \\
$\mathrm{X}^{*} \mathrm{~N}_{\mathrm{d}} / \mathrm{N}_{\mathrm{C}}$ & 508.2 & 574.3 & 575.1 & 740.4 \\
& 1.043 & 1.000 & 0.993 & 1.338 \\
\hline
\end{tabular}

Table B-6 shows the relative proportions of the three oxygen subclasses present in each acid fraction for each temperature cut. As discussed previously, from a qualitative aspect in Figures B-1 - B. 8 and confirmed here quantitatively, phenols are the most prominent oxygen functional group, particularly in the lower temperature fractions. The higher temperature fractions have higher contributions from hindered phenols and carboxylic acids. The higher coal contents result in more phenolic groups in both temperature ranges. 
TABLE B-6. - Quantitative subdivision of oxveen functionalities

\begin{tabular}{|lrrrr|}
\hline Coal, percent & 2 & 20 & 30 & 40 \\
\hline & & & & \\
$175-350^{\circ} \mathrm{C}$ & & & & \\
$-\mathrm{COOCH}_{3}$ & 5.1 & 1.5 & 0.4 & 0.5 \\
$-\left(\mathrm{CH}_{3}\right.$ & 75.2 & 90.2 & 97.1 & 94.8 \\
$-\mathrm{OCH}_{3}$ (hind.) & 19.7 & 8.3 & 2.5 & 4.7 \\
$350-538^{\circ} \mathrm{C}$ & & & & \\
$-\mathrm{COOCH}_{3}$ & 9.1 & 3.9 & 0.8 & 1.3 \\
$-\mathrm{OCH}_{3}$ & 57.3 & 82.3 & 87.5 & 86.6 \\
$-\mathrm{OCH}_{3}$ (hind.) & 33.6 & 13.8 & 11.7 & 12.1 \\
\hline
\end{tabular}

In these equations $N_{c}$ and $N_{d}$ represent the quantity of ${ }^{13} \mathrm{C}$ contained in the sample in the coprocessing acid fraction and in the derivatizing methyl groups, respectively. The coefficients 0.011 and 0.99 are the natural abundance of ${ }^{13} \mathrm{C}$ and the enriched content of ${ }^{13} \mathrm{CH}_{3} \mathrm{I} . \mathrm{I}$ is a scaling constant of undetermined value relating the quantity of ${ }^{13} \mathrm{C}$ to its NMR integral response. Equations 1 and 2 may be rearranged to determine the values of $N_{c} I$ and $N_{d} l$ :

$$
\begin{aligned}
& N_{c} I=\left(12 R+0.01124\left(12 R-13_{R}\right)\right) / 0.011 \\
& N_{d} I=\left(13_{R}-12 R\right) / 0.979
\end{aligned}
$$

The values of $N_{d} / N_{c}$ in Table B-5 are determined from $\left(N_{d} I\right) /\left(N_{c} I\right)$. Determination of the average number of carbon atoms per molecule are based on the assumption that the typical acid is monofunctional with a mean formula of $\left(\mathrm{C}_{\mathrm{X}} \mathrm{H}_{1.5 \mathrm{x}} \mathrm{Y}\right)$. $\mathrm{Y}$ represents either nitrogen or oxygen and is taken to have atomic weight of 15 . The values of $X$ represerting the number of carbon atoms per molecule are determined from the equivalent weights of Table B-3 by the relations:

$$
X=(E W-15) / 13.5 \quad \text { Eq. } 5
$$

The last row in each distillate section, $\mathrm{XN}_{\mathrm{d}} / \mathrm{N}_{\mathrm{c}}$, represents the estimate of the total number of functional groups per molecule for each of the acid fractions. 
Table B-7 shows the values for the net enhancement of ${ }^{13} \mathrm{C}$ integral response due to the derivatization procedure. The numbers shown are the difference between the ${ }^{13} \mathrm{CH}_{3}$ and the ${ }^{12} \mathrm{CH}_{3}$ integral values over each zone beiween 5 and $65 \mathrm{ppm}$ for each acid fraction. The sums of these values for each sample are shown in the last row of both distillace ranges. Ratios of individual enhancement values to the total of each set (the fractional values of enhancement) are multiplied by the total number of functional groups per molecule to obtain the number of specific functional groups per molecule shown in Table B-8.

TABLE B-7. - Net peak integral values

\begin{tabular}{|lrrrr|}
\hline Coal, percent & 2 & 20 & \multicolumn{1}{c}{30} & \multicolumn{1}{c|}{40} \\
\hline $175-350^{\circ} \mathrm{C}$ & & & & \\
$-0,49-65 \mathrm{ppm}$ & 514.70 & 1043.43 & 1005.22 & 1111.22 \\
$-\mathrm{N}, 28-49 \mathrm{ppm}$ & 296.90 & 159.82 & 39.66 & 51.89 \\
$-\mathrm{B} / \mathrm{S}, 5-28 \mathrm{ppm}$ & 78.03 & 17.98 & 4.00 & 14.79 \\
& & & & \\
Total & 889.63 & 1218.23 & 1048.88 & 1177.90 \\
& & & & \\
$350-538^{\circ} \mathrm{C}$ & 102.87 & 315.27 & 357.07 & 436.58 \\
$-0,49-65 \mathrm{ppm}$ & 388.83 & 240.35 & 193.21 & 224.14 \\
$-\mathrm{N}, 28-49 \mathrm{ppm}$ & 27.33 & 60.06 & 24.72 & 47.26 \\
$-\mathrm{B} / \mathrm{S}, 5-28 \mathrm{ppm}$ & & & & \\
& 519.03 & 615.68 & 575.00 & 707.98 \\
Total & & &
\end{tabular}


TABLE B-8. - Number of functional groups per average molecule

\begin{tabular}{|lllll|}
\hline Coal, percent & 2 & 20 & 30 & 40 \\
\hline $175-350^{\circ} \mathrm{C}$ & & & & \\
$-0,49-65 \mathrm{ppm}$ & 0.58 & 1.11 & 1.02 & 1.07 \\
$-\mathrm{N}, 28-49 \mathrm{ppm}$ & 0.34 & 0.17 & 0.04 & 0.05 \\
$-\mathrm{B} / \mathrm{S}, 5-28 \mathrm{ppm}$ & 0.09 & 0.02 & 0.00 & 0.01 \\
& & & & \\
Total & 1.02 & 1.30 & 1.06 & 1.14 \\
& & & & \\
$350-538^{\circ} \mathrm{C}$ & & & & 0.83 \\
$-0,49-65 \mathrm{ppm}$ & 0.21 & 0.51 & 0.62 & 0.42 \\
$-\mathrm{N}, 28-49 \mathrm{ppm}$ & 0.78 & 0.39 & 0.33 & 0.09 \\
$-\mathrm{B} / \mathrm{S}, 5-28 \mathrm{ppm}$ & 0.06 & 0.10 & 0.04 & 1.34 \\
& & & & \\
Total & 1.04 & 1.00 & 0.99 & \\
\hline
\end{tabular}

Values for the total number of functional groups generally fall near 1.0 , and it is probable that all of the coprocessing acids are essentially monofunctional. The 20 percent coal, $175-350^{\circ} \mathrm{C}$ sample shows a value of 1.3 in this study However, this sample was shown by the GC/MS study to be almost entirely monofunctional i composition with only a small amount of bisphenols as difunctional content. Some errors in the NMR spectra integral values arising from baseline correction or in the nonaqueous titration may account for values that are significantly different from 1.0 .

\section{B.8 Mass Spectral Analyses}

Neutral aromatic fractions of the $350-538^{\circ} \mathrm{C}\left(662-1000^{\circ} \mathrm{F}\right)$ distillates and the whole neutral fractions of the $175-350^{\circ} \mathrm{C}\left(347-662^{\circ} \mathrm{F}\right)$ distillates were analyzed in detail by mass spectrometry (MS). The procedure used was based on the Teeter (3) method. This determines 18 saturate and aromatic hydrocarbon types and 4 aromatic sulfur-containing species.

Saturates of the $350-538^{\circ} \mathrm{C}$ distillate were analyzed in detail by mass spectrometry. The procedure is the ASTM D 2786 method, a low-resolution MS analysis developed for petroleum saturate fraction samples. It was carried out in a CEC 21-103 mass spectrometer with sample introduction through a vapor expansion volume. 


\section{B.9 Elemental Analyses}

Elemental compositions of all distillates, residues, and fractions derived from them were determined. Carbon and hydrogen were determined with a Perkin-Elmer $240^{\circ} \mathrm{C}$ Elemental Analyzer. All analyses were run at least in duplicate. To conserve material in cases where fractions were quite small and to provide a uniform basis for all sample analyses, nitrogen and sulfur were determined by the Antek chemiluminescence method and the microcoulometric procedures, respectively. Oxygen values are reported as the net difference from 100 percent based on the reported values of carbon, hydrogen, nitrogen, and sulfur.

\section{B.10 Infrared Spectroscopy}

Infrared spectra were recorded on dichloromethane solutions of LC fractions using a PerkinElmer Model 283 double beam dispersive instrument. Concentrations ranged from 10-20 mg/mL; $0.5-\mathrm{mm}$ path length $\mathrm{KBr}$ liquid cells were employed. Concentrations of acidic nitrogen in acid fractions were calculated using the response of the N-H stretching band of dibenzo[a,i]carhazole for calibration.

\section{B.11 Carbon Isotope Ratios}

Carbon isotope ratio analyses were performed under the direction of Dr. Michael Engle at the School of Geology and Geophysics, Energy Center, University of Oklahoma, Norman, OK.

\section{B.12 References}

1. Green, J. A., J. B. Green, R. D. Grigsby, C. D. Pearson, J. W. Reynolds, J. Y. Shay, G. P. Sturm, Jr. J. S. Thomson, J. W. Vogh, R. P. Vrana, S. K.-T. Yu, B. H. Diehi, P. L. Grizzle, D. E. Hirsch, K. W. Hornung, S.-Y. Tang, L. Carbognani, M. Hazos, V. Sa hez. Analysis of Heavy Oils: Method Development and Application to Cerro Negro heavy Petroleum. Final Technical Report NIPER-452, v. 1 and 2 (NTIS Report Nos. DE90000200 and DE90000201, December 1989).

2. Green, J. B., B. K. Stierwalt, J. A. Green, and P. L. Grizzle. A Comparison of Nonaqueous Titrametric, Infrared Spectrometric, and HPLC Methods for Analysis of Polar Compound Classes in SRC-II. Fuel, v. 64, 1985, pp. 1571-1580.

3. Teeter, R. M. Mass Spec Rev, v. 4, 1985, pp. 123. 
APPENDIX C

DETAILED RESULTS, LIGHT DISTILLATE ANALYSIS 
TABLE C-1. - PIANO analysis light distillate, $40 \%$ coal run

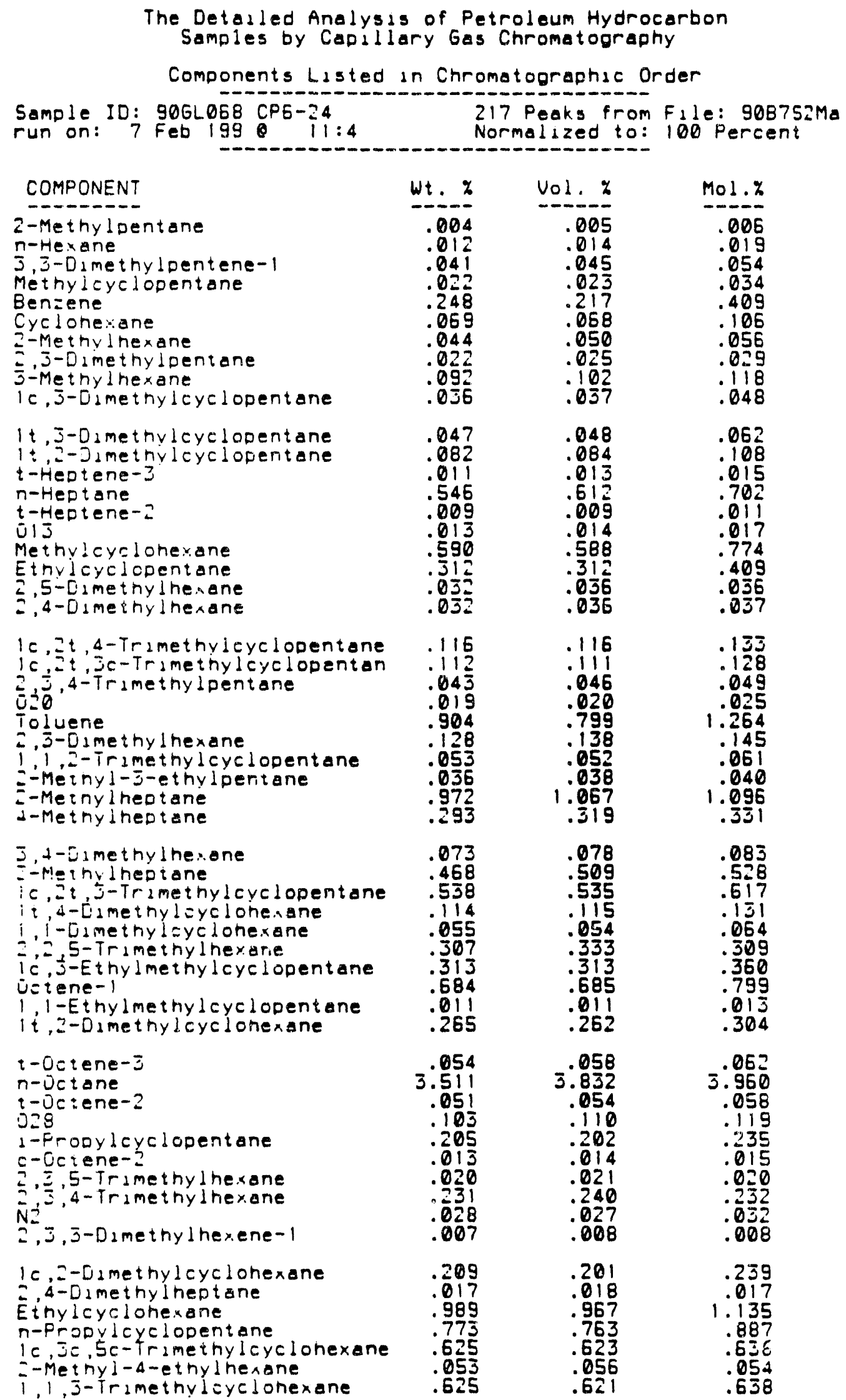


TABLE C-1. - PIANO analysis light distillate, $40 \%$ coal run (contirued)

1,1,4-Trimethyleyclohexane 3,3-Dimethy lheptane

.291

.042

.289

.167

.297

2,5-0ime thy Ihep tane

.189

N5 4-Dimethyl hep tere-1

.240

.186

NG

.087

1.914

Ethylbenzene

Ic, it at-Trimethylcyclohexane 2-Methyloctene-1

.215

N8

$m-x y l e n e$

p-xylene

.165

.057

1.047

.031

.270

1.693

.212

.185

.056

1.510

.933

(3)

.344

I 50

4-Ethyl heptane

.28

.249

4-Methyloctane

?-Methyloctane

.850

1.240

NII

.037

.211

Ic It, 4c-Trimethyleyclohexane

.40

J-Metriyloctane

1.835

.032

.157

3.j-Dlethylpentane

1,1,2-ir dmethyleyclohexane

o-xylene

16

NII Methyioctene-J

Nonene-

1-Eutyleyclopentane

.147

.077

.125

2.016

.076

.983

.373

.449

.293

.361

.300

.262

.905

1. .332

.040

.208

.388

1.952

.217

.253

2.100

.220

.174

. .058

1.271

.031

N15

NIE;t-7-Met hyloctene-3

$t-$ Nonene- 5

$2, \overline{3}-0$ imet hyl heptene-2

n-Nonane

I, 1-Merhylethyleyclohexane NiE

:-Propy!benzene

$c-$ Nonene-j

.228

.111

.196

.242

7.342

.773

.304

.251

.149

.079

.120

1.756

.879

1.424

.956

.420

.472

.346

.282

.251

.854

1.245

.037

.216

1.809

iv 20

LFropy leyclonexane

I1!

I. - Dlmethrioctane

-1-Dimethyloctane

Nล่ว

I. - O d methy loctane

n-Eutylcyclopentane

$N=3$

.225

.147

.078

.128

.446

1.076

1.003

.394

.458

(2)

.233

.200

.205

7.8244

.735

.010

.223

$7 . \frac{256}{374}$

.788

.310

.010

.243

114

$N=4$

n-Frooylbenzene

j, 6-0 d methyloctane

j-Methyi-5-ethyl heot ane

N25

1-Methyi-j-ethylbenzene 1-Methy1-4-ethylbenzene NIE

.536
.275
.347
.291
.056
.238
.638
.362
.225
.166

.565

.552

.330

.275

.053

1.554

1.240

.230

2.092

.396

.840

.330

.542

.302

. .333

.426

2. 197

.379

.747

.572

.319

2.319

.803

.165

$=, 3-D_{2}$ methy loctane

i, 5, - Trimethylbenzene

I 15

N2?

I1 17

5-Me thy I nonane

Z-Methylnonane

I-Metny 1-Z-ethylbenzene

I-Etnvisetane

.171
.594
.092
.135
.711
3.227
1.550
1.704
1.138
.604

.299

.249

.250

1.407

1.122

.159

1.894

.354

.901

.490

.274

.306

.392

.149

.718

.089

.141

.687

3.115

1.481

1.615

1.507
.583

.080

.130

2.820

1.341

1.462

1.401 
TABLE C-1. - PIANO analysis light distillate, $40 \%$ coal run (continued)

\begin{tabular}{|c|c|c|c|}
\hline 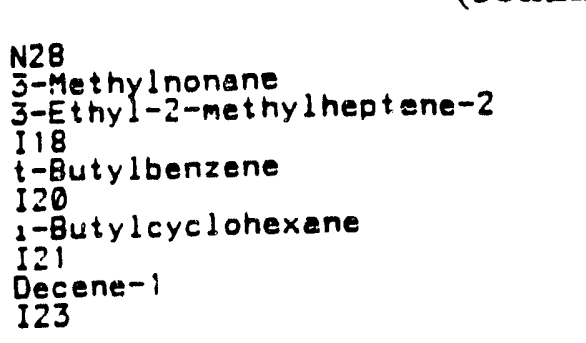 & $\begin{array}{r}.124 \\
1.741 \\
.288 \\
.158 \\
2.263 \\
1.758 \\
.585 \\
.450 \\
.078 \\
.595\end{array}$ & $\begin{array}{r}.119 \\
1.820 \\
.315 \\
2.156 \\
2.083 \\
1.822 \\
.486 \\
.466 \\
.081 \\
.616\end{array}$ & $\begin{array}{r}.114 \\
1.576 \\
.273 \\
.136 \\
2.172 \\
1.592 \\
.464 \\
.408 \\
.072 \\
.539\end{array}$ \\
\hline 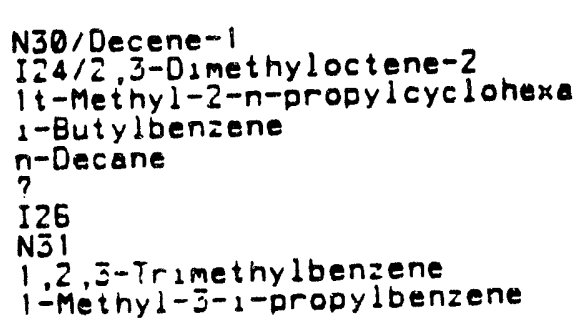 & $\begin{array}{r}.183 \\
.224 \\
.260 \\
.212 \\
7.979 \\
.099 \\
.242 \\
.264 \\
.828 \\
.330\end{array}$ & $\begin{array}{r}.176 \\
.232 \\
.249 \\
.191 \\
8.380 \\
.103 \\
.251 \\
.253 \\
.710 \\
.293\end{array}$ & $\begin{array}{r}.169 \\
.203 \\
.239 \\
.204 \\
7.224 \\
.089 \\
.199 \\
.220 \\
.887 \\
.316\end{array}$ \\
\hline 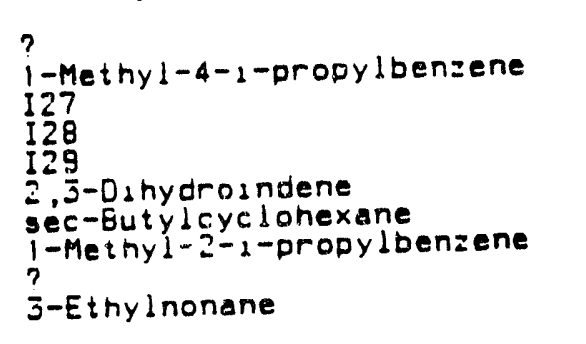 & $\begin{array}{r}.243 \\
.247 \\
.107 \\
.106 \\
1.138 \\
.173 \\
1.361 \\
.096 \\
.289 \\
.498\end{array}$ & $\begin{array}{r}.216 \\
.220 \\
.111 \\
.110 \\
1.179 \\
.137 \\
1.282 \\
.079 \\
.253 \\
.513\end{array}$ & $\begin{array}{r}.233 \\
.237 \\
.088 \\
.087 \\
.938 \\
.188 \\
1.250 \\
.087 \\
.277 \\
.411\end{array}$ \\
\hline 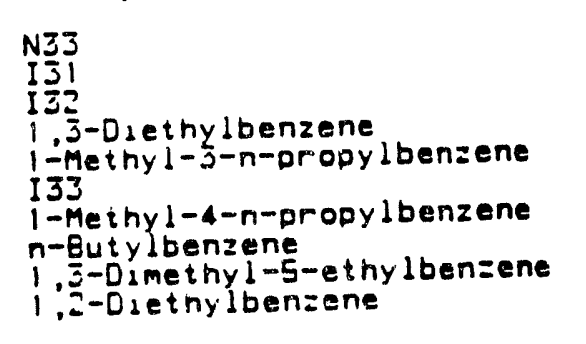 & $\begin{array}{l}.958 \\
.692 \\
.207 \\
.389 \\
.681 \\
.107 \\
.321 \\
.142 \\
.307 \\
.127\end{array}$ & $\begin{array}{l}.918 \\
.717 \\
.198 \\
.345 \\
.686 \\
.111 \\
.286 \\
.127 \\
.268 \\
.111\end{array}$ & $\begin{array}{l}.800 \\
.570 \\
.173 \\
.374 \\
.653 \\
.088 \\
.308 \\
.136 \\
.295 \\
.122\end{array}$ \\
\hline 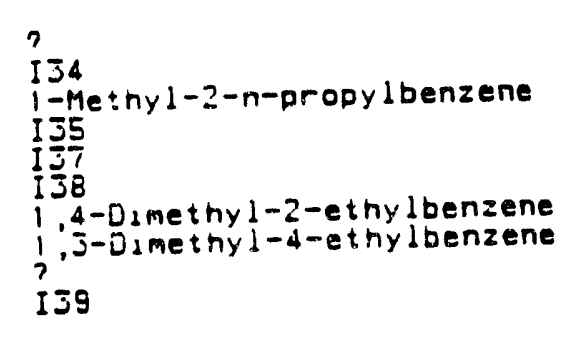 & $\begin{array}{l}.744 \\
.892 \\
.191 \\
.370 \\
.3773 \\
.5253 \\
.213 \\
.182 \\
.075 \\
.042\end{array}$ & $\begin{array}{l}.649 \\
.924 \\
.168 \\
.384 \\
.387 \\
.542 \\
.186 \\
.162 \\
.067 \\
.054\end{array}$ & $\begin{array}{l}.714 \\
.735 \\
.183 \\
.305 \\
.308 \\
.331 \\
.204 \\
.158 \\
.065 \\
.282\end{array}$ \\
\hline $\begin{array}{l}1,2-0 \text { methyl-4-ethylbenzene } \\
? \\
140 \\
1,3-0 \text { methy } 1-z-e t h y l b e n z e n e \\
141 \\
142 \\
? \\
1-\text { Methyl-4-t-buty lbenzene } \\
1,2-0 \text { dmethy } 1-3-e t h y l b e n z e n e\end{array}$ & $\begin{array}{l}.441 \\
.083 \\
.047 \\
.075 \\
.108 \\
.000 \\
.095 \\
.054 \\
.127 \\
.067\end{array}$ & $\begin{array}{l}.387 \\
.073 \\
.048 \\
.065 \\
.112 \\
.207 \\
.098 \\
.067 \\
.0675 \\
.057\end{array}$ & $\begin{array}{l}.423 \\
.080 \\
.038 \\
.073 \\
.089 \\
.165 \\
.078 \\
.053 \\
.111 \\
064\end{array}$ \\
\hline 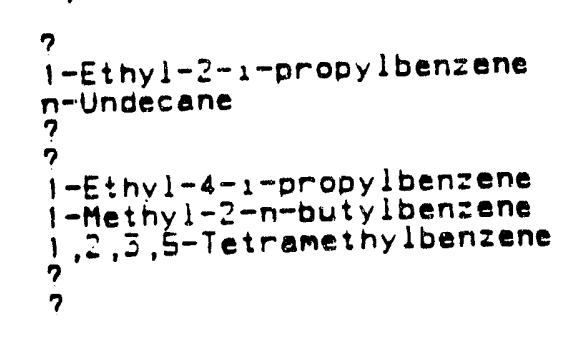 & $\begin{array}{l}.007 \\
.028 \\
1.074 \\
.052 \\
.008 \\
.015 \\
.020 \\
.019 \\
.048 \\
.038\end{array}$ & $\begin{array}{r}.006 \\
.024 \\
1.107 \\
.055 \\
.009 \\
.013 \\
.017 \\
.016 \\
.042 \\
.033\end{array}$ & $\begin{array}{l}.007 \\
.024 \\
.885 \\
.043 \\
.007 \\
.013 \\
.017 \\
.018 \\
.046 \\
.057\end{array}$ \\
\hline$?$ & $\begin{array}{l}.029 \\
.021\end{array}$ & $\begin{array}{l}.025 \\
.018\end{array}$ & $\begin{array}{l}.028 \\
.020\end{array}$ \\
\hline
\end{tabular}


TABLE C-1. - PIANO analysis light distillate, $40 \%$ coal run (continued)

\begin{tabular}{|c|c|c|c|}
\hline $\begin{array}{l}? \\
143 \\
\text { A3 } \\
1-E \text { thy } 1-2-n-p r o p y l b e n z e n e \\
1-M e t h y 1-3-n-b u t y 1 \text { benzene } \\
1,3-01-2-p \text { ropylbenzene } \\
? 1-t-M e t h y 1-2-(4 M P) \text { cyclopenton }\end{array}$ & $\begin{array}{l}.024 \\
.103 \\
.011 \\
.037 \\
.081 \\
.035 \\
.031 \\
.022\end{array}$ & $\begin{array}{l}.021 \\
.105 \\
.009 \\
.032 \\
.070 \\
.030 \\
.027 \\
.021\end{array}$ & $\begin{array}{l}.023 \\
.078 \\
.009 \\
.032 \\
.071 \\
.028 \\
.025 \\
.017\end{array}$ \\
\hline $\begin{array}{l}? \\
1,4-D_{1}-1-D r o d y l b e n z e n e \\
? \\
? \\
\text { Naphthalene } \\
1,2-D_{1}-n-D r o d y l \text { benzene } \\
\text { n-Dodecane }\end{array}$ & $\begin{array}{l}.024 \\
.015 \\
.012 \\
.019 \\
.027 \\
.013 \\
.038\end{array}$ & $\begin{array}{l}.023 \\
.013 \\
.011 \\
.016 \\
.020 \\
.011 \\
.039\end{array}$ & $\begin{array}{l}.019 \\
.012 \\
.010 \\
.015 \\
.027 \\
.011 \\
.029\end{array}$ \\
\hline
\end{tabular}




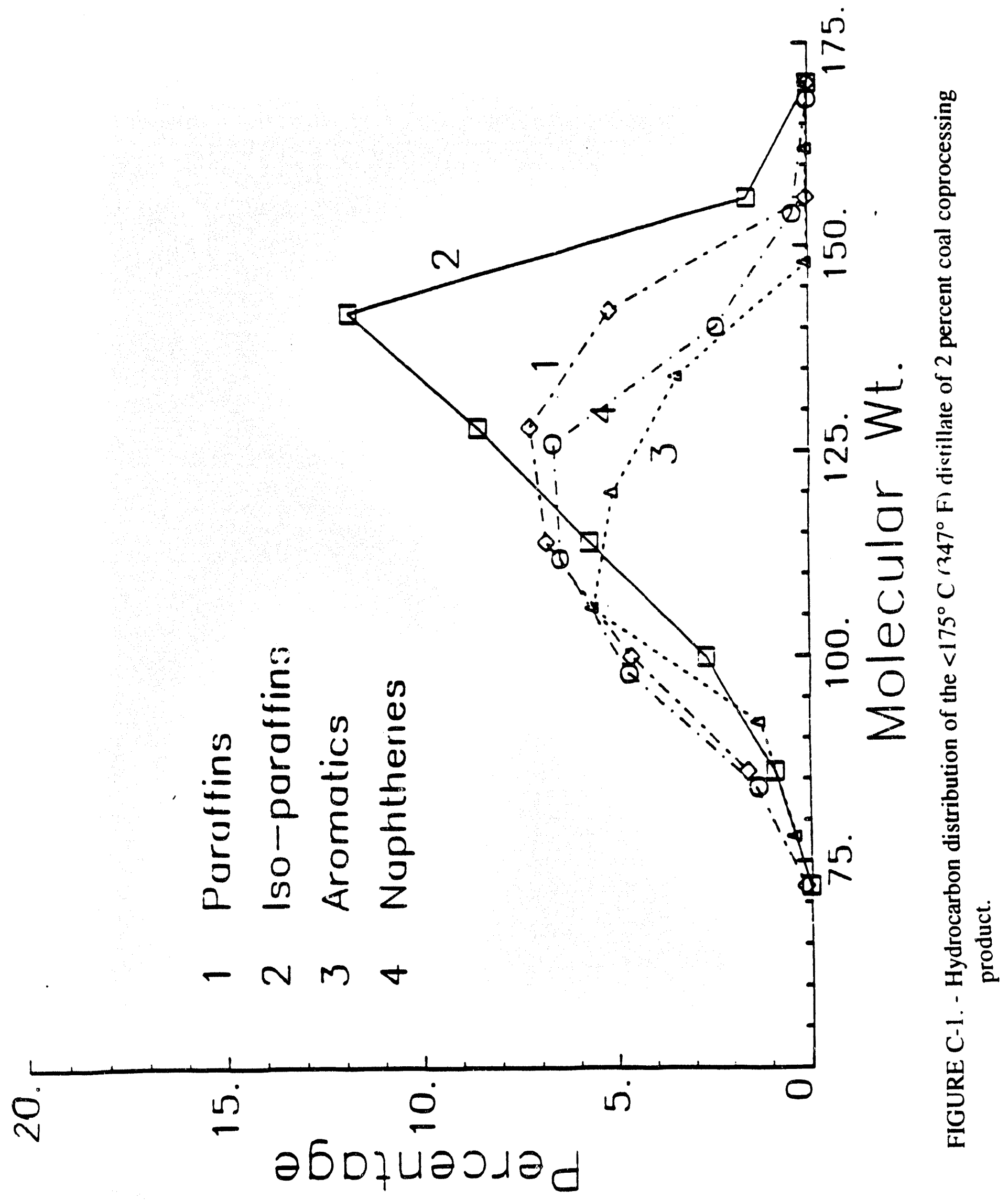




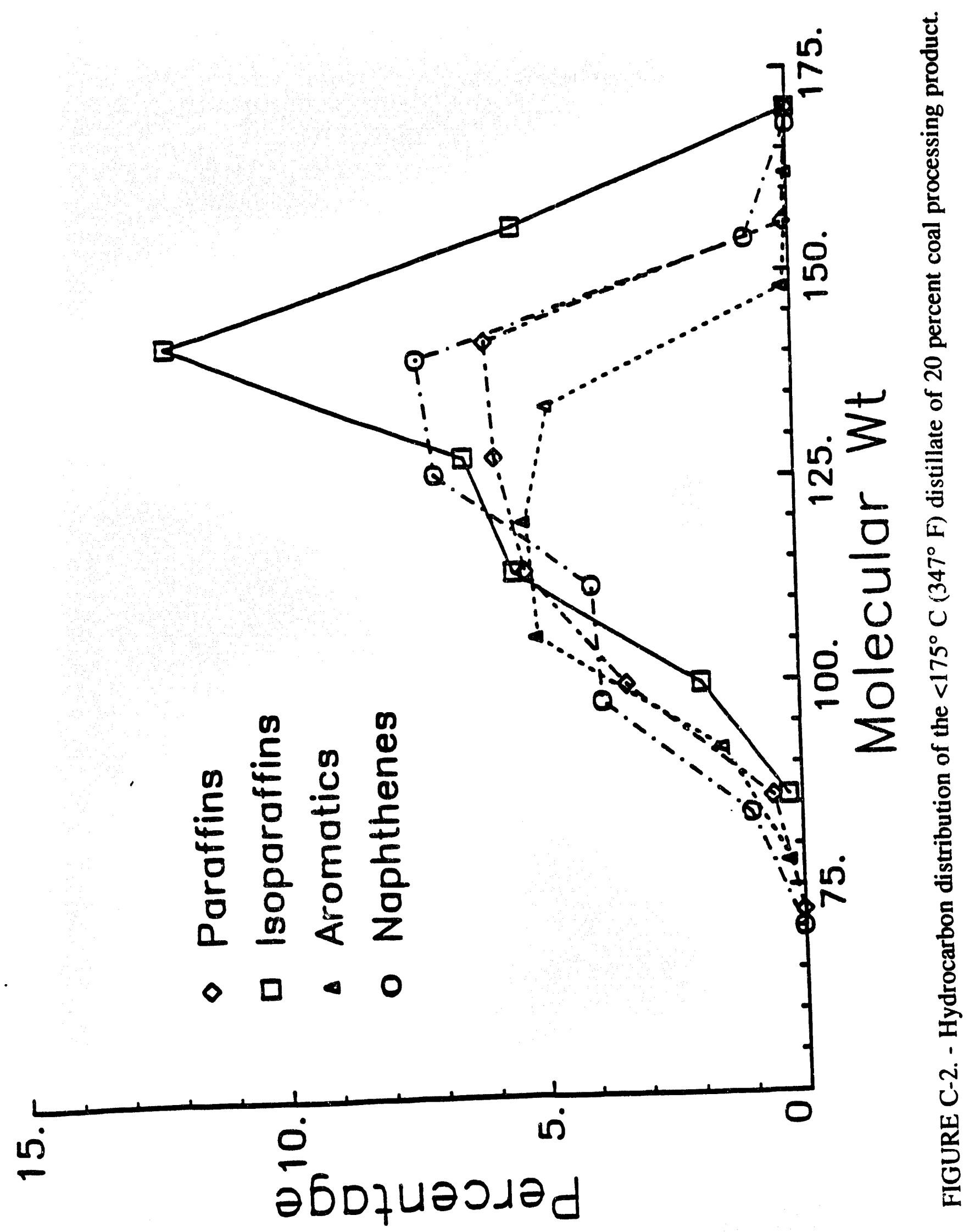




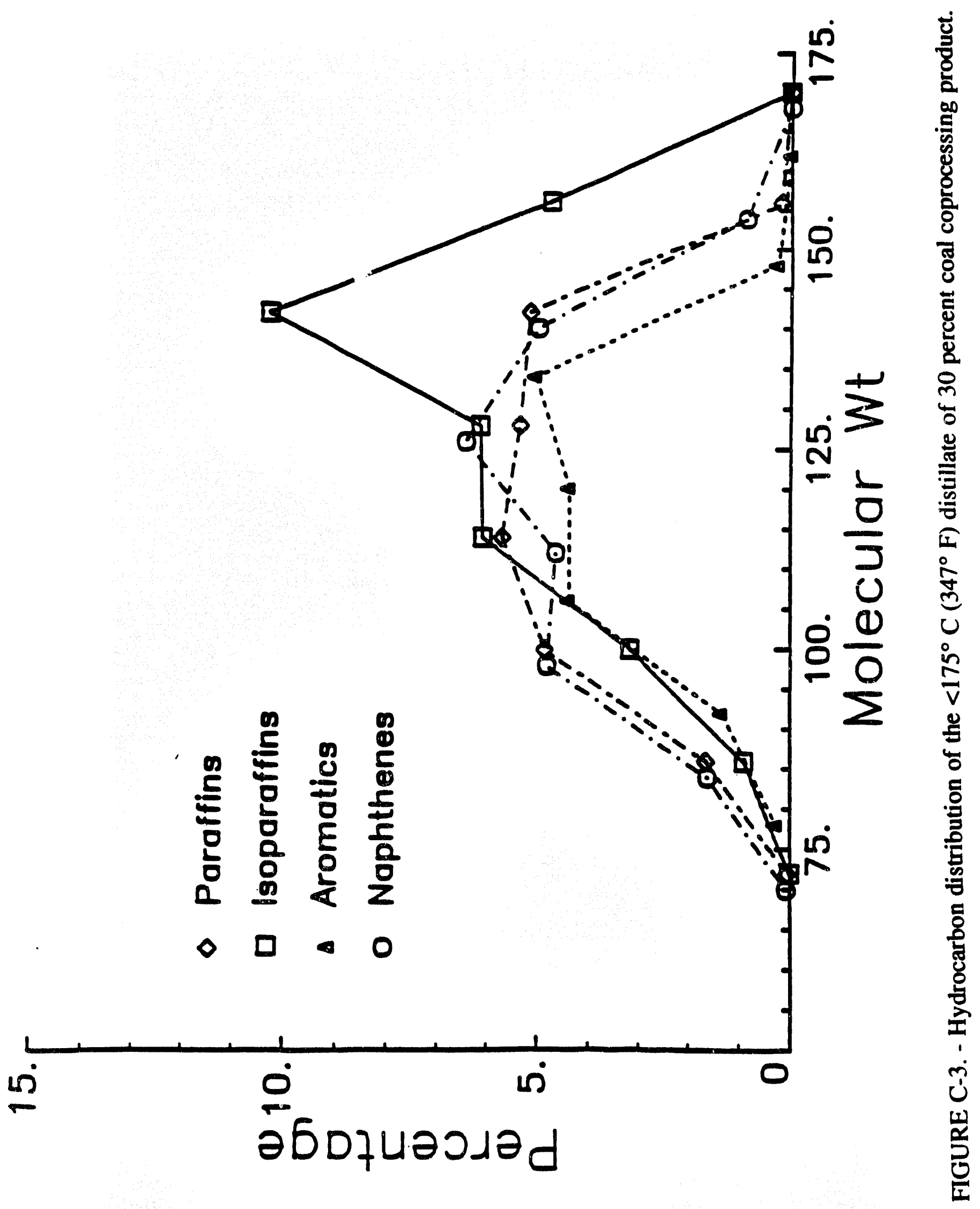




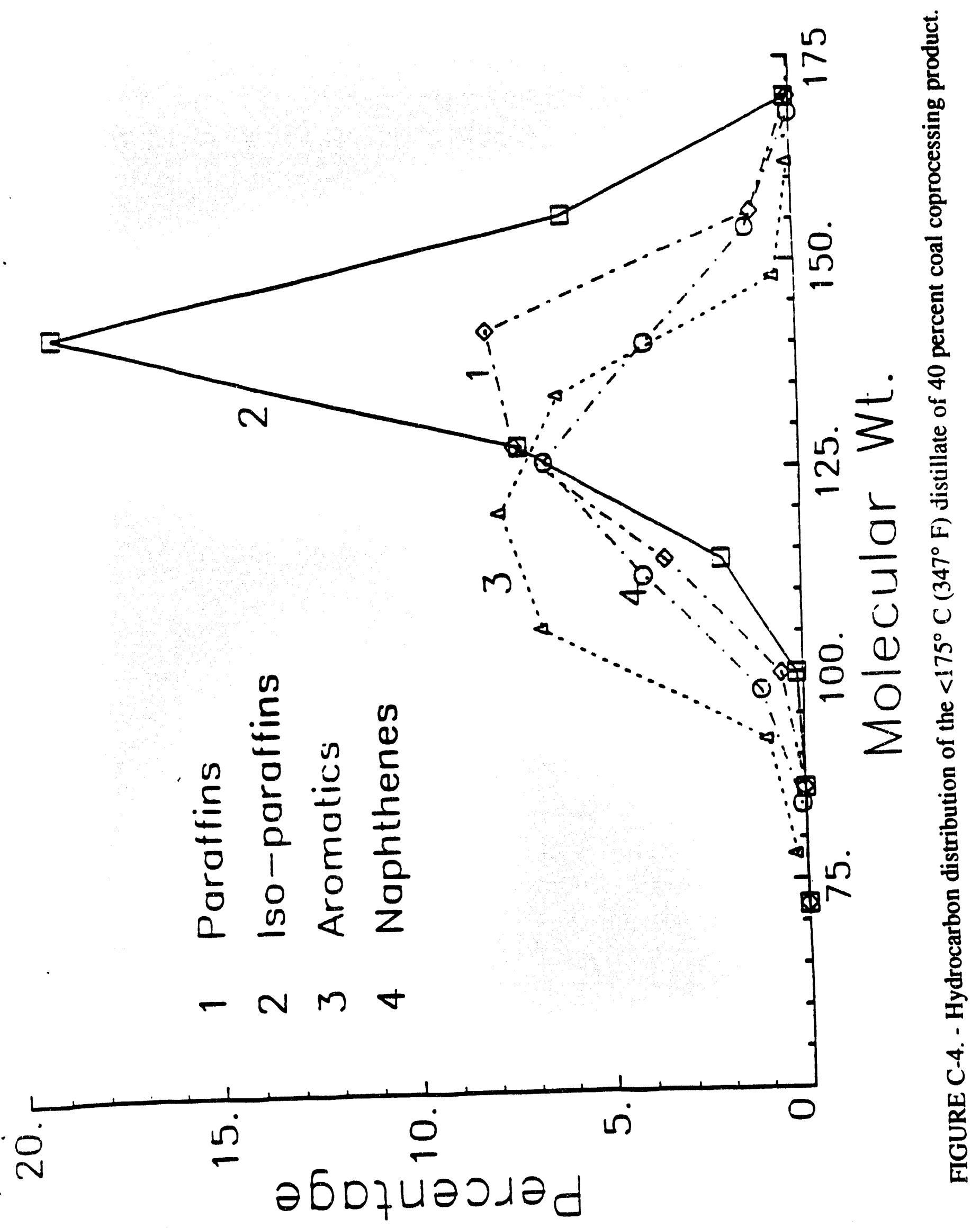

3-9 

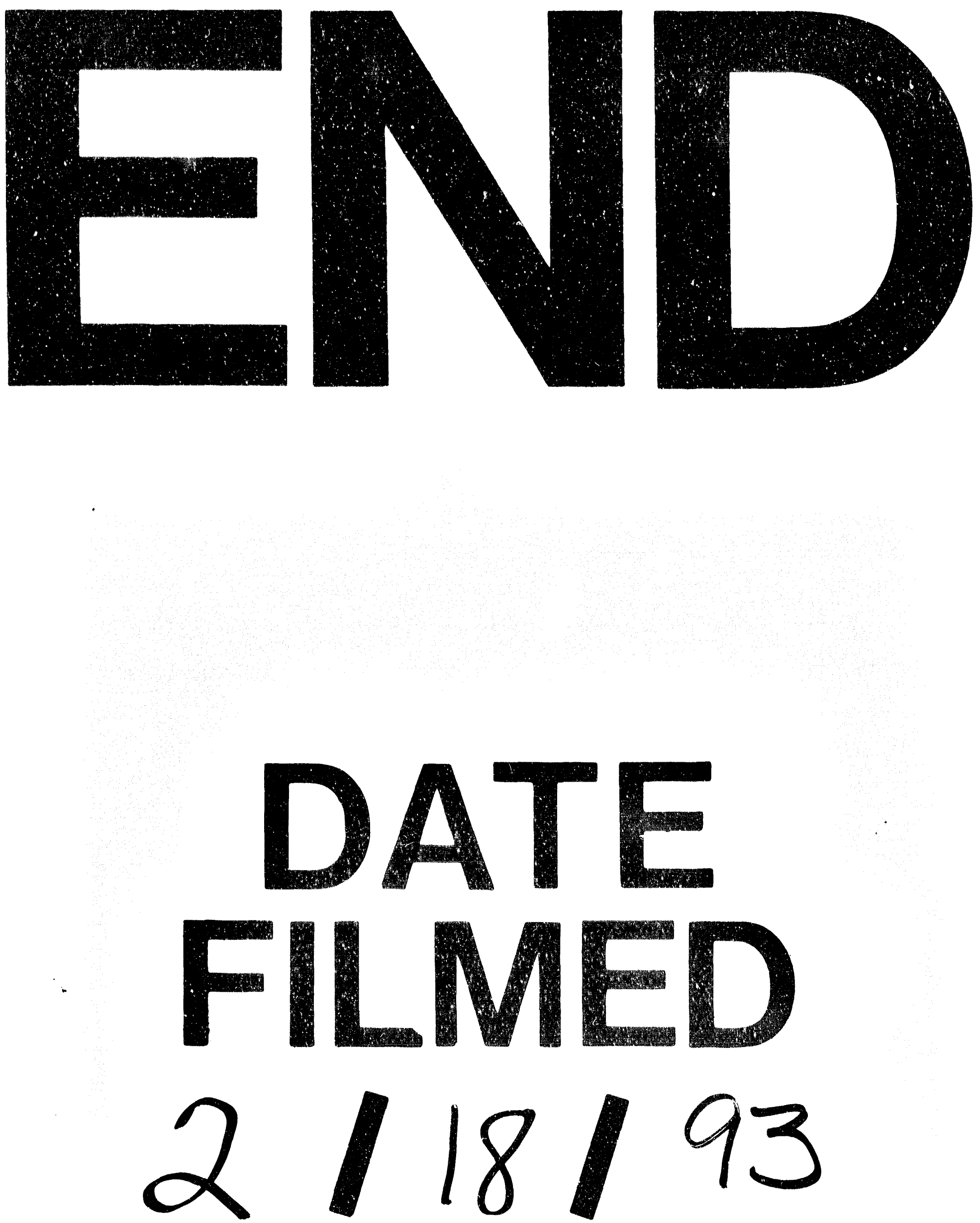
